\title{
Program of the
}

Manufacturing Engineering Laboratory

\section{6}

U.S. DEPARTMENT OF COMMERCE Technology Administration National Institute of Standards and Technology

Infrastructural Technology,

Gaithersburg, MD 20899

Measurements, and Standards

for the

U.S. Manufacturing Industries

QC 



\section{Program of the}

\section{Manufacturing \\ Engineering \\ Laboratory}

1996

Infrastructural Technology,

Measurements, and Standards

for the

U.S. Manufacturing Industries
U.S. DEPARTMENT OF COMMERCE Technology Administration

National Institute of Standards and Technology

Gaithersburg, MD 20899

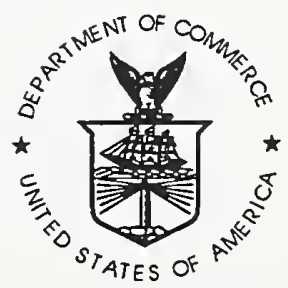

U.S. DEPARTMENT OF COMMERCE Michael Kantor, Secretary

TECHNOLOGY ADMINISTRATION

Mary L. Good, Under Secretary for Technology

NATIONAL INSTITUTE OF STANDARDS

AND TECHNOLOGY

Arati Prabhakar, Director 


\section{Abstract}

The NIST Manufacturing Engineering Laboratory works with the U.S. manufacturing industries to develop and apply infrastructural technology, measurements, and standards to meet their needs. This report summarizes the resources, objectives, needs addressed, accomplishments, and plans for the projects carried out by the Manufacturing Engineering Laboratory in support of U.S. industry.

\section{Keywords}

infrastructural technology, manufacturing, manufacturing engineering, manufacturing technology, measurements, metrology, standards

\section{Disclaimer}

Certain commercial products are identified in this report to specify the work completely. Such identification does not imply recommendation or endorsement by the National Institute of Standards and Technology, nor does it imply that the products mentioned are necessarily the best available for the purpose.

\section{For More Information}

Manufacturing Engineering Laboratory

National Institute of Standards and Technology

Building 220, Room B322

Gaithersburg, MD 20899-0001

Phone 301-975-3400

Fax 301-948-5668 


\section{Table of Contents}

1995: The Year in Review ................................ 1

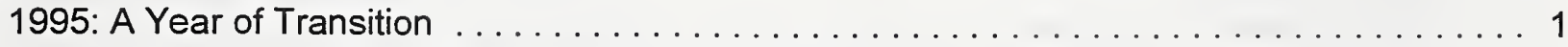

1995: MEL Moves In New Directions . . . . . . . . . . . . . . . . . . . . . . . . . . . . . . . . . . 1

1995: Organizational Milestones-New Leadership . . . . . . . . . . . . . . . . . 2

1995: Technical Milestones-Contributions In Metrology, Technology, and Standards ...... 3

1995: Guided Through Change By A Vision . . . . . . . . . . . . . . . . . . . 7

Elements of a Strategic Plan $\ldots \ldots \ldots \ldots \ldots \ldots \ldots \ldots \ldots \ldots \ldots \ldots \ldots$

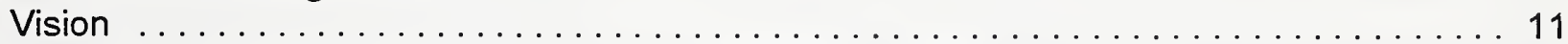

Mission ................................................... 11

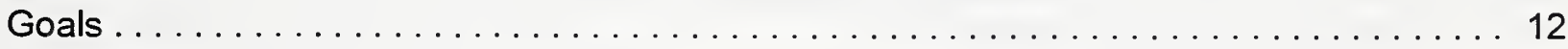

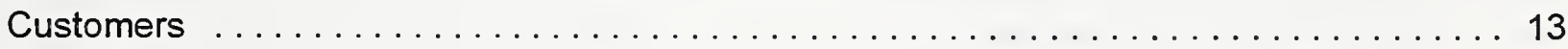

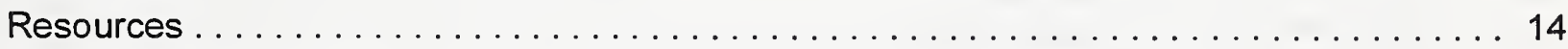

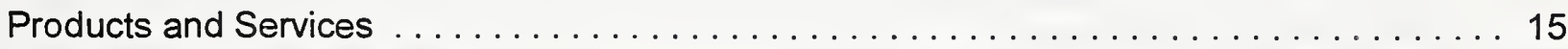

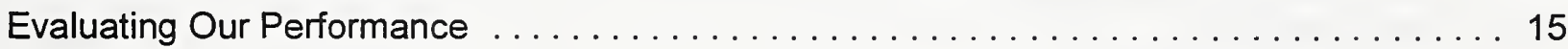

Technical Thrusts . . . . . . . . . . . . . . . . . . . . . . . 18

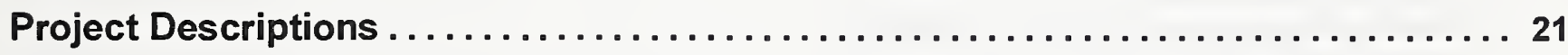

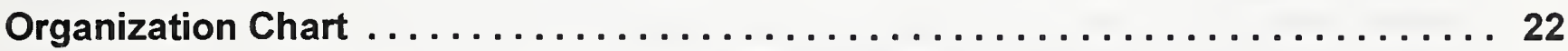

National Advanced Manufacturing Testbed (NAMT) . . . . . . . . . . 23

Characterization, Remote Access, and Simulation of Hexapod Machines . . . . . . . . . . 24

Development of Machine Tool Performance Representation Models and of a Machine Data

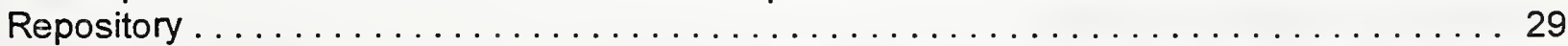

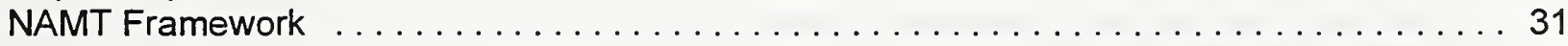

Nanomanufacturing of Atom-based Standards $\ldots \ldots \ldots \ldots \ldots \ldots \ldots \ldots \ldots \ldots \ldots \ldots \ldots \ldots$

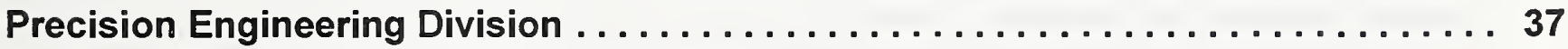

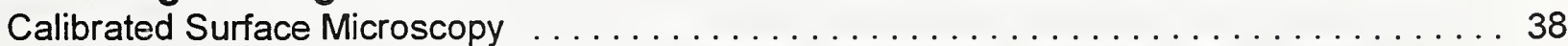

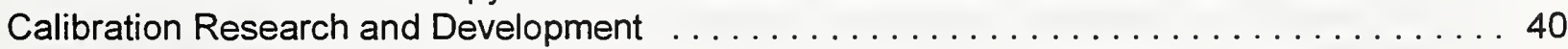

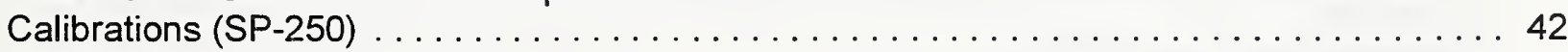

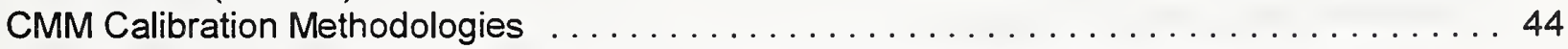

Collaboration in Dimensional Metrology With the Oak Ridge Metrology Center (ORMC) . . . 46

Complex Form Dimensional Metrology $\ldots \ldots \ldots \ldots \ldots \ldots \ldots \ldots \ldots \ldots \ldots \ldots$

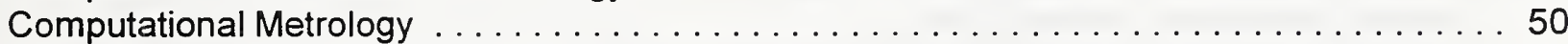

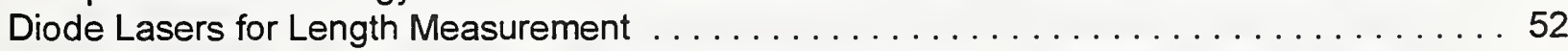

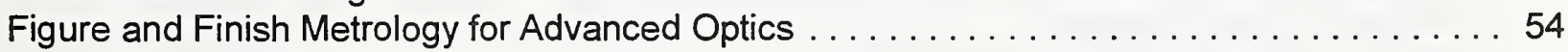

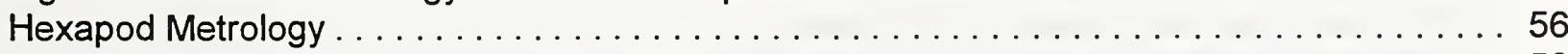

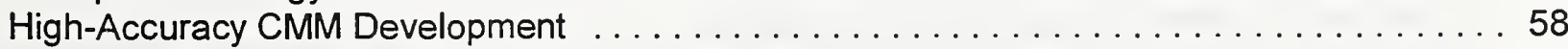

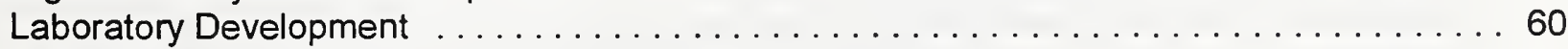

Large-Scale Coordinate Metrology . . . . . . . . . . . . . . . . . . . . . . . 62

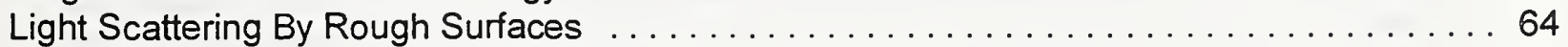

Linewidth Correlation . . . . . . . . . . . . . . . . . . . . . . . . . . . . . . 66

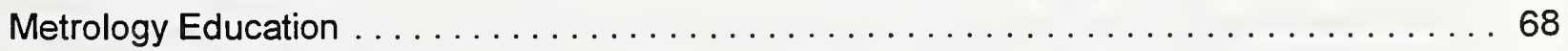

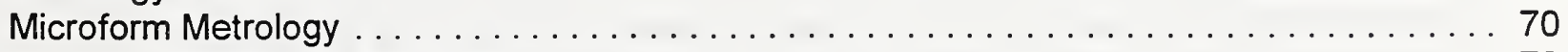

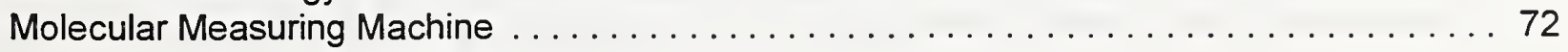


Nanoelectronics Competence . . . . . . . . . . . . . . . . . . . . . . . . . . . 74

NIST Line Scale Interferometer Upgrading . . . . . . . . . . . . . . . . . . 76

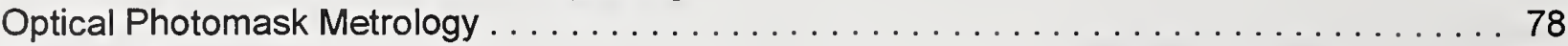

Overlay Metrology . . . . . . . . . . . . . . . . . . . . . . . . . . . . . . 79

Quality System Pilot Project . . . . . . . . . . . . . . . . . . . . . . . . 81

Scanning Electron Microscope Linewidth Metrology . . . . . . . . . . . . . . . . 83

SEMATECH Liaison . . . . . . . . . . . . . . . . . . . . . . . . . . . . . 86

SPM Tip Preparation and Characterization $\ldots \ldots \ldots \ldots \ldots \ldots \ldots \ldots \ldots \ldots$

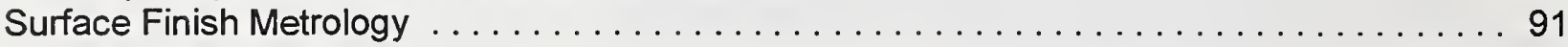

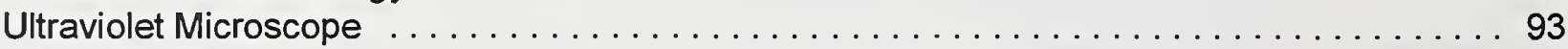

Wafer Flatness . . . . . . . . . . . . . . . . . . . . . . . . . . . . 95

Automated Production Technology Division . . . . . . . . . . . . . . . 97

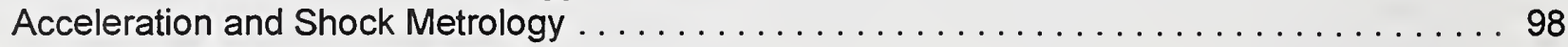

Acoustical Metrology Services . . . . . . . . . . . . . . . . . . . . . . . . . . . . . . . . . 100

Artifact Mass to Watt Competence . . . . . . . . . . . . . . . . . . . . . . . . . . . . . . . . 102

Closed-Loop Manufacturing . . . . . . . . . . . . . . . . . . . . . . . . . . . . . . . . 104

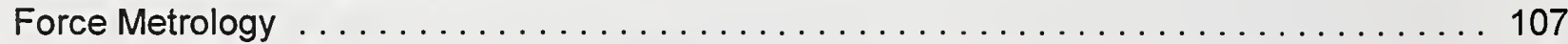

Hearing Aid Metrology . . . . . . . . . . . . . . . . . . . . . . . . . . . . . . . . . . . . . 109

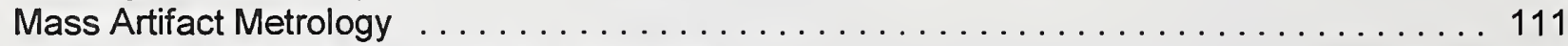

Precision Machining of Advanced Materials . . . . . . . . . . . . . . . . . . . 113

Process Modeling . . . . . . . . . . . . . . . . . . . . . . . . . . . . . . . . . 115

Quality Control For Advanced Materials and Manufacturing Processes . . . . . . . . . . . . 117

Sensor Interface for Closed-Loop Manufacturing . . . . . . . . . . . . . . . . . . . . . . . . . 119

Spindle Characterization . . . . . . . . . . . . . . . . . . . . . . . . . . . 121

Ultrasonic Calibrations Services . . . . . . . . . . . . . . . . . . . . . . . . . . . . . . . 123

Intelligent Systems Division . . . . . . . . . . . . . . . . . . . . 125

Advanced Deburring and Chamfering System (ADACS) . . . . . . . . . . . . . . . . . . 126

Automated Welding Manufacturing System (AWMS) . . . . . . . . . . . . . . . . . . . . 128

Enhanced Machine Controller (EMC): A Testbed For Open Architecture Controller Standards 130

Next Generation Inspection System (NGIS) . . . . . . . . . . . . . . . . . . . . . . . . 132

Operator Interface for Virtual and Distributed Manufacturing . . . . . . . . . . . . . . . 134

Reference Model Architecture/Joint Architecture . . . . . . . . . . . . . . . . . . . . . . . . . 136

RoboCrane®: An Integration Testbed for Large-Scale Manufacturing and Construction

Automation ... . . . . . . . . . . . . . . . . . . . . . . . . . . . . . . . . . . . . . . . . 139

Software Development Process . . . . . . . . . . . . . . . . . . . . . . . . . . . . . . 141

Manufacturing Systems Integration Division . . . . . . . . . . . . . 143

Apparel Information Technologies . . . . . . . . . . . . . . . . . . . . . . . . . . . . . . 144

Application Protocol Development Environment (APDE) . . . . . . . . . . . . . . . . . 147

APs for DoD and Industry . . . . . . . . . . . . . . . . . . . . . . . . . . . . . . . . . . 150

Computer-Aided Manufacturing Engineering . . . . . . . . . . . . . . . . . . . . 152

Computer-Integrated Manufacturing Framework . . . . . . . . . . . . . . . . . . . . . . . . 154

Dimensional Tolerancing and Computational Metrology . . . . . . . . . . . . . . . . . 156

Engineering A La Carte: Improving the Interoperability of Distributed Engineering Software

Tools ... . . . . . . . . . . . . . . . . . . . . . . . . . . . . . . . . . . . . . . . . 159

Engineering Design Testbed . . . . . . . . . . . . . . . . . . . . . . . . 161

Enhanced Integration of CAD With Design Support and Manufacturing Engineering Systems 163

Flexible Design-For-Assembly (DFA) Through Conceptual Assembly Modeling . . . . . . . . 165

Healthcare Industry: Analysis of Research on Heterogeneous Information Systems . . . . . 167 
Improving the Design Process by Predicting Downstream Values of Design Attributes . . . . 168 Integration of Real-Time Scheduling and Shop Floor Data Collection . . . . . . . . . . 170 Manufacturing Enterprise Integration . . . . . . . . . . . . . . . . . . . . . . . . . . . . 172

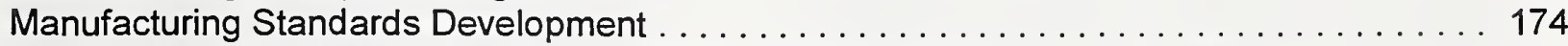

Modeling Features With Shape Algebras and Formal Logic . . . . . . . . . . . . . . 177

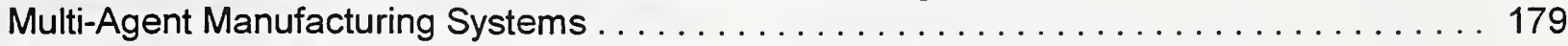

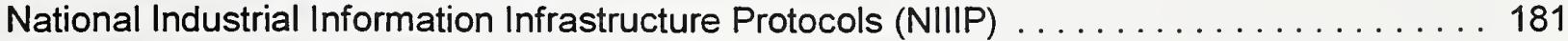

Participation in the Apparel Research Network Program . . . . . . . . . . . . . . . . . . . . 183

Process Planning Testbed . . . . . . . . . . . . . . . . . . . . . . . . . . . . . . . 185

Rapid Response Manufacturing (RRM) Intramural Project . . . . . . . . . . . . . . . . . . 187

SIMA Advanced Manufacturing Systems and Networking Testbed (AMSANT) . . . . . . . 190

SIMA Process Planning Applications . . . . . . . . . . . . . . . . . . . . . . . . 193

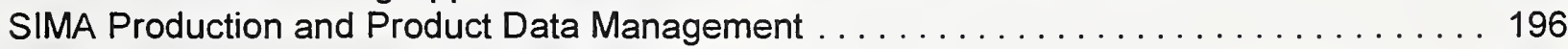

Step Conformance Testing . . . . . . . . . . . . . . . . . . . . . . . . . . . . 198

STEP Implementation Prototypes (SIP) . . . . . . . . . . . . . . . . . . . . . . . . . . 201

Systems Integration for Manufacturing Applications (SIMA) Program . . . . . . . . . . 204

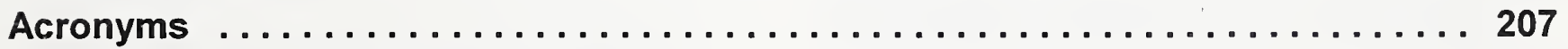




\section{5: THE YEAR IN REVIEW}

Through its research results and services in metrology and infrastructure technology, the Manufacturing Engineering Laboratory (MEL) supports U.S. industry by strengthening its measurements and standards foundation. MEL's program in support of industry is broadly based. It stretches from basic metrology and national standards' traceability to manufacturing information exchange and systems integration technologies. It encompasses machine and process characterization methods and intelligent machine and process control technologies.

Industry uses MEL's measurement-related research results and data to realize interface standards, manufacturing systems architectures and models, and manufacturing engineering tools. Based upon the impact of its work, MEL is a primary resource for industry in infrastructure technology, measurements, and standards.

\section{5: A YEAR OF TRANSITION}

In 1995, MEL continued to improve its measurement expertise and the services it provides, continued to upgrade its facilities, and moved into new technologies in anticipation of more demanding needs by industry in the future. MEL also changed its leadership and launched a unique new flagship program. Each of the individual changes enabled it to serve its customers in industry better.

MEL has consistently had a successful record of meeting manufacturers' needs for measurements and science-based standards, research results, calibration services, measurement tools, test methods, and software conformance tests. The success comes partly from the collaboration with industry; through collaboration, MEL researchers learn first-hand about industry needs.
Individual firms and consortia are collaborating with us to develop new technologies and standards, particularly in a collaborative testbed environment. Manufacturers, suppliers, vendors, and standards organizations throughout industry are working with us to move toward true information-technology-based manufacturing. MEL's accomplishments in this past year of 1995 have contributed to U.S. industry's significant progress toward next-generation manufacturing.

Although 1995 was a year of transition in MEL, many technical projects reached significant milestones. These technical accomplishments, along with the organizational changes and the building of a new manufacturing testbed, bring the promise of new horizons for MEL. Even as the federal government endured a budgetary crunch in 1995, and the Congress initiated a national debate on federal research roles and directions, MEL continued moving toward the technologies and standards that will enable the needed infrastructure for twenty-first century manufacturing.

\section{5: MEL MOVES IN NEW DIRECTIONS}

It has been over a decade since MEL launched the then-advanced and pioneering research testbed called the Automated Manufacturing Research Facility (AMRF). The AMRF goal was to develop tools to integrate the individual machines, workstations, and functions of a factory into a smoothly operating whole. The AMRF provided a path for computer integrated manufacturing that helped create the current manufacturing model.

However, times and needs have changed. Manufacturers have resolved AMRF-era problems. Manufacturers now face a new set of challenges. In today's global environment, U.S. manufacturers must continuously im- 
prove precision and optimize designs and processes to achieve greater product reliability and quality. They constantly have to exact greater control over each manufacturing function to ensure quality.

Without better control and better precision and quality, U.S. manufacturers will be left behind in the global economic race. To help keep them in the race, MEL is building a new exemplar for twenty-first century manufacturing: a testbed for remotely capturing and analyzing data, sharing information, demonstrating manufacturing feasibility, building consensus, and learning collaboratively. Its name is the National Advanced Manufacturing Testbed (NAMT). It will be a nationwide, cross-disciplinary, open-access, multisite testbed for distributed and virtual manufacturing.

Results from the NAMT will help propel U.S. manufacturers into the next century with needed infrastructure technologies, both at the systems and equipment levels. Advanced metrology, control, and interoperability technologies developed collaboratively with industry in the NAMT will help create a new manufacturing model for tomorrow's global economic competition: true informationtechnology-based manufacturing.

We are entering an era where changing customer values are driving markets to change continuously. If it is to thrive, industry must respond by continuously changing also. For this to happen, it must constantly develop the enabling infrastructure technology to meet the changing challenges.

Therefore, MEL is changing too. Our work is evolving toward enhanced-accuracy, in-process manufacturing metrology and informationdriven manufacturing. This will extend our work on open-system standards for manufacturing system interoperability and for product and process data exchange into such areas as supply-chain integration. We are committed to helping U.S. manufacturers prosper in the next century.

The following sections outline some of MEL's significant 1995 milestones.

\section{5: ORGANIZATIONAL MILE- STONES-NEW LEADERSHIP}

In August, Dr. Richard H.F. Jackson took the helm as director of MEL. Dr. Jackson had been deputy director for eight years. In October, Dr. Jackson chose Mark Luce as his deputy and appointed Gary Carver as his scientific advisor. Mr. Luce had been the director of the interlaboratory Systems Integration for Manufacturing Applications program in MEL's Manufacturing Systems Integration Division. Also, a new chief, Richard Rhorer, was selected for the Fabrication Technology Division.

The Office of Industrial Relations and the Office of Manufacturing Programs were combined under the name "Office of Manufacturing Programs." Dr. Merrill Hessel was named the office chief. He is responsible for the new National Advanced Manufacturing Testbed (NAMT) and the annual National Conference on Advanced Manufacturing.

The 1995 conference was the second annual conference. Held at NIST in April, it had as its theme: "Toward a Common Agenda." Its overall goal was to take the first steps toward a consensus national agenda for manufacturing technology that could lead to a technology development plan for next-generation manufacturing systems. The national agenda will guide the manufacturing technology programs of the federal agencies. The conference emphasized the need for government, industry, academia, and workforce organizations to work together to develop and support manufacturing infrastructure programs of mutual benefit. 
The conference featured keynote speakers from industry and government, industry and government panels, and six concurrent workshops. The government panel speakers described and discussed the work of the National Science and Technology Council (NSTC) Committee on Civilian Technology (CCIT), and its subcommittees on Manufacturing Infrastructure and Advanced Manufacturing Processing. The industry panel members, who were from seven key industrial sectors, identified infrastructure and industry-sector-specific issues and needs. The concurrent workshops addressed infrastructure needs and priorities, based upon the industry panel discussions and draft white papers prepared by the CCIT Subcommittee on Manufacturing Infrastructure.

In February 1995, the National Initiative for Product Data Exchange (NIPDE) was successfully completed on schedule. Under Dr. Hessel's direction since its inception, NIPDE was a three-year industry-government program to increase the visibility to U.S. industry of product data exchange, and to accelerate the development, implementation and delivery of the international Standard for the Exchange of Product Model Data (STEP). The Initiative accomplished broad industry participation, developed capability action plans to define product data exchange needs in critical areas, and set up an electronic library, the National Product Data Exchange Resource Center, to provide up-to-date project descriptions and information on product data exchange. Before its conclusion, NIPDE activities were transferred to appropriate industry and government organizations, such as the U.S. Product Data Association and the NIST IGES/PDES Office.

\section{5: TECHNICAL MILESTONES- CONTRIBUTIONS IN METROLOGY, TECHNOLOGY, AND STANDARDS}

MEL's research particularly helped the discrete-part manufacturing industry. This industry relies upon machining to produce most high accuracy and high quality discrete products, mainly high-technology products. MEL's work on characterizing and controlling the machining process has enabled discretepart manufacturers to make dramatic improvements to machining processes and tools.

\section{MEL-Department of Energy Y-12 Facility Interagency Team Wins a "Hammer Award"}

An interagency team led by MEL staff in the Precision Engineering Division won Vice President Gore's Hammer Award for Customer Service. The award, only forty of which are granted annually throughout the federal government, recognizes federal organizations that overcome institutional barriers to meet customer needs.

The interagency team, comprised of MEL staff and staff from the Department of Energy's Y12 facility in Oak Ridge Tennessee, developed a new calibration service. The team innovatively designed a mechanism for a NIST calibration service to be performed by another federal agency's staff at its own facilities. The new service calibrates step gages on a large, high-accuracy coordinate measuring machine located at the Y-12 facility. NIST staff provide the technical and administrative control and $Y$ 12 staff carry out the actual calibrations. The service is needed by manufacturers of automobiles, aircraft, and other mechanical products who use step gages as industrial length standards. 
Interim Testing Artifact Becomes an Immediate Winner

Coordinate measuring machines (CMMs) are widely used throughout the manufacturing sector for discrete part measurement. A significant problem facing the users of CMMs is the lack of information on machine performance between scheduled calibrations. Often, calibrations are on a fixed cycle, typically six to twelve months. Meanwhile, a CMM can become out of calibration and reject good parts or accept bad ones.

To improve CMM reliability, MEL developed a measurement artifact and procedure for rapidly evaluating the performance of CMMs. The NIST Interim Testing Artifact (ITA) and its associated measurement procedure provides comprehensive evaluation of machine performance in less than 30 minutes. The results of this measurement increase CMM users' knowledge of their machine's measurement capability, and give them confidence that their measurement process is under control. Further, by diagnosing problems early and quickly, maintenance can be done as needed, instead on some fixed schedule.

A number of manufacturers are using the ITA in commercial environments. Sheffield Measurement Division of Giddings \& Lewis, a major U.S. coordinate measuring machine manufacturer, is now offering the ITA as a commercial product. In a separate effort, Boeing Commercial Airplane Group, in its first cooperative research and development agreement (CRADA) with a federal agency, is beginning to use the ITA in their CMM quality program. Boeing used the ITA, after an earthquake in Seattle Washington, to check CMMs for damage. The results showed that the CMMs suffered no detrimental effects and enabled Boeing to avoid the substantial expense and downtime that would have been required to recalibrate the machines.

Additionally, Boeing is currently extending the use of this MEL technology to machines tools with in-process measurement capabilities. Similarly, under a CRADA, Caterpillar Inc. is testing ITAs throughout the company.

\section{Rockwell Hardness Standards Get a Foundation in Precision Metrology}

The microform calibration of a small part includes both (1) the measurement, to micrometer or better resolution, of complex profile forms and position errors and (2) the determination of deviations from a specified profile and surface texture. An example of a microform calibration is the calibration of the geometrical parameters of Rockwell diamond indenters used for the hardness testing of materials. There is a strong industrial need to unify Rockwell hardness tests worldwide. MEL has addressed this need and has developed a Rockwell diamond indenter calibration that is traceable to fundamental standards. This calibration will unify Rockwell hardness standards through fundamental metrology rather than by the current performance comparisons. The NIST calibration procedure uses a commercial stylus instrument and a specified set of calibration and check standards.

An ISO Technical Committee meeting on Rockwell hardness standards

(ISO/TC164/SC3) was held at NIST in March. The delegates visited the Rockwell hardness calibration laboratory in the Metallurgy Division and the MEL surface and microform calibration laboratory. Before the committee meeting, a round-table discussion on the strategy of unifying international Rockwell hardness standards was held. In that discussion, NIST researchers pointed out that the unified European Rockwell Hardness Standard Scale is a "performance-based standard system." Therefore, it has disadvantages of non-traceability to fundamental metrology and an unknown systematic offset with respect to a "properly defined" Rockwell hardness scale. The NIST 
approach to unifying international Rockwell hardness standards, i.e., the "properly defined" scale, is through fundamental metrology. The metrology-based Rockwell hardness reference standards include a dead-weight testing machine (developed by the Instituto di Metrologia "G. Colonnetti," Italy, and in operation at NIST) and a standard class of Rockwell diamond indenters, which are more tightly controlled for dimension and form than previous classes of such indenters. The indenters are measured with a highaccuracy microform calibration system, such as the one developed by MEL. The testing machine and the indenters are used to create, maintain, and reproduce the Rockwell hardness scale and to unify the international Rockwell hardness standards. The response to the NIST approach was that a subcommittee be formed and that extensive testing of the microform and the performance of several types of indenters from Italy, Germany, Japan, and the United States be initiated.

\section{Acoustic Microscopy Made More Practical}

A novel approach to acoustic microscopy developed by MEL researchers uses a piezoelectric polymer transducer having a large aperture and a cylindrical focus. With this approach, material properties such as the elastic moduli and the homogeneity and anisotropy, can be determined. MEL researchers have filed a patent disclosure.

\section{Octahedral Hexapod, Representing a New Class of Machine Tools, Begins Testing}

In the spring of 1995, MEL received and installed an Ingersoll Octahedral Hexapod Machine. This is a new experimental class of machine tool based upon a parallel kinematic, exo-skeletal geometry. The innovative design features a Stewart platform suspended from an octahedral support frame. The octahedral hexapod machine tool combines a rigid frame with six-axes machining capability. Machine tools based upon such parallel kinematic configurations represent the first major departure from conventional machine tool design in nearly a century.

In today's global manufacturing environment, improved quality requires ever-tightening geometric tolerances, more sophisticated part geometries, and advanced materials. This is pushing U.S. manufacturers toward complex, high-precision, multiprocess and multiaxis machining operations. Parallel-actuated machine tools such as the Octahedral Hexapod offer the potential to do more than one operation on a single machine.

Also, in today's manufacturing environment, "leanness," reconfigurability, and "agility" are increasingly essential. Parallel structure machines are adaptable to the new environment because they do not have permanent foundations, are mechanically modular, and can be disassembled and reassembled easily. MEL is working with several machine tool builders and users in industry and government to explore and characterize this new machine tool configuration.

The research on the Hexapod Machine is cross-disciplinary; a variety of manufacturing technologies are being explored to further understanding of the capabilities of this new machine tool. Some representative goals of the collaborative effort include performance characterization, application of existing national standards, data representation and exchange (especially opportunities for standardization), and machine tool control (especially application of open-architecture controllers). The long term goal is to develop this new class of machine tool to where it can be inserted reliably into manufacturing systems. 
Molecular Measuring Machine Enters Service

This year the Molecular Measuring Machine $\left(\mathrm{M}^{3}\right)$ was officially announced as in "practical service." As proof, the results of measurements of the widths of electrical interconnects in integrated circuits were presented at an international conference. For this study, $\mathbf{M}^{3}$ operated unattended for forty hours straight, making about one million separate position measurements, with $0.1 \mathrm{~nm}$ resolution, to obtain an image of a $3 \mu \mathrm{m} \times 67 \mu \mathrm{m}$ area of a chrome line on a glass substrate. The results were used to help resolve the discrepancy between electrical and optical linewidth measurements and to improve the accuracy of linewidth standards produced by MEL for the semiconductor industry.

The Molecular Measuring Machine is a stateof-the-art, two-dimensional, scanning probe microscope designed to achieve one nanometer total uncertainty for point-to-point measurements over a $50 \mathrm{~mm} \times 50 \mathrm{~mm}$ area. In a sense, $M^{3}$ is a high resolution coordinate measuring machine that uses scanning tunneling and atomic force microscope probes to image atoms. The instrument has a state-ofthe-art temperature control system that maintains temperature stability to $100 \mu \mathrm{K}$, and an advanced seismic and acoustic vibration isolation system. The displacements are measured with a custom-built, state-of-the-art heterodyne interferometer.

Although testing is expected to continue for at least another year, the $\mathrm{M}^{3}$ is already helping semiconductor manufacturers to understand systematic differences between optical and electrical linewidth measurements and to develop measurement aids for aligning masks for optical lithography. $\mathrm{M}^{3}$ will be used to calibrate a variety of measurement references that manufacturers can use to check the accuracy of their own measurement artifacts.

$\mathrm{M}^{3}$ will allow using nature's own geometry to validate measurements. For example, crystallographic interatomic spacings could serve as molecular rulers. Also, $\mathrm{M}^{3}$ can be used to study what happens when one or more atoms are removed from the surface of a crystal.

Over the coming months, work will continue to characterize $\mathrm{M}^{3 \text { s }}$ s performance and to map irregularities in the motions of moving parts and other sources of measurement uncertainty. Since $\mathrm{M}^{3}$ is the only machine of its kind in the world, the jobs of refining and enhancing its capabilities may continue for years, even as it performs measurement services that will help U.S. industry stake its claims on the molecular frontier.

\section{Standard for the Exchange of Product Model Data (STEP) is Released}

The twelve documents that make up the initial release of STEP were published as International Standard ISO 10303. The documents, consisting of 2104 pages, fulfill the goal of a single world standard for product data representation and digital exchange.

Until STEP, each function in the manufacturing process has had its own view of the information about the product. This makes it difficult to share knowledge among functions, a problem acerbated by the trend toward distributed manufacturing. Now, with STEP, one product data standard exists to integrate the different perspectives and to enable worldwide digital exchange of product and manufacturing information.

STEP is a format for capturing product information in a computerized, systemindependent representation. It provides for the representation and exchange of product models with enough content to permit direct interpretation by advanced application programs without human intervention. A STEP representation of a product contains all the data needed to completely define a 
product over its expected life cycle. This includes the product shape and tolerances, materials, part composition, assembly relationships, and all the information needed for design, analysis, manufacture, test, inspection, and support of the product.

The initial release of STEP proves the STEP technology architecture but addresses only two application areas, drafting and product configuration management. Work is underway on twenty-five additional application areas that span a wide range of manufactured products.

\section{Enhanced Machine Controller Is Introduced to Actual Production}

The controller is a key component of manufacturing machines because it determines their performance, throughput, usability, and integratibility with sensors and with the rest of the factory environment. Open architecture technology will enable improved controllers and lower costs.

Work on the enhanced machine controller is aimed at developing public domain, open system interfaces that will support interchangeable software for machine tool controllers, robot controllers, coordinate measuring machine controllers, and other manufacturing equipment. A fully tested and documented enhanced machine controller for a 4-axis horizontal machining center was installed at the General Motors (GM) Powertrain plant in Pontiac, Michigan. The GM controller is the first production-tested controller that conforms to an interface specification that was developed in collaboration with the Department of Energy's Technologies Enabling Agile Manufacturing (TEAM) program.

Another open architecture machine tool controller was transferred to the Defense General Supply Center (DGSC) in Mechanicsburg, Pennsylvania. This controller utilizes commercially available hardware and software from multiple vendors that are integrated under a common set of application programming interfaces. DGSC will use the technology to rebuild and retrofit machine tools used by the Defense Department.

An industry-MEL consortium is evaluating proposed EMC standards in production applications. Members of the consortium include GM, Ford, Chrysler, Boeing, and United Technologies Research Center.

\section{CMM Algorithm Testing and Evaluation Test Service Is Inaugurated}

The MEL Algorithm Testing and Evaluation Program for Coordinate Measuring Systems has had the first five industry customers for its new NIST Special Test Service. The test service compares a customer's fit results to NIST reference algorithm results. The customer receives a Report of Special Test that summarizes the performance of the customer's coordinate measuring system software. With ISO 9000 certification becoming more of a requirement among manufacturing inspection systems, the new service offers U.S. manufacturers a domestically available source for coordinate measuring system performance testing. In addition, customers may obtain the NIST reference algorithm for their own use.

\section{5: GUIDED THROUGH CHANGE BY A VISION}

In the past, manufacturing organizations massproduced products to gain economies of scale. Today, in partnership with their suppliers, manufacturers are incorporating advanced technologies to make the manufacturing process, from designing to recycling, more flexible and responsive. To meet today's challenges, manufacturers must push flexibility and responsiveness to the ultimate. They must become more fluid in structure and more adaptable in business practices. They must produce individualized products to meet the 
unique needs of each of their customers-and they will need to do it ever more rapidly.

"Intelligence," in all its different meanings and nuances, will be key to successful twenty-first century manufacturing. People at all levels in all parts of manufacturing organizations must use their intelligence (the faculty to think and reason) to decide more quickly and reliably, using all available information. Also, they must continually learn new skills and new technologies throughout their careers. Machine intelligence (the capacity to acquire and apply knowledge) will be needed to ensure that equipment and systems respond quickly and automatically to changing conditions. Marketing intelligence (received information or news) will need updating constantly to enable firms to respond to customers' desires for new and improved products. Finally, gathering intelligence (secret information) about competitors by both manufacturers and governments will probably become more commonplace than it is today.
We in MEL are observing and studying (intelligently, we believe) the rapidly changing trends in manufacturing so that we can continue into the next century meeting the needs of our customers in industry. We are guided and energized by the MEL vision: " $A$ world-class national research laboratory recognized as the primary resource for infrastructural technology, measurements, and standards for the U.S. manufacturing industries." We intend to remain world class, and-as we too change to meet the challenge-we confidently believe that industry will continue to recognize us as a "primary resource." The reason we are confident is unambiguous: we will work hard to continue our traditions of leadership and partnership with the manufacturing industries in infrastructural technology, measurements, and standards. 


\section{Elements of a Strategic Plan}

The primary aim of a manufacturing enterprise is to deliver quality products that meet the needs of its customers. The primary aim of the Manufacturing Engineering Laboratory (MEL) is to work with its customers, the U.S. manufacturing industries, to develop and apply infrastructural technology, measurements, and standards to meet their needs.

Manufacturing is not just fabricating products from raw materials. Although the essence of manufacturing is transforming materials into products, modern manufacturing encompasses a wider variety of activities. Manufacturing activities start with product development planning, such as representing and exchanging knowledge about the product's form, dimensions and function, designing the product, and planning the production process.

Other manufacturing activities include controlling production machines and processes. Examples are handling materials, scheduling production, sensing and interpreting data before, during, and after production, and communicating between workers and machines. Finally, manufacturing activities include assembly, packaging, quality assurance, and marketing. Added to the activities of manufacturing, the issues of timeliness, cost effectiveness, safety, environmental friendliness, and reliability are critical factors in every manufacturing operation. As the leading federal laboratory for infrastructural technology, measurements, and standards for manufacturing, MEL supports a wide range of manufacturing activity areas and issues. MEL gives U.S. manufacturing industry tools that it uses to improve efficiency and competitiveness.

Manufacturing is vital to the U.S. economy. Manufactured products represent approximately twenty percent (about $\$ 1$ trillion) of our gross national product. Manufacturing industries employ twenty-one million people, about seventeen percent of the total workforce. Every 100 new manufacturing jobs creates over sixty nonmanufacturing jobs. A healthy and robust manufacturing infrastructure that produces quality, customer-valued products, enables U.S. industry to compete successfully in international markets. A strong manufacturing infrastructure also allows the nation to sustain its economic growth, maintain a high standard of living, create jobs, and provide a strong national defense. By anticipating and addressing the needs of U.S. manufacturing industries for the next generation of physical and informational measurements and standards, MEL contributes to U.S. industrial competitiveness and economic prosperity.

$M E L$

supports the manufacturing technology infrastructure.

MEL contributes to U.S. competitiveness and economic prosperity.

Increased global competition is causing dramatic changes in the way products are manufactured. The rapidly changing competitive environment makes it necessary for U.S. industry to accelerate the development and application of advanced manufacturing technologies. The acceleration ensures the United States of future competitiveness in both national and international markets. MEL provides U.S. industry with state-of-the-art manufacturing architectures, models, data, and algorithms in advanced manufacturing technologies to help accelerate manufacturing technology development. 
The Manufacturing Engineering Laboratory works with its customers to identify critical needs in the advanced manufacturing technology infrastructure that supports U.S. industrial competitiveness. To address the critical needs, the Laboratory's activities are divided into four key thrusts: manufacturing systems integration, intelligent machines and systems, manufacturing metrology, and manufacturing processes and equipment. MEL's program consists of selected technical projects within these thrusts. The projects assist U.S. industry in developing necessary MEL helps meet critical industry new technology, measurements, and standards. 


\section{Vision \\ A world-class national research Laboratory recognized as the primary resource \\ for infrastructural technology, measurements, and standards \\ for the U.S. manufacturing industries.}

The Manufacturing Engineering Laboratory (MEL) is the leading federal laboratory for measurement-related research and development in manufacturing infrastructural technology. MEL's research and development leads to standards, test methods, and data that are crucial to industry's success in exploiting advanced manufacturing technology. Such technology can improve productivity and quality, reduce cost and time to market, increase profits, support higher wages, and lower the environmental impact of manufacturing operations.

While maintaining that vital and unique role, MEL has broadened its scope to encompass infrastructural technology. In cooperation with industry, MEL has become the federal government's key resource for supporting technology development in advanced manufacturing and for transferring manufacturing technology to industrial applications. MEL focuses on manufacturing supplier and user industries, and on industrial applications of advanced manufacturing technology to construction, transportation, environmental restoration, and health care. In this broader scope, MEL's work includes measurement, planning and control, communication, and methods for developing, representing, and communicating knowledge about products and processes.

\section{Mission}

To improve the competitiveness of U.S. manufacturing by working with industry to develop and apply infrastructural technology, measurements, and standards.

The Manufacturing Engineering Laboratory is unique because it serves the whole enterprise, in each of the manufacturing sectors, over the whole range of technologies. To carry out its mission, MEL:

Conducts research on manufacturing infrastructural technologies, Participates in manufacturing-related standards development, Provides measurement services to manufacturing industries, Provides manufacturing integration testbeds, Develops next-generation manufacturing metrology, and Collaborates with industry on new manufacturing technology. 


\section{Goals}

Through a strategic planning process, the Manufacturing Engineering Laboratory management established five goals for the Laboratory. The goals relate to traceability, measurements and standards, manufacturing architectures implementation, and customer satisfaction.

Traceability

Measurements and standards

Manufacturing architectures

Implementation
Goal 1: To establish MEL as the pinnacle of the traceability pyramid of physical and informational measurements for U.S. manufacturing products, processes, and services.

The MEL research, development, and technology transfer programs embrace both physical and informational technologies. MEL maintains and makes accessible to industry traceability to national standards in length, mass, force, vibration, acoustic, and ultrasonic measurements, as well as to certain software testing systems and enterprise management tools.

\section{Goal 2: To anticipate and address the needs of U.S.} manufacturing industry for the next generation of physical and informational measurements and standards.

The Laboratory develops test and measurement techniques and provides calibration, measurement and test services to support industry needs. By monitoring the trends in requested services, consulting with industry on anticipated new requirements, and participating in new manufacturing technology development, MEL can forecast future industry measurement and standards needs. MEL also participates in private sector committees that develop formal documentary standards.

\section{Goal 3: To provide U.S. industry with state-of-the-art} manufacturing architectures, models, data, and algorithms.

MEL efforts in this area help create new generic architectures, such as those for machine controllers. MEL works to enable interoperability among manufacturing equipment and software tools and to anticipate necessary standards.

\section{Goal 4: To foster the development and implementation of} advanced manufacturing systems, processes, and equipment.

MEL efforts to foster the development and implementation of advanced manufacturing technology include the development of measurement techniques to characterize machines, and tools and their interactions with machined parts. MEL also works to develop the data, sensors, and models necessary for in-process gauging and controling. This reduces life cycle costs associated with man- 
ufacturing equipment by defining open, public domain specification and programing interfaces for equipment components.

\section{Goal 5: To improve customer satisfaction and MEL operational effectiveness.}

MEL continually seeks informal feedback from customers in daily interactions and more formally in workshops designed to solicit customer needs. Continuous improvement is pursued. Strategic planning, consensus building, and encouraging all staff to participate in decisionmaking are techniques used to spark improvements in MEL operational effectiveness.

Customer Satisfaction

\section{Customers}

The Manufacturing Engineering Laboratory has three types of customers: customers whom we directly assist, sponsors outside of NIST who fund our work, and oversight bodies who assess or evaluate the impact of our work. These customers represent industry, government, academia, standards organizations, consortia, technical societies, and the public. They include users of our services and products, and participants in our programs.

Oversight is through a formal chain and includes taxpayers, the Department of Commerce, the Office of Science and Technology Policy, the Office of Management and Budget, and Congress, as well as outside reviewing bodies such as the National Research Council.

MEL provides consultations, products, and services, including physical measurement services such as calibrations and standard reference materials. In exchange, the outside sponsors and users of our consultations, products, and services provide direct or in-kind financial support. During the years 1985 to 1993, funding from sponsors represented over half of the total MEL budget. These outside organizations, usually other government agencies, used the unique technical expertise of MEL scientists and researchers to enhance their own work, to meet their own goals, or to solve their measurement problems. However, for MEL to accept funding and agree to do the work, there are criteria that ensure mutual benefits. They include technical merit, potential for economic benefits, matching with MEL goals and priorities, meeting specific industry needs, availability of resources, and potential for collaboration and relationships with others.

MEL is proud of its reputation of responsiveness to its customers. By including customer satisfaction as one of its goals, MEL is demonstrating its commitment to serving those who can benefit from our work. 


\section{Resources}

The Manufacturing Engineering Laboratory receives its operating funds both from the NIST budget and from outside sources, mainly other government agencies. In fiscal year 1994, for the first time in ten years, funding from the NIST budget exceeded funding obtained from other sources. In fiscal year 1995, the STRS/OA ratio increased further.

MEL's total funding in fiscal year 1995 was $\$ 40,929,000$. Of this, $\$ 24,251,000$ came from the NIST budget and $\$ 8,916,000$ came from other government agencies. A smaller portion, $\$ 2,477,000$, came from NIST's Advanced Technology Program and Manufacturing Extension Partnership. The remainder of the budget was from reimbursable services such as calibrations, standard reference materials, the services of the Fabrication Technology Division, and from cooperative research and development agreements and miscellaneous expenses and income.

Source of Funding

NIST budget [Scientific and Technical Research and Services (STRS)]

Other government agencies $(\mathrm{OA})$

NIST Advanced Technology Program and

Manufacturing Extension Partnership

[Industrial Technology Services (ITS)]

Other [calibrations, standard reference materials, cooperative research and development agreements, miscellaneous expenses and income, and Fabrication Technology Division's services.
Amount (in thousands)

$\$ 24,251$

$\$ 8,916$

$\$ 2,477$

$\$ 5,285$

The human resources in the Manufacturing Engineering Laboratory are the staff and guest researchers. Currently, there are 183 scientists and engineers, 37 technicians, 37 wage grade employees, and 45 support personnel, including clerical employees. Among the scientists and engineers, $28 \%$ hold $\mathrm{PhDs}$, 32\% hold master's degrees, and $40 \%$ hold bachelor's degrees. 


\section{Products and Services}

The Manufacturing Engineering Laboratory delivers products and services to its customers through communications, collaborations, demonstrations, equipment transfers, reimbursable services, and participation in voluntary standards organizations. Each of these mechanisms can be equally effective, depending upon the need that is being met. MEL communications include technical publications, presentations, and consultations. Important communication forums are conferences, workshops, and standards working groups where representatives from outside NIST discuss and develop action plans with us to meet industry needs. Attending meetings, visiting other organizations, and hosting visitors to our facilities contribute to communications.

Collaborations involve a wide range of joint activities. One type of collaboration is direct collaboration with outside partners on research and development projects. Testbeds are an effective way to collaborate with others on advanced technology and standards development and testing. Collaborations also include staff participation in standards organizations and professional societies. The enablers for direct collaborations are contracts, grants, cooperative research and development agreements (CRADAs), and guest researcher agreements. A new enabler will be the recently established industrial fellowship program.

Sometimes, collaborations lead to MEL installing hardware or software at a customer's or partner's location. Such installations serve to implement MEL-developed advanced technology quickly and to provide a test of the technology under actual operating conditions in a manufacturing environment.

Reimbursable services are the paid services that MEL provides, including calibration and fabrication services, and standard reference materials.

\section{Evaluating Our Performance}

The Manufacturing Engineering Laboratory sets its priorities, and evaluates its performance based upon the benefits realized by U.S. industry. Because of the variety and breadth of the work in MEL, the evaluation procedures must be flexible. Therefore, instead of specific criteria, a set of performance metrics is applied.

The performance metrics that form the basis of MEL's evaluation system are both qualitative and quantitative measurements of its economic and competitive impact. Performance metrics are made up of activity, progress, output, and significance metrics.

Activity metrics are measures of the size of the effort that led to a particular result and how many customers the result affected. Customers, interactions, staffing, and budget are included in activity metrics. The following are examples of information developed from activity-related measures that may be used to evaluate a project or assess a service.

Amounts of resources applied to the work

Number of interactions with customers

Amount of participation in consortia and standards organizations 
Time spent on cooperative research with industry and other federal agencies

Number of customers served and income generated

Use of unique facilities and testbeds by outside organizations

In-kind contributions by outside organizations

Progress Metrics are measures of achievement that indicate the status of a project or service. Progress metrics examine milestones and the results of internal and external reviews. Specific examples that apply progress metrics are:

Progress Metrics

Output Metrics

Significance Metrics
Degree to which program plans are successfully executed

On-time achievement of milestones

On-schedule delivery of results

Decrease in time required for deliverables

Development of unique research facilities and testbeds

Success in attracting, developing, and retaining a diverse, world class staff

Positive feedback from National Research Council Assessment Panel

Output metrics are the quantitative measures of productivity. Typically, MEL measures its output by the numbers of countable actions, collaborations, or deliverables as shown in the following list.

Significance metrics are the measures of the quality, value, and impact of the results on U.S. industry. The following examples show the way MEL measures significance.
Papers and reports published
Patents and licenses awarded
Technical achievements
Active CRADAs
Joint projects with other NIST laboratories and outside partners
Guest workers
Workshops and conferences
Standard reference materials produced
Calibrations and fabrication services performed

Economic and competitive impact of technical results, patents, and licenses

Success in technology transfer to customers

Quality and relevance of technical output

Uniqueness and quality of research facilities, services and capabilities

Ability to provide critical advanced calibration, fabrication, and SRM services not available elsewhere

Ability to anticipate and establish critical SRM, calibration and fabrication services to meet new needs

Customer services compare well against a "best practice" benchmark

Number of companies claiming to be benefited by output

Degree of innovation

Leadership in outside activities

Awards and external recognition 
Education and experience level of staff

Distribution of staff among engineering and science disciplines

Diversity of staff

Quality of papers published

Number of invited papers and presentations

Press coverage

Results of the assessment panel and extent to which recommendations were followed

Results of surveys and impact studies indicating high quality or significant impact 


\section{Technical Thrusts}

As part of its strategic planning and strategy implementing process, the Manufacturing Engineering Laboratory focuses on four technical thrust areas: Manufacturing Systems Integration, Intelligent Machines, Manufacturing Metrology, and Manufacturing Processes and Equipment. By focusing on the thrust areas, MEL is better able to concentrate its expertise in the most important areas to help U.S. manufacturers and to improve the manufacturing technology infrastructure.

\section{Thrust 1: Develop Interface Standards to Support a Fully-Integrated Set of Manufacturing Systems That Demonstrate a Virtual Manufacturing Enterprise}

MEL addresses the information technology needs of manufacturers by concentrating on computer-integrated, electronically-networked manufacturing technologies and applications. Emphasis is on the development, implementation, testing, and dissemination of interface standards. The goal is a fully integrated set of interface standards to support a virtual manufacturing enterprise. The information technologies include integration frameworks, data representations, and data/knowledge exchange. The information technologies and applications are primarily product data exchange, design engineering, manufacturing systems engineering tools, and electronic commerce.

Manufacturing

In product data exchange, the work concentrates on the methods, tools, and conformance testing systems for application protocols that will be part of the new Standard for Exchange of Product Model Data (STEP). Design engineering and production systems work is on technologies and Systems Integration standards in support of environments for mechanical part production and apparel, and on systems integration to support those environments. Application areas includes the design of products, processes, and enterprises; planning and scheduling; process modeling; shop floor control; simulation; inspection; assembly; and machining.

The manufacturing systems engineering tools effort develops new technologies, methods, computer-aided tools, and standards for future engineering manufacturing systems. It develops engineering principles, design methodologies, and design tools for use in specifying, designing, building, testing, and evaluating both manufacturing engineering and real-time intelligent control systems.

Efforts in the area of electronic commerce address the development of technology and standards required to conduct commerce electronically and build an overall enterprise environment for manufacturing. 


\section{Thrust 2: Develop Performance Measures and Interface Standards to Support Industry Needs in Manufacturing}

Intelligent machine control is one of the most frequently mentioned technologies in surveys and lists of critical needs in manufacturing. Intelligent machines technology is a critical enabling component of advanced control systems for controlling machines, factories, processes, traffic, and vehicles. This thrust encompasses intelligent machines, open systems architecture, and simulation and modeling. These technologies are cross-disciplinary and foster collaboration among industry, universities, and government agencies.

Intelligent Machines and Systems

Manufacturing Metrology
Work on intelligent machines includes reference model architectures for intelligent controls, transformation of sensory data into models and knowledge databases, open systems architecture, simulation and modeling, development of metrics and performance measures, and standards. Plans for the work include demonstrating an integrated intelligent machine system testbed incorporating visual perception, force controlled manipulation, product and process models, simulation based reasoning, path planning, mobility, advanced operator interfaces, and development of engineering methods and computer-aided software engineering (CASE) tools.

The open systems architecture work seeks to improve the performance and functionality of manufacturing processes, machines, and tools. The work is developing interface standards for integrating commercial components from multiple suppliers. This enables modularity, extensibility, and portability of software across platforms.

Simulation and modeling efforts concentrate on validating methods, techniques, and technologies. These help management and technical personnel make better decisions about the design and control of manufacturing systems.

\section{Thrust 3: Address Industry Needs for Fast, Reliable Measurements by Developing Measurement Systems and Standards}

The manufacturing metrology thrust incorporates research, development and services that provide more effective metrology support to U.S. manufacturing industries. Work under this thrust covers the chain of traceability from national standards through working standards to industrial process-control measurements, inspections and tests. The manufacturing metrology thrust focuses on dimensional and mechanical metrology, dimensional measurement inspection and test systems, nanotechnology, and advanced material processing manufacturing systems.

Dimensional and mechanical metrology work includes state-of-the-art calibration services and standard reference materials, as well as the research and development needed to provide them. The work covers the units of length and mass and the derived units of acceleration, sound pressure, dynamic displacement, sound reflectivity, and force.

Dimensional measurement inspection and test systems are the systems used by manufacturing industries for achieving and assessing the conformity of the dimensions of manufactured parts and assemblies to design tolerances. Sensor technology is addressed, as well as the processing of sensory data and the development of intelligent control algorithms. 
Nanometrology efforts deal with the standards and technology associated with measurement of dimensions which are nanometers in size. Activities include application of the molecular measuring machine for calibrations; research and development support; development and application of scanning probe microscopies; and calibrated artifacts for probe size.

Advanced material processing manufacturing systems are sensor-based computer-controlled automated systems that integrate material processing and material shaping operations for the manufacture of final discrete part products. This includes atomic scale processes that can be used to build-up increasingly larger multi-atom features.

\section{Thrust 4: Advance the State of the Art of High-Speed and High-Precision Manufacturing by Sensor-Based Metrology, Process Modeling, and Process Control}

The manufacturing processes and equipment thrust combines precision machining, nontraditional machining, manufacturing systems engineering tools, and fabrication services. Precision machining efforts work toward improving the accuracy of machine tools, coordinate measuring machines, and other machines that use sensor technology. These efforts include better characterization technologies for machines, processes, and tools and better integration of inprocess and post-process measurement and control. The objective is to develop a science base for precision material removal and shaping processes and for sensor-based adaptive control of precision machining processes. In the long term, this will extend beyond metal cutting and forming to manufacturing with other materials.

Nontraditional machining systems efforts aim to increase the flexibility of unconventional manufacturing processes and machine materials in specialty grinding, turning, milling, machining, casting, and stereo lithography.

Manufacturing systems engineering tools involves developing new technologies, methods, tools, and standards to implement computer-aided tools for the engineering manufacturing systems of the future. The objective is to investigate critical areas pertaining to engineering U.S. factories and to identifying and developing solutions for computer-aided factory engineering. This work accelerates the application of computer technology to the design and engineering of manufacturing systems.

Fabrication services provides design, fabrication, modification, and repairs to ultra-precise scientific instruments, apparatus, and equipment in support of NIST research and services. 


\section{Project Descriptions}

The following project descriptions outline the resources, objectives, needs addressed, accomplishments, and plans for projects in the Laboratory. Five-year plans include the years 1996 through 2000 . The project plans summarize the work of the Manufacturing Engineering Laboratory and provide a basis for building an even stronger program that will meet industry needs in the future.

The description of each project is in two parts. The first part is two pages of information on the project's resources, objectives, needs addressed, previous-fiscal-year accomplishments, and current-fiscal-year plans. The second part is a chart showing the planned schedule for major activities during fiscal years 1996 through 2000 . In the five-year-plan charts, the acronyms STRS represents scientific and technical research and services and OA represents other agency. (A complete list of acronyms begins on page 207.)

Under "Staff," the project leader's name is in capital letters. An asterisk identifies staff members who work part time on the project.

Except for the projects within the NAMT, which are presented first, the projects are grouped into the technical divisions of the Manufacturing Engineering Laboratory. MEL is organized into one office, four technical divisions, and the Fabrication Technology Division, as shown on the following organization chart. 


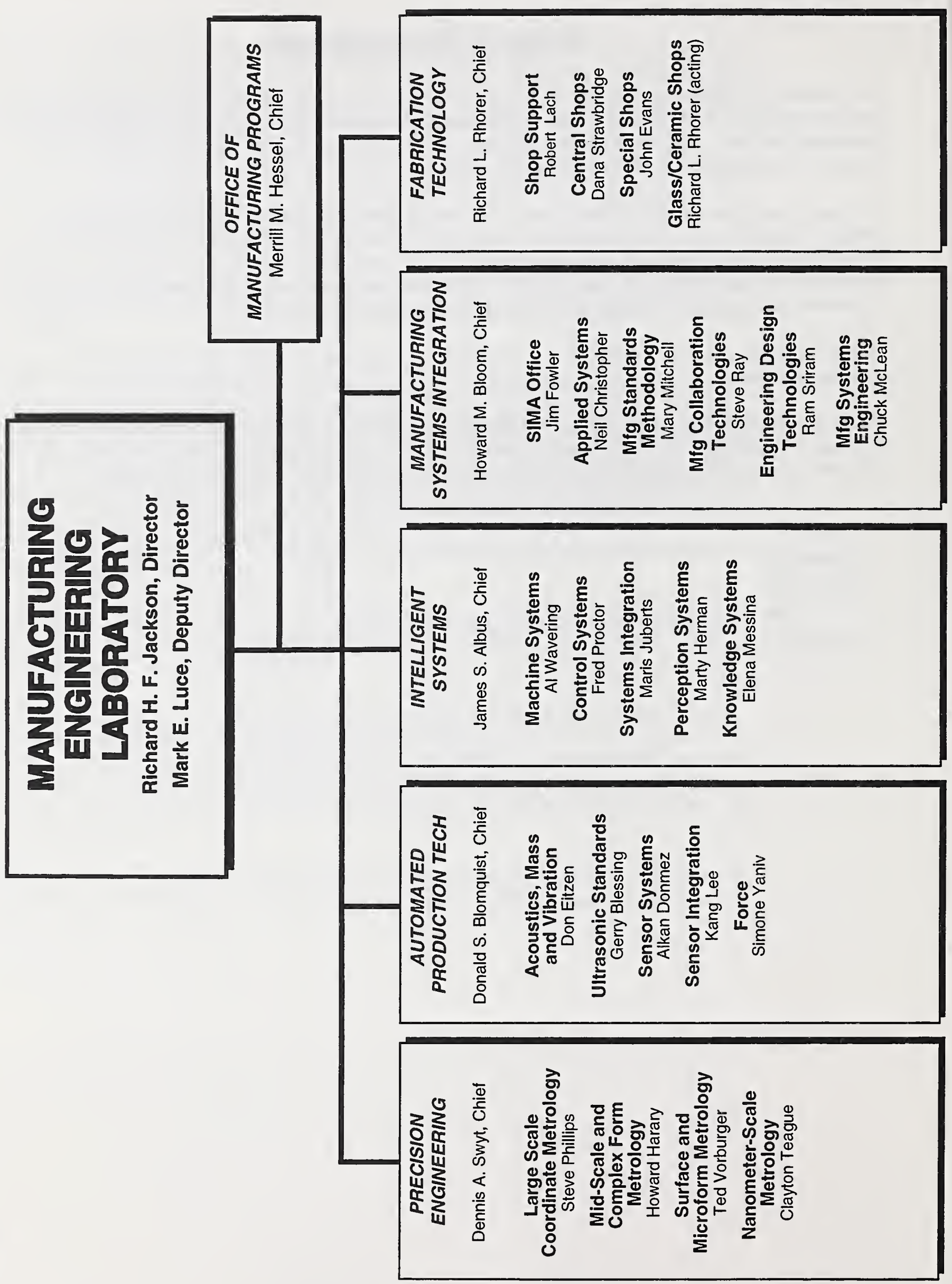




\section{NATIONAL \\ ADVANCED \\ MANUFACTURING \\ TESTBED \\ (NAMT)}

The National Advanced Manufacturing Testbed (NAMT) is a new program to address the research needs for technologies and standards for distributed and virtual manufacturing. The goals of the NAMT are to provide the infrastructure to enable companies to design and manufacture products rapidly and to speed U.S. industry's evolution toward distributed and virtual manufacturing.

NAMT researchers are developing the scientific basis and technical underpinnings necessary to achieve manufacturing environments that are shared, accessible, integrated, and information based. The research focuses on measurements, communication protocols, interfaces, and other standardes and infrastructural technologies.

NAMT researchers, located in their home environments, cooperate on an array of advanced manufacturing research projects. Their efforts benefit from a shared foundation of supporting technologies for textual, audio, and visual communications as well as common sets of computing tools, such as databases, electronic software repositories, and modeling and simulation programs. Current and future work will concentrate on overcoming complexities that prevent "plug and play" interoperability across dispersed and disparate manufacturing systems. 
Staff: (4.4 staff years) ALBERT WAVERING, *Tom Wheatley, *Joe Falco, *Nicholas Dagalakis, *Fred Rudder, *Hans Soons, *Bob Lach, *Evan Wallace

Project Objective and MEL Thrust(s) Supported: To develop methods to characterize and extend the limits of performance of a new class of Stewart platform-based machine tools in terms of accuracy, productivity, and versatility, through the development and implementation of virtual and distributed manufacturing technology. Manufacturing Metrology, Manufacturing Processes and Equipment, Virtual and Distributed Manufacturing

Need(s) Addressed: A new class of machine tools based on parallel kinematics (also known as Stewart platform or hexapod machines) has recently been introduced. They offer a unique combination of stiffness, speed, dexterity, and accuracy characteristics. Machine tool users are interested in applying these new machine tools to complex contoured parts such as molds, dies, and jet engine components. These manufacturers are looking to this new machine tool technology in search of higher productivity and part quality. U.S. machine tool manufacturers are currently a step ahead of foreign competitors in the development of parallel machine tool technology. If progress can be made in establishing parallel machines as viable tools for precision manufacture, it could alter the future of the machine tool industry world wide. The technology leadership of U.S. machine tool manufacturing must be maintained in this changing environment.

Ever-increasing tolerance demands and productivity improvements are required for U.S. manufacturers to remain competitive. More sophisticated part geometries dictate increased use of multi-axis machining capability. Parallel-actuated machine tools have the potential to meet these needs. NIST has been approached by machine tool builders and users who consider developments in this field to be an important factor in achieving future productivity gains. They are looking to NIST for performance evaluation techniques to apply to these new machine configurations, and for assistance in exploring the limits of this technology in terms of positioning accuracy and resolution, speed and productivity, and advanced control capabilities.

Technical Approach: The approach to be followed for development of performance evaluation techniques will be to use the ANSI/ASME B5.54-1992, Methods for Performance Evaluation of computer Numerically Controlled Machining Centers and ISO 230 as starting points for characterization. Modifications will then be proposed to these test procedures as necessary to make them more appropriate for hexapod machines. This aspect of the project also involves interaction with the APTD NAMT project in developing more complete characterizations of Stewart platform machine tool performance.

To explore the accuracy potential of hexapod machines, laser-based metrology will be investigated for strut length measurement and microactuation will be examined for improved strut positioning resolution. Another possible use for microactuation is for active damping to reduce strut vibrations. These strut-based enhancements will be implemented first on a single strut mounted on a test stand, then migrated to the full machine. Thermal modeling and compensation will be necessary to achieve high accuracy strut length measurements. Another important means for improving the machine accuracy will be to develop improved calibration techniques for identifying the kinematic parameters of the machine. This calibration may be based on measurements from conventional ball bar, laser ball bar, or a NIST-developed six degrees-of-freedom positioning sensor, used along with an iterative gradient search algorithm based on the Jacobian which relates small changes in kinematic parameters to corresponding spindle platform motions.

To implement distributed manufacturing capabilities, this project will leverage work that has been done at Sandia Laboratories using high-bandwidth dedicated communications for remote interaction. In addition to replicating this high-performance, but relatively expensive, network communications channels for real-time video and sensor data communications, alternatives for providing similar services which would be more 
accessible to universities and small companies (with a performance compromise), will be explored. Electronic communications will also be used in working with industry partners to transfer part program and measurement result data. A World Wide Web site will be created as a mechanism to share project results, both with collaborators and the public.

The virtual manufacturing elements of this project consist of simulation tools that will be developed to allow prediction and visualization of hexapod machine behavior. This will provide important capabilities for trying out test parts prior to actual machining, which will be useful in joint work with industry partners. An incremental approach will be followed to develop the desired simulation capabilities. First, purely kinematic relationships will be implemented. Then detail will be added to improve the simulation fidelity using rigid-body dynamics or lumped-parameter stiffness models, and finite-element analysis for modeling structural dynamics. The modeling and simulation aspects of this project will benefit from and contribute to the characterization and capability modeling efforts of the APTD NAMT project.

To extend machine controller Application Programmer Interfaces (APIs) to accommodate special requirements of hexapod machines, and to allow more flexibility and access in modifying controller functionality, an Enhanced Machine Controller (EMC) will be installed on the Hexapod. This will lead to the modification and extension of the API standards currently being developed within the Enhanced Machine Controller Project. This controller will be tested using the strut and machine simulations, and the test strut hardware. Modifications necessary for implementation on the full machine (primarily PLC) will then be added and the resulting EMC controller will be installed. The original controller will be kept intact such that the two controllers can be switched in and out as necessary. The Hexapod EMC controller will also tie into standards being developed within the Manufacturing Systems Integration Division NAMT project by integrating it with a shop level controller, a Product Data Management (PDM) system, and an object oriented database (OODB) using the Common Object Request Broker Architecture-based (CORBA) SEMATECH CIM Framework.

\section{FY95 Accomplishments:}

- Performed detailed design of microactuator retrofit for a single strut.

- Worked toward adapting EMC controller for use with Octahedral Hexapod.

- Trained NIST personnel to operate the Hexapod machine.

- Installed Hexapod machine and test strut in AMTST.

- Procured additional equipment necessary for machine operation (tooling, riser blocks, etc.)

- Constructed and performed preliminary testing of prototype single-strut microactuator.

- Performed initial tests with laser distance measuring device on the test strut.

- Converted a Pratt \& Whitney part program for use with the Hexapod.

- Procured control and dynamic systems modeling, analysis, and simulation software.

- Developed prototype software for computing Hexapod kinematics, stiffness, workspace, joint limits, and strut collisions.

\section{FY96 Plans:}

- Develop effective kinematic calibration technique (with APTD, PED).

- Extend DOE Distributed Manufacturing capability to Hexapod.

- Establish Hexapod project web server (with MSID).

- Develop Hexapod modeling and simulation capabilities using Pro/Engineer and Telegrip.

- Implement EMC for test strut.

- Install laser metrology system on test strut.

- Integrate laser metrology system with motion controller.

- Conduct performance tests of laser metrology system on test strut.

- Develop first-generation part placement optimization tools (with University of Maryland). 
- Perform tests to identify dynamic parameters (with OSU).

- Continue to work with machine tool users to perform tests and identify candidate applications (with Pratt \& Whitney).

- Conduct workshop on Advanced Machine Tool Structures.

- Publish report of project results.

Five-Year Plan Goals vs. Fiscal Years:

\begin{tabular}{|c|c|c|c|c|c|}
\hline $\begin{array}{l}\text { CHARACTERIZATION, REMOTE ACCESS, AND } \\
\text { SIMULATION OF HEXAPOD MACHINES }\end{array}$ & 96 & 97 & 98 & 98 & 00 \\
\hline \multicolumn{6}{|l|}{ Performance Characterization [STRS] } \\
\hline \multicolumn{6}{|l|}{$\begin{array}{l}\text { Perform baseline metrology and performance } \\
\text { characterization tests }\end{array}$} \\
\hline \multicolumn{6}{|l|}{ Perform basic machining tests } \\
\hline \multicolumn{6}{|l|}{$\begin{array}{l}\text { Develop and test metrology system for } \\
\text { characterizing tool tip positioning accuracy for vector } \\
\text { motion across work volume }\end{array}$} \\
\hline Develop error model for parallel machines & $\square$ & & & & \\
\hline \multicolumn{6}{|l|}{$\begin{array}{l}\text { Develop techniques to measure or estimate } \\
\text { parametric errors }\end{array}$} \\
\hline \multicolumn{6}{|l|}{ Perform machining tests of complex parts } \\
\hline \multicolumn{6}{|l|}{$\begin{array}{l}\text { Develop modifications to B5 and ISO } 230 \text { as } \\
\text { necessary }\end{array}$} \\
\hline \multicolumn{6}{|l|}{$\begin{array}{l}\text { Carry out performance characterization tests to } \\
\text { evaluate machine modifications }\end{array}$} \\
\hline \multicolumn{6}{|l|}{ Distributed Manufacturing [STRS] } \\
\hline \multicolumn{6}{|l|}{ Establish internal network connections } \\
\hline \multicolumn{6}{|l|}{$\begin{array}{l}\text { Replicate T1-based DOE remote interaction } \\
\text { capabilities }\end{array}$} \\
\hline \multicolumn{6}{|l|}{$\begin{array}{l}\text { Enhance T1-based services (e.g., add video control } \\
\text { operator interface, remote sensor data interface) }\end{array}$} \\
\hline \multicolumn{6}{|l|}{ Establish WWW hardware and page organization } \\
\hline \multicolumn{6}{|l|}{$\begin{array}{l}\text { Populate WWW page with project information and } \\
\text { results }\end{array}$} \\
\hline \multicolumn{6}{|l|}{ Develop network interface to EMC controller } \\
\hline \multicolumn{6}{|l|}{ Virtual Manufacturing [STRS] } \\
\hline \multicolumn{6}{|l|}{$\begin{array}{l}\text { Develop CAD model-based kinematic simulation of } \\
\text { Hexapod }\end{array}$} \\
\hline \multicolumn{6}{|l|}{ Develop NC program previewing capability } \\
\hline Develop EMC interface (for testing and development) & & & & & \\
\hline
\end{tabular}




\begin{tabular}{|c|c|c|c|c|c|}
\hline $\begin{array}{l}\text { CHARACTERIZATION, REMOTE ACCESS, AND } \\
\text { SIMULATION OF HEXAPOD MACHINES }\end{array}$ & 96 & 97 & 98 & 99 & 00 \\
\hline $\begin{array}{l}\text { Develop workspace analysis and part placement } \\
\text { optimization tools }\end{array}$ & & $\bar{E}$ & & & \\
\hline $\begin{array}{l}\text { Perform dynamic parameter identification } \\
\text { experiments }\end{array}$ & & & & & \\
\hline Develop lumped-parameter stiffness model & & 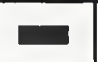 & & & \\
\hline Incorporate rigid body dynamics into simulation & & - & & & \\
\hline Incorporate nonlinear effects (e.g., friction, backlash) & & - & & & \\
\hline Incorporate tool-workpiece interaction model & & & & & \\
\hline $\begin{array}{l}\text { Incorporate finite element analysis of structural } \\
\text { dynamics }\end{array}$ & & & & & \\
\hline Develop machine design tools & & & & & \\
\hline Performance Enhancement [STRS] & & & & & \\
\hline $\begin{array}{l}\text { Develop and test prototype laser distance metrology } \\
\text { system for test strut }\end{array}$ & & & & & \\
\hline $\begin{array}{l}\text { Integrate and test prototype microactuation system } \\
\text { for test strut }\end{array}$ & & & & & \\
\hline Develop model-based control algorithms & & & & & \\
\hline $\begin{array}{l}\text { Retrofit metrology and microactuator enhancements } \\
\text { to full machine }\end{array}$ & & & & & \\
\hline Develop thermal control and/or compensation & & 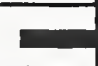 & & & \\
\hline Implement chatter control and/or compensation & & & $=$ & & \\
\hline Investigate high-speed machining on Hexapod & & & & 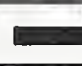 & \\
\hline EMC Implementation & & & & & \\
\hline $\begin{array}{l}\text { Develop initial implementation of EMC-based } \\
\text { controller }\end{array}$ & & & & & \\
\hline Test EMC controller on test strut & $=$ & a & & & \\
\hline Test EMC controller using simulation of machine & & 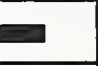 & & & \\
\hline $\begin{array}{l}\text { Integrate laser distance metrology and } \\
\text { microactuation }\end{array}$ & & 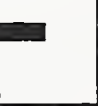 & & & \\
\hline $\begin{array}{l}\text { Integrate EMC controller with SLC, PDM, and OODB } \\
\text { using CORBA-based Sematech CIM Framework }\end{array}$ & & 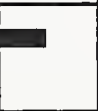 & & & \\
\hline $\begin{array}{l}\text { Make modifications necessary to install EMC on full } \\
\text { machine }(I / O)\end{array}$ & & & & & \\
\hline Install EMC on full machine and test & & 国 & & & \\
\hline Implement on-machine part probing & & & & & \\
\hline
\end{tabular}




\begin{tabular}{|c|c|c|c|c|c|}
\hline $\begin{array}{l}\text { CHARACTERIZATION, REMOTE ACCESS, AND } \\
\text { SIMULATION OF HEXAPOD MACHINES }\end{array}$ & 96 & 97 & 98 & 99 & 00 \\
\hline $\begin{array}{l}\text { Integrate performance enhancements (model-based } \\
\text { control, thermal compensation, high-speed spindle, } \\
\text { etc.) }\end{array}$ & & & & & \\
\hline
\end{tabular}




\section{Title: DEVELOPMENT OF MACHINE TOOL PERFORMANCE REPRESENTATION MODELS AND OF A MACHINE DATA REPOSITORY}

Staff: (4.2 staff years) ${ }^{*}$ D. Blomqu ist, ${ }^{*}$ A. Donmez, ${ }^{*}$ A. Ling, ${ }^{*}$ D. Gilsin, ${ }^{*}$ H. Harary, ${ }^{*}$ A. Wavering, ${ }^{*} \mathrm{~K}$. Jurrens.

Project Objective and MEL Thrust(s) Supported: To create a virtual manufacturing environment in cooperation with Caterpillar, Inc. And the University of North Carolina to simulate the complete manufacturing cycle so that industry can reduce the time for new product introduction by elimination of the necessity to machine and inspect prototype parts. Manufacturing Processes and Equipment.

Need(s) Addressed: To reduce the design and production cycles, manufacturers need robust tools to predict their manufacturing capabilities before they start manufacturing prototypes for new products. The conventional sequence of operations starts with the raw stock of material and the design information. From these pieces of information a process plan is developed that takes into account existing machines tools following the process plan and inspected on CMMs after production to verify the conformance to the specifications. Carrying out these operations for prototyping purposes is a very costly effort, since, in general, the outcome cannot be predicted with existing design and analysis tools. Creating a virtual manufacturing environment to simulate the complete manufacturing cycle presents a unique opportunity for industry to reduce the time for new product introduction.

Technical Approach: The major challenge in creating a virtual manufacturing environment is representing machine tools'performance capabilities and the resulting part geometries when these machine tools are used to produce parts and CMMs are used to inspect the parts. Currently, there is no provision in the machine tool or CMM standard to store the performance information in any electronic/computer media. The lack of standard representation of this type of information prevents the creation of machine data repositories to test different simulation algorithms and compare one machine' performance against many other machines within a similar category. The technical approach is a joint effort among the four technical divisions in the Manufacturing Engineering Laboratory, Caterpillar, Inc., and the University of North Carolina at Charlotte to develop methods for the creation of a machine tool performance data repository. To achieve this goal, first a standard format for representing meaningful machine tool performance data must be created, including provisions for storing information such as error notation, sign conventions, axis designations, machine structural descriptions etc. Once the format is evaluated for its applicability a data base structure will be developed to accommodate this data format. In the next step, machine tools at NIST, the University of North Carolina at Charlotte and selected ones at Caterpillar plants will be characterized to obtain the data needed to populate the depository. In addition, remote access mechanisms will be developed to allow remote access by project participants.

\section{FY96 Plans:}

- Develop project plans.

- Scope out needed infrastructure.

- Procure required equipment.

- Demonstrate distributed and virtual manufacturing cpabilities.

Related Developments: Related research at North Carolina State at Charlotte, sponsored by Caterpillar. 
Five-Year Plan Goals vs. Fiscal Years:

\begin{tabular}{|l|l|l|l|l|l|}
\hline $\begin{array}{l}\text { DEVELOPMENT OF MACHINE TOOL PERFORMANCE } \\
\text { REPRESENTATION MODELS AND OF A MACHINE DATA } \\
\text { REPOSITORY }\end{array}$ & 96 & 97 & 98 & 99 & 00 \\
\hline $\begin{array}{l}\text { Sponsor and industrial workshop to ascertain industry } \\
\text { requirements [STRS] }\end{array}$ & & & & & \\
\hline $\begin{array}{l}\text { Develop data format for representation of machine tool } \\
\text { performance data [STRS] }\end{array}$ & & & & & \\
\hline Evaluate in cooperation with industry data format [STRS] & & & & & \\
\hline $\begin{array}{l}\text { Develop database structure to accommodate machine tool } \\
\text { performance data [STRS] }\end{array}$ & & & & & \\
\hline $\begin{array}{l}\text { Obtain new machine tool data and convert old data to new } \\
\text { format [STRS] }\end{array}$ & & & & & \\
\hline Develop repository [STRS] & & & & \\
\hline $\begin{array}{l}\text { Populate repository with existing information [STRS] } \\
\text { Complete development of improved/new accelerometer } \\
\text { calibration for } 20 \mathrm{kHz} \text { to } 40 \mathrm{kHz} \text { [STRS] }\end{array}$ & & & & & \\
\hline $\begin{array}{l}\text { Complete development of improved accelerometer } \\
\text { calibration for } 3 \mathrm{~Hz} \text { to } 1 \mathrm{kHz} \text { [STRS] }\end{array}$ & & & & & \\
\hline
\end{tabular}


Staff: (7 staff years) Edward Barkmeyer, NEIL CHRISTOPHER, *Alcan Donmez, Howard Moncarz, *Steve Osella, *David Sauder, *Harry Scott, Selden Stewart, Evan Wallace, ${ }^{*}$ Ted Vorburger

Project Objective and MEL Thrust(s) Supported: Contribute to U.S. industrial competitiveness by working with industry to develop standards for the integration of engineering design, planning, and production software systems. This project will accomplish its objective by collaborating with related projects to develop system integration specifications, information models, and reference software implementations. The project will promote the results of its collaborations into formal standards processes. Manufacturing Systems Integration.

Need(s) Addressed: In response to marketplace demands, U.S. manufacturing enterprises are taking competitive advantage of geographically diverse resources by forming strategic partnerships and distributing manufacturing operations. The NAMT Framework project will prototype a manufacturing software system that supports distributed design engineering, manufacturing engineering, production engineering, and production operations for discrete parts manufacturing. This prototype will be based on emerging infrastructure technologies that are likely candidates for international standardization. It will be the experimental basis for further development of standards and specifications. The standards and specifications will focus manufacturingspecific information that is exchanged between manufacturing systems. The prototype standards, and specifications will be used by the U.S. manufacturing community in the creation of distributed systems tailored to the needs of particular manufacturing enterprises.

Technical Approach: In the project's first development cycle, the prototype will be a distributed system consisting of a shop controller, an inspection workstation controller, a product data management system, an object-oriented database, and a "guardian" interface for monitoring system operations. In the second development cycle the Framework project will add a controller for the NIST Hexapod machine tool and two or more manufacturing engineering software applications such as simulation and process planning. The second development cycle will incorporate links to manufacturing applications located at the site of at least one industry partner. Subsequent development cycles will add design engineering applications, additional links to industry sites and will demonstrate virtual manufacturing in a distributed environment. Industry collaboration, technology transfer, consensus building and standards development will be performed in parallel with the prototype development.

The NAMT Framework project will incorporate prior work performed in NIST's Manufacturing Engineering Laboratory (MEL). The prior work includes the Manufacturing Systems Integration (MSI) project, the Enhanced Machine Control (EMC) project, the Next Generation Inspection System (NGIS) project, the Quality In Automation (QIA) project, and the Systems Integration of Manufacturing Applications (SIMA) program. The NAMT Framework project will collaborate with the NAMT Hexapod project and the NAMT Machine Tool Performance project. This project will also share technical deliverables with the National Industrial Information Infrastructure Protocol (NIIIP) program, the Technologies Enabling Agile Manufacturing (TEAM) program, and the SEMATECH Computer Integrated Manufacturing Applications Framework (CIM-F) project.

The NAMT Framework project will employ the Object Management Group's (OMG) Common Object Request Broker Architecture (CORBA) to describe the interfaces and implement the communications among the software components. It will work through the OMG's Manufacturing Task Force (MfgTF) and the Real-time Special Interest Group to build consensus on issues relating to distributed manufacturing systems. This project will work through ISO Technical Committee 184 Sub-committee 4 (ISO TC184/SC4) on issues relating to product data modeling, representation, and exchange. It will work through ISO Technical Committee 184 Subcommittee 5 (ISO TC184/SC5) on issues relating to manufacturing enterprise architectures. 
FY95 Accomplishments:

- Developed the Technical Corrigendum of the Draft International Standard ISO 10303 Part 21, Standard Data Access Interface (SDAI).

- Completed the final edits to ISO 11404 Language Independent Datatypes and transmitted to Geneva for publication.

- Performed baseline testing of Object Request Brokers over the wide area network for use in distributed manufacturing system in collaboration with the Software Engineering Institute.

- Prototyped a distributed object system of Sandia design analysis software by employing CORBAbased tools in collaboration with the Software Engineering Institute and Sandia National Laboratory.

- Completed the "SIMA Reference Architecture - Part 1 Activity Model" for industry review and publication.

- Collaborated with on the development on a generic controller shell and messaging with the NIST Joint Control Architecture project.

- Hosted NIST Architect's Roundtable workshop of participants from national consortia and began working toward convergence of architectural concepts and essential standards.

\section{FY96 Plans:}

- Prototype a distributed manufacturing system consisting of manufacturing equipment controllers, manufacturing engineering software, and information management systems by employing object technology, pre-standard information models, message models, and interface designs.

- Develop new pre-standard models of manufacturing information for part measurement and quality control operations using inspection workstations and related equipment.

- Evaluate the opportunities to generalize the SEMATECH CIM Framework into the discrete parts manufacturing domain by analyzing the equipment controller messaging model, the manufacturing information models, the interface specifications, and the underlying communications model.

- Participate in the Object Management Group Manufacturing Task Force to evaluate and promote manufacturing specific common object facilities.

- Convene the second NIST Architect's Roundtable and a NIST conference on CIM Frameworks for the manufacturing industry.

Related Developments: (1) Completion of the SEMATECH Computer Integrated Manufacturing (CIM-F) Application Framework Specification version 1.3 and CIM-F C+ Reference Implementation. (2) Establishment of the OMG Manufacturing Task Force to accommodate the manufacturing industry's requirements of the Common Object Request Broker Architecture (CORBA) and NIST's membership in the OMG. (3) Establishment of the TEAM Integration Thrust group effort in developing consensus on a framework for distributed manufacturing systems. (4) Announcement of the NIST ATP TIMA program awards.

\section{Five-Year Plan Goals vs. Fiscal Years:}

\begin{tabular}{|c|c|c|c|c|c|}
\hline NAMT FRAMEWORK & 96 & 97 & 98 & 98 & 00 \\
\hline $\begin{array}{l}\text { Create Cycle } 1 \text { Prototype system implementation based on } \\
\text { Sematech CIM-F, OMG CORBA, NIST Enhanced Machine } \\
\text { Controller, and pre-standard models of manufacturing } \\
\text { information. Reference Architecture specifying design, } \\
\text { planning, and production engineering activities and } \\
\text { information sources [STRS] }\end{array}$ & & & & & \\
\hline
\end{tabular}




\begin{tabular}{|c|c|c|c|c|c|}
\hline NAMT FRAMEWORK & 98 & 97 & 98 & 98 & 00 \\
\hline $\begin{array}{l}\text { Generalize and publish interfaces, information models, and } \\
\text { messaging specifications created in Cycle } 1 \text { [STRS] }\end{array}$ & & & & & \\
\hline $\begin{array}{l}\text { Submit pre-standard information models interfaces and } \\
\text { message specifications to the appropriate standards } \\
\text { processes and participate in consensus building [STRS] }\end{array}$ & & & & & \\
\hline $\begin{array}{l}\text { Create Cycle } 2 \text { Prototype system implementation based on } \\
\text { Cycle } 1 \text { developments enhancements and refinements. } \\
\text { Extend the work to link to at least one other remotely located } \\
\text { framework implementation. Include control of the Hexapod } \\
\text { machine tool and additional manufacturing engineering } \\
\text { applications [STRS] }\end{array}$ & & & $=$ & & \\
\hline $\begin{array}{l}\text { Generalize and publish interfaces, information models, and } \\
\text { messaging specifications created in the Cycle } 2 \text { prototype } \\
\text { development [STRS] }\end{array}$ & & & $=$ & & \\
\hline $\begin{array}{l}\text { Submit pre-standard information models interfaces and } \\
\text { message specifications developed in Cycle } 2 \text { to the } \\
\text { appropriate standards processes and participate in } \\
\text { consensus building [STRS] }\end{array}$ & & & & $\mathbf{m}$ & \\
\hline $\begin{array}{l}\text { Create Cycle } 3 \text { prototype system implementation based on } \\
\text { Cycle } 2 \text { developments Extend the work to include } \\
\text { applications in engineering design operations and evaluate } \\
\text { the use of agent based programs [STRS] }\end{array}$ & & & $=$ & ש & \\
\hline $\begin{array}{l}\text { Generalize and publish interfaces, information models, and } \\
\text { messaging specifications created in the Cycle } 3 \text { prototype } \\
\text { development [STRS] }\end{array}$ & & & & $=$ & \\
\hline $\begin{array}{l}\text { Submit pre-standard information models interfaces and } \\
\text { message specifications developed in Cycle } 3 \text { to the } \\
\text { appropriate standards processes and participate in } \\
\text { consensus building [STRS] }\end{array}$ & & & & & \\
\hline
\end{tabular}


Staff: (3.5 staff years) ${ }^{*}$ Brad Damazo, *Dick Rhorer, *Dennis Swyt, *Clayton Teague, *Ted Vorburger, *Evan Wallace, ${ }^{*}$ Tom Wheatley, ${ }^{*}$ Ric Silver, ${ }^{*}$ John Dagata, ${ }^{*}$ Joe Fu, $*$ Ron Dixson,

Objective and MEL Thrust(s) Supported: The objective of this project is to support the advance of the technology and practice of distributed-and-virtual manufacturing in the nano-regime by development of the means to fabricate prototype atom-based microelectronic dimensional standards in a distributed-and-virtualmanufacturing mode. Manufacturing Metrology

Need(s) Addressed: In our vision of the future of microelectronic manufacture, atom-based microelectronic devices and standards, which will need to live their entire lives under vacuum, will be produced not, as now, within one vacuum chamber in a clean-room facility at one site but within separate vacuum chambers, including those within different clean-room facilities and at different sites. Each of these separate sites would carry out some specialized function in the overall manufacture of a either a device or lithographic mask, including R\&D, design, fabrication, inspection, processing or repair. There are three major types of industry needs to achieve this vision of distributed-and-virtual nanomanufacturing: first, standard-interface transport systems for moving in-process materials between among sites; second, the standard-interface control systems to allow teleoperation of atomic-resolution inspection instruments such as scanning probe microscopes; and, third, standard manufacturing information architectures and representations specific to the instruments, devices and processes of nanomanufacturing, including, design data of devices and masks and real-time diagnostic information of SPMs.

Technical Approach: The project has three major tasks and associated deliverables:

(1) Vacuum Suitcase: The first major task is development of a standardized-interface, portable, shippable chamber to allow physical transport under vacuum of wafers and other substrates undergoing processing in highvacuum systems in clean-room facilities at geographically different locations. These different locations can be different facilities at the same site or different sites. The shippable chamber, being called a "vacuum suitcase," is an essential element in the move from an AMRF-paradigm physically monolithic processing chamber to a NAMT-paradigm physically distributed processing system. In collaboration with vendors of vacuum equipment and users of such equipment, this project will develop a prototype "vacuum suitcase" for transfer of wafers and substrates between the PED UHV-STM, the EEEL MBE machine, the Sandia wafer-processing system and related industry systems.

(2) SPM Remote Teleoperation Testbed: The second major task is demonstration of remote diagnostic operation of scanned-probe-microscopy systems using standard data representations and controller interfaces. With the increasing requirement for microelectronic wafer processing and device fabrication completely within cleanroom environments, there is a growing need for not only automated control of processes and roboticmanipulation of wafers and carriers, but remote "through-the-clean-room-wall" teleoperation of scanned probe microscopes used for inspection of fabricated microstructures and remote "from-a-vendor's-firm" teleoperation of such SPMs for instrument trouble-shooting. In collaboration with vendors and users of SPM instruments, the project will develop a test bed for the identification of standard interface needs and issues in SPM teleoperation and supply results to the voluntary standards process.

(3) Atom-Based Dimensional Calibration Standards: The third and last major task of this project is demonstration of feasibility of fabrication of artifacts with dimensioned features derived from atomic-lattice properties. With the decrease in the size and tolerances of dimensioned features in micro-, nano-, and quantumelectronic devices, there is need for artifacts as calibration standards which have feature sizes and uniformities in geometry which are nanometer and sub-nanometer in scale. Rather than depending on the removal or addition of material to form dimensioned features of arbitrary size and shape, an alternative for the fabrication of 
calibration standards with nanometer-scale dimensions and high geometric perfection is to use controlled natural processes (such as lattice dislocations) which yield features of size and shape determine by crystal lattice spacings and geometries. In collaboration with vendors and users of commercial dimensional calibration standards, the project will demonstrate feasibility of fabricating such atom-based calibration standards.

FY96 Plans:

- Enlist industrial conferees, collaborators, and formal partners.

- Demonstrate current vacuum and design technology version of vacuum suitcase.

- Draft functional specifications of three major subsystems (teleoperation SEM or SPM; vacuum suitcase; and atom-based artifact).

- Test motion control and interface on prototype SEM or SPM for teleoperation.

- Design and fabricate functionally-specified vacuum suitcase.

- Manually fabricate first prototype of one atom-based artifact.

Related Developments: Further the development of the Molecular Measuring Machine toward design goal measurement uncertainty.

Five-Year Plan Goals vs. Fiscal Years:

\begin{tabular}{|l|l|l|l|l|l||}
\hline \hline $\begin{array}{l}\text { NANOMANUFACTURING OF ATOM-BASED } \\
\text { STANDARDS }\end{array}$ & 96 & 97 & 98 & 99 & 00 \\
\hline $\begin{array}{l}\text { Demonstration of standardized-interface transport of in- } \\
\text { vacuum artifacts [STRS] }\end{array}$ & & & & & \\
\hline $\begin{array}{l}\text { Demonstration of standardized-interface remote diagnostic } \\
\text { operation of SPM [STRS] }\end{array}$ & & & & & \\
\hline $\begin{array}{l}\text { Pilot fabrication of atom-based dimensional calibration } \\
\text { standard [STRS] }\end{array}$ & & & & & \\
\hline
\end{tabular}




\section{PRECISION \\ ENGINEERING \\ DIVISION}

\section{MISSION:}

Conducts research and development in precision-engineered length-metrology-intensive systems, both measuring and production machines. Provides delivery of industriallyimportant length-related measurements, standards, and infrastructural technology services in support of U.S. manufacturing's products and processes. Features of interest range in size from multiple meters to sub-nanometer and are measured by framed and frameless general and special-purpose measuring probes, machines, and systems, employing the spectrum of optical, mechanical, electrical and quantum-mechanical phenomena, beginning with firstprinciples realization of the Sl unit of length by means of stabilized lasers and displacement interferometry. 
Staff: $(2.5$ staff years $) *$ T. VORBURGER, R. Dixson, J. Fu, V. Tsai, *P. Sullivan

Objective and MEL Thrust(s) Supported: The project objective is to support high resolution surface microscopies used by U.S. manufacturing industries for micrometer scale metrology. Manufacturing Metrology

Need(s) Addressed: Manufacturers of integrated circuits, opto-electronic devices, data storage media, and optical components use high resolution surface microscopy for quality and process control. Manufacturers require standards to verify proper instrument calibration and maintain process control. Uncalibrated measurements impact yield, process development costs, scaling from pilot lines to high throughput manufacturing, and correlation of product attributes with process models. Calibrated microscopy is an enabling technology for the manufacture of digitally based consumer products. This market, driven by the convergence of the information and entertainment industries, is projected to grow to three trillion dollars by the year 2002. [1] In 1994, the manufacture of microelectronic devices comprised a world market of $\$ 85$ billion.

Technical Approach: Atomic force microscopy (AFM) has evolved rapidly since its invention in 1986. AFM has revolutionized surface microscopy, allowing the acquisition of surface topography from both conducting and nonconducting surfaces with unprecedented lateral and vertical resolution. Indeed, AFM has demonstrated a lateral resolution of $0.3 \mathrm{~nm}$ and a vertical resolution of $0.01 \mathrm{~nm}$. To date, this microscopy has not been used by NIST for making traceable measurements. The cornerstone of this project is the development of an AFM with traceability to the wavelength of light in all three coordinate axes.

This "calibrated" AFM (CAFM) will be used to calibrate pitch and height artifacts for use in U.S. industry. The instrument will calibrate pitch artifacts ranging in size from approximately $5 \mu \mathrm{m}$ down to $0.5 \mu \mathrm{m}$ and height artifacts ranging from approximately $1 \mu \mathrm{m}$ down to $0.3 \mathrm{~nm}$.

Scanning electron microscopy (SEM) is used throughout industry. SEM is used for inspecting products for defects, contamination, and conformance to geometrical tolerances. Additionally, reliability personnel often rely on SEM to determine the cause of product failure. Accurate, reproducible SEM measurements are dependent upon the availability and use of magnification standards for microscope calibration.

Our mission includes the calibration of Standard Reference Material (SRM) 484, a magnification standard for SEMs. SRM 484 allows SEM operators to calibrate their instruments over magnifications ranging from $1000 \times$ to $20000 \times$. Seven previous issues of this popular SRM have been sold. The current issue, SRM $484 \mathrm{~g}$, was calibrated in FY95. The project's current metrology SEM is aging. During FY96, we will test the Amray metrology SEM in the Nano-Scale Metrology Group for the calibration of SRM 484.

\section{FY95 Accomplishments:}

- Performed high precision pitch measurements with the CAFM, which compared favorably with other techniques.

- Performed initial step height measurements with the CAFM and observed interesting tip-sample interactions, which will require further investigation.

- Installed improved X-Y motion stage on the CAFM.

- Completed the measurements for certification of SRM 484g.

- Provided measurement support for two opto-electronics companies receiving ATP funding.

- Provided measurement support for VLSI Standards Inc., a leading manufacturer/marketer of industrial calibration artifacts.

- Published five articles in scientific journals and conference proceedings. 
FY96 Plans:

- Set up formal calibration facility using the C-AFM for the calibration of pitch/height artifacts: upgrade instrumentation; develop calibration data acquisition and analysis procedures; determine measurement uncertainty; calibrate pitch/height artifacts. An example goal for calibration is $1 \mathrm{~nm}$ expanded uncertainty for $100 \mathrm{~nm}$ height measurements and $3 \mathrm{~nm}$ expanded uncertainty for $3 \mu \mathrm{m}$ pitch measurements.

- Continue technical support of CRADA partners (Park Scientific Instruments, VLSI Standards Incorporated, and Optex Corporation).

- $\quad$ Present and publish at least three papers at the SPIE Lithography Conference.

- Complete measurements of linewidth prototype under Digital Semiconductor CRADA.

- Test Amray metrology SEM for use in calibration of SRM 484.

Related Developments: Two senior staff members of this project have recently taken positions with the same instrument manufacturer. We have reassigned J. Fu to this project and have also secured the services of university contractor, P. Sullivan (part-time).

Five-Year Plan Goals vs. Fiscal Years:

\begin{tabular}{|c|c|c|c|c|c|}
\hline CALIBRATED SURFACE MICROSCOPY & 96 & 97 & 98 & 99 & 00 \\
\hline \multicolumn{6}{|l|}{$\begin{array}{l}\text { Upgrade equipment and methods for CAFM microscope } \\
\text { calibration services [STRS, SEMATECH] }\end{array}$} \\
\hline \multicolumn{6}{|l|}{$\begin{array}{l}\text { Operate calibration service of pitch/height artifacts for } \\
\text { calibration of AFM microscopes [STRS] }\end{array}$} \\
\hline \multicolumn{6}{|l|}{$\begin{array}{l}\text { Provide microscopy measurement support and consultation } \\
\text { for Uniphase, Park Scientific Instruments, Optex, VLSI } \\
\text { Standards, and other CRADA partners [STRS] }\end{array}$} \\
\hline \multicolumn{6}{|l|}{ Calibrate SEM magnification standard (SRM 484h) [STRS] } \\
\hline \multicolumn{6}{|l|}{$\begin{array}{l}\text { Perform SRM } 484 \text { magnification standard calibration on } \\
\text { Nano-Scale Metrology group's SEM [STRS] }\end{array}$} \\
\hline $\begin{array}{l}\text { Provide calibration support for front-end-of-line AFM wafer } \\
\text { microscopy at Digital Semiconductor and other integrated } \\
\text { circuit manufacturing companies [STRS] }\end{array}$ & & & & & \\
\hline
\end{tabular}

Footnote [1]:

John Scully, former CEO Apple Computer (1992). 
Staff: (2.0 Staff Years) JOHN STOUP, Ted Doiron, Jay Zimmerman, Bryon Faust

Objective and MEL Thrust(s) Supported: To improve the MEL dimensional measurement capabilities in the areas of length, form, diameter, and flatness. Manufacturing Metrology

Need(s) Addressed: NIST is required to provide traceability to physical and intrinsic national standards that insure standardization for the manufacturing industry of the United States. Pressure for improved dimensional measurement capabilities has been increasing with rapid technological advances in the manufacturing industry. Improvements in NIST measurement capabilities will have direct economic benefits for our calibration clients by allowing them into areas of design and research previously unapproachable due to measurement constraints. The increased emphasis on global economic standardization and reciprocity requires NIST to maintain levels of measurement capability equal to those in other national laboratories around the world.

Technical Approach: Using newly developed techniques and software, we will extend the capabilities of existing MEL dimensional calibration equipment to their practical limits. State-of-the-art statistical process control and environmental compensation and monitoring are NIST strengths in the field of dimensional calibration. Improvements in these areas will produce higher accuracy with lower associated uncertainties for these measurements. Further improvements in these areas will be addressed by analyzing new equipment and processes that are currently available commercially. With cooperation from our calibration clients and equipment manufacturers, we will develop improved calibration services in several ways. We will procure new equipment and implement NIST measurement techniques and statistical process control to extend their capability. We will use unique data collection algorithms and measurement principles to develop new eqipment with improved accuracy and range. We will exploit existing commercial equipment by introducing it into areas not originally intended for its use and develop new approaches to attack long term measurement limitations.

\section{FY95 Accomplishments:}

- Implemented a laser based micrometer for absolute measurements of wires and cylinders into the NIST dimensional calibration services.

- Delivered the laser micrometer to Newark Air Force Base as per the contract.

- Developed SRM's for 126 micron wire diameter and ferrule diameter.

- Analyzed the performance of the Pratt \& Whitney labmaster in the area of plain ring calibration.

- Received and performed initial testing on the Zygo phase stepping interferometer.

- Analyzed the AAMACS angle calibration system for implementation as a calibration instrument.

\section{FY96 Plans:}

- Complete the artifact positioning system and micrometer enclosure for environmental control.

- Continue development of a cylindricity calibration with check standards and SPC using existing MEL equipment.

- Continue the development of the ZYGO phase stepping interferometer for dilatometry and gage block interferometry.

- Develop the AAMACS angle positioning instrument into a viable measurement resource.

- Implement a comparison version of the laser micrometer for all wire and cylinder calibration requirements complete with flexible contact configurations.

- Explore the possibilities of the new Strang Viewer-based gage block phase measurement method and implement if possible.

- Implement a green laser in the long gage block interferometry system. 
Five-Year Plan Goals vs. Fiscal Years:

\begin{tabular}{|l|l|l|l|l|l|}
\hline CALIBRATION RESEARCH AND DEVELOPMENT & 96 & 97 & 96 & 99 & 00 \\
\hline $\begin{array}{l}\text { Complete the artifact positioning system and micrometer } \\
\text { enclosure for environmental control [STRS, Calibration] }\end{array}$ & & & & & \\
\hline $\begin{array}{l}\text { Continue development of a cylindricity calibration with check } \\
\text { standards and SPC using existing MEL equipment [STRS, } \\
\text { Calibration] }\end{array}$ & & & & & \\
\hline $\begin{array}{l}\text { Explore the possibility of a new beyond the state-of-the-art } \\
\text { cylindricity capability [STRS, Calibration] }\end{array}$ & & & & & \\
\hline $\begin{array}{l}\text { Continue the development of the ZYGO phase stepping } \\
\text { interferometer for dilatometry and gage block interferometry } \\
\text { [STRS, Calibration] }\end{array}$ & & & & & \\
\hline $\begin{array}{l}\text { Develop the AAMACS angle positioning instrument into a } \\
\text { viable measurement resource [STRS, Calibration] }\end{array}$ & & & & & \\
\hline $\begin{array}{l}\text { Implement a comparison version of the laser micrometer for } \\
\text { all wire and cylinder calibration requirements complete with } \\
\text { flexible contact configurations [STRS, Calibration] }\end{array}$ & & & & & \\
\hline $\begin{array}{l}\text { Explore the possibilities of the new Strang Viewer based } \\
\text { gage block phase measurement method and implement if } \\
\text { possible [STRS, Calibration] }\end{array}$ & & & & & \\
\hline $\begin{array}{l}\text { Implement a green laser in the long gage block } \\
\text { interferometry system [STRS, Calibration] }\end{array}$ & & & & & \\
\hline \hline
\end{tabular}


Staff: (4.9 staff years) ERIC STANFIELD, Bryon Faust, Alan Rannals, Mike Stocker, *Danny Taylor, *Eddie Erber, *Dennis Everett, *Ted Doiron, *Jay Zimmerman, *John Stoup, *Jack Stone

Objective and MEL Thrust(s) Supported: To assist industry, government, academia by providing highaccuracy calibrations, traceability to national standards, and expert technical advice. Manufacturing Metrology

Need(s) Addressed: Target customers: domestic and international private industry and government. Target customer needs: high-accuracy calibration of dimensional artifacts, traceability to national standards, technical assistance, and reasonable calibration turnaround time and cost.

Technical Approach: Perform quality calibrations by reporting parameter specific data with the lowest attainable uncertainty in a test report format which includes a NIST test number specific to each test.

\section{FY95 Accomplishments:}

- $\quad$ Performed calibrations using the new NIST developed laser displacement horizontal micrometer to measure cylinder and thread wire diameter, yielding lower uncertainty than previously attainable.

- Continued developing technical procedures which provided further documentation in the effort to develop a calibration quality system in compliance with ANSI/NCSL Z540-1-1994.

- Completed approximately $\$ 420 \mathrm{~K}$ in calibrations

- Completed international NORAMET Measurement Round Robin with NRC (Canada) and CENAM (Mexico).

- Continued customer service improvement through more accurate price quotes, turnaround times, and increased attention to customer requests.

\section{FY96 Plans:}

- Fully integrate the new laser displacement horizontal micrometer into all absolute and comparison measurements performed on cylinders, thread wires, plug gages, pin gages, and possibly ball calibrations.

- Continue enhancing the capabilities of the gear measurement lab to encompass calibration of all gear artifacts as well as all automated API calibrations.

- Announce and begin a 2D grid plate calibration service on the Moore M48 CMM, which will address a large industry backlog of these artifacts that need calibration and traceability to national standards.

- Obtain full operational status of the AAMACS (Advanced Automated Master Angle Calibration System) for calibration of autocollimators, polygons, optical squares, optical wedges, and angle blocks, which will result in more efficient turnaround time, lower uncertainty, and a wider range of measurement capabilities.

- Implement an on-line system for determining penetration corrections for different materials on the mechanical gage block calibration system, allowing for replacement of contact tips without adversely affecting uncertainty and statistical control parameters.

- Continue documenting calibration processes in the form of technical procedures, as well as, improving measurement and customer service processes which are in line with developing a measurement services quality system. 
Five-Year Plan Goals vs. Fiscal Years:

\begin{tabular}{||l|l|l|l|l|l||}
\hline CALIBRATIONS (SP-250) & 96 & 97 & 98 & 98 & 00 \\
\hline $\begin{array}{l}\text { Decrease turnaround time to an average of four weeks for } \\
\text { all standard calibrations [Calibration fees] }\end{array}$ & & & & & \\
\hline $\begin{array}{l}\text { Fully integrate a measurement services quality system } \\
\text { which will be in compliance with ANSI/NCSL Z540-1-1996 } \\
\text { [Calibration fees] }\end{array}$ & & & & & \\
\hline $\begin{array}{l}\text { Replace the Pulfrich Viewer with the newly acquired ZYGO } \\
\text { Interferometer for performing flatness calibrations } \\
\text { [Calibration fees] }\end{array}$ & & & & & \\
\hline $\begin{array}{l}\text { Develop and offer a high-accuracy cylindricity calibration } \\
\text { service in accordance with requests from different sectors of } \\
\text { private industry [Calibration fees] }\end{array}$ & & & & & \\
\hline
\end{tabular}


Staff: $\left(2.4\right.$ staff years) ${ }^{*}$ BORCHARDT, *Phillips, ${ }^{*}$ Caskey, ${ }^{*}$ Estler, ${ }^{*}$ Sawyer, ${ }^{*}$ Ward

Objective and MEL Thrust(s) Supported: To develop methodologies and artifacts for CMM calibration, performance evaluation, and task specific measurement uncertainty assessment, in support of ANSI, ISO, and DOD metrology standards. Manufacturing Metrology

Need(s) Addressed: U.S. industry, the metrology standards community, and DOD, are currently in a period of rapid transition regarding CMM evaluation and traceability. International competitiveness is forcing compliance with ISO standards such as the recently completed ISO-10360 CMM standard. This has created a significant need for the development, characterization, and calibration of high precision artifacts. Additionally, the internationally recognized goal of achieving CMM traceability is driving research on techniques to quantify CMM performance sufficiently will to evaluate task specific measurement uncertainty. Presently, evaluating CMM task specific uncertainty is difficult even in the best laboratories, and hopelessly complex and expensive to implement in industry. Understanding the CMM hardware interactions at a level sufficient to develop procedures and equipment which can be cost effectively implemented in industry is urgently needed. Similarly, the military is developing an interservice CMM calibration program for use throughout DOD. The goal of this effort is to provide increased quality assurance and establish the traceability of CMM measurements for all DOD sites. A unified approach to CMM evaluation and traceability will reduce duplication of effort in complying with a multitude of standards, which currently are insufficient to establish task specific measurement uncertainty. Such a unified approach will improve the quality of manufactured parts through increased understanding of the measurement process and create a viable means of establishing traceablity for coordinate measuring machines.

Technical approach: To achieve this goal NIST is working on two broad fronts: (1) creating and coordinating national, international, and DOD standard specifications; and (2) conducting research into CMM performance issues and subsequent artifact development. NIST is actively involved on both ANSI and ISO standard committees. Previously, NIST has shown that the metrological issues of artifact mounting, not the geometrical design, has lead to discrepancies between different performance standards. Using this information, NIST has developed kinematically mounted artifact systems, including the CMM Interim Testing Artifact, to rapidly detect CMM errors. Currently, research is being conducted to leverage this technology into providing detailed information regarding CMM measurement uncertainty. Consequently such efforts could unify national and international CMM standards while gaining additional information regarding CMM measurement capability. NIST is presently leading an DOD effort to create an interservice CMM standard which will embody these concepts, provide industrially viable metrology artifacts, and the methodologies needed to conduct the procedure. Specifically, NIST is investigating ball step gauge designs which are mechanically stable at less than $1 \mu \mathrm{m} / \mathrm{m}$ for lengths up to $1.5 \mathrm{~m}$.

\section{FY95 Accomplishments:}

- Drafted and completed "Guidelines for CMM Interim Testing" to be included in the ANSI B89.4 Standard (in press).

- Deployed CMM Interim Testing Artifact to additional sites including Naval Warfare Assessment Center.

- Developed versions 1 and 2 of ball step gauge prototype artifact.

\section{FY96 Plans:}

- Produce first thermally and mechanically stable ball step gauge prototype.

- Develop prototype mounting and indexing system for the step gauge.

- Coordinate gauge calibration procedure with Large Scale Metrology project 
- Initiate national and international effort to unify CMM standards.

- $\quad$ Produce first draft of DOD standard containing proposed unifying performance concepts.

Five-Year Plan Goals vs. Fiscal Years:

\begin{tabular}{|c|c|c|c|c|c|}
\hline CMM CALIBRATION METHODOLOGIES & 96 & 97 & 98 & 99 & 00 \\
\hline $\begin{array}{l}\text { Demonstrate performance evaluation and CMM uncertainty } \\
\text { assessment capability [STRS, OA] }\end{array}$ & & & & & \\
\hline $\begin{array}{l}\text { Deploy operational test system to industrial test site for } \\
\text { evaluation [STRS, OA] }\end{array}$ & & & & & \\
\hline $\begin{array}{l}\text { Complete DOD CMM standard and procedures and field test } \\
\text { at DOD site [STRS, OA] }\end{array}$ & & & & & \\
\hline Resolve outstanding standardization issues [STRS, OA] & & & & & \\
\hline
\end{tabular}


Title: COLLABORATION IN DIMENSIONAL METROLOGY WITH THE OAK RIDGE METROLOGY CENTER (ORMC)

Staff: (0.1 Staff Years) ${ }^{*}$ TED DOIRON, *Howard Harary

Objective and MEL Thrust(s) Supported: To use the capabilities available at ORMC to support and enhance PED's ability to deliver world-class precision measurement services to industry. Manufacturing Metrology

Need(s) Addressed: Documented needs of American industry for previously unavailable NIST calibration services for long step gages and end standards, two dimensional reference standards, and other basic dimensional measurement services.

Technical Approach: Establish and conduct a pilot project for the conduct of certain NIST calibrations at ORMC under the metrological and administrative control of the PED. The Pilot Program was established in 1994 and is continuing. The program has been very successful, measuring a number of U.S. step gages at uncertainties comparable or better than any in the world. The collaboration continues with current work to develop methods to measure the coefficient of thermal expansion of artifacts, and the development of a long waybed micrometer.

\section{FY95 Accomplishments:}

- Calibration of 10 step gages. Comparisons made with PTB and DKD in Germany.

- Thermostat designed and built for the dilatometer. Lab space allotted at ORMC, and the programming for end standards was completed.

- Room environmental system rebuilt for long waybed micrometer. Initial tests of data collection, analysis, and deformation corrections made.

\section{FY96 Plans:}

- Measure motion errors on Y-axes of both ORMC high accuracy CMMs and implement an error map for $\mathrm{X}$ and $\mathrm{Y}$.

- Test NIST and PTB ball plate calibration algorithms on mapped machines Develop detailed uncertainty budget for ball plates.

- Begin system tests on dilatometer, including thermal time constants and length tracking.

- Begin tests of long waybed micrometer, including thermal stability and gradient studies, timemotion studies for measurements, and develop uncertainty budget.

Related Developments: The ORMC Gear Laboratory has been completed and joint studies of gear artifacts, with NIST, have begun. This effort is a TRP-funded, three-year program, of which this is the final year.

Five-Year Plan Goals vs. Fiscal Years:

\begin{tabular}{|l|l|l|l|l|l|l|}
\hline $\begin{array}{l}\text { COLLABORATION IN DIMENSIONAL METROLOGY WITH } \\
\text { THE OAK RIDGE METROLOGY CENTER (ORMC) }\end{array}$ & 96 & 97 & 98 & 98 & 00 \\
\hline $\begin{array}{l}\text { Continue operation of the Pilot Program for step gages and } \\
\text { long end standards [OA] }\end{array}$ & & & & & \\
\hline $\begin{array}{l}\text { Expand Pilot Program to include ball plate hole plate } \\
\text { calibrations [OA] }\end{array}$ & & & & & \\
\hline
\end{tabular}




\begin{tabular}{|l|l|l|l|l|l||}
\hline $\begin{array}{l}\text { COLLABORATION IN DIMENSIONAL METROLOGY WITH } \\
\text { THE OAK RIDGE METROLOGY CENTER (ORMC) }\end{array}$ & 96 & 97 & 99 & 99 & 00 \\
$\begin{array}{l}\text { Develop and implement system to measure thermal } \\
\text { properties of dimensional gages [OA] }\end{array}$ & & & & & \\
\hline $\begin{array}{l}\text { Develop long waybed micrometer for low-cost, high } \\
\text { accuracy calibration of end standards [OA] }\end{array}$ & & & & & \\
\hline
\end{tabular}


Staff: (2.1 staff years) HOWARD HARARY, *Edgar Erber, ${ }^{*}$ Dennis Everett, *Ted Doiron

Objective and MEL Thrust(s) Supported: To develop and extend the world-class dimensional measurement capabilities of MEL to forms with complex shapes (e.g., gears, turbine blades, propellers) in satisfaction of industry's advanced measurement needs. Manufacturing Metrology

Need(s) Addressed: Responds to an industry pull for the (re)establishment of NIST as the pinnacle of traceability for complex form 3-D artifacts for gear manufacturers and users (automotive, heavy equipment, aerospace, marine), and other industries. Traceability is a necessity if industry is to maintain the quality and interchangeability of its parts and assemblies, and compete effectively in the world marketplace.

Technical Approach: Building on MEL existing expertise in the measurement of API thread gages we will (1) expand our services to include other complex form artifacts and (2) lower the uncertainty for these measurements. A state-of-the-art high accuracy coordinate measuring machine (CMM), in a suitable temperature and humidity controlled environment, with flexible software is used to measure the complex forms. Each measurement is accompanied by a measurement uncertainty to assure traceability to the international standard of length. The uncertainty is at state-of-the art or better (as determined by national laboratories benchmarking). Measurement conditions and procedures will be continually tested and refined in an effort to reduce the uncertainty of the measurement process. We are working closely with our industrial clients through our relationship with ASME's Committee on Gear Metrology (COGM) and the American Gear Manufacturers Association (AGMA) to guarantee that the program addresses industry needs and to ensure customer satisfaction.

\section{FY95 Accomplishments:}

- Installed, error mapped, and "super tweaked" a new high-accuracy CMM in a state-of the-art temperature $\left( \pm 0.1^{\circ} \mathrm{C}\right)$ and humidity $( \pm 2 \%)$ controlled environment. Exhaustive performance testing assured that the result was a national standards laboratory-class CMM.

- Inaugurated a new gear artifact measurement service for involutes in cooperation with DOE Oak Ridge/Y12--a service which was received with excellent customer satisfaction by industry. The two-sigma ( $95 \%$ confidence level) measurement uncertainty is $0.9 \mu \mathrm{m}-$-a level which is world-class among national standards laboratories.

- Developed and applied a new method for the determination of the uncertainty of complex form measurement called the "step-by-step comparator" or "measurement de-composition" method. This new method of calculating uncertainty was applied to the measurement of the involute artifact to fulfill a requirement of establishing measurement traceability.

\section{FY96 Plans:}

- Extend the gear artifact calibration service to lead and pin master artifacts.

- Participate in an international round-robin for gear artifacts organized by the British Gear Measurement Center at the University of Newcastle.

- Perform a complex form measurement needs assessment for the aerospace and other industries.

Related Developments: Assisted M\&M Precision Systems, a manufacturer of specialized gear measurement equipment, in the planning and execution of their ATP-funded project to develop the next generation of gear measuring machine. Consulted with Ford Motor Co. on the measurement of production gears on a CMM. 
Five-Year Plan Goals vs. Fiscal Years:

\begin{tabular}{|c|c|c|c|c|c|}
\hline COMPLEX FORM DIMENSIONAL METROLOGY & 96 & 97 & 98 & 99 & 00 \\
\hline $\begin{array}{l}\text { Extend the measurement services to master lead, index anc } \\
\text { pin artifacts, and master gears [STRS, OA] }\end{array}$ & & & & & \\
\hline $\begin{array}{l}\text { Enlarge the measurement service to other complex forms to } \\
\text { meet the needs of the aerospace, automotive and marine } \\
\text { industries (e.g. turbine blades, airfoils and propeller blades) } \\
\text { [STRS, OA] }\end{array}$ & & & & & \\
\hline $\begin{array}{l}\text { Investigate the use of non-contact measurement } \\
\text { technologies to increase the speed and density of complex } \\
\text { form measurements in cooperation with the RAMM ATP } \\
\text { funded consortium [STRS, OA] }\end{array}$ & & & & & \\
\hline
\end{tabular}


Staff: (3 staff years) TYLER ESTLER, *Steve Phillips, Bruce Borchardt, * Ted Hopp * Marjorie McClain, ${ }^{*}$ Chris Witzgall, * Keith Eberhardt, * Mark Levenson

Project Objective and MEL Thrust(s) Supported: To develop on a firm mathematical basis the quantification of CMM error/uncertainty sources, and the propagation of these error/uncertainty sources into the feature inspection results. The CMM Calibration Methodologies project addresses CMM hardware errors which result in point coordinate measurement uncertainty; this project propagates these and other sources of error/uncertainty including effects of the sampling strategy and part form error into the feature measurement. Manufacturing Metrology

Need(s) Addressed: In coordinate metrology, including more than 20,000 CMMs in U.S. industry, there is no rigorous methodology to determine if part dimensions conform to design specifications, or to accurately estimate the statistical confidence of measurement results. As a consequence, manufacturers have no way to assign realistic uncertainties to CMM measurements, leading in some cases to applying overly-conservative part tolerances which increases manufacturing costs. There is a strong industrial need for a systematic approach towards a generalized solution to this computational problem; this will give a competitive advantage for those manufacturers who can accurately predict uncertainties in their CMM measurements of complex workpieces. Additionally, since many of these error sources are poorly understood, the mathematical analysis and subsequent characterization of these errors can allow them to be predicted and hence eliminated through compensation. This procedure can increase the accuracy of CMM measurements via calculation, resulting in increased price-toperformance ratios of inspection systems.

Technical Approach: NIST will develop computational models of CMM measurement processes that build upon our accomplishments in mapping and software correction of quasi-static machine positioning errors. This work will include quantitative estimates of the size and effect of the measurement uncertainty arising from errors due to: the point sampling strategies and their interactions with part form errors, CMM probing errors, and CMM machine hardware errors (as evaluated in the CMM Calibration Methodologies project). For example, systematic errors due to touch trigger probes are known to be a major CMM error source with a typical magnitude of $10-12 \mu \mathrm{m}$ (per B89.4 probing tests). By a detailed mathematical model such probing errors could, in principle, be reduced to the random (non repeatable) component of approximately 1-2 $\mu \mathrm{m}$. Statistical evaluation of this method will determine the effectiveness of this approach and quantify residual uncertainties. Similarly, computer simulations based on these mathematical models will estimate (first using random errors and later with systematic errors) the combined uncertainty due to all interactions in a manner consistent with the ISO Guide to the Expression of Uncertainty in Measurement (1993). This provides explicit rules for uncertainty computation in terms of error sources and sensitivity coefficients, given a model of their functional relationships--which is the focus of this project.

\section{FY95 Accomplishments:}

- Developed touch trigger probe error model for straight vertical styli configurations which improves probe performance by a factor of four.

- Published probe results at the 1995 ASPE annual conference.

- Extended the probe model to include horizontal and other probe orientations while maintaining factor of four increase in performance.

- Submitted extensive paper to Precision Engineering describing probing model.

- Drafted paper describing the interaction of probing errors (given by the probing model) with simple sampling strategies for circle measurements.

- Published book chapter on CMM performance evaluation. 
FY 96 Plans:

- Implement probe model using sparse data sets.

- Coordinate with US industry regarding technology transfer of probe model.

- $\quad$ Produce preliminary prototype of simulation software.

- Publish paper on interaction of probing errors and simple sampling strategies for circle measurements.

- Work with ANSI and ISO standards for a unified CMM measurement uncertainty statement.

Five-Year Plan Goals vs. Fiscal Years:

\begin{tabular}{|l|l|l|l|l|l||}
\hline COMPUTATIONAL METROLOGY & 96 & 97 & 98 & 99 & 00 \\
\hline $\begin{array}{l}\text { Model probing errors with offset stylus configurations } \\
\text { [Competence] }\end{array}$ & & & & & \\
\hline $\begin{array}{l}\text { Develop CMM error model using calibration data as input } \\
\text { [Competence] }\end{array}$ & & & & & \\
\hline $\begin{array}{l}\text { Implement CMM error model in software for simulation of the } \\
\text { measurement process [Competence] }\end{array}$ & & & & & \\
\hline $\begin{array}{l}\text { Research robustness issues of CMM features based on } \\
\text { sampling strategies [Competence] }\end{array}$ & & & & & \\
\hline $\begin{array}{l}\text { Integrate sampling strategy, algorithm selection, and error- } \\
\text { mapped CMM to test uncertainty computation for selected } \\
\text { geometric feature(s) [Competence] }\end{array}$ & & & & & \\
\hline $\begin{array}{l}\text { Demonstrate mathematically defensible CMM uncertainty } \\
\text { computation on error-mapped CMM using traceable NIST- } \\
\text { calibrated artifact with known geometry [Competence] }\end{array}$ & & & & & \\
\hline
\end{tabular}


Staff: (2.0 staff years) ${ }^{*}$ JACK STONE, Lowell Howard, *Bill Penzes, ${ }^{*}$ Fred Scire.

Objective and MEL Thrust(s) Supported: To use emerging diode laser technologies to develop next generation length measurement tools. Manufacturing Metrology.

Need(s) Addressed: A disparate array of customers in the large scale manufacturing and semiconductor industries will be served by a variety of projects that address length measurement from the tens of meters to the picnometer level. Large scale manufactures such as the aerospace, automotive and shipbuilding industries need improved ease of use for high accuracy measurement systems to lower the cost of quality control metrology. Semiconductor manufacturers working towards atomic sized critical dimensions will benefit by having higher accuracy SRMs made possible by adding traceable metrology to a variety of NIST calibration tools. Future NIST needs will be supported by building a competence base with diode laser systems for length measurement, which are already beginning to enter the commercial marketplace.

Technical Approach: Improve large scale manufacturing through the use of absolute interferometry systems based upon tunable diode lasers. Such systems can facilitate measurements of distances up to $50 \mathrm{~m}$ with an accuracy limited only by index of refraction uncertainties $(10 \mu \mathrm{m}$ or better at $10 \mathrm{~m})$. An absolute interferometer is tolerant of temporary signal loss, giving a flexibility not found in incremental type displacement systems. In a first design, $670 \mathrm{~nm}$ tunable diode laser will be used in conjunction with a fixed laser to achieve resolution similar to a displacement interferometer without the need to displace a mirror to effect a length measurement. Later designs will be incorporated into 3-D measurement systems and new index of refraction measuring techniques integrated into our system. Nano-scale measurements will be addressed by teaming frequency tracking Fabry-Perot interferometry with tunable diode lasers and newly available microwave measurement technology. The use of microwave technology permits Fabry-Perot interferometers of a practical size (10 to 25 $\mathrm{mm}$ ) allowing integration into piezoelectric actuators and calibration artifacts. Resolutions will be obtained in the picnometer domain with accuracy ultimately expected to reach tens of picometers or better. Ultimately, the system will be integrated into NIST SRM calibration tools for step height measurement and nano-scale metrology.

\section{FY95 Accomplishments:}

Absolute Interferometer

- $\quad$ Assembled \& tested first version with accuracy of $20 \mu \mathrm{m}$.

- Published report of polarization mixing in interferometers.

Dynamic Displacement Artifact

- Completed metrology flexure stage and mirror assembly.

- Completed 20-bit high voltage programmer.

- Achieved phase-modulated servo locking of metrology cavity.

Source Development

- Successfully collaborated with Boulder on fast sweeping diode laser now being incorporated into our interferometer. Joint conference paper submitted by Time and Frequency Division and PED.

- Built and tested second-generation iodine stabilized lasers.

\section{FY 96 Plans:}

Absolute Interferometer

- We hope to achieve an order of magnitude better results using our new diode laser built at Boulder. 
- Finish homodyne system for comparison with heterodyne system of fringe interpolation.

- $\quad$ Extend test range to at least 5 meters and identify problems.

Dynamic Displacement Artifact

- Achieve fiber optic coupling of metrology flexure stage to laser system.

- Build and test differential wavelength meter for coarse tuning of diode laser to He-Ne wavelength.

- Build and test ultra-stable $633 \mathrm{~nm}$ diode laser capable of stable heterodyning with a He-Ne laser.

Related Developments: Ongoing collaboration with Boulder on diode sources. Refine/build additional I2 stabilized laser system.

Five-Year Plan Goals vs. Fiscal Years:

\begin{tabular}{|c|c|c|c|c|c|}
\hline DIODE LASERS FOR LENGTH MEASUREMENT & 96 & 97 & 98 & 99 & 00 \\
\hline \multicolumn{6}{|l|}{ Test new (Boulder) diode laser in our interferometer [STRS] } \\
\hline \multicolumn{6}{|l|}{$\begin{array}{l}\text { Build prototype homodyne absolute interferometer and } \\
\text { compare performance to heterodyne system [STRS] }\end{array}$} \\
\hline \multicolumn{6}{|l|}{ Test, troubleshoot and evaluate uncertainties [STRS] } \\
\hline \multicolumn{6}{|l|}{$\begin{array}{l}\text { Integrate and test absolute interferometer with 3-D } \\
\text { measuring system [STRS] }\end{array}$} \\
\hline \multicolumn{6}{|l|}{$\begin{array}{l}\text { Build miniature DDA for Talystep and scanned probe } \\
\text { microscopes [STRS] }\end{array}$} \\
\hline \multicolumn{6}{|l|}{ Integrate DDA into SRM calibration tools [STRS] } \\
\hline \multicolumn{6}{|l|}{$\begin{array}{l}\text { Continue collaboration with Boulder on laser source } \\
\text { development [STRS] }\end{array}$} \\
\hline \multicolumn{6}{|l|}{ Industrial collaborations and dissemination [STRS] } \\
\hline $\begin{array}{l}\text { Investigate/integrate new technologies as they become } \\
\text { available [STRS] }\end{array}$ & & & & & \\
\hline
\end{tabular}




\title{
Title: FIGURE AND FINISH METROLOGY FOR ADVANCED OPTICS
}

\author{
Staff: $(1.3$ staff years $){ }^{*}$ C. J. EVANS, *R. Polvani, *P. J. Sullivan, *R. E. Parks
}

Objective and MEL Thrust(s) Supported: The objective of the project is to develop traceable measurement techniques to measure deviations from the ideal form of advanced optics, including aspherics, to be used in soft X-ray projection lithography (SXPL). Departures from the ideal form with spatial wavelengths ranging from a fraction of the $\mathrm{x}$-ray wavelength $(13 \mathrm{~nm})$ to the full aperture of the part $(300 \mathrm{~mm})$ must be measured. In that range, figure error, comprised of the long spatial wavelength deviations, causes degradation of the image quality. The surface finish, comprised of the short spatial wavelengths, causes diffusely scattered light and degradation of contrast. Manufacturing Metrology.

Need(s) Addressed: The continuing drive for ever smaller integrated circuit feature sizes means that the fundamental physical limits of lithography using transmissive optics and near visible illumination will be exceeded early in the next decade. SXPL is one attractive replacement technology and one in which the U.S. currently has a technological lead; feature sizes below $0.1 \mu \mathrm{m}$ have been produced by SXPL over small field sizes in laboratory systems. Economic production, however, will require large field sizes and good optical efficiency, in turn requiring extremely accurate optical elements with superb surface finish. Companies attempting to make these optics do not have the measurement capabilities they need, and they cannot make what they cannot measure. These optics may be the heart of the next generation of lithography systems, themselves the machine tools of the silicon industry. That industry is worth $\$ 85$ billion per year.

Technical Approach: NIST work has shown that atomic force microscopes (AFMs) and visible phase measuring interferometers (PMIs) have the necessary resolution for finish and figure measurement, respectively. Commercially available instruments, as supplied, are insufficiently accurate. NIST has developed a calibrated AFM that can establish the traceability of optical surface finish measurements. The instrument has on-line calibration in the $X$ and $Y$ directions using laser interferometry that will ultimately be accurate to $\pm 3 \mathrm{~nm}$. Calibration in the Z-direction of $\pm 0.1 \mathrm{~nm}$ will be provided by a capacitance gauge, which in turn is calibrated off-line using laser interferometry.

PMIs can be extremely repeatable but do not currently have the absolute accuracy needed. Concepts for a system combining a PMI with high precision slideways have been developed and, over the next three years, will be implemented (in collaboration with an industrial vendor) in a new measurement capability, known as the NIST X-ray Optics Calibration Interferometer (XCALIBIR). The goal is less than $1 \mathrm{~nm}$ peak-to-valley uncertainty in measurement of aspheric optics up to $300 \mathrm{~mm}$ diameter with focal lengths up to 2 meters. To achieve this we will also need to be able to measure flat and spherical wavefronts to similar accuracies-capabilities that are included in the new system's design.

In addition to the above efforts, we are developing techniques for inspecting subsurface damage and residual stress of optics under the Ballistic Missile Defense Program.

\section{FY95 Accomplishments:}

- Completed specifications and initiated procurement of XCALIBIR.

- Demonstrated improvements in systematic error correction scheme for commercially available PMIs.

- Developed a formalism for calculation of $\mathrm{x}$-ray scattering from multilayers using AFM topography maps as input data. 
FY96 Plans:

- Perform a profile measurement of an optical surface spanning spatial wavelengths from $2 \mathrm{~nm}$ to $100 \mathrm{~mm}$ and calculate the power spectral density function from these data.

- Install special hardware to measure Pathfinder Optics for laser interferometric gravity wave observatory.

- Oversee and facilitate on-schedule development of XCALIBIR.

- Research non-destructive methods for measurement of residual stress and subsurface damage in sapphire.

Related Developments: C. Evans, R. Parks, and P. Sullivan are all members of the ISO Technical Committee 172 on Optical Instruments and C. Evans is a member of TC3 Working Group 15 on Reference Temperature. Both committees are active in writing new standards.

Five-Year Plan Goals vs. Fiscal Years:

\begin{tabular}{|l|l|l|l|l|l||}
\hline $\begin{array}{l}\text { FIGURE AND FINISH METROLOGY FOR ADVANCED } \\
\text { OPTICS }\end{array}$ & 96 & 97 & 98 & 99 & 00 \\
\hline Procure XCALIBIR [STRS] & & & & & \\
\hline Commission XCALIBIR as a calibration service [STRS] & & & & & \\
\hline $\begin{array}{l}\text { Demonstrate an uncertainty of } \pm 1 \mathrm{~nm} \text { for measurement of } \\
\text { aspheric surfaces with XCALIBIR [STRS] }\end{array}$ & & & & & \\
\hline
\end{tabular}


Staff: (1.5 staff years) FRED RUDDER, *Ron Hartsock, *Bruce Borchardt

Objective and MEL Thrust(s) Supported: Develop metrology system to characterize the positioning accuracy of the AMTST Ingersoll Octahedral Hexapod machining center and a metrology system to provide enhanced positioning accuracy of the machining center. The characterization system shall apply to the class of machining centers based upon the Stewart platform concept. The metrology system for enhanced positioning accuracy is specific to the Ingersoll configuration of the Stewart platform concept. Manufacturing Metrology

Need(s) Addressed: Machining centers based upon the Stewart platform concept promise to introduce a degree of precision machining productivity and production economy not possible with conventional machine tool structural configurations. The combination of structural rigidity, high-speed tool positioning, and full sixaxis motion control are features that have drawn the attention of the automotive and aerospace industries and the tool, die and mold manufacturers. Since the machine configuration is not based upon fixed-axis mechanics but upon computationally-intensive servo-control algorithms, the need to perform tool position metrology for this class of machine tools is critical both for characterizing the positioning accuracy of the tool tip and evaluating the performance guarantees of such systems. Further, since the motion control is based upon feedback of linear displacement measurements and models of the Stewart platform kinematics the real-time metrology of this new class of machine tools is essential to realizing the performance potential. Precision material removal is an essential function of U.S. manufacturing industries and the potential for increasing productivity that is offered by Stewart platform machine tools will likely be an important element in maintaining U.S. manufacturing competitiveness.

Technical Approach: The project has two distinct objectives: develop metrology tools for directly characterizing tool tip positioning accuracy for the generic class of machine tools and implement on-machine metrology to enhance the positioning accuracy of the Ingersoll Hexapod system of the NIST Advanced Machine Tool Structure Testbed. To achieve the first objective we are implementing a metrology system to characterize, simultaneously, the six degree of freedom motion of the tool tip as the machine tool performs a straight line vector move across its work volume. This metrology system is not machine specific and can be used for any particular implementation of the Stewart platform concept. The system utilizes a reference straight-edge, six linearly variable displacement transducers for straightness and angular motion, and a laser interferometer for linear displacement measurement. The second objective is long term and considers the specific configuration of the NIST Hexapod system. The current concept is to use a laser-based displacement measuring system to provide strut extension data in conjunction with an end-of-strut PZT microactuator. Specific details of the configuration are now being implemented on the NIST Hexapod Strut Test Stand. Characterization of the tool tip positioning accuracy and the thermal state of the NIST Hexapod is the first step in defining the machining potential of the NIST Hexapod system.

\section{FY95 Accomplishments:}

- Completed design, fabrication, and assembly of tool-tip metrology fixture.

- Completed design, fabrication, and installation of optical metrology system.

- Initiated tool-tip metrology measurements for characterization.

- Initiated installation of thermocouples and conducted thermography scans of the Hexapod structure and components.

\section{FY96 Plans:}

- Assemble and calibrate metrology system.

- Develop data acquisition software for metrology system. 
- Continue metrology characterization using laser system.

- Develop designed experiments for machine metrology characterization.

- Analyze metrology data and report results of project at year-end.

Five-Year Plan Goals vs. Fiscal Years:

\begin{tabular}{|l|l|l|l|l|l||}
\hline HEXAPOD METROLOGY & 96 & 97 & 99 & 99 & 00 \\
\hline $\begin{array}{l}\text { Implement metrology systems and procedures for } \\
\text { characterizing positioning accuracy and controlling motion of } \\
\text { machine tools based upon the Stewart platform concept } \\
\text { [STRS, ATP, OA] }\end{array}$ & & & & & \\
\hline $\begin{array}{l}\text { Develop metrology system for characterizing tool tip } \\
\text { positioning accuracy for vector motion across work volume } \\
\text { [STRS, ATP] }\end{array}$ & & & & & \\
\hline $\begin{array}{l}\text { Design and assemble hardware and develop data } \\
\text { acquisition software for metrology system [STRS, ATP] }\end{array}$ & & & & & \\
\hline $\begin{array}{l}\text { alibrate system and conduct designed experiments to } \\
\text { characterize positioning accuracy of NIST Hexapod machine } \\
\text { tool [STRS, ATP] }\end{array}$ & & & & & \\
\hline $\begin{array}{l}\text { Analyze metrology data and report results [STRS, ATP] } \\
\text { Report details of metrology system and procedures } \\
\text { developed to ASME Standards Committee B5: Machine } \\
\text { Tools-Components, Elements, Performance and Equipment } \\
\text { [STRS, ATP] }\end{array}$ & & & & & \\
\hline $\begin{array}{l}\text { Develop concepts for implementation of on-machine motion } \\
\text { control metrology system for NIST Hexapod [STRS]. }\end{array}$ & & & & & \\
\hline $\begin{array}{l}\text { Implementation of on-machine metrology system for NIST } \\
\text { Hexapod [STRS, OA]. }\end{array}$ & & & & & \\
\hline $\begin{array}{l}\text { Refine and demonstrate on-machine metrology system for } \\
\text { NIST Hexapod [STRS, OA]. }\end{array}$ & & & & & \\
\hline
\end{tabular}




\section{Staff: (1.0 staff years) *TED DOIRON, ${ }^{*}$ Jack Stone, ${ }^{*}$ Mike Stocker}

Objective and MEL Thrust(s) Supported: Support industry two dimensional measurements through calibration of grid plates, development of calibration algorithms, a standardized uncertainty budget, and by organizing interlaboratory comparisons. Manufacturing Metrology

Need(s) Addressed: There are needs for traceability for two dimensional measurements at two different scales. The large scale measurement systems make measurements at the 2 micrometer uncertainty level on artifacts up to 1 meter square. The artifacts include PC boards, arrays of components, and flat panel displays. These systems will be supported by calibrations of grid plates on the Moore M-48 measuring machine.

The small scale measuring systems are used by the semiconductor mask industry. These systems have ranges up to $200 \mathrm{~mm}$ square, and have repeatability in the 10-100 nanometer range. Since NIST does not have an instrument with these capabilities, we are working toward standardizing measurement procedures and the development of an industry interlaboratory comparison system which would provide interim standards.

Technical Approach: For the large scale measuring machines, the NIST M48 CMM will provide calibration uncertainties in the $0.3-0.5 \mu \mathrm{m}$ range. This system was finished in FY95 and is now in service.

We are building a small range measuring machine as a test bed for measurement algorithms, and as a test instrument to work on deriving error budgets. We plan to develop measurement algorithms which use our best measurement, one dimensional line-scales, along with multiple measurements in different orientations on the new 2-D machine, to provide a calibration of both the grid plate and the measuring machine. We also hope to begin a collaboration with a university researcher and graduate student.

\section{FY95 Accomplishments:}

- The Moore M48 machine is now in service for grid plate calibration. Tests on a $600 \times 600 \mathrm{~mm}$ plate show that uncertainties below $0.5 \mu \mathrm{m}$ are possible on a routine basis. Because of the large number of grid plates in service, and in need of calibration, we expect to use the machine exclusively for calibrations for the next year.

- The smaller 2-D measuring machine is running. We are in the process of upgrading the video processing board and camera.

\section{FY96 Plans:}

- This year we will begin development of algorithms for the small grid plates. We have made an extensive literature search and have studied previous attempts to calibrate three dimensional coordinate measuring machines with ball plates. We will modify these methods as a starting point for our work. We are also working to perfect robust algorithms for finding the grid mark on plates. Since the commercial systems all have different sensors, we will explore systematic effects of different sensors of the grid measurements. With our video based system, we will be able to emulate most of the currently used sensor systems. 
Five-Year Plan Goals vs. Fiscal Years:

\begin{tabular}{|l|l|l|l|l|l||}
\hline HIGH-ACCURACY CMM DEVELOPMENT & 98 & 97 & 98 & 98 & 00 \\
\hline Implement 2-D calibrations for Grid Plates on the M48 & & & & & \\
\hline Develop small experimental 2-D machine & & & & & \\
\hline Survey practice for 2-D standards in lithography industry & & & & & \\
\hline Perform interlaboratory comparisons for 2-D measurements & & & & & \\
\hline
\end{tabular}




\section{Staff: (1.0 staff years) Brian Scace}

Objective and MEL Thrust(s) Supported: The objective of the project is to provide PED and MEL personnel with solutions to physical environmental issues affecting reported research results. Manufacturing Metrology

Need(s) Addressed: The immediate target customers for project output are PED and MEL researchers. The target customer's technical needs vary with each specific problem addressed. An entire research facility, such as the PED Moore M48 facility, may be provided from concept through design, construction, and acceptance testing. In other cases, a specific problem area may be addressed such as retro-fit of improved temperature controls or vibration isolation and damping. The project also provides for coordination and supervision of both in-house assets (Plant Division) and outside architectural and engineering firms and contractors to complete construction or modifications to the researcher's satisfaction. The customer-project personnel are free to pursue other project goals in parallel with facility construction/modification. This results in a savings in time while providing a laboratory environment within which best results may be attained.

Although this activity may be considered technical "support" in nature, it should be understood that, as manufacturing metrology continues to be developed and refined, the environment within which this is performed must also evolve. While the majority of the project's effort is directed internally (within MEL), its effect is felt indirectly with reported results from customer-projects to industry as well as directly through such forums as NCSL.

Technical Approach: As new levels of accuracy in manufacturing metrology are required, it is becoming increasingly apparent that the current PED/MEL research facilities are obsolete. The project's approach to this issue is manifested in two forms.

First, the project works with PED/MEL researchers to upgrade individual facilities within the current General Purpose Laboratories (GPLs). An example of this approach is the FY94 removal of a technically flawed vibration isolation system in rooms B26/28 in building. 220 and replacing it with a solid floor system of appropriate mass so as to eliminate amplification of incoming ground vibrations induced by vehicular traffic, footfall, and building mechanical systems. The resulting usable space was then renovated to accommodate the Surface Roughness SRM Calibration effort. Although originally PED-specific, this project hopes to take this approach MEL-wide.

Second, the project serves as MEL's input to the Capital Improvement of Facilities Project (CIFP). The CIFP, part of the Office of Administration, is responsible for the construction of the Advanced Technology Laboratories (ATLs) on both campuses and for complete renovation of selected GPLs, again on both campuses. In this capacity, the project directly communicates with MEL researchers, recognized outside experts in the field of advanced facility design, contracted A\&Es, contractors, and the CIFP office to insure that MEL researcher's technical needs are addressed.

\section{FY95 Accomplishments:}

- Completed temperature control enclosure for the PED Leitz coordinate measuring machine. This facility, in Rooms B07-09, building 220, provides an environment about a large metrological frame with the following thermal specifications:

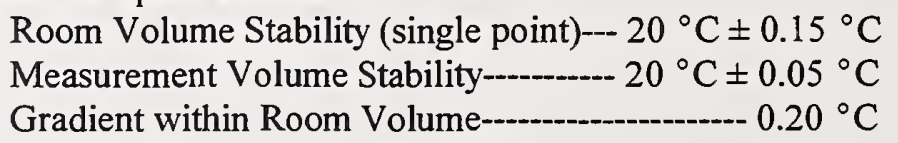


- Supervised renovation or design/construction of facilities for MEL divisions under the FY95 MEL Space Rationalization Plan. This was accomplished with maximum utilization of available funding from outside of the Laboratory, thus giving researchers valuable renovated space at minimal cost to MEL.

- Completed retrofit of Large Object Metrology Facility with direct digital control (DDC) of temperature in lieu of previous pneumatic system. This solution permits temperature control to $\pm 0.30{ }^{\circ} \mathrm{C}$ single point stability.

- Maintained working relationship with CIFP, and the firms Earl Walls, HDR, and CRSS Constructors regarding MEL staff technical concerns with respect to the ATL project. This includes, but is not limited to, representing MEL on the ATL Technical Advisory Committee, representing PED during construction of the Vibration Isolation Testbed in building 220, serving on the Technical Evaluation Board for temperature control systems for the Temperature Control Testbed in building 226.

\section{FY96 Plans:}

- Complete design phase and begin construction of SEM and Probe Research Facilities.

- Complete renovation of Complex Form Metrology space.

- Complete design phase of ATL as MEL technical representative to CIFP.

- Complete renovation/construction of Large Object Metrology facility.

Related Developments: The project leader is a member of the National Conference of Standards Laboratories (NCSL) Laboratory Facilities Committee and is participating in the updating of the NCSL Recommended Practice RP-7 Laboratory Design.

Five-Year Plan Goals vs. Fiscal Years:

\begin{tabular}{|l|l|l|l|l|l||}
\hline LABORATORY DEVELOPMENT & 96 & 97 & 98 & 99 & 00 \\
\hline Represent MEL regarding technical quality of ATL [STRS] & & & & & \\
\hline $\begin{array}{l}\text { Design and construct retrofit of individual GPL technical } \\
\text { spaces per PED program requirements and develop this } \\
\text { activity's base across the whole of MEL [STRS, OA] }\end{array}$ & & & & & \\
\hline $\begin{array}{l}\text { Coordinate fit-out of ATL space and preliminary migration } \\
\text { plan for those elements of MEL displacing to the ATL } \\
\text { [STRS] }\end{array}$ & & & & & \\
\hline
\end{tabular}




\section{Staff: (3.3 staff years) CHARLES J. FRONCZEK, *Steve Phillips, ${ }^{*}$ Tyler Estler, $*$ Ron Hartsock, ${ }^{*}$ Greg} Caskey, *David Ward

Objective and MEL Thrust(s) Supported: To (1) develop (ANSI and ISO) standardized tests for large scale three-dimensional coordinate metrology instrumentation, (2) provide high accuracy dimensional calibration of large scale artifacts, and (3) assist U.S. industry in the use of large scale coordinate metrology. Manufacturing Metrology

Need(s) Addressed: Large-part manufacturing is requiring ever decreasing tolerances. Many large-scale parts, even in high technology applications, lack interchangeability due to dimensional variation. For example, a large commercial aircraft may contain over one ton of shims needed to assemble the plane. This additional weight can cost approximately $\$ 1 \mathrm{M}$ per year per plane in additional operation costs. Furthermore, replacement parts need to be custom made since proper dimensional alignment cannot be achieved. These dimensional metrology problems result in increased component costs, operating costs, down time in maintenance due to custom fitting, and pollution. Presently, large scale coordinate metrology is a relatively neglected field which lacks specific ANSI or ISO standards for metrology instrumentation. Consequently, it is not uncommon to discover that different measurement systems, e.g., laser trackers, theodolites, and articulating arm CMMs, may repeatedly give significantly different results. Similarly, the domestic infrastructure for high accuracy calibrations of large dimensional standards is nearly nonexistent and manufacturers often must rely on foreign metrology equipment vendors for calibration services.

Technical Approach: Large-scale coordinate metrology problems are addressed on several fronts in this project. National and international standard committees are being established to specify the metrology characteristics of measurement instrumentation. NIST participation on these standard bodies is essential to insuring that domestic manufacturing needs are addressed. Simultaneously, NIST will conduct research into theodolites and laser tracker systems to determine and quantify the error sources and seek methods for error elimination. This research will be coordinated with U.S. industry to target difficult manufacturing problems. In addition, the development of the Large Scale Metrology Calibration and Research Laboratory will provide a facility to perform high accuracy calibrations and measurements. For example, the long length interferometric measuring machine, once completed, will provide measurement capability at an accuracy target level of $0.25 \mu \mathrm{m}$ $+0.4 \mu \mathrm{m} / \mathrm{m}$ for measurements up to $6 \mathrm{~m}$.

\section{FY95 Accomplishments:}

- Completed temperature survey of Large Scale Metrology Calibration and Research Laboratory.

- Specifications for environmental control of facility to $0.1{ }^{\circ} \mathrm{C}$ established.

- Mechanical design of the long length interferometric measuring machine completed.

- Large Scale Metrology Calibration and Research Laboratory space acquired and renovations are underway.

- Laser tracker system under contract.

- Established ANSI standard draft of theodolite calibration procedure.

\section{FY96 Plans:}

- Complete temperature control of Large Scale Metrology Calibration and Research Laboratory.

- Fabricate and assemble the long length interferometric measuring machine.

- Demonstrate the long length interferometric measuring machine to $\pm(0.5 \mu \mathrm{m}+0.7 \mu \mathrm{m} / \mathrm{m})$ accuracy.

- Coordinate with U.S. aerospace firms regarding targeted research topics.

- Document procedures and measurement uncertainty of long tape calibration service. 
- Address DOD large scale metrology problems.

Five-Year Plan Goals vs. Fiscal Years:

\begin{tabular}{||l|l|l|l|l|l||}
\hline Large Scale Coordinate Metrology & 96 & 97 & 98 & 99 & 00 \\
\hline $\begin{array}{l}\text { Improve the long length interferometric measuring machine } \\
\text { to } \pm 0.25 \mu \mathrm{m}+0.4 \mu \mathrm{m} / \mathrm{m} \text { [STRS] }\end{array}$ & & & & & \\
\hline $\begin{array}{l}\text { Conduct large scale artifact round robins with other national } \\
\text { laboratories [STRS] }\end{array}$ & & & & & \\
\hline Coordinate ANSI and ISO theodolite standards [STRS] & & & & & \\
\hline Initiate ANSI laser tracker standard [STRS] & & & & & \\
\hline $\begin{array}{l}\text { Develop large scale artifact for intercomparison of several } \\
\text { different technologically based measurement instruments } \\
\text { [STRS] }\end{array}$ & & & & & \\
\hline
\end{tabular}




\section{Staff: (2.1 staff years) E. MARX, B. C. Park, ${ }^{*}$ T. V. Vorburger}

Objective and MEL Thrust(s) Supported: To complement work done within the division and elsewhere at NIST with calculations of electromagnetic wave scattering by, different media, to enhance the practicality of light scattering instruments for measuring the roughness of machined surfaces, and to study the correlation between light scattering measurements and stylus profiling techniques. Manufacturing Metrology.

Need(s) Addressed: The theoretical component of this effort interacts with established and new initiatives at NIST that include scattering of light and other electromagnetic waves. Examples are programs related to $x$-ray optics and multilayer surfaces, particles on surfaces representing contamination in the semiconductor industry, round robin comparisons of measurements of the power spectral density (PSD) of semiconductor surfaces, and the deterioration of paint coatings in industrial applications. A supporting effort is the study of scattering of electromagnetic waves by dielectric wedges, a geometry that represents edges on real objects and the interface between a particle and a plane. The measurement of the surface roughness is becoming increasingly important in industry, because more stringent surface specifications are required as products tend to miniaturize and become more precise in functioning. The optical techniques are recently finding many applications in the measurement of surface finish as non-contact, non-destructive methods. As a rapid and area-averaging method, light scattering is most promising for on-line measurement, which is essential for the best quality control. There are many current needs for the light scattering technique: development of a new light scattering instrument; improvement of the existing commercial instruments; and correlation with conventional techniques such as stylus profiling.

Technical Approach: Scattering of electromagnetic waves by different objects is calculated using integral equations derived from Maxwell's equations. These equations are exact, incorporate the outgoing-wave condition, and rigorous methods such as this one are required in the resonance region, in which the dimensions of the scatterer are comparable to the wavelength of light. Integral equations also facilitate the concentration of sampling points in regions of interest. A full three-dimensional problem involves a large number of unknowns, a number that is limited by the memory available even on mainframe computers; the single integral equation method has been used to reduce the memory requirements. Each geometrical configuration requires a specialized representation that takes into account the characteristics of the scatterer.

Experiments will be conducted with a commercial light scattering instrument. This instrument has been used to measure roughness of crankshaft, rocker arm, wind tunnel model surfaces, and many other turned and ground surfaces. Despite the fact that the instrument has been useful for diverse engineering surfaces, it still needs to be improved to measure surfaces with greater wavelengths (greater than several hundred micrometers) or finer roughness (less than several nanometers in $R_{\jmath}$ ). In its present optical configuration, the instrument has limited angular resolution. The scheme of the project is to improve the performance with a modification of the illumination optics so that a collimated beam, instead of a focused beam, is incident on the specimen. The expected improvements are higher angular resolution and a wider range of sensitivity to roughness height and spatial wavelength than currently available from the instrument. These will enable the measurement of specimens with greater wavelength and finer roughness than is achievable presently.

\section{FY95 Accomplishments:}

- Developed codes to compute the scattering cross section of two touching perfectly conducting or dielectric spheres.

- Developed a code for the scattering of $\mathrm{x}$-rays by a perfectly conducting rough patch, which required the use of spline fits to two-dimensionally rough surfaces.

- Calculated the behavior of fields near the edge of a dielectric wedge for arbitrary direction of 
incidence and polarization.

- Initiated an analysis of measurements of rough surfaces and their PSDs as part of an industry-led round robin comparison.

\section{FY96 Plans:}

- Compute code of $\mathrm{x}$-ray scattering by dielectric or finitely conducting rough surfaces and multilayers.

- Develop code and compute light scattering by a spherical dielectric particle on a dielectric plane surface.

- Analyze and coordinate the round robin of PSD measurements.

- Modify the illumination optics of the light scattering instrument based on geometrical optics.

- Analyze the performance of the light scattering instrument: investigate light scattering from turned and ground surfaces; correlate the scattering parameters to the roughness parameters based on stylus instruments to determine the increase in instrument sensitivity; determine the envelope of operation in roughness-wavelength space.

- Consult with personnel of Optical Dimensions in the development of their scattering gauge for moderately rough surfaces.

Related Developments: A small instrument company, Optical Dimensions, has recently developed a light scattering gauge for measuring surface roughness. We are initiating a cooperative project with them in order to understand the surface properties measured by the technique.

Five-Year Plan Goals vs. Fiscal Years:

\begin{tabular}{||l|l|l|l|l|l||}
\hline LIGHT SCATTERING BY ROUGH SURFACES & 96 & 97 & 98 & 99 & 00 \\
\hline Work cooperatively with Optical Dimensions [STRS] & & & & & \\
\hline $\begin{array}{l}\text { Participate on Sematech Microroughness and Particle } \\
\text { Sizing Task Force [STRS] }\end{array}$ & & & & & \\
\hline $\begin{array}{l}\text { Demonstrate use of a practical light scattering instrument for } \\
\text { measuring turned components [STRS] }\end{array}$ & & & & & \\
\hline $\begin{array}{l}\text { Develop theoretical criteria for detectability of small particles } \\
\text { on rough surfaces [STRS] }\end{array}$ & & & & & \\
\hline
\end{tabular}


Staff: (1.5 staff years), *J. VILLARRUBIA, ${ }^{*}$ S. Jones, ${ }^{*} \mathrm{M}$. Postek, ${ }^{*}$ J. Potzick, ${ }^{*} \mathrm{C}$. Teague, ${ }^{*} \mathrm{R}$. Dixson, ${ }^{*} \mathrm{R}$. Allen, ${ }^{*}$ M. Cresswell, ${ }^{*}$ L. Linholm

Objective and MEL Thrust(s) Supported: To improve linewidth measurement capabilities within PED and other related NIST groups through comparative experiments among practitioners of different measurement techniques. Manufacturing Metrology

Need(s) Addressed: NIST is responsible for providing linewidth SRM's and/or calibration services to meet the needs of U.S. industry. Presently, our only linewidth standards are optical photomask standards, the minimum linewidth of which is $0.5 \mu \mathrm{m}$ with a total uncertainty (using the new rules for uncertainty calculation) of $\sim 50 \mathrm{~nm}$ at a two-sigma confidence level. To support present and future semiconductor technologies, industry needs to measure sub-micrometer lines with uncertainties, as identified by SEMATECH, of $20 \mathrm{~nm}$ or better. The magnetic recording and photographic industries have gap width and grain size measurement requirements at approximately the same scale. Neither NIST nor other national laboratories presently offer a linewidth measurement service or SRM with this level of accuracy.

Physical linewidth determination with any microscopic technique requires modeling of the probe/sample interaction in order to identify edge locations. One barrier to accurate linewidth determination has been acquisition of models in which we can have the required level of confidence. A second barrier is lack of consensus on the definition of linewidth.

Technical Approach: Linewidth measurement capabilities at NIST span several techniques, including optical, scanning electron, and scanned probe microcopies for physical linewidth as well as electrical techniques to measure the average width of conducting paths. This project seeks cooperative interactions among paractitioners of the various techniques. This cooperation will include information exchange among practitioners of the various methods. It will also include design and eventual execution of experiments for cross-technique comparison of measurements.

We will cooperatively design experiments to measure the same linewidth artifacts by two or more techniques. Experimental design will include all factors relevant to good measurement practice, including sample handling, definition of linewidth for purposes of this experiment, and a manufacturable linewidth artifact or artifacts measurable by multiple techniques. If possible, we will design a single artifact measurable by all of the methods. If this proves impractical, we might design several artifacts optimized for pair-wise comparisons linking all of the methods. We will seek industry cooperation in the fabrication of these artifacts. In parallel with efforts to design artifacts with desirable features, we will seek opportunities to begin measurements with specimens either in hand or easily accessible, despite their less desirable properties.

The goal of measurements on these artifacts will be to document any existing discrepancies between methods. In the unlikely event that no such discrepancies are found, confidence in all of the techniques (including the probe/sample interaction models) would be significantly enhanced. In the more likely event of discrepancies, identification of the sources and remediation will enhance NIST's overall linewidth capabilities.

\section{FY95 Accomplishments:}

- The team completed a draft report describing industry linewidth requirements, the team's present measurement capabilities, work in progress, and issues/problems for each of the four linewidth measurment methods.

- The team designed a linewidth specimen based upon SIMOX and BESOI technologies. The specimen admits of several measurement modes of progressively increasing risk and reward. 
- We estabished a collaboration with Sandia National Laboratory for specimen fabrication. Sample fabrication will use a preferential etch of single-crystal $\mathrm{Si}$ on $\mathrm{SiO}_{2}$ designed to produce line profiles with crystallographically determined vertical sidewalls with very low edge roughness.

\section{FY96 Plans:}

- Report specimen design in appropriate forums.

- Complete fabrication of first set of linewidth specimens.

- Agree on procedures for sample handling and storage.

- Create a working definition of linewidth.

- Begin linewidth measurements on specimens.

Five-Year Plan Goals vs. Fiscal Years:

\begin{tabular}{|c|c|c|c|c|c|}
\hline LINEWIDTH CORRELATION & 96 & 97 & 99 & 99 & 00 \\
\hline Report specimen design in appropriate forums [STRS] & 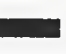 & & & & \\
\hline Fabricate 1st set of linewidth specimens [STRS] & 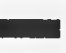 & & & & \\
\hline $\begin{array}{l}\text { Agree on procedures for sample handling and storage } \\
\text { [STRS] }\end{array}$ & 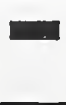 & & & & \\
\hline Create a working definition of linewidth [STRS] & & & & & \\
\hline $\begin{array}{l}\text { Perform first linewidth measurements on specimens using } \\
\text { all of the techniques [STRS] }\end{array}$ & & & & & \\
\hline $\begin{array}{l}\text { Develop revised edge location models and/or linewidth } \\
\text { working definition to reconcile differences uncovered in } \\
\text { measurements [STRS] }\end{array}$ & & & & & \\
\hline $\begin{array}{l}\text { Test revised models/definitions by iterating the fabrication, } \\
\text { measurement, and model revision steps above [STRS] }\end{array}$ & & & & & \\
\hline $\begin{array}{l}\text { Develop one of the linewidth artifacts into a linewidth SRM } \\
\text { [STRS] }\end{array}$ & & & & & \\
\hline
\end{tabular}




\section{Title: METROLOGY EDUCATION}

Staff: (0.1 staff years) *TED DOIRON, *John Stoup, *Janet Land

Objective and MEL Thrust(s) Supported: Provide educational services to other, primarily private industry, metrologists. Manufacturing Metrology

Need(s) Addressed: There is almost no educational resources in dimensional metrology. There are only three community colleges that offer two year associate degrees in metrology, and no four-year colleges at all.

Technical Approach: We have developed two different seminars; one, a two-day course on the general principles of Dimensional Metrology, and the other a three-day seminar on Gage Block Calibration. In conjunction with the Gage Block Seminar, we have written a 150 page monograph. We have also given a number of $1 / 2$-day tutorials on limited subjects such as cylinder calibration and the requirements of NCSL Z540-1 Calibration Laboratory Standard.

We are also part of two nascent efforts to start a metrology courses at the college level. Along with our colleagues at the DOE/Oak Ridge Metrology Center (DOE/ORMC) in Oak Ridge, TN, we are working with the Industrial Engineering faculty of North Carolina State A\&T University (NCS A\&T) to attract funding and equipment for a number of coursed in their curriculum. We have also begun talks with Montgomery College in an effort to interest them in offering a Quality Engineering curriculum which would include dimensional metrology.

\section{FY95 Accomplishments:}

- $\quad$ The Gage Block Seminar at the NIST Gaithersburg Site was again filled (24 participants).

- The first Dimensional Metrology Seminar, held in conjunction with the Measurement Science Conference, was held in Anaheim in January. The course was full, and we have been asked to give the seminar again next year.

- A $1 / 2$-day tutorial on the technical aspects of NCSL Z540-1 for dimensional laboratories was given twice to a total of 50 participants.

- The Gage Block Handbook, covering most of the material in the Gage Block Seminar, was published as NIST Monograph 180.

\section{FY96 Plans:}

- The two seminars and the Z540 Tutorials will be given, again in cooperation with the Measurement Science Conference.

- We will begin to plan a number of new $1 / 2$-day tutorials on specialized topics of interest to industrial dimensional metrologists.

- We will continue to work with our colleagues at NCS A\&T and Montgomery College to start programs which will provide metrology education at the college level.

Five-Year Plan Goals vs. Fiscal Years:

\begin{tabular}{|l|c|c|c|c|c|}
\hline METROLOGY EDUCATION & $\mathbf{9 6}$ & $\mathbf{9 7}$ & $\mathbf{9 8}$ & $\mathbf{9 9}$ & $\mathbf{0 0}$ \\
\hline Present and revise Gage Block Seminar [STRS] & & & & & \\
\hline Present and revise DM Seminar at MSC meeting [STRS] & & & & & \\
\hline Assist NCS A\&T in developing metrology courses [STRS] & & & & & \\
\hline
\end{tabular}




\begin{tabular}{|l|l|l|l|l|l||}
\hline METROLOGY EDUCATION & 96 & 97 & 98 & 99 & 00 \\
\hline $\begin{array}{l}\text { Confer with Montgomery College on quality curriculum } \\
\text { [STRS] }\end{array}$ & & & & & \\
\hline
\end{tabular}




\section{Staff: $(0.7$ staff years $) *$ J.F. SONG, *T.V. Vorburger}

Objective and MEL Thrust(s) Supported: To develop NIST microform metrology including calibration systems based on both stylus and optical techniques, calibration and check standards, and uncertainty procedures. To develop a NIST metrology approach, based on NIST microform metrology, for standardization of both U.S. and international Rockwell hardness measurements. This includes the development of the NIST Standard Grade Rockwell Diamond Indenters for use as the common artifacts in a forthcoming international round robin to establish the worldwide unified Rockwell scale and to unify the international Rockwell hardness standards. Manufacturing Metrology

Need(s) Addressed: Recent developments in computer technology, micro-electronics and precision engineering, as well as U.S. and international standardization efforts for Rockwell hardness standards, have resulted in a new area in surface metrology, called microform metrology. In microform metrology, the complex 3-D surface features in the micrometer scale must be quantified for their shape and size including dimensions, curves, angles, profile deviations, and alignment errors, as well as surface roughness with measurement uncertainties compatible with tolerance requirements.

One of the requirements for microform metrology came from U.S. and international work in Rockwell hardness standardization. Rockwell hardness is the most widely tested materials property for metal products. The United States has had no national laboratory for Rockwell standards. International comparisons have shown significant differences ( \pm 0.9 HRC, 1984). In contrast, during the 1980's, the EU countries unified their Rockwell C hardness (HRC) scales to $\pm 0.3 \mathrm{HRC}$. With the development of the ISO 9000 quality standards, the unified EU scale is presenting a challenge to the United States. This technical barrier to trade will directly affect the $\$ 75$ billion U.S. metal products industry, the $\$ 170$ billion U.S. automobile industry, and the $\$ 93$ billion aerospace industry, as well as machinery and many other industries.

Technical Approach: Because there was no metrology approach to verify precisely the geometric correctness of the Rockwell indenters, the EUHRC scales had to be unified through hardness performance comparisons. The performance-based EU scale lacks traceability to fundamental metrology, has an unknown bias to the correct scale, and lacks reproducibility, and therefore, cannot be used for unifying the U.S. and the international Rockwell scales.

Based on the NIST microform calibration system using a stylus technique, a NIST approach was proposed to establish a metrology-based Rockwell standard system through the development of the NIST Standard-Grade Rockwell Diamond Indenters. Another microform calibration system using an optical technique is also proposed to verify these indenters. The NIST standard indenters, combined with the use of the NIST standard testing machine in MSEL's Metallurgy Division and standardized testing conditions, are proposed to create, maintain, and reproduce the metrology-based Rockwell hardness scale in the U.S. and overcome the unknown bias in the EU performance-based HRC scale. The NIST SRM indenters and the NIST SRM hardness blocks (to be developed in MSEL) will transfer the established NIST metrology-based Rockwell hardness scale to U.S. industry, as well as to the world. The NIST metrology-based Rockwell hardness standard system will establish a worldwide unified Rockwell scale traceable to fundamental metrology.

\section{FY95 Accomplishments:}

- Published uncertainty report for NIST microform calibrations in J. Res. NIST.

- Calibrated 40 Rockwell indenters, which came from IMGC (Italy), MPA (Germany), NRLM (Japan), NAMAS (U.K.), Stroh (Germany), and U.S industry. The calibration results have shown good accuracy; eleven geometrically unified indenters showed close agreement in their performance 
in MSEL's hardness machine.

- Visited NRLM (Japan), NIM (China), conducted comparisons on geometry measurements and hardness tests, presented talks on the NIST metrology approach, and obtained support from NRLM and NIM.

- $\quad$ Published two papers describing the NIST metrology approach at the 9th International Symposium on Hardness Testing, 11/95, Germany, and obtained support from PTB and NPL.

\section{FY96 Plans:}

- Complete the second version of the uncertainty program for reporting calibration uncertainties of Rockwell diamond indenters.

- Complete the data transfer from the Form Talysurf instrument to a PC computer for uncertainty reports.

- Complete the NIST calibration service for Rockwell indenter microform calibrations.

- Complete 50 NIST SRM 2809 Rockwell indenter calibrations.

Five-Year Plan Goals vs. Fiscal Years:

\begin{tabular}{|l|l|l|l|l|l||}
\hline MICROFORM METROLOGY & 96 & 97 & 96 & 96 & 00 \\
\hline \begin{tabular}{|l} 
Automate the existing NIST microform calibration system \\
based on the stylus technique
\end{tabular} & & & & & \\
\hline $\begin{array}{l}\text { Develop an optical microform calibration system for the } \\
\text { microform calibrations at NIST }\end{array}$ & & & & & \\
\hline $\begin{array}{l}\text { Complete certification of NIST SRM 2809 Rockwell } \\
\text { Indenters }\end{array}$ & & & & & \\
\hline Develop the NIST calibration service for Rockwell Indenters & & & & & \\
\hline $\begin{array}{l}\text { Develop a series of NIST Standard Grade Rockwell } \\
\text { Indenters }\end{array}$ & & & & & \\
\hline $\begin{array}{l}\text { Participate in an international round robin for a worldwide } \\
\text { unified Rockwell standard (in cooperation with MSEL's } \\
\text { Metallurgy Division) }\end{array}$ & & & & & \\
\hline
\end{tabular}


Staff: (3 staff years) *J. KRAMAR, *J. Dagata, *L. Howard, *J. Jun, *B. Penzes, *F. Scire, *J. Villarrubia, ${ }^{*} \mathrm{C}$. Teague

Objective and MEL Thrust(s) Supported: To develop a coordinate-measuring machine with sub-nanometer probe resolution and one nanometer total uncertainty within a measuring volume of $50 \mathrm{~mm} \mathrm{x}$ $50 \mathrm{~mm} \times 0.1 \mathrm{~mm}$. To utilize this instrument in the measurement and calibration of artifacts that will support industry — particularly the semiconductor manufacturing industry—in its needs for line width, pitch, and especially feature placement metrology. Manufacturing Metrology; Advanced Manufacturing Processes and Equipment

Need(s) Addressed: The Molecular Measuring Machine $\left(\mathrm{M}^{3}\right)$ project was conceived and developed in direct response to deficiencies in measurement capabilities at NIST that were and are projected to be a serious limiting factor in certain high technology industries. At the time the project was started, the minimum uncertainty in line spacing measurements at NIST was $10 \mathrm{~nm}$ for line spacings from $5 \mathrm{~mm}$ to $50 \mathrm{~mm}$ and only $25 \mathrm{~nm}$ for line spacings of $1 \mu \mathrm{m}$ to $50 \mu \mathrm{m}$. Physical line width measurement uncertainties were about $50 \mathrm{~nm}$ for line widths ranging from $0.5 \mu \mathrm{m}$ to $10 \mu \mathrm{m}$. The U.S. precision optics and microelectronics industries have repeatedly requested that NIST reduce the measurement uncertainties of these quantities to the $0.1 \mathrm{~nm}$ to $1.0 \mathrm{~nm}$ range. These requests are motivated by the availability of commercial instruments with resolutions in the $100 \mathrm{pm}$ to 10 pm range, and by the increasingly smaller critical dimensions on all microelectronic circuit elements. As an example, the Semiconductor Industry Association roadmap is calling for line width measurement uncertainties (three sigma) of four atoms, i.e., $1 \mathrm{~nm}$, by the year 2001.

Technical Approach: Our response is to build the NIST Molecular Measuring Machine $\left(\mathrm{M}^{3}\right)$, a state-of-the-art, two-dimensional, coordinate-measuring machine designed to achieve $1 \mathrm{~nm}$ total uncertainty for point-to-point measurements over a $50 \mathrm{~mm} \mathrm{X} 50 \mathrm{~mm}$ area while accommodating surface height variations of as much as $100 \mu \mathrm{m}$. The sensing probes are scanning tunneling and atomic force microscopes, which give an imaging resolution that extends to the atomic (sub-nanometer) scale. The displacements are measured with a custom-built, state-of-the-art, heterodyne interferometer having a measurement resolution of $10 \mathrm{pm}$ with a 2 $\mathrm{kHz}$ bandwidth. In order to achieve these metrological goals the instrument also incorporates a state-of-the-art temperature control system which maintains temperature stability to $100 \mu \mathrm{K}$ as well as an advanced seismic and acoustic vibration isolation system. This instrument will provide most of the aforementioned measurement capabilities requested by the U.S. precision optics and microelectronics industries. It will be used to measure line spacing, line width, and feature-placement artifacts that can be used to calibrate the industries' measuring machines. In addition to providing these metrological capabilities, $\mathrm{M}^{3}$ is also to be used as an exploratory tool in the rapidly growing field of nanotechnology.

\section{FY95 Accomplishments:}

- Demonstrated the operation of $\mathrm{M}^{3}$ in a vacuum of $10^{-5} \mathrm{~Pa}$.

- Demonstrated the operation of the temperature control system in vacuum at a $1 \mathrm{mK}$ fluctuation level.

- Improved the reliability of the $\mathrm{M}^{3}$ interferometer system electronics to an estimated mean-time-between-failures of six months.

- Demonstrated the ability to map out a surface over a full millimeter length in a continuous section of surface 5 micrometers wide. This was accomplished under automated, interferometer-based, computer control over a period of ten days.

\section{FY96 Plans:}


- Produce an initial error map for the fine-motion carriages and the superfine scanner.

- Issue a calibration report for the $0.2 \mathrm{~mm}$ and $0.4 \mathrm{~mm}$ pitch gratings submitted by researchers at MIT.

- Demonstrate the integrated operation of an improved Z-axis motor which includes a capacitance gage displacement sensor.

- Submit for publication a paper describing an $\mathrm{M}^{3}$ pitch measurement of the laser-focused atomically deposited (LFAD) chromium grating artifact.

Five-Year Plan Goals vs. Fiscal Years:

\begin{tabular}{|c|c|c|c|c|c|}
\hline MOLECULAR MEASURING MACHINE & 96 & 97 & 98 & 99 & 00 \\
\hline $\begin{array}{l}\text { Calibrate existing artifacts and develop and calibrate new } \\
\text { artifacts that will be appropriate for transferring the } \\
\text { measurement capabilities of } M^{3} \text { to industry [STRS, OSRM, } \\
\text { Fees] }\end{array}$ & & & & & \\
\hline $\begin{array}{l}\text { Upgrade all necessary sub-systems of } \mathrm{M}^{3} \text { to bring them into } \\
\text { full compliance with their advertised performance } \\
\text { specification goals [STRS] }\end{array}$ & & & & & \\
\hline $\begin{array}{l}\text { Refine the software and hardware control of } \mathrm{M}^{3} \text { to make it } \\
\text { more user-friendly, i.e., more easily taught to new operators, } \\
\text { less prone to operator or system errors, and more } \\
\text { thoroughly documented [STRS] }\end{array}$ & & & & & \\
\hline $\begin{array}{l}\text { Develop specific procedures for measuring the repeatability } \\
\text { of motion and for creating an error map of the } \mathrm{M}^{3} \text { coarse- } \\
\text { and fine-motion carriages and apply these procedures to } \\
\text { improve the metrological capabilities [STRS] }\end{array}$ & & & & & \\
\hline $\begin{array}{l}\text { Increase the versatility of } \mathrm{M}^{3} \text { by modifying the probe system } \\
\text { to include an atomic-force microscope [STRS] }\end{array}$ & & & & & \\
\hline $\begin{array}{l}\text { Evaluate the tribological performance of candidate load- } \\
\text { bearing pads for use on the } \mathrm{M}^{3} \text { diamond-turned slideways. } \\
\text { Then exchange the current pad/slideway system for this } \\
\text { improved combination [STRS] }\end{array}$ & & & & & \\
\hline $\begin{array}{l}\text { Design, install and test a six-degree-of-freedom, active, } \\
\text { vibration-isolation system for } \mathrm{M}^{3} \text { [STRS] }\end{array}$ & & & & & \\
\hline
\end{tabular}




\section{Title: NANOELECTRONICS COMPETENCE}

Staff: $(0.8$ staff years $) *$ J. DAGATA, ${ }^{*}$ L. Howard

Objective and MEL Thrust(s) Supported: Develop a comprehensive understanding of nanofabrication needs and practices by working closely with members of EEEL on the fabrication and measurement of ultraprecise electrometer circuits based on single-electron-tunneling devices. Advanced Manufacturing Processes and Equipment.

Need(s) Addressed: There is a need for NIST to improve its ability to measure fundamental electrical constants and properties. The next generations of devices and circuits which will make this possible require critical control of structural dimensions on the nanometer scale. The development of routine fabrication methods for these circuits provides a well-defined test case for PED to confront the challenges of nanomanufacturing.

Technical Approach: Integrated processing within PED's controlled ambient facility and ultrahigh vacuum STM will be used to carry out the fabrication of critically dimensioned structures of functional electrical devices. The ability to perform electrical tests by AFM/STS of the structures prior to sending them to EEEL for full-scale evaluation is a key quality-control element of this approach.

\section{FY95 Accomplishments:}

- Controlled ambient facility and its components designed, procured and delivered. Testing of completed system is now underway.

FY96 Plans:

- Complete development of LabVIEW-based data acquisition system for AFM/STS.

- Fabricate silicon nanostructures by AFM-patterned oxidation.

- Design and test chip mask set and chip carrier.

Five-Year Plan Goals vs. Fiscal Years:

\begin{tabular}{|l|l|l|l|l|l||}
\hline NANOELECTRONICS COMPETENCE & 96 & 97 & 98 & 99 & 00 \\
\hline $\begin{array}{l}\text { Complete development of LabVIEW-based data acquisition } \\
\text { system for AFM/STS [Competence] }\end{array}$ & & & & & \\
\hline $\begin{array}{l}\text { Measure surface charge on insulating substrates using } \\
\text { AFM/STS and correlate with charge offset phenomena } \\
\text { [Competence] }\end{array}$ & & & & & \\
\hline $\begin{array}{l}\text { Fabricate silicon nanostructures by AFM-patterned oxidation } \\
\text { [Competence] }\end{array}$ & & & & & \\
\hline $\begin{array}{l}\text { Design and test chip mask set and chip carrier } \\
\text { [Competence] }\end{array}$ & & & & & \\
\hline $\begin{array}{l}\text { Demonstrate capability of using AFM/STS potentiometry in } \\
\text { conjunction with fabrication process to alter the resistance of } \\
\text { nanostructures in a controlled manner [Competence] }\end{array}$ & & & & & \\
\hline $\begin{array}{l}\text { Fabricate and characterize SET device structures } \\
\text { [Competence] }\end{array}$ & & & & & \\
\hline
\end{tabular}




\begin{tabular}{|l|c|c|c|c|c||}
\hline NANOELECTRONICS COMPETENCE & 96 & 97 & 98 & 99 & 00 \\
\hline $\begin{array}{l}\text { Fabricate and characterize SET circuits with 5-10 devices } \\
\text { per circuit [Competence] }\end{array}$ & & & & & \\
\hline
\end{tabular}


Staff: $(1.0$ staff year $) *$ WILLIAM PENZES, *John Beers, *Jau Jun, ${ }^{*}$ Fred Scire, ${ }^{*}$ Clayton Teague

Project Objective and MEL Thrust(s) Supported: To maintain NIST capability for line scale measurements at a world-class level. Manufacturing Metrology

Need(s) Addressed: The line scale interferometer (LSI) serves a pivotal role in NIST measurements of the distance between two features-line scale measurements--for distances ranging from 10 micrometers up to 1 meter. It supports advanced measurement needs of the integrated circuit industry by providing calibrations of reticles for photo and x-ray masks, as well as line-scale calibrations for optical line scale artifact manufacturers and manufacturers of various type of grid plates. Some of the U.S. corporations often requesting ultra-high accuracy line scale measurements are IBM, ITT, Boeing Co, ACU-RITE, Corning, Inc., AMP, Iin. and Master Images. It remains the NIST reference for international practical comparisons of the meter. Finally, it serves as the NIST internal practical tie to the ISO definition of the meter for gage block measurements, ball-bar measurements, optical and SEM linewidth measurements and electrical test structure measurements.

This project addresses four areas of improvement: (1) increasing the line detector resolution, (2) upgrading of the data acquisition and control computer system and interfaces, (3) improvements in the resolution and accuracy of the displacement interferometer, and (4) improvements in the mechanical structure to permit simultaneous comparison of the wavelengths of two lasers. For the first area, the LSI presently utilizes a scanning photo-electric microscope capable of measuring scales with line width of 1 to 100 micrometers wide. Addition of a scanning capacitance line detector (SCLD) to the LSI will enable measurement of lines with widths as narrow as $10 \mathrm{~nm}$.

Technical Approach: To develop a SCLD, a design based on a successful earlier NIST design is being built and tested. In this design, the detector capacitor is placed in one leg of a carrier-operated series resonant bridge. The sensitivity depends on the carrier frequency, the stand-off distance, the tip diameter, the detectable line width and the $\mathrm{Q}$ of the bridge components. The effect of all these parameters are currently being investigated experimentally and theoretically. Upgrading the data acquisition and control computer system will utilize a new high performance PC, making all the necessary hardware modifications, redesigning the measurement procedure, rewriting the data acquisition and control software, and installing a new data acquisition, data analyzing, instrument control and advanced graphic software. Interferometer improvements planned will include adoption of the phase measurement improvements from $\mathrm{M}^{3}$ and, after a careful design study, some means to overcome uncertainties from index of refraction effects.

\section{FY95 Accomplishments:}

- Completed the electronic and mechanical designs and assembled of scanning capacitance line detector using planned $10 \mathrm{MHz}$ circuit design.

- Demonstrated the line detection capability of the new probe design.

- Designed and procured Invar materials for installing a more thermally stable mechanical mount for the LSI remote interferometer.

- Purchased a 486DX/66 personal computer for the LSI.

- The $100 \mathrm{MHZ}$ scanner head was designed and fabricated.

- Flow chart was developed for the new data acquisition and control program for the LSI PC.

- Purchased and evaluated a Keithley Model 2002 DVM for the LSI reference PRT measurement.

FY96 Plans:

- Hardware: (1) Install the new laser mounting platforms at both sides of the LSI, (2) Modify the 
laser access hole at right end of the chamber by rerouting the internal copper piping, (3) Design, fabricate and install kinematic mounts for the laser heads at both ends, (4) Improve the LSI housing by covering it with a laminate or other surface treatment, and (5) Upgrade, if possible the internal microscope lens system.

- Instrumentation: (1) Procure and install an A/D data acquisition board for the PC, (2) Procure and install an HPIB Interface board and install, (3) Hook up the reference PRT to the Keithley 2002 multimeter, (4) Connect all TC to the new Keithley 705 scanner and measure temperature with the Keithley 182 Nanovoltmeter, (5) Connect all peripheral instruments to the PC through IEEE-488 line, and (6) Purchase a complete HP laser and interferometer system.(laser head, counter, interferometer with reference, corner cube and beam bender).

Five-Year Plan Goals vs. Fiscal Years:

\begin{tabular}{|c|c|c|c|c|c|}
\hline NIST LINE SCALE INTERFEROMETER UPGRADING & 96 & 97 & 98 & 98 & 00 \\
\hline \multicolumn{6}{|l|}{$\begin{array}{l}\text { Design, construct a Scanning Capacitive Line } \\
\text { Detector(SCLD] for the LSI based on discrate/hybrid } \\
\text { electronics [STRS] }\end{array}$} \\
\hline \multicolumn{6}{|l|}{$\begin{array}{l}\text { Install new temperature data acquisition and control } \\
\text { electronics for LSI [STRS] }\end{array}$} \\
\hline \multicolumn{6}{|l|}{$\begin{array}{l}\text { Rewrite LSI data acquisition and control computer program } \\
\text { [STRS] }\end{array}$} \\
\hline \multicolumn{6}{|l|}{$\begin{array}{l}\text { Design, construct a SCLD for LSI utilizing fully integrated } \\
\text { circuit electronics [STRS] }\end{array}$} \\
\hline \multicolumn{6}{|l|}{ Upgrade LSI computer and interfaces to peripherals [STRS] } \\
\hline \multicolumn{6}{|l|}{$\begin{array}{l}\text { Upgrade LSI control electronics by converting all existing } \\
\text { prototype circuit boards to printed circuit boards [STRS] }\end{array}$} \\
\hline \multicolumn{6}{|l|}{$\begin{array}{l}\text { Design SRM (scales) for length standards which can be } \\
\text { measured by optical, electrical test structure and capacitive } \\
\text { sensing methods [STRS] }\end{array}$} \\
\hline \multicolumn{6}{|l|}{$\begin{array}{l}\text { Furbish the LSI with lodine Stabilized Laser to increase } \\
\text { measurement capability and accuracy [STRS] }\end{array}$} \\
\hline \multicolumn{6}{|l|}{$\begin{array}{l}\text { Complete optical and mechanical modifications of the LSI to } \\
\text { enable dual wavelength comparison [STRS] }\end{array}$} \\
\hline $\begin{array}{l}\text { Conduct design study to evaluate relative } \\
\text { advantages/disadvantages of using interferometer paths in } \\
\text { vacuum, controlled gas environment, and two color index of } \\
\text { refraction measurement [STRS] }\end{array}$ & & & & & \\
\hline
\end{tabular}


Staff: (1.0 staff years) ${ }^{*}$ JAMES POTZICK, *Rick Silver, *Carol Vezzetti, *Patricia Snoots

Objective and MEL Thrust(s) Supported: Maintain and improve quality of SRM 473, SRM 475, and SRM 476 and their availability to industry. Manufacturing Metrology

Need(s) Addressed: Accurate measurement and control of feature sizes on IC photomasks is critical to current and advanced IC manufacturing process. This photomask linewidth SRM is the established standard for linewidth measurement among photomask vendors and users. Calibration uncertainty is expected to decrease, market demand is expected to increase, and stock must be maintained.

Technical Approach: Specify and procure high quality photomasks for SRM 473, inspect, calibrate using existing green light calibration system (or the UV microscope, when operational), maintain records, package and deliver to OSRM for sale. Take steps to reduce calibration uncertainty.

FY95 Accomplishments:

- Wrote purchase specifications for SRM 473, evaluated bid proposals, selected vendor, issued purchase contract.

- Photomasks were received and calibrated.

- Sent one of the newly calibrated SRM 473 photomasks to NPL in England for exchange with one of their photomask standards, for international intercomparison measurements. Measurements completed.

FY96 Plans:

- Present symposium paper describing results of NIST-NPL comparison.

- Rewrite SP 260 for SRM 473.

- Complete packaging and delivery of SRM 473 to OSRM.

- Participate with NPL and PTB in measuring their proposed EU $0.2 \mu \mathrm{m}$ linewidth standard, if possible at that time.

Five-Year Plan Goals vs. Fiscal Years:

\begin{tabular}{|l|l|l|l|l|l||}
\hline OPTICAL PHOTOMASK METROLOGY & 96 & 97 & 98 & 99 & 00 \\
\hline $\begin{array}{l}\text { Maintain and improve software and hardware of green-light } \\
\text { photomask calibration system to assure ability to meet } \\
\text { future customer demand [STRS] }\end{array}$ & & & & & \\
\hline $\begin{array}{l}\text { Contact PTB in Germany with proposal to exchange } \\
\text { photomask standards for international comparison [STRS] }\end{array}$ & & & & & \\
\hline $\begin{array}{l}\text { Complete transition of calibrations to the UV Microscope } \\
\text { [STRS] }\end{array}$ & & & & & \\
\hline $\begin{array}{l}\text { Maintain collaboration with EU and other national } \\
\text { laboratories in optical linewidth measurement [STRS] }\end{array}$ & & & & & \\
\hline
\end{tabular}


Staff: (1.5 staff years) R. SILVER, ${ }^{*}$ J. Potzick, ${ }^{*}$ B. Larrabee, ${ }^{*}$ C. Teague, ${ }^{*}$ F. Scire, ${ }^{*}$ A. Singer, ${ }^{*}$ L. Carroll

Objective and MEL Thrust(s) Supported: Design and implement an optical based overlay metrology system for the study and calibration of feature overlay on silicon wafers resulting from two or more patterning steps in IC fabrication. To design, procure, and calibrate Si-based standards in support of overlay metrology. Manufacturing Metrology, Advanced Manufacturing Processes and Equipment.

Need(s) Addressed: NIST is responsible to the U.S. microelectronics industry for developing calibration standards in support of semiconductor IC production. With many fabrication lines turning out more than 2000 wafers per week and with over 600 die per wafer, improvements in metrology can often improve yield which translates into substantial financial gains. Metrology issues are particularly critical in overlay measurement since the reduction in feature sizes of VLSI circuitry puts increasing demands on pattern placement of one level relative to another. This is widely recognized as one of the primary elements of concern in yield management. NIST currently offers no overlay standards and there is, consequently, an immediate need for the development of overlay calibration instrumentation and standard artifacts.

Pattern placement of the various levels is typically monitored through a series of box-in-box patterns, each in a different plane. The overlay offset is determined by optical measurements of the box center lines where each box is in a different plane. Any misalignment in the overlay metrology system will translate into an artificial overlay offset, referred to as tool induced shift (TIS). Additionally, there are residual errors caused by asymmetries in the box in box edges or covering layers (resist) known as wafer induced shift. A set of standard artifacts and procedures needs to be developed to align overlay measurement systems and eliminate TIS. Similarly, the aligned instruments must then be calibrated with standard artifacts to yield accurate overlay offsets.

Technical Approach: The technical strategy is divided into two segments: (1) instrumentation development, and (2) design and calibration of standard artifacts. The measurement system is designed for maximum accuracy and repeatability (high throughput is not essential for the NIST calibration system). The system is an optical reflection mode instrument, operational in either a bright field or confocal mode, with interferometry on three orthogonal axes also capable of monitoring the stage tilt. Additional instrumentation requirements are the option to scan the sample in any one of the three orthogonal axes, the ability to rotate the sample, and fully automated image recognition. Proper optical alignment in the Z-direction is critical. Similarly, precise stage motion is essential to ensure that $\mathrm{Z}$-axis focussing motion is decoupled from $\mathrm{X}$ - and $\mathrm{Y}$-axis motion since this will also add an erroneous shift to the image.

The first aim of the NIST standards program is to develop better methods to characterize tool induced shift (TIS). The goal is to ensure that the overlay tool is operating within an appropriate TIS specification. This will be accomplished by the development of a "tool kit" with procedural and artifact standards to assist in alignment of the optical and mechanical elements of the overlay metrology system. These tools would allow calibration of residual $\mathrm{X}$ - and $\mathrm{Y}$-motions during focussing in the Z-direction, adjustment and alignment of the illumination source, and calibration of the CCD pixels. Once the tool is aligned and TIS free, it may be used to characterize wafer induced shift of the test specimen.

Preparation of standard artifacts for this purpose is the second goal of the NIST program. Since user test patterns frequently have asymmetries in the edges and covering layers which are user specific, the NIST approach is to develop calibrated, wafer induced shift free standard artifacts. The edge geometry of these samples may be verified by SEM or AFM techniques. The final result would be wafer induced shift-free standards for the calibration of TIS free optical overlay tools. 
This system is capable of large distance scans to $89 \mathrm{~mm}$ in the $\mathrm{X}$ and $\mathrm{Y}$ directions without compromising the interferometry accuracy or the structural rigidity. Materials used in the metrology loop and the mechanical components were chosen to minimize thermal effects on the measuring process. Since thermal effects become the dominant error for long distance scans, the accuracy of these measurements can be substantially enhanced with a temperature control system. The addition of such a control system will make this instrument capable of state-of-the-art two-dimensional grid measurements.

\section{FY95 Accomplishments:}

- Completed the design of the reflection mode optical overlay metrology system.

- Procured all the major optical, translation stage, interferometry, and computer acquisition components for the overlay metrology system.

- Developed principles and design of standard artifacts for overlay metrology.

FY96 Plans:

- Complete the construction and demonstrate initial measurement capabilities.

- Begin formal qualification process for microscope and $x-y-z$ metrology system.

- Investigate the key issues in overlay metrology and complete the design of overlay standard artifacts. Submit proposal to SRM office for funding.

- Present paper at SPIE on the NIST overlay metrology project.

- Participate in the SEMI standards committee as task force leader on overlay metrology.

\section{Five-Year Plan Goals vs. Fiscal Years:}

\begin{tabular}{|l|l|l|l|l|l||}
\hline OVERLAY METROLOGY & 96 & 97 & 98 & 99 & 00 \\
\hline $\begin{array}{l}\text { Complete construction and demonstrate full operation of all } \\
\text { optical and mechanical components [OMP, STRS] }\end{array}$ & & & & & \\
\hline $\begin{array}{l}\text { Write and install the software modules enabling electronic } \\
\text { feedback and control of stage motion, interferometric } \\
\text { position measurements, photometer optical intensities, and } \\
\text { CCD full field digital imaging [OMP, STRS] }\end{array}$ & & & & & \\
\hline $\begin{array}{l}\text { Complete image recognition software, full analog and digital } \\
\text { filtering, and internal graphics capabilities [OMP, STRS] }\end{array}$ & & & & & \\
\hline $\begin{array}{l}\text { Develop modeling techniques for edge analysis and pitch } \\
\text { determination, in the reflection mode, necessary for overlay } \\
\text { measurements [OMP, STRS] }\end{array}$ & & & & & \\
\hline $\begin{array}{l}\text { Acquire overlay standards (both alignment and calibration) } \\
\text { for SRM certification [OSRM] }\end{array}$ & & & & & \\
\hline $\begin{array}{l}\text { Investigate effects of covering layers, resist, and material } \\
\text { thicknesses on apparent overlay shifts [STRS] }\end{array}$ & & & & & \\
\hline $\begin{array}{l}\text { Participate in development of reflection mode optical } \\
\text { linewidth measurements and modeling techniques [OMP, } \\
\text { STRS)] }\end{array}$ & & & & & \\
\hline
\end{tabular}


Title: QUALITY SYSTEM PILOT PROJECT

Staff: $(1.0$ staff years $){ }^{*}$ JANET LAND, $*$ Eric Stanfield, $*$ Ted Doiron, ${ }^{*}$ Mike Stocker, ${ }^{*}$ John Stoup

Objective and MEL Thrust(s) Supported: The objective is to provide documentation for the Calibrations Laboratory based on conformance with ANSL/NCSL Z540. Manufacturing Metrology.

Need(s) Addressed: The target customers are those companies that send their dimensional artifacts to NIST for calibration. NIST, through NVLAP, will begin to accredit calibration laboratories to the U.S. version of ISO Guide 25 (NCSL Z540-1). We are documenting our current quality system in the fashion of the international standard, which provides use with adequate documentation for our own uses and acts as a model for outside high-accuracy laboratories.

Technical Approach: Creating procedures based on current practices; documenting the current quality system, providing policies and objectives; and developing procedures for parts of the standard for which we currently do not have formalized systems in place. This project ends in July 1997.

\section{FY95 Accomplishments:}

- Continued discussions concerning instituting policies and procedures for the calibration laboratory based on ANSI/NCSL Z540.

- Wrote draft procedures for customer information and calibration folder handling and draft procedures for gage block and ring calibrations.

- Project Leader was named Team Leader for the Measurement Services Quality Team. The Team, including Janet Land, Eric Stanfield, and Ted Doiron, received training in ANSI/NCSL Z540 and began designing a Quality Manual. Four staff members (Doiron, Veale, Stocker, and Stoup) attended the National Voluntary Laboratory Accreditation Program (NVLAP) Technical Expert for Assessing Calibration Laboratories training. Staff performed two laboratory assessments at the DOE Y-12 facility in Oak Ridge, TN and Lockheed Martin in Sunnyvale, CA.

FY96 Plans:

- Refine and implement ANSI/Z540.

- Continue determining Z540 requirements for certification and continue writing the operating policies and procedures for this laboratory.

- Write Quality Manual, completing documentation of calibration procedures.

Five-Year Plan Goals vs. Fiscal Years:

\begin{tabular}{|l|l|l|l|l|l||}
\hline QUALITY SYSTEM PILOT & 98 & 97 & 98 & 98 & 00 \\
\hline $\begin{array}{l}\text { Define and implement the ANSI/NCSL Z540 for the } \\
\text { laboratory [STRS] }\end{array}$ & & & & & \\
\hline $\begin{array}{l}\text { Determine requirements for Z540 certification and continue } \\
\text { writing procedures [STRS] }\end{array}$ & & & & & \\
\hline Write quality manual [STRS] & & & & & \\
\hline Complete documentation of calibration procedures [STRS] & & & & & \\
\hline
\end{tabular}




\begin{tabular}{|l|l|l|l|l|l|l|}
\hline QUALITY SYSTEM PILOT & 96 & 97 & 98 & 99 & 00 \\
\hline $\begin{array}{l}\text { Achieve certification through inspection from accrediting } \\
\text { agency [STRS] }\end{array}$ & & 7 & & & \\
\hline
\end{tabular}




\section{Title: SCANNING ELECTRON MICROSCOPE LINEWIDTH METROLOGY}

Staff: $\left(3.0\right.$ staff years) $*$ M. POSTEK, ${ }^{*}$ S. Jones, ${ }^{*}$ R. Larrabee, ${ }^{*}$ W. Keery, ${ }^{*}$ L. Carroll

Project Objective and MEL Thrust(s) Supported: The SIA road map targets scanning electron microscopes as the metrology tool of choice for use in semiconductor production up through the year 2001. The objectives of this program are to develop standards, specifically those related to the measurement of linewidth, for the scanning electron microscope. This entails a multidimensional program including: understanding the function and signal generation in the SEM, developing NIST metrology instruments for the certification of standards, and developing the necessary artifacts and calibration procedures. Manufacturing Metrology.

Need(s) Addressed: The manufacturing of present-day integrated circuits requires that certain measurements be made of the submicrometer structures composing the device with a high degree of precision. The accuracy of these measurements is also important, but more so in development and pilot lines. The measurements of minimum feature sizes known as critical dimensions (CD) are made to insure proper device operation. NIST is responsible to U.S. industry for developing length intensive measurement capabilities and calibration standards. This project supports all aspects of this need since scanning electron microscopy is the major microscopical technique used for this submicrometer metrology. NIST addresses this need by providing (or is currently developing) standards and measurement techniques for these measurement instruments.

Technical Approach: The development of SEM linewidth standards is a multidimensional project. This project is being tackled through several thrusts fully supported by the semiconductor industry. The major areas (each with several sub-areas) are described .

Standard Reference Material (SRM) 2090--Primary to SEM metrology is the calibration of the magnification of the instrument. SRM 2090 is an SEM magnification standard that will function at the low beam voltages used in the semiconductor industry and will have capability down to $0.2 \mathrm{~mm}$ pitch. A prototype with $0.2 \mathrm{~mm}$ lines and spaces was fabricated by the Nanofabrication Facility at Cornell University as a proof of concept and was used in a round robin study that clearly demonstrated the need for this standard. Texas Instruments was contracted to supply the first production run of the artifact with $0.1 \mathrm{~mm}$ lines and spaces and has recently delivered over 180 of these research artifacts. To speed the availability of this artifact to the industry (while the final certification details are being completed) the artifact has been released as Research Material 8090.

Sharpness Standard-- The performance characteristics of the SEM is extremely important to precise and accurate metrology. A sharpness standard and evaluation procedure is being developed to monitor (or compare) SEM image quality. It is based on etched biphasic glass or an etching defect called "grass." NIST is working with Texas Instruments on its development, and with industry on the use of this standard and procedure in the production environment. The "ISAAC" SEM image analysis system previously developed at NIST is being used to analyze the images obtained from the test samples delivered by Texas Instruments and to develop an quantitative method for instrument evaluation.

Monte Carlo Modeling-- Improvements are being made in the previously developed Monte Carlo computer model of beam-electron interaction with the sample that leads to a theoretical prediction of the SEM image profile of a feature. This model was originally developed to find edge location criteria for use in measuring the submicrometer features on masks used in $\mathrm{x}$-ray lithography. The model has now been extended to include profiles of secondary and backscattered-electrons, as well as, the original transmitted. Work has progressed to include multiple parallel lines (to study proximity effects), and to include 3-dimensional objects (such as vias). NIST is currently collaborating with Digital Equipment Corporation and SEMATECH to include the characteristics of production SEMs into the model for the purpose of verification and comparison to actual experimental and production line data. 
Combined SEM/SxM--Metrology at the nanometer level requires an intimate knowledge of the characteristics and the position of the edges being measured. A proof of concept measurement instrument combining an SEM and an scanned probe instrument will be placed in operation to investigate and facilitate comparison measurement.

\section{FY95 Accomplishments:}

- Issued RM8090.

- Completed on time all the SEM metròlogy elements of the SEMATECH contract.

- Completed the design, construction and implementation of the NIST metrology instrument and began to investigate the problems associated with the certification of SRM 2090.

- Held a follow-up to the NIST Workshop on "Electron Beam Interaction Modeling for Metrology and Microanalysis in the Scanning Electron Microscope."

- Completed the ISAAC development and established a user friendly algorithm for the measurement of SEM sharpness.

- $\quad$ Pursued techniques for the cleaning of electron beam induced contamination from SEM samples such as SRM 2090.

\section{FY96 Plans:}

- $\quad$ Issuance of SRM 2090

- Obtain delivery and place the combined SEM/SxM into operation.

- Continue to pursue techniques for the cleaning of electron beam induced contamination.

- Develop approaches to the elimination of SEM contamination.

- Investigate SPM tip performance through direct monitoring with an SEM

- Continue the development sequence of the Monte Carlo Modeling (MONSEL) series and compare model data with actual SEM data. This is being facilitated through interaction with industrial partners.

- Measure the AT\&T x-ray mask and SCALPEL mask with the SEM metrology instrument and compare to the electron beam model data.

Five-Year Plan Goals vs. Fiscal Years:

\begin{tabular}{|l|l|l|l|l|l||}
\hline $\begin{array}{l}\text { SCANNING ELECTRON MICROSCOPE LINEWIDTH } \\
\text { METROLOGY }\end{array}$ & 98 & 97 & 98 & 99 & 00 \\
\hline $\begin{array}{l}\text { Acquire production batches of SRM 2090 certify and issue } \\
\text { the standard [STRS, OSRM, OMP] }\end{array}$ & & & & & \\
\hline $\begin{array}{l}\text { Ovide improved measurement methods for x-ray masks and } \\
\text { SCALPEL masks to support x-ray lithography [STRS, OMP] }\end{array}$ & & & & & \\
\hline $\begin{array}{l}\text { Attempt comparative measurements between SEM and } \\
\text { SPM metrologies using the new combined instrument } \\
\text { [STRS, OMP] }\end{array}$ & & & & & \\
\hline $\begin{array}{l}\text { Improve the accuracy of thick layer metrology of photo-resist } \\
\text { structures using the application of Monte Carlo modeling } \\
\text { and associated experimentation [OMP, STRS] }\end{array}$ & & & & & \\
\hline $\begin{array}{l}\text { Develop and issue thick layer SEM linewidth standard } \\
\text { [OMP, STRS] }\end{array}$ & & & & & \\
\hline
\end{tabular}




\begin{tabular}{||l|l|l|l|l|l||}
\hline \begin{tabular}{|l|l|l||} 
SCANNING ELECTRON MICROSCOPE LINEWIDTH \\
METROLOGY
\end{tabular} & 96 & 97 & 98 & 99 & 00 \\
\hline $\begin{array}{l}\text { Upgrade equipment and methods for large sample } \\
\text { (300 mm) metrology - SEM/SPM system [OMP, STRS] }\end{array}$ & & & & & \\
\hline $\begin{array}{l}\text { Acquire environmental microscope to facilitate the study of } \\
\text { specimen charging and high aspect SPM tip generation } \\
\text { [STRS] }\end{array}$ & & & & & \\
\hline Move to Metrology Building [STRS] & & & & & \\
\hline
\end{tabular}




\section{Staff: $(0.3$ staff years $) *$ M. POSTEK}

Objective and MEL Thrust(s) Supported: SEMATECH is a consortium of U.S. semiconductor manufacturers. The purpose of this project is to maintain a working relationship with SEMATECH and its member companies targeting the measurement needs of the semiconductor industry relative to the dimensional measurement capabilities of the Precision Engineering Division. The continuing purpose of this program is for NIST to apply its metrology knowledge to selected SEMATECH lithography and metrology development activities. The targeted measurement technologies are: scanning electron microscope metrology, optical metrology, and scanned probe metrologies. This program is well within the charter and mission of NIST, and such collaboration is the best way for SEMATECH to achieve the key metrology objectives necessary for the success of current and future lithography programs at SEMATECH and its member companies. Manufacturing Metrology.

Need(s) Addressed: The manufacturing of current integrated circuits requires that certain measurements, e.g., linewidth, line spacing, and overlay, be made of the submicrometer structures composing the circuits with a high degree of precision. The accuracy of these measurements is also important, but more so in the development and pilot lines. The measurements of minimum feature sizes known as critical dimensions (CD) are made in order to insure proper device operation and as an indicator of manufacturing process stability. NIST is responsible to U.S. industry for the development of length intensive measurement capabilities and calibration standards. This project supports all aspects of this need. Optical metrology, scanning electron microscopy and scanned probe microscopies are the major techniques used for this submicrometer metrology. NIST addresses this need by providing (or currently developing) standards and measurement techniques for these measurement instruments.

Technical Approach: NIST will maintain a working relationship with SEMATECH through representation at appropriate technical advisory board meetings. NIST will assist SEMATECH and its member companies with its technical expertise in lithometrology and propose projects for SEMATECH collaboration and funding in areas where NIST can bridge the identified gaps between the expressed needs and present capabilities.

FY95 Accomplishments:

- Submitted on time the NIST J93 Project Final Report.

- Participated at several SEMATECH metrology meetings.

FY96 Plans:

- Continue SEMATECH consultation and interaction.

Related Developments: Continued SEMATECH funding is unlikely due to a fundamental change in the funding structure and direction of SEMATECH. However, it is imperative that NIST maintain a liaison with SEMATECH because of its importance in the semiconductor industry. The project leader participates on several SEMATECH working groups and technical advisory boards. 
Five-Year Plan Goal vs. Fiscal Years:

\begin{tabular}{|c|c|c|c|c|c|}
\hline SEMATECH LIAISON & 96 & 97 & 98 & 99 & 00 \\
\hline $\begin{array}{l}\text { Continue interactions with SEMATECH and maintain a NIST } \\
\text { presence at necessary SEMATECH functions [STRS] }\end{array}$ & & & & & \\
\hline
\end{tabular}


Staff: $\left(2.0\right.$ staff years) ${ }^{*}$ R. SILVER, ${ }^{*}$ J. Villarrubia, ${ }^{* J}$. Dagata, ${ }^{*} \mathrm{C}$. Teague, ${ }^{*}$ S. Jones, ${ }^{*}$ M. Postek, ${ }^{* J}$. Kramar, ${ }^{*}$ S. Berg-Cross

Objective and MEL Thrust(s) Supported: This project will develop techniques for the preparation of SPM tips with reproducible geometries and the direct characterization of the SPM tip geometry and dimensions. These well characterized probe tips will then be used to measure samples with photolithographically defined or canonically ordered surfaces on the nanometer length scale followed by a determination of their performance in these dimensional measurements. Manufacturing Metrology, Advanced Manufacturing Processes and Equipment.

Need(s) Addressed: NIST is responsible to U.S. industry for developing length intensive measurement capabilities and calibration standards in the nanometer scale regime. The new class of scanned probes have unparalleled resolution and offer the most promise for meeting these needs of the microelectronics industry. However, before this resolution can be translated into precise, accurate dimensional measurement capabilities, the scanned probe instruments must be fully calibrated. This requires accurate dimensional characterization of SPM tips.

All images obtained with a scanned probe microscope are a convolution of the sample being measured, the SPM tip geometry, and any tip-sample interactions. As a result, SPM linewidth measurement uncertainties are dominated by the uncertainty in tip shape. On the macroscopic scale tip shapes can vary by $10 \mu \mathrm{m}$ to $20 \mu \mathrm{m}$ while the microscopic geometry is often uncontrollable. These variations in tip geometry and the inability to accurately measure tip dimensions are a major limitation to measurement accuracy and are the primary concern of SPM industrial users. The tip shape also has a profound effect on measurement stability and tip longevity as is often seen in pitch calibrations. These adverse effects are frequently encountered in NIST measurement instruments such as M-cubed and the calibrated AFM. These measurement limitations are addressable.

The key to accurate metrology is to develop methods for the production of known reproducible tip shapes, the accurate measurement of tip geometry, and models which interpret imaging data to extract real feature dimensions. NIST is currently developing the means for the reproducible production and characterization of SPM tips, such as the field-ion-field-electron microscope (FIFEM). The FIFEM will enable us to put an approximately $5 \mathrm{~nm}$ uncertainty on the geometrical shape of a tip with a $50 \mathrm{~nm}$ radius. This instrument can also be used for field evaporation which produces tips with controlled microscopic geometries. This project is focused on the systematic correlation of FIFEM results with SPM measurements to be performed in parallel with conventional scanning electron microscope (SEM) and optical measurements. An additional result of this project is the development of standard artifacts to verify tip performance and surface reconstruction procedures. We are performing a comprehensive study on the relationship between tip fabrication, cleaning processes and tip performance.

Technical Approach: The technical strategy can be broken into four thrust areas: (1) tip preparation, (2) direct geometrical tip characterization (FIFEM, SEM), (3) characterization artifacts (atomically ordered surfaces, nanometer-scale defined topography, linewidth samples), and (4) modeling (extract physical feature dimensions, determine tip geometry).

We will focus our efforts on two tip materials, PtIr and W. The strategy is to develop PtIr and W tips for systematic measurements on atomically ordered silicon surfaces. We will develop the STM tip etching, field evaporation, and cleaning procedures which reliably yield stable $\mathrm{W}$ tips and produce atomic resolution on $\mathrm{Si}$ (7x7) surfaces. We will develop the necessary cleaning procedures, both in-situ (blast mode) and ex-situ, which allow transportation of the tips between the various SPM's at our disposal. This project will proceed in parallel with the existing effort at NIST for the comprehensive development of nanometrology capabilities. Specifically, 
the results from the measurements will be used by the current effort to extract physical feature dimensions and provide an accurate means of measuring topographical features (e.g., $100 \mathrm{~nm}$ linewidths or $1 \mathrm{~nm}$ step heights). The primary tools for direct tip characterization will be the FIFEM for 1 to $100 \mathrm{~nm}$ radii tips, and SEM analysis for larger tip features. We will make an effort to determine which new methods (e.g., TEM) can be developed to enhance the overlap region of these techniques.

For sample preparation, we will utilize the existing in-situ processing apparatus and techniques from the UHV STM and concentrate on the reproducible production of atomically ordered Si surfaces and Si (111) step and terrace structures. The use of these cananonically ordered surfaces will also enable us, in future measurements, to delineate physical/chemical interactions between tip and specimen from pure geometrical interactions.

We will determine the tip processing, cleaning and deoxidation techniques which allow transfer of well characterized tips to other measurement facilities and determine the stability of the probe tips in the uncontrolled environment. The longer term technical strategy is the development of in-situ stabilized, atomically ordered surfaces which can be transferred to other measurement instruments such as M-cubed. This work builds on the current efforts for the development and characterization of nanometer scale standard artifacts such as atomically ordered surfaces and linewidth samples.

\section{FY95 Accomplishments:}

- Completed the design and procured the major components for the FIFEM in the UHV STM.

- Developed techniques in the UHV Prep Chamber for preparation of atomically ordered surfaces. Installed system heating capabilities.

- $\quad$ Publications on SPM tip modeling work (J. Villarrubia), development of software for tip reconstructions.

- Completed preliminary study and development of techniques for SEM analysis of SPM tips.

\section{FY96 Plans:}

- Complete the construction and implementation of the FIFEM in the UHV STM. Demonstrate tip fabrication by field evaporation.

- Use input from our SEM facility to enhance the tip characterization effort.

- Determine effects of atmospheric exposure on clean tips and the steps required for tip transportation.

- Obtain quantitative understanding of the routinely used in-situ blast cleaning techniques.

- Use the existing UHV Prep Chamber for preparation of atomically ordered silicon surfaces. These surfaces should have routinely achievable long range atomic order.

- Publish results from the tip modeling effort on the development of software for tip reconstruction from image analysis.

- Facilitate data exchange between the acquisition systems and the computer modeling facility. Combine the experimental results with the modeling results and prepare a summary report.

\section{Five-Year Plan Goals vs. Fiscal Years:}

\begin{tabular}{|l|l|l|l|l|l||}
\hline SPM TIP PREPARATION AND CHARACTERIZATION & 96 & 97 & 98 & 99 & 00 \\
\hline $\begin{array}{l}\text { Complete construction and testing of the UHV FIFEM. } \\
\text { Implement modeling techniques which use the FIFEM } \\
\text { results to give direct geometrical characterization of SPM } \\
\text { tips [STRS] }\end{array}$ & & & & & \\
\hline
\end{tabular}




\begin{tabular}{|c|c|c|c|c|c|}
\hline SPM TIP PREPARATION AND CHARACTERIZATION & 96 & 97 & 99 & 99 & 00 \\
\hline \multicolumn{6}{|l|}{$\begin{array}{l}\text { Develop techniques for controllable in-situ field evaporation } \\
\text { and ambient etching SPM tip preparation. [STRS }\end{array}$} \\
\hline \multicolumn{6}{|l|}{$\begin{array}{l}\text { Prepare atomic artifacts, consistent with other PED } \\
\text { nanoscale projects, for tip characterization. Develop the } \\
\text { techniques necessary to stabilize these canonically ordered, } \\
\text { UHV prepared surfaces so they can be transferred to other } \\
\text { measurement facilities (M-cubed, SEM, CAFM etc.). [STRS] }\end{array}$} \\
\hline \multicolumn{6}{|l|}{$\begin{array}{l}\text { Develop modeling techniques which yield bounds on tip } \\
\text { sizes directly from imaging and compare these results to } \\
\text { geometrical sizes determined from FIFEM and SEM. [STRS] }\end{array}$} \\
\hline \multicolumn{6}{|l|}{$\begin{array}{l}\text { Advance SEM measurement capabilities in coordination with } \\
\text { TEM and FIFEM to give accurate characterization of SPM } \\
\text { tip properties. [STRS] }\end{array}$} \\
\hline \multicolumn{6}{|l|}{$\begin{array}{l}\text { Measure nanometer-scale, topographically defined features } \\
\text { with tips which have been well characterized, and obtain } \\
\text { dimensionally accurate measurements of the features. } \\
\text { [STRS] }\end{array}$} \\
\hline \multicolumn{6}{|l|}{$\begin{array}{l}\text { Design and certify standards for tip characterization based } \\
\text { on the results of the preceding experiments and simulations } \\
\text { [STRS, OSRM] }\end{array}$} \\
\hline $\begin{array}{l}\text { Investigate and develop new techniques for tip } \\
\text { characterization and fabrication as they become available. } \\
\text { [STRS] }\end{array}$ & & & & & \\
\hline
\end{tabular}




\section{Title: SURFACE FINISH METROLOGY}

Staff: (3.3 staff years) *T. V. VORBURGER, T. B. Renegar, C. K. Rymes, *J. F. Song, T. Doi

Project Objective and MEL Thrust(s) Supported: To develop and maintain the measurement systems and physical standards that underpin industry's measurements of surface finish and step height, to support industry's efforts to develop national and international documentary standards in this area, and to lead worldwide standardization efforts in selected subareas. Manufacturing Metrology.

Need(s) Addressed: The surface finish affects the function of a wide range of industrial products including mechanical parts, semiconductors, optics, ship hull surfaces, and roadways. The surfaces of these products must be specified and measured for surface finish. Since the surface finish topography of nearly all industrial parts is highly complex, the measurement of surface finish relies on detailed measurements of surface peaks and valleys and statistical algorithms and sampling procedures to characterize them. NIST calibrations and measurement research are critical to maintain an accurate national measurement system for surface finish as are NIST contributions to standardization efforts to derive mutually agreeable and meaningful measurement results. An important part of this system is accurate calibration of critical surface features including step height for the semiconductor industry. The surface finish affects the operation of components in the $\$ 170$ billion auto industry (U.S.) and the $\$ 93$ billion aerospace industry (U.S.) as well as other mechanical systems. It figures in the manufacture of $\$ 85$ billion worth of integrated circuits (worldwide) and it affects the function of several billion dollars of optical components.

Technical Approach: We primarily use stylus-type profiling instruments to perform calibrations of standards and tests of industrial components. These profiling instruments are calibrated with master artifacts calibrated by optical interferometry. As an example of our capabilities, the $2 \sigma$ uncertainty for our step height calibration is as small as $\pm 0.5 \mathrm{~nm}$ depending on the step height being calibrated. Using new techniques we are continuously upgrading either the hardware and software of these instruments or the calibration of our master artifacts or producing new standard reference materials (SRMs). We do these things to improve the accuracy, automation, and flexibility of our instruments and to meet new customer requirements. During FY 96, our emphasis will be to develop surface-profile data analysis software that uses digital filtration to be consistent with ISO standards. We will also improve the uncertainty of our small step height calibrations (height values below $300 \mathrm{~nm}$ ).

\section{FY95 Accomplishments:}

- Completed the statistical analysis and drafted the certification of SRM 2073a, the second issue of a sinusoidal roughness standard with $3 \mu \mathrm{m}$ roughness average and $100 \mu \mathrm{m}$ spatial wavelength.

- Edited the draft standard on surface texture (ASME B46) and received approval for publication from the American Society of Mechanical Engineers and the American National Standards Institute.

- Completed development of a new data acquisition system for step height calibration and performed the first calibration with the new system.

\section{FY96 Plans:}

- Perform final editing of the ASME B46 Standard resulting in a FY96 publication date.

- Complete the data acquisition system for surface finish calibrations including ISO standard Gaussian filters; perform the first surface finish calibrations with the new system.

- Improve the turnaround time of the surface finish and step height calibration service to one month.

- Complete the measurements of the NIST $100 \mathrm{~nm}$ step height master by phase measuring interferometry and stylus techniques; develop improved uncertainty budgets for measurements with the step and for calibration with phase measuring interferometry.

- Complete editing of the manuscript "Stylus/Laser Surface Calibration System" for publication in an 
archival journal.

Related Developments: The ASME Committee B46 has a strong influence on our projects and is strongly influenced by our results. Vorburger coordinates the development of the B46 Standard and Sullivan has recently taken a new B46 Subcommittee chair for three dimensional methods. In turn, the B46 official representation remains strong in the International Organization for Standardization's Technical Committee 57, itself an active committee.

Five-Year Plan Goals vs. Fiscal Years:

\begin{tabular}{|c|c|c|c|c|c|}
\hline SURFACE FINISH METROLOGY & 96 & 97 & 98 & 99 & 00 \\
\hline $\begin{array}{l}\text { Purchase specimens and complete the measurements and } \\
\text { certification of SRM } 2071 \text { a, sinusoidal roughness specimen } \\
\text { with } 0.3 \mu \mathrm{m} \text { roughness and } 100 \mu \mathrm{m} \text { spatial wavelength } \\
\text { [OSRM, STRS] }\end{array}$ & & & & & \\
\hline $\begin{array}{l}\text { Complete the integration of a Y-axis table into the calibration } \\
\text { system for surface roufness SRMs in order to automate fully } \\
\text { the surface sampling of these measurements [STRS] }\end{array}$ & & & & & \\
\hline $\begin{array}{l}\text { Continuously improve the accuracy and turnaround of the } \\
\text { existing surface finish and step height calibration service } \\
\text { [Calibration Fees] }\end{array}$ & & & & & \\
\hline $\begin{array}{l}\text { Revise uncertainty budgets for calibrations with master step } \\
\text { heights smaller than } 1 \text { micrometer, including data from three } \\
\text { independent techniques [STRS] }\end{array}$ & & & & & \\
\hline $\begin{array}{l}\text { Develop use of standard data formats and other virtual and } \\
\text { distributed techniques for metrology of three dimensional } \\
\text { surfaces [STRS] }\end{array}$ & & & & & \\
\hline
\end{tabular}




\section{Title: ULTRAVIOLET MICROSCOPE}

Staff: (1.5 staff years) *JAMES POTZICK, *Rick Silver, *Leon Carroll, *Amy Singer

Objective and MEL Thrust(s) Supported: To complete construction and qualification of the NIST Scanning UV Microscope. Manufacturing Metrology

Need(s) Addressed: NIST Photomask Linewidth SRMs are are the only traceable linewidth standards issued by NIST at this time. They are used throughout the world to calibrate photomask metrology tools, and by the scanning probe microscope community. Present calibration uncertainty and linewidth range fail to meet industry needs in calibration accuracy and linewidth range.

Technical Approach: The present green light calibration system is incapable of meeting the needs. The UV microscope is intended to replace that system. Some of the features of the UV instrument are: operation in UV as well as visible light to improve smallest measurable linewidth to $0.25 \mathrm{um}$; structural design based on a Stewart platform for improved stability and lower vibration; use of a commercial computer-controlled dc motor/leadscrew scanning stage and $\mathrm{z}$-axis coarse focusing actuators for less vibration, improved stage motion control, longer scan range, more accurate feature positioning, and wider focus range; inclusion of a UV CID camera image monitor; replacement of the (former) slit aperture with a pinhole sampling aperture for raster scanning (instead of one-dimension scanning).

Reduce calibration uncertainty by measuring at UV wavelengths where chrome is less transparent (and where the photomask will be used), and by reducing vibration. In addition, the longer scan range will be used for calibrating the Optical Microscope Magnification Standard (new SRM 2800). The pinhole raster scan will allow measuring tilt (wrt measurement axis), taper, and curvature of photomask lines.

A successor to SRM 473 Photomask Linewidth Standard is planned, extending the linewidth range to 0.25 um. There has been discussion of 1:1 steppers at $248 \mathrm{~nm}$ or $193 \mathrm{~nm}$ illumination, where this linewidth range will be needed, and all of our customers queried have indicated a desire for $0.25 \mathrm{um}$ standard.

Extend the project to allow acquisition of through-focus aerial image data for comparison with modeling results.

\section{FY95 Accomplishments:}

- This project has been funded by Director's Reserve, STRS, and (formerly) SEMATECH, and has received wide industry interest.

- The basic structure has been completed, illumination optics completed, imaging optics and alignment nearly completed.

- High resolution low noise UV and green light raster traces have been obtained and compared.

- Flow charts for the complex computer control and data acquisition program have been prepared.

- One paper published, one patent pending.

\section{FY96 Plans:}

- Install computer controlled coarse- and fine-focus.

- Write computer programs for instrument control, data acquisition, and linewidth SRM calibration.

- Compare linewidth measurements on new and old systems; estimate uncertainty. 
Five-Year Plan Goals vs. Fiscal Goals:

\begin{tabular}{|l|l|l|l|l|l|}
\hline ULTRAVIOLET MICROSCOPE & 96 & 97 & 98 & 99 & 00 \\
\hline $\begin{array}{l}\text { Obtain data necessary to characterize performance of } \\
\text { microscope and estimate uncertainty [STRS] }\end{array}$ & & & & & \\
\hline $\begin{array}{l}\text { Develop and execute a plan for making the transition from } \\
\text { calibrating photomasks on the green light system to the UV } \\
\text { Microscope [STRS] }\end{array}$ & & & & & \\
\hline $\begin{array}{l}\text { Program the system to calibrate the new SRM 2800, Optical } \\
\text { Microscope Magnification Standard [STRS] }\end{array}$ & & & & & \\
\hline
\end{tabular}




\section{Title: WAFER FLATNESS}

Staff: $(1.4$ staff years $) *$ C. J. EVANS, *R. E. Parks, P. J. Sullivan

Objective and MEL Thrust(s) Supported: The objective of the project is to develop metrology and manufacturing methods for the production of smooth substrates for very large scale integrated circuits and to allow optimization of in-process chemo-mechanical planarization. Continuously decreasing integrated circuit feature sizes force down the acceptable wafer surface defect size, while productivity concerns are driving up the substrate diameter. Decreasing feature size is also focusing attention on silicon-on-insulator substrates as an alternative to bulk silicon. Manufacturing Metrology.

Need(s) Addressed: Wafers need to be locally flat--over at least the die site--in many IC production processes. In others, particularly chemo-mechanical planarization, productivity may be increased if wafers are globally flat. In all these processes, wafers are mounted on a variety of chucks which can affect local and global flatness. Traceable metrology for flatness over $300 \mathrm{~mm}$ apertures is not available and, according to SEMATECH, is seen by wafer vendors as a fundamental constraint to introduction of $300 \mathrm{~mm}$ wafers. Improved metrology may lead to inherently flatter substrates which will be easier to polish to the required defect levels as wafer size increases. Improved production methods are also needed to bring down the costs of siliconon-insulator (SOI) substrates. Either silicon or SOI substrates will be the feedstock for the IC industry which is worth $\$ 85$ billion per year.

Technical Approach: NIST work has shown that $10 \mathrm{~nm} 2 \sigma$ uncertainty flatness measurements can be made on $150 \mathrm{~mm}$ diameter substrates using current interferometers. Two routes will be taken to extend that performance: a modified Ritchey-Common configuration will be used on the existing NIST $150 \mathrm{~mm}$ aperture interferometer to extend its range to $300 \mathrm{~mm}$ diameter, with some minor loss of accuracy. In parallel, a new $300 \mathrm{~mm}$ aperture interferometer (XCALIBIR) with target uncertainties of the order of $1 \mathrm{~nm}$ is being developed for a range of applications including flatness (see separate MEL 1996 Project Description "Figure and Finish Metrology for Advanced Optics"). These interferometers will be used to evaluate a variety of chucking concepts, including adaptive chucks. With increased wafer diameters, new techniques are needed for measurement of thickness variations; a novel IR interferometer is being evaluated.

Given appropriate metrology, increased productivity in both the production of substrates and the in-process planarization steps requires both incremental improvements of current processes and evaluation of novel procedures. New combinations of chemical and mechanical processes will be evaluated for silicon-on-sapphire substrate production. New lap concepts will be evaluated. Use of adaptive chucks in planarization processes will be investigated. Close collaborations will be established with, amongst others, SOI substrate, stepper, and polishing consumables suppliers.

\section{FY95 Accomplishments:}

- Demonstrated silicon polishing with low cost renewable lap

- Implemented modified Ritchey-Common configuration on NIST interferometer

- Demonstrated high stock removal rate, low damage lapping of sapphire substrates

- Conceptualized novel IR interferometer for thickness variation measurement.

\section{FY96 Plans:}

- Demonstrate two step silicon polishing process based on rapidly renewable lap.

- Demonstrate IR interferometer. 
Five-Year Plan Goals vs. Fiscal Years:

\begin{tabular}{|l|l|l|l|l|l||}
\hline WAFER FLATNESS & 96 & 97 & 98 & 99 & 00 \\
\hline $\begin{array}{l}\text { Procure and commission hardware for Ritchey-Common } \\
\text { configuration [STRS] }\end{array}$ & & & & & \\
\hline $\begin{array}{l}\text { Evaluate 300 mm chuck performance using Ritchey- } \\
\text { Common [STRS, CRADA] }\end{array}$ & & & & & \\
\hline $\begin{array}{l}\text { Commission XCALIBIR and operate as a calibration service } \\
\text { [STR] }\end{array}$ & & & & & \\
\hline Evaluate chuck concepts [STRS] & & & & & \\
\hline Design, fabricate and test adaptive chucks [STRS,CRADAs] & & & & & \\
\hline Perform two stage silicon polishing with novel laps [STRS] & & & & & \\
\hline $\begin{array}{l}\text { Perform sapphire polishing process development } \\
\text { [STRS,CRADA] }\end{array}$ & & & & & \\
\hline Demonstrate IR interferometer [DE,STRS] & & & & & \\
\hline
\end{tabular}

96 


\section{AUTOMATED \\ PRODUCTION \\ TECHNOLOGY \\ DIVISION}

\section{MISSION:}

Develops and maintains competence in integration of machine tools and robots and develops the interfaces and networks necessary to combine robots and machines into workstations and workstations into manufacturing cells; develops and maintains computer-assisted techniques for generation of computer code necessary for integration of machine tools and robots; develops and maintains competence in the processes and techniques necessary for manufacturing high-accuracy parts; maintains competence in mass measurements, engineering measurements, and sensors, both static and dynamic, of force and force-related quantities, and other parameters required by the discrete parts industry; and with the nature of the measurement process and the transducers as well as the development, characterization, and calibration of transducers used in discrete parts manufacturing. 
Staff: $(1.6$ staff years $) *$ D. Eitzen, B. PAYNE, $*$ D. Evans, ${ }^{*}$ C. Shoemaker.

Objective and MEL Thrust(s) Supported: To provide U.S. industry with the best possible measurement services in dynamic motion (vibration) metrology that industry needs and demands, and to remain the recognized top of the traceability chain in sinusoidal and transient acceleration. To assist in applying this measurement capability to solve manufacturing needs such as accurate, fast actuator design. To provide special measurement expertise required by industry such as the evaluation of micromachined accelerometers. To assist U.S. sensor manufacturers to build sensor test platforms for product development. To improve the realization and delivery of services for acceleration measurement. To harmonize national and international standards on accelerometer calibration and vibration measurement. Manufacturing Metrology

Need(s) Addressed: Through its physical measurement services, special measurements, consulting, and standards work (most notably committees of ASA and IEC) this vibration project impacts a very broad spectrum of manufacturing and production industries. Vibration measurements are used for environmental testing, diagnostics, product development, condition monitoring, process control, servo sensors, global positioning. Industry requirements are not being fully met in this metrology area; great accuracies and a wider range of frequencies are required. Some of the economic impacts involve very high volume. In the auto industry, which is but one example of a segment relying heavily on acceleration measurements, many tens of staff years are spent measuring accelerations on vehicles for air bag deployment systems and for ride control for a specific vehicle class. Delivery of systems in vehicles is measured in millions of units. Competitiveness and quality are obvious goals addressed by the project.

Technical Approach: The center of the approach is to maintain and significantly improve the accuracy and range of accelerometer measurement services, to continue our national and international standards committee work, and to undertake selected industrial measurement projects and DoD support when focused directly on our needs. For example the Supershaker work is largely funded by the Air Force (CCG) and is designed to provide us (and the Air Force) with a new generation of shakers for improved accelerometer calibration. One of the technical challenges in improving accelerometer calibrations is to develop "pure" mechanical acceleration; acceleration that is sensibly zero in all but one direction, is purely sinusoidal at a single frequency but adjustable over many orders in frequency and several orders in magnitude. The shakers currently used to try to generate these motions were designed several decades ago and need to be modernized. Another challenge is the accurate measurement of mounting element motion. Special interferometry will be the principle tool for determination of actual element motion and for servo inputs.

\section{FY95 Accomplishments:}

- Delivered about 90 reports of calibration on more than 60 accelerometers.

- Completed an agreement on intercomparison of shock calibration with NMRL, Japan, and completed all NIST first round measurements.

- Completed the initial performance evaluation of the first generation Supershaker and began the design of the second generation.

- Supported international trade by training two guest researchers in vibration metrology from Mexico and Brazil.

- Published two papers on the performance of the first generation supershaker.

\section{FY96 Plans:}

- Complete 70-90 calibration reports on 40-60 accelerometers.

- Complete first phase of shock measurements intercomparison with NRLM, Japan. 
- Complete the desgn of the second generation supershaker.

- Continue standards committee work in ASA and ISO; maintain chair in vibrations.

- Improve Supershaker performance and begin reevaluation.

Five-Year Plan Goals vs. Fiscal Years:

\begin{tabular}{|l|l|l|l|l|l||}
\hline ACCELERATION AND SHOCK METROLOGY & 96 & 97 & 98 & 99 & 00 \\
\hline $\begin{array}{l}\text { Continue to deliver calibration reports on vibration and } \\
\text { shock accelerometers [OA] }\end{array}$ & & & & & \\
\hline $\begin{array}{l}\text { Conntinue standards development work through ASA and } \\
\text { IEC; maintain vibration chair [STRS] }\end{array}$ & & & & & \\
\hline $\begin{array}{l}\text { Complete the development of prototype No. 1 of the } \\
\text { advanced accelerometer calibrator [AF, STRS] }\end{array}$ & & & & & \\
\hline $\begin{array}{l}\text { Complete the MEL/CAML research on finite element } \\
\text { analysis model for application to shaker [STRS, AF] }\end{array}$ & & & & & \\
\hline $\begin{array}{l}\text { Complete development of improved acceierometer } \\
\text { calibrationwith reduced uncertainty at selected frequencies } \\
\text { in the range of } 2 \mathrm{kHz} \text { to } 20 \mathrm{kHz} \text { [STRS, AF] }\end{array}$ & & & & & \\
\hline $\begin{array}{l}\text { Complete development of improved/new accelerometer } \\
\text { calibration for } 20 \mathrm{kHz} \text { to } 40 \mathrm{kHz} \text { [STRS] }\end{array}$ & & & & & \\
\hline $\begin{array}{l}\text { Complete development of improved accelerometer } \\
\text { calibration for } 3 \mathrm{~Hz} \text { to } 1 \mathrm{kHz} \text { [STRS] }\end{array}$ & & & & & \\
\hline
\end{tabular}




\section{Staff: $(1.4$ staff years $) *$ D. Eitzen, $*$ D. Evans, V. NEDZELNITSKY, ${ }^{*}$ R. Wagner}

Objective and MEL Thrust(s) Supported: To provide U.S. industry with the best possible measurement services for acoustical devices (particularly microphones) that industry needs and demands. To remain the recognized top of the traceability chain in free-field and pressure calibration of microphones. To provide special measurement expertise required by industry in developing revolutionary new sensors such as micro-machined silicon microphones and semiconductor tunneling hydrophones. To improve the realization and delivery of calibration services for acoustical quantities. To harmonize national and international standards on acoustical instrumentation and microphone calibration. Industry has been particularly demanding of services at higher frequencies. Manufacturing Metrology.

Need(s) Addressed: Through its physical measurement services, special measurements, consulting, and standards work (extensive with ASA and IEC) this acoustic metrology project impacts a broad spectrum of U.S. industries and concerns such as acoustic measurements for noise control and abatement, safety and health programs product development acceptance testing, condition monitoring, and object detection. Industry requirements are not being fully met in this metrology area; calibration services at higher frequencies is the most pressing need. Needs for measurements of electromagnetic interference effects on acoustical instrumentation are quickly escalating. Some of the economic impacts are very large. Acoustic measurements of new jet engine noise levels can have multi billion dollar impacts. Acoustic measurements in product development in the auto industry are extensive. National goals in health and safety are also very strongly affected.

Technical Approach: The center of the approach is to maintain and significantly improve the range of acoustical calibrations, to continue the extensive national and international standards committee work (including chairmanships and U.S. delegation head), and rather critical and extensive special measurements for revolutionary sensor technologies. Benchmarking our measurement services is a part of the approach. Modernization and complete characterization of equipment is essential as is development of new measurement algorithms and signal processing techniques.

\section{FY95 Accomplishments:}

- Delivered about 50 acoustic transducers calibration reports.

- Completed recalibration of NIST microphones by absolute reciprocity.

- Completed one invited paper and several invited talks.

- Supported international trade by two extensive consultations in Meexico and training of Guest Researchers.

- Completed microphone study to diagnose the discrepancies in the intercomparison of microphones conducted by the EU.

- Performed special measurements for Draper Laboratory on development of micromachine.

\section{FY96 Plans:}

- Perform microphone calibrations as required by industry.

- Continue standards leadership and development work.

- Benchmark " $1 / 2$ inch" microphone free-field reciprocity calibration.

- Demonstrate further how NIST microphone calibration data is an order of magnitude closer to model predictions than results of the recent European intercomparison.

- Make measurements on additional prototype micromachined sensors for Draper Laboratory and on semiconductor tunneling hydrophone for NADC. 
Related Developments: Inconsistencies are observed in the intercomparison of microphone calibations conducted by the EU.

Five-Year Plan Goals vs. Fiscal Years:

\begin{tabular}{|l|l|l|l|l|l||}
\hline ACOUSTICAL METROLOGY SERVICES & 96 & 97 & 98 & 99 & 00 \\
\hline $\begin{array}{l}\text { Continue to deliver calibration reports on acoustical } \\
\text { instruments [OA] }\end{array}$ & & & & & \\
\hline $\begin{array}{l}\text { Continue leadership and harmonization of national and } \\
\text { international standards [STRS] }\end{array}$ & & & & & \\
\hline $\begin{array}{l}\text { Make special measurements on revolutionary sensors in } \\
\text { support of industry sensor development [OA] }\end{array}$ & & & & & \\
\hline $\begin{array}{l}\text { Complete development of acoustic calibration service to } \\
\text { double the current frequency range [STRS] }\end{array}$ & & & & & \\
\hline $\begin{array}{l}\text { Develop measurement service for effects of electromagnetic } \\
\text { interference on acoustical instruments [STRS] }\end{array}$ & & & & & \\
\hline
\end{tabular}




\section{Staff: $\left(3.0\right.$ staff years) $*$ Z. Jabbour, ${ }^{*}$ W. Crupe, ${ }^{*}$ B. Damazo, ${ }^{*}$ D. EITZEN, $*$ J. Keller, $*$ V. Lee.}

Objective and MEL Thrust(s) Supported: To develop a research competence needed to accommodate, transition, and interface between the artifact mass system and future prescription based on physical constants such as is embodied by EEEL's Watt experiment. The objective of the combined effort of EEEL's Watt experiment and this MEL project is to monitor the stability of Pt-Ir artifacts and eventually replace the mass artifact system, the last remaining fundamental unit defined by an artifact (an artifact with known instability at the highest levels of accuracy) with a prescriptional system based on physical constants. However, such a new system would leave the unit dissemination system even more dependent on air buoyancy corrections. Artifacts in controlled environments must be studied carefully. Manufacturing Metrology.

Need(s) Addressed: The mass unit is fundamental to a broad range of manufacturing and producing industries. Some of the obvious segments include drug manufacturers, instrument manufacturers, and state weight laboratories. Further, the mass unit is fundamental to the definition derived for both mechanical and electrical metrology. This leads to a potential impact to clientele spanning virtually all manufacturing and technical communities. The unit of mass is the last remaining fundamental unit defined by an artifact, a situation that is at least inelegant. The artifact is also, at the highest levels, unstable in the time frame of months and years due to ad-or absorbed material and in the time frame of decades due to not-understood mechanisms. The economic impact is obviously enormous and also includes such issues as engineering metrology, material accountability, equity in trade, and medicine and health. The fundamental issues are national and international.

Technical Approach: The technical strategy is to form a snall team with competence in analytical physics, design of experiments, and experimental physics. The first task will be to transfer the detailed analytical and experimental knowledge base in mass measurements, corrections, and realization of the unit; particularly the knowledge base resident (a short time into the future) at NIST and BIPM. One key technical issue to be addressed is the larger correction for air buoyancy resulting from the new unit definition due to the fact that the Watt experiment generates a volumeless force which is compared to an artifact with significant volume. This correction is approximately $150 \mathrm{mg}$ for $1 \mathrm{~kg}$ and the residual uncertainty is troublesome. This uncertainty requires that our present capability in the measurement of the density of solid objects and the density of air be significantly improved. This effort requires the use of a pressure chamber for the kilogram comparator so that constant, accurate, selected environments can be used. It also requires the design and use of two artifacts for air density measurement which will result in a direct measurement of air density. Another required improvement to the dissemination system needed to tie the new and artifact systems together is a dedicated system to measure the (weak) magnetic susceptibility of kilogram standards and an improved system for determining kilogram standard density. An improved understanding of artifact surface phenomena is also required. The other major element of this project is direct support of the Watt experiment itself. This includes newly designed artifacts for the experiment and input to the design of a new Watt balance.

\section{FY95 Accomplishments:}

- Recruited new staff member.

- Designed and ordered a pressure chamber and a new prototype for Watt Experiment.

- Recruited R. Davis from BIPM for a temporary assignment at NIST.

- Ordered new balances for density and magnetic effects.

- Wrote paper on new mass correction. 
FY96 Plans:

- Install mass comparator pressure enclosure.

- Introduce new Pt-Ir prototype for Watt experiment.

- Consult with BIPM on density and on mass comparator operation under stabilized pressure.

- Provide artifact and mechanical support for Watt experiment.

- Attend CCM meeting on mass and density.

Related Developments: Progress on Watt experiment in EEEL and at NPL.

Five-Year Plan Goals vs. Fiscal Years:

\begin{tabular}{|l|l|l|l|l|l||}
\hline ARTIFACT MASS TO WATT COMPETENCE & 96 & 97 & 99 & 99 & 00 \\
\hline $\begin{array}{l}\text { Complete magnetic susceptibility apparatus for measuring } \\
\text { mass standards [STRS] }\end{array}$ & & & & & \\
\hline $\begin{array}{l}\text { Complete apparatus for improved measurement of density } \\
\text { of } 1 \mathrm{~kg} \text { mass standards [STRS] }\end{array}$ & & & & & \\
\hline $\begin{array}{l}\text { Complete methodology and devices for direct measurement } \\
\text { of air density for mass correction [STRS] }\end{array}$ & & & & & \\
\hline Complete mechanical input to new Watt balance [STRS] & & & & & \\
\hline $\begin{array}{l}\text { Determine Watt artifact's mass to 0.01 parts per million } \\
\text { [STRS] }\end{array}$ & & & & & \\
\hline $\begin{array}{l}\text { Complete practical understanding of kilogram mass } \\
\text { standard stability [STRS] }\end{array}$ & & & & & \\
\hline $\begin{array}{l}\text { Close loop on U.S. prototype 20 mass standard and Watt to } \\
\text { within 3 parts per billion [STRS] }\end{array}$ & & & & & \\
\hline
\end{tabular}


Staff: (7.0 staff years) *A. DONMEZ, H. Bandy, ${ }^{*}$ B. Damazo, *D. Gilsinn, M. Hahn, *K. Harper, M. Kennedy, *L. Marchetti, H. Soons, *N. Wilkin, *W. Wyatt, ${ }^{*}$ K. Yee.

Objective and MEL Thrust(s) Supported: The closed-loop manufacturing project fosters the development and implementation of advanced manufacturing systems, processes, and equipment through the development of the basic infrastructural tools needed to control manufacturing processes, to improve the accuracy of manufactured parts, and to reduce lead-time to allow for the production of quality products in a cost-effective and flexible manner. Manufacturing Processes and Equipment, Manufacturing Metrology.

Need(s) Addressed: This project supports a broad spectrum of manufacturing industries, including the machine tool, aerospace, automotive and electronics industries. To compete effectively in global markets, U.S. industry needs to manufacture high-precision products reliably, predictably, in a timely manner at competitive costs. This requires a high degree of control over manufacturing processes, including the machines, tooling, and the inspection systems used in manufacturing. A "total control" strategy necessitates the characterization of all the elements involved in manufacturing processes. This characterization is time-consuming and can involve a few months to a year depending upon the machine features and the level of precision required. Machining processes and equipment, therefore, need to be understood better and all the factors influencing the precision of the manufactured product have to be taken into account.

Technical Approach: In collaboration with U.S. industry and ATP, the closed-loop manufacturing project addresses various components of the precision machining processes and concentrates on development of the methods required to characterize manufacturing equipment including machine tools and their interactions with workpieces. These are being investigated as follows: (1) To insure that APTD addresses the most urgent needs of industry, a series of industrial workshops are being sponsored. Findings from these workshops are utilized to direct and refine the project long-term plan. (2) To improve manufacturing processes, pre-, intermittent-, and post-process sensor-based control techniques and software algorithms are being developed that incorporate geometrical, thermal and dynamic tool error compensation techniques. (3) To allow for timely sensory fedback, on-machine part inspection and analysis techniques are being developed as are methods for the fast characterization of geometric, thermal and dynamic errors, including fast ball-bar and grid plate techniques. (4) To increase U.S. industry access to world markets, work is ongoing with both national and international standards group to harmonize U.S. machine tool standards with international standards.

\section{FY95 Accomplishments:}

- Published report on critical research needs for leading-edge technology developments in machining and precision.

- Installed new CCM and integrated it into the QIA control architecture.

- Carried out performance evaluation of the newly acquired CMM.

- Evaluated the new 2-D grid plate for fast machine tool characterization.

- Carried out machine tool characterization and cutting tests on a new piston turning machine to evaluate the robusteness of the piston turning machine error compensation methodology.

- Assumed secretariat of ISO/TC 39/SC2 "Test conditions for metalcutting machine tools"

- Continued work on national and international standards.

- Published several papers and reports on various aspects of closed-loop manufacturing techniques.

- Completed literature survey of error models and kinematics of parallel actuated manipulators, in particular those for a Stewart platform configuration.

- Began development of a kinematic error model that describes the effect of strut length error on Stewart platform location. 
FY96 Plans:

- Sponsor a workshop on motion control and drive elements.

- Integrate QIA database at CMM controller.

- Continue work on national and international standards, including the development of a national standard for the performance evaluation of turning centers.

- Provide Sectretariat to ISO/39/SC2 and leadership on the development of standards for the evaluation of the thermal effects in machine tools

- Develop a motion control actuator system for testing performance parameters of motion control boards.

- Develop a high-speed machining testbed in cooperation with McDonnell Douglas

- Investigate effectiveness and practicality of machine tool enclosures as a means of controlling thermal effects.

- Complete and document kinematic error model for Stewart platforms and identify meaningful error parameters.

- Characterize the thermal errors of the Ingersoll Hexapod machine tool and develop models and compensation strategies.

- Begin development of practical performance measures and performance evaluation methods for the Hexapod machine tool suitable for standardization

Five-Year Plan Goals vs. Fiscal Years:

\begin{tabular}{|c|c|c|c|c|c|}
\hline CLOSED-LOOP MANUFACTURING & 98 & 97 & 98 & 98 & 00 \\
\hline \multicolumn{6}{|l|}{$\begin{array}{l}\text { Develop fast machine characterization techniques to } \\
\text { increase the cost effectiveness of real-time accuracy } \\
\text { enhancement using predictive machine tool models [STRS, } \\
\text { OA] }\end{array}$} \\
\hline \multicolumn{6}{|l|}{$\begin{array}{l}\text { Evaluate the robustness of fast characterization techniques } \\
\text { [STRS, OA] }\end{array}$} \\
\hline \multicolumn{6}{|l|}{$\begin{array}{l}\text { Develop process control techniques using Neural Networks } \\
\text { and expert systems models for machining processes [STRS] }\end{array}$} \\
\hline \multicolumn{6}{|l|}{$\begin{array}{l}\text { Demonstrate closed loop machining based on the multi loop } \\
\text { control architecture defined during the earlier QIA project to } \\
\text { increase the quality of discrete part manufacturing } \\
\text { processes [STRS, OA] }\end{array}$} \\
\hline \multicolumn{6}{|l|}{$\begin{array}{l}\text { Extend the closed loop machining techniques and } \\
\text { algorithms to cylindrical grinding for the use of the } \\
\text { automotive industry [STRS, OA] }\end{array}$} \\
\hline \multicolumn{6}{|l|}{$\begin{array}{l}\text { Develop a high-speed machining testbed to investigate high } \\
\text { speed machining performance and increase the accuracy of } \\
\text { high speed machining for the aerospace industry [STRS] }\end{array}$} \\
\hline $\begin{array}{l}\text { Support the manufacturing industry infrastructure by } \\
\text { developing improved methods for machine tool metrology, } \\
\text { standards for evaluation of performance of various types of } \\
\text { machine tools and other manufacturing equipment [STRS] }\end{array}$ & & & & & \\
\hline
\end{tabular}




\begin{tabular}{|l|l|l|l|l|l||}
\hline CLOSED-LOOP MANUFACTURING & 96 & 97 & 98 & 99 & 00 \\
\hline $\begin{array}{l}\text { Collaborate with industry in the development of an ISO } \\
\text { standard on the evaluation of thermal effects of machine } \\
\text { tools [STRS] }\end{array}$ & & & & & \\
\hline $\begin{array}{l}\text { Collaborate with industry to develop a national standard for } \\
\text { the performance evaluation of CNC turning centers [STRS] }\end{array}$ & & & & & \\
\hline $\begin{array}{l}\text { Investigate the use of advanced sensors in machining } \\
\text { applications and their integration to the control systems } \\
\text { [STRS, OA] }\end{array}$ & & & & & \\
\hline
\end{tabular}


Staff: (5.1 staff years) S. YANIV, T. Bartel, R. Peterson, R. Seifarth, S. Ho, *K. Yee, * Bill Crupe.

Objective and MEL Thrust(s) Supported: To provide the U.S. manufacturing industry with the highaccuracy force measurement services that they need to remain competitive in both the national and world markets. To provide top of the traceability chain in force measurements. To provide the National Conference of Weight and Measures with the technical support they need in legal metrology. To assure the compatibility of U.S. force metrology standards with those of other nations. To harmonize U.S. force standards with international standards. To improve the realization and delivery of services to industry. Manufacturing Metrology.

Need(s) Addressed: Through its force measurement services, special tests, consulting and standards work (e.g., ASTM, OIML), the project supports the broadest possible spectrum of manufacturing industries, including aerospace, automotive, nuclear, defense, chemical, electrical, materials, and other industries, academia and government. The project provides the means for the users of the force metrology program to assure traceability to national and international standards, and contributes to quality and safety in manufacturing. In addition, through this project, NIST performs as the technical arm of the National Conference of Weight and Measures for the National Type Evaluation Program for Load Cells, and provides industry a means to compete in international markets by demonstrating compliance with the force requirements set forth by the Organization Internationale de Metrologie Legale (OIML) R60.

Technical Approach: The force group plans to modernize the delivery of its services, upgrade present services where required, and refurbish the deadweight machines or primary national force standards. In addition, the group will continue its work with national and international standards groups to insure that barriers to world markets are minimized for U.S. manufacturers. To that end the group will continue to benchmark its capabilities against the national laboratories of other nations, and serve as the technical arm for both the National Conference of Weight and Measures and the NIST Office of Weight and Measures.

\section{FY95 Accomplishments:}

- Performed over 1700 force measurements for industry and delivered over 200 test reports.

- Began the refurbishing of the $25,000 \mathrm{lbf}$ deadweight machine.

- Completed a paper on the comparison of creep and creep recovery of load cells tested in accordance with U.S. and international standard methods.

- Continued participation in national and international standards.

- Provided consultations as needed to industry, academia and government.

- Held discussions with an EU Laboratory on mutual recognition of test results for load cells.

- Completed the automation of the data acquisition and analysis system for the $12 \mathrm{Mlbf}$ deadweight machine.

- Improved delivery of force measurement services by increasing the flexibility of data analysis software by incorporating new curve fitting procedures that allow up to 5 th order curve-fitting.

\section{FY96 Plans:}

- Perform force calibrations and special tests as needed by Industry, government and Academia.

- Begin refurbishing of the $500 \mathrm{lbf}$ deadweight machine.

- Begin recalibration of the weights of the $500 \mathrm{lbf}$ machine.

- Continue work on national and international standards; strive to harmonize international and national standards.

- Provide consultations to industry, academia and government laboratories as needed. 
- Initiate preparation of a the Physical Measurment Service procedures manual of the Force Group.

Related Developments: ISO/IEC activities in quality management (e.g., ISO 9000 standards, IEC Guide 25).

Five-Year Plan Goals vs. Fiscal Years:

\begin{tabular}{||l|l|l|l|l|l||}
\hline FORCE METROLOGY & 96 & 97 & 98 & 99 & 00 \\
\hline Perform calibrations and special tests as needed [STRS] & & & & & \\
\hline $\begin{array}{l}\text { Complete refurbishing of the 25,000 lbf deadweight machine } \\
\text { [STRS] }\end{array}$ & & & & & \\
\hline Refurbish the 500 lbf deadweight machine [STRS] & & & & & \\
\hline $\begin{array}{l}\text { Recalibrate the weights of the 500 lbf deadweight machine } \\
\text { [STRS] }\end{array}$ & & & & & \\
\hline Refurbish 112,000 lbf deadweight machine [STRS] & & & & & \\
\hline Refurbish 300,000 lbf deadweight machine [STRS] & & & & & \\
\hline Refurbish 1,000,000 lbf deadweight machine [STRS] & & & & & \\
\hline $\begin{array}{l}\text { Continue participation in national and international } \\
\text { standards development [STRS] }\end{array}$ & & & & & \\
\hline
\end{tabular}


Staff: (1.9 staff years) E. BURNETT, ${ }^{*}$ V. Nedzelnitsky, ${ }^{*}$ D. Eitzen, $*$ D. Evans, ${ }^{*}$ R. Wagner.

Objective and MEL Thrust(s) Supported: To provide the Department of Veterans Affairs (VA), and the public, with evaluated data on hearing aids so that a rational match can be made between patient needs and available aids. To develop complex test methodologies, often extremely software intensive, necessary to test ever-more complex sophisticated hearing aids. To provide the necessary standards support for hearing aids. To assist hearing aid manufacturers in the development of better aids. To communicate the results of these tests in a clear and open way. To provide acoustic and related technical support as needed by the VA and their suppliers. Manufacturing Metrology.

Need(s) Addressed: Through special facilities and instrumentation, anthropomorphs, complex measurement algorithms, extensive software development, and sophisticated signal processing, this hearing aid metrology project fulfills the health, information and support needs of the VA and supports the industrial development of improved aids by manufacturers. It also provides the public with useful needed health aid information. The VA is the largest purchaser of hearing aids and the need for test results for a rational aid selection criteria (developed by VA) is great.

Technical Approach: The center of the approach is the development of special facilities, instrumentation, complex measurement algorithms, software, and signal processing to provide valid measurements on diverse and constantly changing hearing aid devices. The approach also includes standards support for hearing aid technology, consulting with manufacturers, and technical support for the VA on measurement protocols and support for equipment purchases, e.g., audiology booths.

\section{FY95 Accomplishments:}

- Completed development of new radically different test procedures for new generation of hearing aids.

- Evaluated several dozen new custom and "multi-focus" hearing aids.

- Provided extensive consultations to the VA on shielding requirements and test procedures for hearing booths required for VA procurements.

- Completed technical report to VA on new procedures and evaluation results on hearing aids.

- Continued standards support work for hearing aid technology.

- Continued support for hearing aid manufacturers.

\section{FY96 Plans:}

- Complete development of new radically different test procedures for new generation of hearing aids.

- Evaluate several dozen new hearing aids supplied by VA.

- Complete technical report to VA on new procedures and evaluation results on hearing aids.

- Continue standards support work for hearing aid technology.

- Continue support for hearing aid manufacturers.

Five-Year Plan Goals vs. Fiscal Years:

\begin{tabular}{|l|c|c|c|c|c||}
\hline HEARING AID METROLOGY & 96 & 97 & 98 & 99 & 00 \\
\hline $\begin{array}{l}\text { Complete development of new radically different test } \\
\text { procedures for new generation of hearing aids [OA] }\end{array}$ & & & & & \\
\hline
\end{tabular}




\begin{tabular}{|l|l|l|l|l|l||}
\hline HEARING AID METROLOGY & 96 & 97 & 98 & 99 & 00 \\
\hline $\begin{array}{l}\text { Evaluate several dozen new hearing aids per year as } \\
\text { supplied by VA [OA] }\end{array}$ & & & & & \\
\hline $\begin{array}{l}\text { Complete technical report to VA on new procedures and } \\
\text { evaluation results on hearing aids [OA] }\end{array}$ & & & & & \\
\hline $\begin{array}{l}\text { Continue standards support work for hearing aid technology } \\
\text { [OA] }\end{array}$ & & & & & \\
\hline Continue support for hearing aid manufacturers [OA] & & & & & \\
\hline $\begin{array}{l}\text { Provide needed acoustic consulting to VA and hearing aid } \\
\text { manufacturers [OA] }\end{array}$ & & & & & \\
\hline \hline
\end{tabular}


Staff: $(2.9$ staff years $) * Z$. Jabbour, $*$ W. Crupe, ${ }^{*}$ D. EITZEN, $*$ V. Lee, L. Martinez, *J. Keller

Objective and MEL Thrust(s) Supported: To provide U.S. industry with the highest-accuracy services in mass metrology that industry needs and demands, to remain the recognized top of the traceability chain in mass. To assist in the realization of derived units such as force and pressure. To provide special measurement services required by industry such as solid density measurements. To assure the compatibility of U.S. mass measurement with those of other nations and of international standards with those of the United States. To improve the realization and delivery of mass measurement services and to conduct the applied research necessary to achieve these services. Manufacturing Metrology.

Need(s) Addressed: The mass unit is fundamental to a broad range of manufacturing industries and to commerce. Some of the obvious segments include drug manufacturers, instrument manufacturers, power companies, and state weight laboratories. Further, the mass unit is fundamental to the definition of derived units in both mechanical and electrical metrology. This leads to a potential impact to clientele spanning virtually all manufacturing and technical communities. The economic impact is obviously enormous and also includes such issues as engineering metrology, material accountability, equity in trade, and medicine and health. The fundamental issues are national and international.

Technical Approach: The essential technical approach is to maintain and improve a core competence in the realization and dissemination of the unit of mass, in the measurement of density (solid, liquid, and air) and in the measurements leading to the realization of derived units such as force and pressure. In addition considerable effort must be performed with exacting accuracy and great care and the entire chain of realization of the unit and of the check and working standards must be maintained. This includes international benchmarking of our mass artifacts. The publication of papers on mass metrology is an important part of this strategy.

\section{FY95 Accomplishments:}

- Prepared about one hundred calibration reports on hundreds of weights.

- Completed the transfer of the U.S. prototype (20) kilogram (U.S. basic mass standard) to working standards.

- Completed project for OSRM on density.

- Published three papers, gave six talks, and assisted in two workshops on mass measurement.

\section{FY96 Plans:}

- Perform calibrations and prepare calibration reports as required by industry and state weight laboratories.

- Complete special tests on deadweight machines components as needed by industry.

- Perform density measurments for indutry and OSRM.

- Through BIPM complete benchmarking of $1 \mathrm{~kg}$ mass standard through international intercomparison of $1 \mathrm{~kg}$ stainless steel standards.

Five-Year Plan Goals vs. Fiscal Years:

\begin{tabular}{|l|l|l|l|l|l||}
\hline MASS ARTIFACT METROLOGY & 96 & 97 & 98 & 99 & 00 \\
\hline $\begin{array}{l}\text { Perform calibrations and prepare calibration reports as } \\
\text { required by industry and state weight laboratories [OA] }\end{array}$ & & & & & \\
\hline
\end{tabular}




\begin{tabular}{|l|l|l|l|l|l||}
\hline MASS ARTIFACT METROLOGY & 96 & $\mathbf{9 7}$ & $\mathbf{9 8}$ & $\mathbf{9 9}$ & $\mathbf{0 0}$ \\
\hline $\begin{array}{l}\text { Publish papers on new developments in dissemination of } \\
\text { the mass unit [STRS] }\end{array}$ & & & & & \\
\hline Participate in international standards work on mass [STRS] & & & & & \\
\hline $\begin{array}{l}\text { Develop improved measurement service for weights } 100 \mathrm{~g} \\
\text { to } 1 \mathrm{~kg} \text { [STRS] }\end{array}$ & & & & & \\
\hline $\begin{array}{l}\text { Develop improved measurement service } 1 \mathrm{~kg} \text { to } 20 \mathrm{~kg} \\
\text { [STRS] }\end{array}$ & & & & & \\
\hline $\begin{array}{l}\text { Develop improved measurement service } 1 \mathrm{mg} \text { to } 100 \mathrm{~g} \\
\text { [STRS] }\end{array}$ & & & & & \\
\hline $\begin{array}{l}\text { Screen customer } 1 \mathrm{~kg} \text { mass standards for magnetic effects } \\
\text { [OA] }\end{array}$ & & & & & \\
\hline $\begin{array}{l}\text { Make improved measurements of density of customers' } 1 \mathrm{~kg} \\
\text { mass standards [OA] }\end{array}$ & & & & & \\
\hline $\begin{array}{l}\text { Make more accurate direct air density measurements } \\
\text { resulting more accurate mass measurements for customers' } \\
1 \text { kg standards by a factor of 4 [OA] }\end{array}$ & & & & & \\
\hline \hline
\end{tabular}


Staff: $\left(3.3\right.$ staff years) ${ }^{*}$ C.J. EVANS, *M.A. Donmez, ${ }^{*}$ R.S. Polvani, *M.L. McGlauflin, ${ }^{*}$ E. Whitenton, Y. Chou, ${ }^{*}$ M. Davies, ${ }^{*}$ P.J. Sullivan.

Objective and MEL Thrust(s) Supported: The objective of the project is to develop manufacturing methods--including metrology and sensor feedback to open architecture controllers--to allow cost-effective production of tight tolerance components in advanced, difficult-to-machine materials such as ceramics, crystals, and hardened steels. Applications include mechanical, optical and electronic systems ranging from bearings and turbine blades to space optics and magnetic memories. Manufacturing Metrology, Manufacturing Processes and Equipment

Need(s) Addressed: There is an ever increasing trend to both tighter manufacturing tolerances and higher performance materials. Unfortunately, next generation turbine blades will be made from silicon nitride, and require complex, accurate forms with good surface finish and no machining-induced strength limiting effects. Machining costs are currently a high proportion of the total manufacturing cost, and must be reduced if advanced materials are to be cost competitive. Yet, defect density and surface finish must be controlled. Complex interactions between machine characteristics, tool and work materials, and process parameters must be understood as they provide the technological basis for manufacturing processes that will allow introduction of new products based on such materials. Improved grinding techniques will enhance the manufacturability of high-value-added, tight tolerance components. Potential industries impacted include aerospace, transportation, and mass storage.

Technical Approach: The project aims to improve the-state-of-the-art in ductile regime grinding and hard turning. Brittle materials behave in an apparently ductile manner under certain process conditions, allowing defect free ceramic surfaces to be diamond ground with fine grit wheels. Rapid wheel wear, however, means that continuous electromechanical dressing is required of the metal bond wheels; fundamental understanding of the dressing process, and its integration and control via an open architecture controller are required. Appropriate instrumentation will be developed to give sensory feedback for real time control of the grinding process as well. In higher stock removal processes, small variations in work material microstructure seem to have a substantial effect on ceramic machinability and its variation. Loop stiffness and damping appear to have an impact on tool wear as well as surface integrity in hard turning; the new tools of non-linear dynamic analysis are being applied to understanding these effects. Chemical and microstructural effects in CBN tool wear need to be better understood.

\section{FY95 Accomplishments:}

- Completed High-Stiffness Machining Research Test Bed and performed initial ceramics grinding evaluation tests.

- Demonstrated effect of spindle characteristics on hard turning on Moore \# 3 based diamond turning machine.

- Evaluated surface characteristics and mechanical properties of electro-chemically assisted ductile ground silicon nitrides.

- Completed two papers on tool wear and chip morphology.

\section{FY96 Plans:}

- Develop model of chip formation in hard turning.

- Demonstrate effect of tool and workpiece microstructure on $\mathrm{CBN}$ tool wear in finish hard turning.

- Procure and install 4-axis CNC grinder and perform initial evaluations of high-speed ceramics grinding. 
- Establish bench-top techniques for evaluating potential new coolants for electrochemically assisted in process wheel dressing.

Five-Year Plan Goals vs. Fiscal Years:

\begin{tabular}{|l|l|l|l|l|l||}
\hline PRECISION MACHINING OF ADVANCED MATERIALS & 96 & 97 & 96 & 96 & 00 \\
\hline $\begin{array}{l}\text { Develop basic electrochemical theory for dressing process } \\
\text { [STRS] }\end{array}$ & & & & & \\
\hline Complete ceramics machinability studies [STRS, OA] & & & & & \\
\hline $\begin{array}{l}\text { Demonstrate effect of tool and workpiece microstructure on } \\
\text { CBN tool wear in finish hard steel [STRS] }\end{array}$ & & & & & \\
\hline Develop model of chip formation in hard turning [STRS, OA] & & & & & \\
\hline Perform sensor evaluation for grinding control [STRS] & & & & & \\
\hline $\begin{array}{l}\text { Demonstrate effect of tool and workpiece microstructure on } \\
\text { CBN tool wear in finish hard steel [STRS] }\end{array}$ & & & & & \\
\hline $\begin{array}{l}\text { Establish bench-top techniques for evaluating potential new } \\
\text { coolants for electrochemically assisted in process dressing } \\
\text { [STRS] }\end{array}$ & & & & & \\
\hline $\begin{array}{l}\text { Implement one of the newly developed processes in a } \\
\text { production shop floor [STRS] }\end{array}$ & & & & & \\
\hline $\begin{array}{l}\text { Establish the economic benefit derived from the shop floor } \\
\text { implementation described above [STRS] }\end{array}$ & & & & & \\
\hline
\end{tabular}


Staff: (3.7 staff years) ${ }^{*}$ A. DONMEZ, *M. Davies, *D. Gilsinn, *N. Wilkin, A. Ling, W. Wyatt

Objective and MEL Thrust(s) Supported: To develop models of manufacturing processes and equipment for use in manufacturing pre-, post, and in-process control and equipment development, and to provide U.S. industry with state-of-the-art manufacturing data, architecture, models and algorithms. Manufacturing Process and Equipment

Need(s) Addressed: In the absence of adequate modeling tools for manufacturing processes and equipment, process control is almost nonexistent. This increases manufacturing cost significantly--a situation that makes it difficult for U.S. industry to compete in world markets. The closest approximation to process control is the Statistical Process Control (SPC) technique used on the shop floor. Rather than controlling the process, SPC detects changes occurring in the manufactured parts and warns the operator that the fabricated product is out of tolerance. However, SPC does not provide an identification of what parameters need to be modified to bring the system within tolerance. Therefore, corrective actions must be undertaken by the machine operator after the fact based upon experience and/or common sense.

Technical Approach: A generic approach to manufacturing process modeling to achieve high-quality products involves several steps. These steps are (1) identifying critical parameters that define product quality, such as the dimensional tolerances, surface finish, strength, visual consistency, wear resistances, etc.; (2) identifying factors affecting these critical parameters; and (3) establishing relationships between the factors and the parameters. These relationships can be described by deterministic tools such as kinematic, linear and nonlinear dynamics, and finite element models, or they can be described by statistical tools such as regression models. Another type of analytical tool that can be used for this purpose is neural network modeling. Since manufacturing processes are generally nonlinear, linear models that have been traditionally used to predict their performance produced limited success. Recent advances in signal processing for nonlinear dynamics systems combined with the development of better sensors provide a unique opportunity for improved characterization of manufacturing processes. Similarly, recent activities in neural networks research tools have opened new directions in modeling and controlling manufacturing processes and equipment. APTD has carried out some preliminary work using this tool to model machine-tool thermal behavior with success. We plan to elborate on our modeling methods with neural networks as an alternative modeling tool for a variety of manufacturing proceses. Statistical tools have been most commonly used techniques in manufacturing. Their use requires assumptions which may not be valid at all times. The applicability of some new techniques such as Principal Component Analysis (PCA) will be investigated. APTD work in this area has focused primarily on machining. APTD plans to extend, in collaboration with industrial partners, these models to other manufacturing processes such as injection molding, die casting, forming, grinding, and painting. To that effect, CRADAs will be formed with a variety of industries.

\section{FY95 Accomplishments:}

- Organized in cooperation with University of San Diego and Cornell University a government/university/industry workshop on non-linear dynamics applications to manufacturing.

- Established correlation between dynamic characteristic of tool/workpiece system and surface topology in hard turning.

- Carried out preliminary experiments to identify significant research issues in milling flexible workpieces.

- Developed non-linear model of tool/workpiece interface for milling of thin-walled flexible workpieces.

- Applied neural network algorithms to piston turning machine data. 


\section{FY96 Plans:}

- Expand non-linear model for milling thin-walled flexible parts to include changing surface characteristics.

- Measure surface finish of experimental workpieces to verify model.

- Investigate the modal behavior of workpieces.

- Develop non-linear dynamic models for high-speed milling.

Five-Year Plan Goals vs. Fiscal Years:

\begin{tabular}{|c|c|c|c|c|c|}
\hline PROCESS MODELING & 96 & 97 & 98 & 99 & 00 \\
\hline $\begin{array}{l}\text { Statistically correlate the nonlinear dynamic model results } \\
\text { with measured surface characteristics [STRS] }\end{array}$ & & & & & \\
\hline $\begin{array}{l}\text { Implement a Neural Network algorithm in a process control } \\
\text { algorithm [STRS] }\end{array}$ & & & $=$ & & \\
\hline $\begin{array}{l}\text { Use the Neural Network control software in a manufacturing } \\
\text { process control application [STRS] }\end{array}$ & & & & & \\
\hline
\end{tabular}


Title: QUALITY CONTROL FOR ADVANCED MATERIALS AND MANUFACTURING PROCESSES

Staff: (2.9 staff years) ${ }^{*}$ G. Blessing, ${ }^{*}$ N. Hsu, ${ }^{*}$ J. Slotwinski, *S. Fick, *M. Manley, ${ }^{*}$ D. Xiang, ${ }^{*}$ J. Slotwinski.

Objective and MEL Thrust(s) Supported: Develop, test, and apply ultrasonic methods for industrial nondestructive testing and process control needs. This is in response to industrial sectors from sports to automotive to aerospace, who are increasingly turning to composite materials and structures for their high technology products ceramics and ceramics. Ceramics and ceramics-coated metals form another large application sector for this quality control technology. The matrix quantity in the new materials may be a polymer, ceramic, or metal. While a principal feature of these materials is their increased strength-to-weight ratios, they are very heterogeneous on a macro scale. This makes it difficult to control uniformity and to detect discontinuities between and within composite layers. As a result, industry often turns to nondestructive ultrasonic evaluation methods to assess the integrity and quality of these complex materials. But present attempts to apply this technology have had limited success using off-the-shelf sensors, leading us to the development of new focused and point (spherical) transducer methods. Manufacturing Processes and Equipment

Need(s) Addressed: Customer needs especially exist in the aerospace and parts manufacturing sectors. A CRADA has been developed with the Boeing Corporation to apply inspection methods to structural components seeking a correlation between ultrasonic signature and material performance. Karta Technology seeks to develop a quality control program for its ceramic materials. The ultrasonic technique will be an integral part of that effort.

Technical Approach: Ultrasonic techniques previously applied to homogeneous materials will need modification for application to heterogeneous composites. Line-focusing techniques will be developed to define the direction of elastic wave propagation relative to the fiber reinforcement and/or texture in layered materials. Elastic anisotropies ranging from less than one to nearly fifty percent should be assessable.

\section{FY95 Accomplishments:}

- Measured the dynamic elastic bulk properties of porous and dense ceramic and compared to model predictions.

- Implemented an analytical algorithm to assess the material properties (thickness and modulus) of certain coatings on metal substrates.

- Applied a polarization-sensitive transducer to the evaluation of material composite anisotropy.

- An ultrasonic resonant tube cavity was fabricated and evaluated for the detectability of solid particulate in a liquid slurry.

- Completed two papers for publication on quality control of materials.

FY96 Plans:

- Assess the near-surface elastic properties of ceramic materials such as $\mathrm{Si}_{3} \mathrm{~N}_{4}$.

- Interface new imaging software amd mechanical scanner with ultrasonic hardware to enhance signal interpretation and echo-pattern recognition.

- Identify and obtain well characterized composite samples representative of the industrial community's interests.

- Establish new CRADA(s) for industrial partnerships to assure meaningful research and development directions are identified and pursued. 
Five-Year Plan Goals vs. Fiscal Years:

\begin{tabular}{|l|l|l|l|l|l|l||}
\hline \hline $\begin{array}{l}\text { QUALITY CONTROL FOR ADVANCED MATERIALS AND } \\
\text { MANUFACTURING PROCESSES }\end{array}$ & 96 & 97 & 98 & 99 & 00 \\
\hline $\begin{array}{l}\text { On the appropriate composite samples, make elastic } \\
\text { measurements of anisotropy, modulus, etc. [STRS] }\end{array}$ & & & & & \\
\hline $\begin{array}{l}\text { Extend wave propagation modeling using a Green's function } \\
\text { formalism to include nonhomogeneous materials media and } \\
\text { layers [STRS] }\end{array}$ & & & & & \\
\hline $\begin{array}{l}\text { Correlate model predictions with experimental ultrasonic } \\
\text { results, for the lensless line-focus sensor [STRS] }\end{array}$ & & & & & \\
\hline $\begin{array}{l}\text { sist industry in the data analysis of ultrasonic signatures } \\
\text { obtained on structural materials and ceramics, e.g. Boeing } \\
\text { composites and Karta ceramics [STRS] }\end{array}$ & & & & & \\
\hline $\begin{array}{l}\text { Interact with materials and nondestructive testing } \\
\text { communities engaged in composites research with technical } \\
\text { paper presentations and manufacturing site visits [STRS] }\end{array}$ & & & & & \\
\hline $\begin{array}{l}\text { Apply new transducer developments to pulse-echo analysis } \\
\text { of material near-surface damage, especially occurring from } \\
\text { ceramic and glass grinding processes [STRS] }\end{array}$ & & & & & \\
\hline $\begin{array}{l}\text { Analyze and correlate sensory data with various grinding } \\
\text { parameters of industrial interest. Develop and test } \\
\text { signature-analysis software to distinguish material interface } \\
\text { emissions from (background) machine noise [STRS] }\end{array}$ & & & & & & \\
\hline
\end{tabular}




\section{Title: SENSOR INTERFACE FOR CLOSED-LOOP MANUFACTURING}

Staff: (5.2 staff years) ${ }^{*}$ Lisa Fronczek, ${ }^{*}$ Bob Gavin, Ric Shneenman, KANG LEE, Toni Savoy, M. Huff, *M. Hahn, ${ }^{*} \mathrm{~K}$. Yee, ${ }^{*} \mathrm{G}$. Blessing

Objective and MEL Thrust(s) Supported: The objectives of the project are to develop sensors, sensor interface specifications and standards to allow sensor control technologies to be used in closed-loop manufacturing to increase the quality of manufacturing processes and equipment and to reduce the dependence on post-process appraisal, lead-time, rework and manufacturing cost. Manufacturing Processes and Equipment, Manufacturing Metrology.

Need(s) Addressed: Historically, quality control in manufacturing has focused on post-process appraisal (i.e., finding defective parts after the fact). Post-process inspection has several short-comings: the manufacturing cost is already incurred when the error is detected; it is often difficult to isolate the cause(s) of a manufacturing defect; there is significant time lag between the discovery of a defect and the corrective action, and the inspection and corrective measures are costly. Accordingly, today the focus is shifting from post-process control to improved control of the manufacturing process itself through the use of deterministic manufacturing principles. Closed-loop manufacturing--a systematic approach in which information obtained during, in between, and after manufacturing operations is used in feedback loops to control the quality of manufactured parts--is predicated upon the premise that, in an automated environement, manufacturing equipment performs in a sufficient deterministic manner to allow quality assurance thorugh control of the process rather than post-process inspection. The process control ensures that the errors introduced by each step in the manufacturing process are within tolerable ranges regardless of the part(s) produced. With this approach scrap, rework, lead-time and conventional inspection activities are reduced. However, to be successful characterization techniques, models, factory-hardened sensors, and interface standards for controllers and sensors are required to monitor the accuracy of the manufacturing process as well as parameters that can be adjusted to improve accuracy. Industry contacts indicate that despite the growth in the control sensor market, the lack of standards for interfacing sensors and controllers remains an acute problem for industry and results in very high interface costs. For this reason, the Automated Production Technology Division is undertaking a major effort to develop the sensor interface technology and standards needed by the manufacturing industry to take full advantage of the competitive benefits to be derived from closed-loop manufacturing.

Technical Approach: To insure that the most urgent needs of indutry are met first, APTD will continue to sponsor industrial workshops in cooperation with voluntary standards organizations such IEEE and ISA to establish industrial priorities and establish, in cooperation with IEEE, the voluntary standard groups required for the development of the sensor communication interfaces and protocols standards. To demonstrate the benefits to be derived from closed-loop manufacturing, APTD is implementing in cooperation with Portsmouth Naval Shipyard a testbed on a Brown \& Sharp VC 1000 vertical machining center. This testbed will serve as the platform for the integration of the sensor interface specifications which are being developed as part of the standardization process. To maximize the effectiveness of this project and to maximize leverage of resources, the work is closely coordinated with other process modeling, sensor and controller work being done within MEL.

\section{FY95 Accomplishments:}

- Sponsored in cooperation with IEEE a series of workshops to define needs for sensor interface standards.

- Working with IEEE, formed an IEEE/NIST working group on transducers to microprocessors communication interface, and another working group on network communication interface.

- Developed a "proof-of-concept" prototype sensor interface to demonstrate the feasibility of a generic interface that allows interoperability and interchangeability among sensors and networks. 
- Developed the hardware and software required for future installation on the Portsmouth Naval Shipyard closed-loop manufacturing testbed.

\section{FY96 Plans:}

- Develop within the context of the two IEEE/NIST work groups draft standards for IEEE ballot.

- Begin implementation of standard into a prototype for evaluation of standard.

- Sponsor in cooperation with IEEE a workshop to review status of interface standardization efforts and evaluation further needs.

- Complete closed-loop manufacturing testbed at Portsmouth Naval Shipyard.

Related Developments: IEEE efforts to develop standards for sensor interface.

Five-Year Plan Goals vs. Fiscal Years:

\begin{tabular}{||l|l|l|l|l|l||}
\hline $\begin{array}{l}\text { SENSOR INTERFACE FOR CLOSED-LOOP } \\
\text { MANUFACTURING }\end{array}$ & 98 & 97 & 98 & 99 & 00 \\
\hline Develop draft sensor interface standard [STRS, OA] & & & & & \\
\hline $\begin{array}{l}\text { Demonstrate sensor to machine tool interface in production } \\
\text { machine for beta site testing and validation [STRS, OA] }\end{array}$ & & & & & \\
\hline $\begin{array}{l}\text { Draft generic application programming interface } \\
\text { specifications for interfacing sensors and sensor bus with } \\
\text { control modules in pc-based controllers [STRS, OA] }\end{array}$ & & & & & \\
\hline \begin{tabular}{l} 
Complete Testbed [STRS, OA] \\
\hline
\end{tabular}
\end{tabular}


Staff: $(1.5$ staff years $){ }^{*}$ M. Davies, ${ }^{*}$ A. DONMEZ, ${ }^{*}$ C. Evans, ${ }^{*}$ K. Harper, ${ }^{*} \mathrm{~K}$. Yee

Objective and MEL Thrust(s) Supported: The objective of this project is to develop the fundamental knowledge required to understand the relationship between measured spindle performance and manufactured part quality. Manufacturing Processes and Equipment, Manufacturing Metrology.

Need(s) Addressed: U.S. industry has an ever increasing need to produce high precision parts to remain competitive in global markets. Because the majority of manufacturing processes utilize spindles, the accuracy of these components is crucial. In-depth study of the characteristics of a variety of spindle types and the relationship of those characteristics to performance in manufacturing will yield the data required to produce more accurate spindles.

Technical Approach: To improve spindle accuracy, a complete study of the geometric, thermal, and dynamic properties of several different types of spindles will be conducted. Analysis of the axis of rotation errors, thermal distortion, vibration modes, and non-linear dynamic effects will be carried out. The spindle types studied will include rolling element (tapered rollers) bearing, air bearing, and hydrostatic bearing spindles. Based on equipment availability, a ceramic spindle and an electro-magnetic bearing spindle will also be examined. Methodologies for spindle analysis developed in this effort will be made available to industry through publications and presentations in relevant forums. Correlations found between spindle characteristics and performance will also be presented to industry for its use in development of more accurate spindles.

\section{FY95 Accomplishments:}

- Completed dynamic measurements on the Timken tapered roller bearing spindle.

- Completed model of dynamic behavior of the spindle and identified major dynamic modes, their corresponding frequencies, and causes.

- Completed measurements of axial motion at different speed and bearing preloads.

- Identified source of spindle errors.

FY96 Plans:

- Improve existing spindle performance by installing new drive motor.

- Specify requirements for a bearing stifness testing system to evaluated the dynamic stifness of a particular bearing design.

- In collaboration with industry, modify the old axis-of-rotation standard.

- Carry out performance evaluation on new improved system.

Five-Year Plan Goals vs. Fiscal Years:

\begin{tabular}{|l|l|l|l|l|l||}
\hline SPINDLE CHARACTERIZATION & 98 & 97 & 98 & 99 & 00 \\
\hline Upgrade spindle and perform evaluation tests [STRS] & & & & & \\
\hline $\begin{array}{l}\text { Perform dynamic characterization of the air bearing spindle } \\
\text { [STRS] }\end{array}$ & & - & & & \\
\hline $\begin{array}{l}\text { Correlate surface features produced by both hard turning } \\
\text { and diamond turning with the dynamic characteristics of the } \\
\text { air bearing spindle [STRS] }\end{array}$ & & & & & \\
\hline
\end{tabular}




\begin{tabular}{|l|l|l|l|l|l|}
\hline \hline SPINDLE CHARACTERIZATION & 96 & 97 & 98 & 98 & 00 \\
\hline $\begin{array}{l}\text { Compare performance of contact element bearing spindle } \\
\text { with performance of air bearing spindle in both diamond and } \\
\text { hard turning [STRS] }\end{array}$ & & & & & \\
\hline $\begin{array}{l}\text { Perform characterizations and cutting tests on hydrostatic } \\
\text { spindle [STRS] }\end{array}$ & & & & & \\
\hline $\begin{array}{l}\text { Perform similar examinations of ceramic and } \\
\text { electromagnetic bearing spindles, based on equipment } \\
\text { availability [STRS] }\end{array}$ & & & & & \\
\hline Compare performance of various spindles [STRS] & & & & & \\
\hline
\end{tabular}


Staff: $(1.5$ Staff years $) *$ G. BLESSING, $*$ S. Fick, $*$ J. Slotwinski

Objective and MEL Thrust(s) Supported: Deliver ultrasonic calibrations and respond to industrial requests for specific metrology tests in a timely way. A wide variety of industrial sectors periodically requests guidance and evaluation for material quality evaluation and sensor needs in product inspection and process control. Recent examples are from Eriez Magnetics for their array into liquid and paste slurries quality control, Eaton Corporation to develop a quality control procedure for their ceramic materials, and Karta Technology for an assessment of their heat-treated metals. Manufacturing Metrology.

Need(s) Addressed: Industry has had a long-standing need and interest in ultrasonic nondestructive testing methodologies for process control and part inspection. While the present level of calibration requests on reimbursable dollars is low in some areas, we are retaining our capability to respond to industry's interests in distinct areas of calibration. Two of these have resulted in the development of SRMs. The areas of calibration pertain to (1) ultrasonic reference block echo-amplitude measurements, (2) power radiation measurements of transducer output, and (3) sensitivity measurements of acoustic emission (AE) sensors as a function of elastic wave frequency.

Technical Approach: In (1), we deliver an evaluation of the echo-amplitude response from flat-bottom-hole reference artifacts in metal blocks that industry uses to calibrate the sensitivity of its ultrasonic systems to detect material flaws. The principal users are the aerospace and metals industries, e.g., Boeing, Lockheed, Alcoa, and Reynolds Metals. In (2), NIST provides a measure of transducer power output radiation as a function of drive voltage so that the user may have a reference to calibrate the output levels of his system. SRM 1855 was developed as a well-characterized transducer transfer device to the medical community for the evaluation of their diagnostic and therapeutic system. These calibration reference data, for example, assure the safe delivery of patient sonograms. In (3), AE sensors are calibrated for their sensitivity to angstrom-level dynamic material surface displacements occurring in the kilohertz-to-megahertz elastic wave frequency range. This technology is a micro-scale application and analysis of materials, of what happens on a macro scale with seismic waves. The broad industry involved with small and large pressure (gas and fluids) vessels, and storage tanks (e.g., oil) is served with this calibration capability, defined by the ASTM E1 106 practice.

\section{FY95 Accomplishments:}

- Responded to a significant upsurge in ASTM E127-type ultrasonic block calibrations.

- Delivered calibrations of ultrasonic reference blocks, medical-application transducers and AE sensors to industry.

- Cast the AE calibration procedure that is outlined in ASTM E1106 practice into an ISO document.

- Completed preparation of three papers on ultrasonic measurement techniques for publication.

- Chaired ASTM Committee E7.06.02 on ultrasonic reference block calibration methodology to provide leadership for industry's calibration needs in nondestructive testing.

\section{FY96 Plans:}

- Provide ultrasonic calibrations of materials and sensors to industry.

- Publish a NIST Journal of Research paper describing the power radiation pressure measurement technique in detail.

- Assist Boeing and Eriez Magnetics with their materials measurement needs via CRADA terms.

- Develop a CRADA with Karta Technology.

- Develop a CRADA with Eaton Corporation to address some of their measurement needs. 
Five-Year Plan Goals vs. Fiscal Years:

\begin{tabular}{||l|l|l|l|l|l||}
\hline ULTRASONIC CALIBRATIONS SERVICES & 98 & $\mathbf{9 7}$ & $\mathbf{9 8}$ & $\mathbf{9 8}$ & $\mathbf{0 0}$ \\
\hline $\begin{array}{l}\text { In collaboration with industry via ASTM E7.06 committee, } \\
\text { continue to redefine precision limits for aluminum ultrasonic } \\
\text { reference blocks [STRS, Industry] }\end{array}$ & & & & & \\
\hline $\begin{array}{l}\text { Develop improved practices for reference block } \\
\text { methodology, including more sensitive ceramic PZT-type } \\
\text { transducers to replace present usage of quartz transducers } \\
\text { [STRS] }\end{array}$ & & & & & \\
\hline $\begin{array}{l}\text { Continue participation in national and international } \\
\text { standards committee activities (ASTM, IEEE, ISO, etc.) via } \\
\text { balloting, round-robin tests, and holding appropriate chairs } \\
\text { [STRS] }\end{array}$ & & & & & \\
\hline $\begin{array}{l}\text { Develop improved and automated sensor evaluation } \\
\text { scanning system to assess transducer behavior and quality } \\
\text { [STRS] }\end{array}$ & & & & & \\
\hline
\end{tabular}




\section{INTELLIGENT SYSTEMS \\ DIVISION}

\section{MISSION:}

Strives to enhance U.S. industrial competitiveness through the development and application of intelligent systems technologies; develops and maintains competence in intelligent machines and systems, robotics, real-time sensory-interactive control, open-system architectures, software development techniques, simulation and modeling, and methods for intelligent system design and testing; conducts research in techniques for planning and control, world modeling, sensory processing, and interactive graphics for operator interface; works with industry, universities, and other government agencies to implement precommercial prototype open-system architecture, intelligent control systems for a wide variety of applications; applies artificial intelligence techniques to real-time sensory-interactive control for computer-integrated manufacturing systems; supports other NIST laboratories and other government agencies in applications of intelligent systems with high national priority, such as construction, environmental clean-up, transportation systems, mining, and military applications; develops reference model open-system architectures for intelligent control systems; develops methodologies for design and implementation of intelligent control systems; develops methods and tools for software development and testing; develops and tests measures of performance for intelligent control systems, robots, and intelligent machines; and supports the development of new standards for intelligent machine systems, robots, and automated manufacturing systems. 


\section{Title: ADVANCED DEBURRING AND CHAMFERING SYSTEM (ADACS)}

\section{Staff: $\left(0.6\right.$ staff years) ${ }^{*}$ KEITH STOUFFER, *Bob Russell, *guest researcher}

Objective and MEL Thrust(s) Supported: To develop interface standards and performance measures for advanced robotic deburring and chamfering (finishing) systems. Manufacturing Processes and Equipment

Need(s) Addressed: Pratt \& Whitney, as well as industry as a whole, has a great need to automate the finishing process for parts. Manual finishing of parts is very time consuming, inconsistent, and prone to errors that can damage an expensive part beyond repair. Manual deburring and chamfering operations account for approximately $35 \%$ of the final cost associated with the manufacture of product parts. Annual deburring operation costs are currently estimated at $\$ 3.9$ billion nationwide. The price for manual deburring manifests itself in the time required to machine a part at the bench, the cost of a thorough inspection following the bench, the possible subsequent rework and sometimes even the component scrap. Cumulative trauma disorders (most notably carpel tunnel syndrome) can result in high health care costs and lost labor. Automation will largely reduce or eliminate these problem areas.

Technical Approach: The ADACS project consists of two hardware implementations. A robotic implementation, located at NIST in Gaithersburg, MD, incorporates a six-axis Cincinnati Milacron T3-646 as a macro positioning device to carry a two-degree-of-freedom force sensing tool. A machine tool implementation, located at Pratt \& Whitney in East Hartford, CT, incorporates a K\&T 200 machine tool as the macro positioning device to carry the two-degree-of-freedom force sensing tool. The tool has a carbide rotary cutter positioned at the tip. This Chamfering and Deburring End-of-arm Tool (CADET) incorporates active actuators and force sensors to provide control over cutting forces and tool stiffness at the part edges. Each device is controlled separately and is coordinated under the control of the system supervisor using the NIST-developed hierarchical Real-time Control System (RCS). RCS allows feedback from a variety of sensors to be easily integrated with the control of the robot, accommodating for robot inaccuracies which may result from off-line programming. A computer-aided design (CAD) graphical user interface allows the user to graphically select which edges are to be chamfered and specify the machining parameters (feed rate, chamfer depth, direction of cut, etc.) to obtain the required chamfer on each edge. ADACS is a joint project among NIST, United Technologies Research Center (UTRC), and Pratt \& Whitney. NIST is responsible for the development of the advanced CAD-directed, sensorbased control system which coordinates the operations of the robot/machine tool and the deburring tool. UTRC is responsible for the development of the deburring process model and fabrication of an enhanced deburring tool, the Chamfering and Deburring End-of-arm Tool (CADET). Pratt \& Whitney is the factory testbed for the prototype chamfering and deburring cell. Finishing costs are expected to be reduced by $50 \%$ and rework rates are expected to be reduced to nearly $0 \%$. Tolerances on the finished edges will be less than $\pm 0.1 \mathrm{~mm}$ $( \pm 0.003$ in $)$.

\section{FY95 Accomplishments:}

- The Chamfering and Deburring End-of-arm Tool (CADET) has been designed and fabricated. There will now be two integration platforms for the project. The CADET will be integrated with the robotic platform at NIST for finishing of more 3-dimensional parts (Sikorsky helicopter part) and the CADET will be integrated with a CNC at Pratt \& Whitney for use on more tightly features parts (jet engine rotor disk). This will allow immediate implementation of the research obtained from the project.

- The interfaces between the off-line programming software and the motion control software were developed using the Unified Telerobotic Architecture Project (UTAP) standard interface specifications.

- NIST and United Technologies Research Center (UTRC) engineers hosted a demonstration and commercialization open house of the ADACS/CADET technology on July 24, 1995. Companies in 
attendance included FANUC, JR3, Allied Signal Engines, and Robert E. Morris. Several companies have expressed interest in the commercialization of the system, and follow-on discussions are continuing.

- The ADACS project was presented at the DDR\&E Summer Review at the Institute for Defense Analysis in Alexandria, VA

- The papers "ADACS: An Advanced Deburring and Chamfering System," Stouffer, K. and Russell, R. and "The ADACS Implementation of the UTAP Architecture." Russell, R., Michaloski, J, and Stouffer, K., were accepted to be presented at the 6th International Conference on Manufacturing Engineering (ICME 95) in December 1995.

\section{FY96 Plans:}

- Complete technical plan for transfer of technology to Pratt \& Whitney.

- Present ICME 95 conference papers.

- Complete robotic implementation at NIST.

- Complete CNC integration at Pratt \& Whitney.

- Compete capabilities video of the system.

- Prepare final reports summarizing the technology development of the ADACS.

- Final demonstrations are expected to occur in early April 1996.

Related Developments: NIST and UTRC are working in cooperation with several tool and control manufactures to develop a plan to commercially produce the ADACS CADET tool and control system. 


\section{Title: AUTOMATED WELDING MANUFACTURING SYSTEM (AWMS)}

\section{Staff: (1.5 staff years) *MARIS JUBERTS, *Bill Rippey, *Bob Russell, *Joe Falco}

Objective and MEL Thrust(s) Supported: To develop the Advanced Welding Manufacturing System (AWMS) as a testbed for development and evaluation of interface standards autonomous gas metal arc welding. To foster the development and implementation of advanced welding manufacturing systems, processes, and equipment. To provide industry with state-of-the-art open-architecture standards, models, data, and algorithms. Manufacturing Systems Integration, Intelligent Machines, Manufacturing Processes and Equipment

Need(s) Addressed: Welding is used very extensively in the manufacture of many products: welding is a $\$ 5$ billion per year industry. Most welding is done manually, relying on the welder to monitor the process, adjust parameters and guide torches and welding rods around the weld joints. The complexity of welding has kept economical use of automation limited to large quantity use, or to simple process and geometry applications. Other nations are applying automation to welding for manufacturing and are conducting research.

Our target customers are primarily users of automated welding technology in such manufacturing areas as shipbuilding, automotive, and heavy equipment manufacturing and building construction. Lack of progress in welding automation technology has limited the range of applications where machines can perform reliable welds in a cost effective manner.

Users need better design of production processes (e.g., less trial-and-error development of processes, from determining real-time weld parameters to production line layout). They need more flexible capabilities such as easier programming and ability of automated processes to adapt to process variations and to changing product characteristics. Users will benefit form easier integration of multi-vendor systems, and exchange of data among multi-vendor systems for uses such as product design, process design, process planning, and automated process programming.

Technical Approach: (1) Establish a distributed testbed and invite industrial and other government cooperation. We will select some industry applications and demonstrate techniques in the testbed. (2) Integrate process models and control algorithms developed by others (e.g., MRD, INEL) into the testbed and demonstrate them. Initially we will integrate the advanced technology being developed for autonomous GMAW by MRD with advanced robotics technology being developed for intelligent machines by ISD. (3) Address quality needs by using improved process instrumentation and modeling coupled with closed loop control of process variables including voltages, currents, and control of welding tip motion. (4) Emphasize techniques for integration of specialized hardware and software components, especially current commercial products, for improved programming, unattended capabilities to enlarge the scope of products that can be fabricated with automated welding. We will investigate recent efforts to define welding systems by the Navy and others and evaluate architectural concepts and subsystem components already developed. (5) Integrate advanced sensor and process modeling technology being developed by the Materials Reliability Division (MRD) and other researchers and technology providers. (6) Use the AWMS as a development and demonstration site for automated arc welding. Work with welding industry users, technology vendors, and researchers to share sensor and control subsystems, and evaluate them in an integrated welding system. Evaluate and validate data and interface standards developed at NIST and by Industry. Explore integration techniques that make multi-vendor system solutions more effective and easier to build, program, and operate. (7) Overcome current limitations on automated welding and apply it to a wider range of manufacturing applications (e.g., in product mechanical complexity and in economic quantities).

\section{FY95 Accomplishments:}

- Held an industry needs workshop in August 1995. Thirty-two attenders representing government, 
private and university research, technology users, and technology providers gathered for this two-day workshop on welding technology. The purpose was to form recommendations to NIST on how to direct its resources to best meet needs of the manufacturing industry. The meeting produced extensive discussions about technology needs of the welding industry. The needs were broadly divided into standards and technology research. In order to make recommendations to NIST, there was one round of voting to prioritize the subtopics. The top four ranked, indicating where industry has the strongest needs, were: Interface standards for data exchange, electrical and mechanical interface standards, predictive process models and knowledge base, and simulation and off-line programming. NIST will use the ideas expressed in the workshop in forming project plans for AWMS. We will match the highest priority areas to the capabilities, funding and staffing available.

- Demonstrated an arc weld using the Robocrane® for the Workshop attenders. The demo included operation of an arc sensor system developed by MRD-Boulder.

- Attended a meeting of the American Welding Society A9 Committee on Computerization of Welding Data.

- Conducted site visits and meetings with industry and government researchers to discuss cooperative development. (e.g., NIST Boulder, Idaho National Engineering Labs, AMET, ServoRobot, Edison Welding Institute)

- Began renovation of laboratory space.

\section{FY96 Plans:}

- Present workshop results at the AWS annual convention in April 1996 within the meeting of the A9 Committee.

- Purchase a computer and software for sensor and control systems development; purchase a robot arm, integrate it with an arc welding power source and do initial tests; integrate MRD arc length sensor system with arm motion control.

- Pursue CRADAs with industry partners.

- Complete renovation of laboratory area and begin retrofit of gantry robot controller.

Five-Year Plan Goals vs. Fiscal Years:

\begin{tabular}{|l|l|l|l|l|l||}
\hline $\begin{array}{l}\text { AUTOMATED WELDING MANUFACTURING SYSTEM } \\
\text { (AWMS) }\end{array}$ & 96 & 97 & 98 & 99 & 00 \\
\hline $\begin{array}{l}\text { Demonstrate improved process monitoring and control using } \\
\text { MRD arc length sensor system in automated welding. Show } \\
\text { compensation for "unexpected" spot welds and joint } \\
\text { variations [STRS] }\end{array}$ & & & & & \\
\hline $\begin{array}{l}\text { Select a difficult industrial manufacturing application for a } \\
\text { demonstration of intelligent manufacturing [STRS] }\end{array}$ & & & & & \\
\hline $\begin{array}{l}\text { Integrate an industry product, supplied by CRADA, for } \\
\text { process simulation and programming with AWMS [STRS] }\end{array}$ & & & & & \\
\hline $\begin{array}{l}\text { Evaluate control system interfaces being developed by Navy } \\
\text { TRP project by testing them in the AWMS [STRS] }\end{array}$ & & & & \\
\hline $\begin{array}{l}\text { Evaluate STEP APIs for welding product modeling by testing } \\
\text { in the AWMS [STRS] }\end{array}$ & & & & & \\
\hline Participate in AWS standards meetings [STRS] & & & & \\
\hline
\end{tabular}


Title: ENHANCED MACHINE CONTROLLER (EMC): A TESTBED FOR OPEN ARCHITECTURE CONTROLLER STANDARDS

Staff: (2.0 staff years) Fred Proctor, *Bill Rippey, ${ }^{*}$ Will Shackleford, ${ }^{*}$ Sandor Szabo, *Wendell Wallace, *Tom Wheatley, *Tom Kramer

Objective and MEL Thrust(s) Supported: To develop and validate standard interfaces for open architecture machine controllers. Intelligent Machines and Systems, Manufacturing Process and Equipment

Need(s) Addressed: In 1980, nearly half the world's machine tools were manufactured in the United States. Today, U.S. market share has fallen to $10 \%$. Since machine tool technology is considered critical for both civilian and military uses, its is important to recapture some of this market. The controller is the critical component of a machine tool which can change it capabilities. Currently, competition is based on hardware. The EMC project shifts the focus from hardware to software, an area where the United States still has a commanding lead. The benefit is a reduction in the life cycle cost of machine controllers, including training, maintenance, and integration. Other benefits include competitive sources for controller components, and the ability to enhance the capability of the controller with third-party technology.

Technical Approach: An interface specification for open architecture controllers will be developed. This will take place in cooperation with the Department of Energy Technologies Enabling Agile Manufacturing (TEAM) program. A consortium will be established, including representatives from the user, vendor, and third party communities. High-value standard interfaces will be identified, and installations at production test sites will validate that the interfaces support interoperability and extensibility. A standards effort will be undertaken to formalize the interface specifications which result.

\section{FY95 Accomplishments:}

- A controller based on common off-the-shelf hardware and software was installed on a Kearney \& Trecker 4-axis horizontal machining center at the General Motors Powertrain facility in Pontiac, Michigan. Component-swapping tests validated the standard interface to motion control.

- An installation on an SNK 5-axis machining center at the Boeing facility in Auburn, Washington performed by Trellis Software \& Controls verified the interface to program interpretation, for which NIST provided several equivalent versions with different capabilities.

- A series of meetings at the GM Technical Center in Warren, Michigan under the auspices of the TEAM program generated a specification for open controller interfaces currently under review.

\section{FY96 Plans:}

- Extensibility demonstrations at the GM facility will highlight the addition of non-contact probing capabilities on the 4-axis machining center.

- Commercialization of the part program interpreter will take place by Trellis Software \& Controls and their sponsoring partner.

- The EMC consortium will be established, and a review of the interface specifications will take place. Within NIST, these interfaces will form the basis for controllers for robots, coordinate measuring machines, and the Hexapod. 
Five-Year Plan Goals vs. Fiscal Years:

\begin{tabular}{||l|l|l|l|l|l||}
\hline $\begin{array}{l}\text { ENHANCED MACHINE CONTROLLER (EMC): A } \\
\text { TESTBED FOR OPEN ARCHITECTURE CONTROLLER } \\
\text { STANDARDS }\end{array}$ & 96 & 97 & 98 & 99 & 00 \\
\hline $\begin{array}{l}\text { Evaluate open-architecture controller interfaces for a variety } \\
\text { of Intelligent system applications }\end{array}$ & & & & & \\
\hline $\begin{array}{l}\text { Develop performance measures for open-architecture } \\
\text { controller interface standards }\end{array}$ & & & & & \\
\hline $\begin{array}{l}\text { Introduce adaptive and learning systems into open- } \\
\text { architecture controllers }\end{array}$ & & & & & \\
\hline $\begin{array}{l}\text { Open architecture controller standards adopted by national } \\
\text { and international standards organizations }\end{array}$ & & & & & \\
\hline
\end{tabular}


Staff: (2.3 staff years) *MARTIN HERMAN, *Tsai-Hong Hong, *Marilyn Nashman, *William Rippey, *Sandor Szabo

Objective and MEL. Thrust(s) Supported: To demonstrate an integrated coordinate metrology system that uses multiple advanced sensors to obtain a two orders of magnitude increase in coordinate measurement throughput. The integrated system will use an enhanced open architecture controller to control the inspection process on a coordinate measuring machine. Manufacturing Metrology, Intelligent Machines and Systems

Need(s) Addressed: Manufacturers in the automotive and aerospace industries need fast, efficient, accurate, and flexible methods for measuring the geometry of mechanical parts, particularly complex parts (e.g., transmission housings, air foils, turbine blades, engine valve bodies and seats, dies, and molds). Such a capability will provide the ability to tie metrology into process control. Benefits will include increased productivity, increased manufacturer throughput, reduced inventories required, and accelerated time-to-market. It will allow U.S. manufacturers to respond quickly to the identification of new markets and meet new market demands before foreign competitors do.

Technical Approach: NIST is developing sensor processing and control technologies that will allow coordinate measuring machines to be used much more efficiently than with touch trigger probes. The speed and density of data acquisition can be greatly increased with the use of advanced sensors, such as optical, analog touch, and analog capacitance probes. However, such sensors cannot be used without the appropriate controllers to position them at appropriate points and scan them over surfaces. NIST is incorporating a public domain open architecture controller which will allow users and equipment manufacturers to interface new sensors and devices, to modify, the controls to improve performance, and to add new features in response to changing requirements or new technologies.

NIST is a member of the National Center for Manufacturing Sciences (NCMS) Next Generation Inspection System (NGIS) consortium, and has been doing work in concert with the consortium. The goal is to make NIST work on NGIS relevant to the consortium and to effect technology transfer.

\section{FY95 Accomplishments:}

- Integrated a PC into the testbed together with the Sensor Interface Modules (SIMs) from SAMI and Extrude Hone. Demonstrated sensor-servoed surface scanning using the Extrude Hone capacitance probe and its SIM. Implemented the task level of the NIST open architecture controller, which coordinates vision and arm/probe tasks.

- Implemented and integrated a vision hierarchy into the controller, including interfaces to arm controller and world model. Implemented vision algorithms for part segmentation, for probe segmentation, for probe tracking, and for calibrating distance of probe to goal.

- Demonstrated integration of vision with touch for servoing the speed of the probe ... as the probe approaches the edge of the part, it is slowed down to a stop using visual servoing.

- Engaged in considerable interactions with the NCMS NGIS consortium members. Generated project plans, statements of work, and project justifications for a 3-year NGIS Phase 2 effort. Published the following report: Nashman, M., Rippey, W., Hong, T.-H. and Herman, M. "An Integrated Vision Touch-Probe System for Dimensional Inspection Tasks." NISTIR 5678, June 1995.

\section{FY96 Plans:}

- Adapt NIST Enhanced Machine Controller (EMC) for in-process control of inspection on machine tools. Initial scenario will involve using MIDAS probe to measure points on fixture and on part 
surfaces to determine cutting offsets due to spindle growth and tool wear.

- Complete the work with Wizdom Controls involving integrating PC-Probes (a servo level probe control module in the NIST open architecture controller) with Paradym-31 (a Wizdom controller product).

- Complete integration of EMC communications software package into NGIS controller. Integrate EMC timing synchronization software. Modify NGIS controller to conform to EMC Application Programming Interfaces.

- Integrate sensor interface modules (SIMs) from Automated Precision, Inc. and Sensor Adaptive Machines, Inc. for their probes, and demonstrate sensor-servoed surface scanning with them.

- Enhance basic features of the NGIS controller: guarded move, true surface scanning with PID control, determining coordinate system origin.

- Integrate the Automated Precision, Inc. two degree-of-freedom wrist and demo.

- Investigate use of a CAD system to generate probe scanning paths.

- Integrate new vision world model system, which handles predictions and timing differences between vision and arm control. Improve image segmentation capability. Implement camera-to-machine calibration. Improve robustness of probe recognition and tracking.

- Implement user interface for user input of probe goal positions and probe locations on 2-D camera image displayed on the monitor.

- Develop and demo capability for raster scanning over a surface using vision and for inspecting a bore hole using vision.

Five-Year Plan Goals vs. Fiscal Years:

\begin{tabular}{|c|c|c|c|c|c|}
\hline NEXT GENERATION INSPECTION SYSTEM (NGIS) & 96 & 97 & 98 & 99 & 00 \\
\hline \multicolumn{6}{|l|}{$\begin{array}{l}\text { Adapt the NIST open architecture Enhanced Machine } \\
\text { Controller (EMC) for control of inspection tasks, both on } \\
\text { machine tools and coordinate measuring machines; } \\
\text { demonstrate the integration of vision with the NGIS probes; } \\
\text { port the NIST NGIS/EMC controller to the PC environment } \\
\text { for easier technology transfer; demonstrate sensor-servoed } \\
\text { scanning of NGIS probes over curved and complex } \\
\text { surfaces. [STRS] }\end{array}$} \\
\hline \multicolumn{6}{|l|}{$\begin{array}{l}\text { Transfer NIST technology to GM, Ford and other NCMS } \\
\text { NGIS sites [STRS] }\end{array}$} \\
\hline \multicolumn{6}{|l|}{$\begin{array}{l}\text { Work with Wizdom Controls to integrate the NGIS/EMC } \\
\text { open architecture controller into their Paradym-31 software } \\
\text { product [STRS] }\end{array}$} \\
\hline \multicolumn{6}{|l|}{$\begin{array}{l}\text { Integrate CAD-based inspection capability into the NGIS } \\
\text { system [STRS] }\end{array}$} \\
\hline \multicolumn{6}{|l|}{$\begin{array}{l}\text { Develop software for integration into factory quality control } \\
\text { systems [STRS] }\end{array}$} \\
\hline $\begin{array}{l}\text { Demonstrate construction and modification of CAD models } \\
\text { based on sensor data [STRS] }\end{array}$ & & & & & \\
\hline
\end{tabular}




\section{Title: OPERATOR INTERFACE FOR VIRTUAL AND DISTRIBUTED MANUFACTURING}

Staff: (2.7 staff years) *ERNIE KENT, *Ed Amatucci, *Dave Coomb, *Nich Dagalakis, *Joe Falco, *Elena Messina, *Tsung-Ming Tsai

Objective and MEL Thrust(s) Supported: To provide a testbed for the development and evaluation of interface standards for operator interfaces. Manufacturing Systems Integration, Virtual and Distributed Manufacturing

Need(s) Addressed: This project addresses human interface standards for control of distributed and simulated manufacturing systems as developed in a laboratory setting for the AMSANT facility. The focus is not only on remote interaction with shop-floor equipment, but also on interfaces for development, management and control of plant and operations at a variety of levels, such as shop-floor supervisor, production foreman, plant manager, production executives, facility designers, and consultants. The general problem is to collect and present the relevant information at the appropriate level of detail and in the most efficient possible format to a variety of remote decision-makers, and to allow them to interactively examine remote situations and cooperatively control the remote environment.

Technical Approach: Among the significant problems to be addressed are: what kinds of information should flow across the interface, what is the best data format for maximizing operator bandwidth, and what existing and foreseeable interface technologies can best deliver this information? We are attacking these issues through: (1) industry workshops and questionnaires to clarify user needs, (2) definition of standard interfaces between manufacturing databases and operator display systems (in consultation with other SIMA projects), (3) test and evaluation of interface technologies on testbed systems in the AMSANT, and (4) implementation of selected technologies within the AMSANT as interfaces to SIMA projects.

\section{FY95 Accomplishments:}

- The Immersadesk virtual reality environment was installed and made operational. It was interfaced to the existing gear-factory simulation, and subsequently upgraded with a Reality Engine II. A variety of problems relating to the geometry of the projection were solved. This provides a true immersive 3D display with head-tracking for a single user. The system permits real-time views of ongoing operations using information from the database of a real-time factory control system operating a simulated factory model. The data may be differently organized and presented according to the needs of viewers with differing functions.

- A parallel effort has focused on the development of low-cost, multi-user interfaces into manufacturing databases to support cooperative work, with remote access. This technology seeks to employ Internet-based communications among users and manufacturing facilities. A multi-user, real-time, interactive, shared-environment has been created which can be reached from anywhere on the Internet with PC-based equipment and standard phone lines. This virtual environment has both text-based and graphics based components.

- Studies of human factors issues in remote operator interfaces were contracted and are nearing completion of the initial findings. The joint workshop which was held in late 1994 on this subject resulted in questionnaires proceedings which have now been published as NISTRs.

FY96 Plans:

- Study problems of interfacing Deneb-based factory simulation to Immersadesk. If feasible, use this technology to interface SIMA factory simulations. 
- Interface Immersadesk to Hexapod machine tool simulation using TGRIP.

- Develop Internet and WWW-based interfaces to Hexapod machine tool, permitting interactive, multi-user control and feedback with low-cost, PC-based equipment.

- Based on experiences with above, develop initial strawman proposal for standard protocols and formats for information interchange between databases/devices, and operator interface systems.

- Track relevant technology and extend and maintain operator interface testbed in AMSANT accordingly.

Five-Year Plan Goals vs. Fiscal Years:

\begin{tabular}{|l|l|l|l|l|l||}
\hline $\begin{array}{l}\text { OPERATOR INTERFACE FOR VIRTUAL AND } \\
\text { DISTRIBUTED MANUFACTURING }\end{array}$ & 96 & 97 & 98 & 99 & 00 \\
\hline $\begin{array}{l}\text { Install Immersadesk operator Interface for remote Hexapod } \\
\text { [STRS] }\end{array}$ & & & & & \\
\hline $\begin{array}{l}\text { Install Internet-environment operator Interface for remote } \\
\text { Hexapod [STRS] }\end{array}$ & & & & & \\
\hline Install Operator Interface to EMC [STRSj & & & & & \\
\hline Develop Operator Interface Standards [STRS] & & & \\
\hline
\end{tabular}


Staff: (3.2 staff years) HARRY SCOTT, *John Horst, Hui-Min Huang, ${ }^{*}$ Tom Kramer, *Alex Meystel, *Elena Messina, John Michaloski, *Will Shackleford

Objective and MEL Thrust(s) Supported: To develop a detailed design of a reference model architecture to support interface standards for intelligent control of manufacturing processes. To demonstrate, validate and evaluate the NIST reference model architecture through analysis and performance measurements of a simulated and prototype implementation. To provide U.S. industry with state-of-the-art manufacturing architectures and models, foster the development and implementation of advanced manufacturing systems, and anticipate and address the needs of U.S. manufacturing industry for the next generation of advanced manufacturing systems and standards. Manufacturing Systems Integration, Intelligent Machines and Systems

Need(s) Addressed: The lack of a formal, consistent control architecture with a factory-wide scope is evidenced by characteristics of current implementations and their shortcomings. These include implementation of islands of automation exhibiting a low level of integration because of the absence of a common system architecture design model, functionality limited by the inability to integrate the components of multiple developers as the result of proprietary or non-standard interfaces, minimal reusable software components leading to higher cost, arbitrary differences in implementation techniques because a common model is not followed, and a lack of common development tools because of the differences among various architectural approaches. The development of the reference model architecture for intelligent control of manufacturing systems will directly address these needs. A common architecture will promote a higher level of integration and the standardization of subsystem interfaces. Further, since the architecture will no longer be a "moving target," the potential for software reuse is greater, as is the likelihood of creation of development tools that are useful across many applications. The results are cost savings in development and implementation of intelligent control systems for manufacturing.

Technical Approach: Earlier work has shown the feasibility of accomplishing the goal of a single reference model architecture for the intelligent control of complex manufacturing systems. The approach used in achieving this goal is to understand the current and future needs of the manufacturing community and address these in the architecture. The initial version of the architecture reflects RCS, MSI and QIA concepts, and leverages the work of industry/government programs such as NGIS and TEAM/EMC. Validation and evaluation of the architecture is accomplished through a prototype implementation. In FY95, the NGIS facility was chosen as the first implementation testbed for evaluation. This first implementation will directly apply EMC developments in APIs from the General Motors effort, include inspection functionality developed under NGIS and use visualization methods developed under the HPCC Operator Interface project. To facilitate use of such a reference architecture, project staff are working with tool vendors to enhance development tools for implementations under the architecture. A primary goal of the project is specification of interfaces between architectural modules suitable for standardization.

\section{FY95 Accomplishments:}

- Produced draft design of Reference Model Architecture incorporating architectural concepts of RCS, MSI and QIA.

- Developed and documented operational scenario for first implementation and held design review on the task frame conceptual design.

- Designed hardware/software computing infrastructure for first Reference Model Architecture based system for the Next Generation Inspection System (NGIS) testbed.

- Published three papers: (1) H. Huang, "Outline of a Multiple Dimensional Reference Model Architecture and a Knowledge Engineering Methodology for Intelligent System Control," NISTIR 5643, (2) Huang, H., Michaloski, J., Tarnoff, N., and Nashman, M., “An Open Architecture Based 
Framework for Automation and Intelligent System Control" and (3) J. Albus, A. Meystel, “A Reference Model Architecture for Design and Implementation of Semiotic Control in Large and Complex Systems."

\section{FY96 Plans:}

- Complete design and implementation of generic control shell module.

- Define and implement APIs based on TEAM, EMC and MSI messaging.

- Develop operator interfaces, integrating HPCC OI and EMC components.

- Implement and demonstrate first reference model architecture based control in NGIS.

- Develop Phase 2 scenario, including advanced planning, machining and resource handling/management.

- Develop specifications for standard interfaces to planners, plan simulators, and evaluators and schedulers.

- Develop and integrate feature-based machining/inspection concepts in architecture.

- Implement and demonstrate reference model architecture-based control system performing Phase 2 scenario.

Five-Year Plan Goals vs. Fiscal Years:

\begin{tabular}{|c|c|c|c|c|c|}
\hline $\begin{array}{l}\text { REFERENCE MODEL ARCHITECTURE/JOINT } \\
\text { ARCHITECTURE }\end{array}$ & 96 & 97 & 98 & 99 & 00 \\
\hline $\begin{array}{l}\text { Implement and demonstrate first Reference Model } \\
\text { Architecture based control in NGIS [STRS] }\end{array}$ & 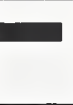 & & & & \\
\hline $\begin{array}{l}\text { Document initial Reference Model Architecture } \\
\text { implementation [STRS] }\end{array}$ & 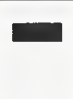 & & & & \\
\hline $\begin{array}{l}\text { Integrate advanced planning, resource } \\
\text { management/handling and feature-based inspection } \\
\text { capabilities and demonstrate in NGIS testbed (Phase 2) } \\
\text { [STRS] }\end{array}$ & & $\mathbf{a}$ & & & \\
\hline Document Phase 2 developments [STRS] & & 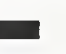 & & & \\
\hline $\begin{array}{l}\text { Evaluate performance and flexibility of Reference Model } \\
\text { Architecture in Hexapod implementation [STRS] }\end{array}$ & & & & & \\
\hline $\begin{array}{l}\text { Evaluate Reference Model Architecture performance in } \\
\text { advanced, sensor-rich environments through integration of } \\
\text { NGIS testbed vision system [STRS] }\end{array}$ & & & & & \\
\hline $\begin{array}{l}\text { Evaluate Hexapod and NGIS implementations and prepare } \\
\text { specifications recommended for standardization via IMES } \\
\text { [STRS] }\end{array}$ & & & $\mathbf{n}$ & & \\
\hline $\begin{array}{l}\text { Document Hexapod and NGIS developments and update } \\
\text { interfaces to recommended standard forms [STRS] }\end{array}$ & & & & & \\
\hline $\begin{array}{l}\text { Develop and demonstrate remote/virtual manufacturing } \\
\text { elements under reference model architecture based control } \\
\text { [STRS] }\end{array}$ & & & & & \\
\hline
\end{tabular}




\begin{tabular}{|l|l|l|l|l|l|}
\hline $\begin{array}{l}\text { REFERENCE MODEL ARCHITECTURE/JOINT } \\
\text { ARCHITECTURE }\end{array}$ & 96 & 97 & 98 & 99 & 00 \\
\hline $\begin{array}{l}\text { Document development of CASE capabilities designed to } \\
\text { facilitate implementation of Reference Model Architecture } \\
\text { based systems [STRS] }\end{array}$ & & & & & \\
\hline $\begin{array}{l}\text { Document experiments in integration of remote/virtual } \\
\text { manufacturing elements under Reference Model } \\
\text { Architecture based control [STRS] }\end{array}$ & & & & & \\
\hline $\begin{array}{l}\text { Apply reference model architecture to domains of } \\
\text { manufacturing other than discrete part, including welding, } \\
\text { mobility and construction; evaluate interfaces and develop } \\
\text { API specifications [STRS] }\end{array}$ & & & & & \\
\hline $\begin{array}{l}\text { Persue standardization of reference model architecture } \\
\text { [STRS] }\end{array}$ & & & & & \\
\hline
\end{tabular}




\section{TITLE: ROBOCRANE®: AN INTEGRATION TESTBED FOR LARGE-SCALE MANUFACTURING AND CONSTRUCTION AUTOMATION}

Staff: (3.6 staff years) R. BOSTELMAN, A. Jacoff, *R. Norcross, ${ }^{*}$ K. Goodwin, ${ }^{*}$ E. Amatucci, ${ }^{*}$ C. Giauque, *W. Wallace, *T. Tsai, *J. Marcinkowski, *B. Weiss, *J. Hanson

Objective and MEL Thrust(s) Supported: To test and validate interface standards for open-systems architectures for intelligent machines and systems. Intelligent Machines and Systems, Manufacturing Processes and Equipment

Need(s) Addressed: Industry needs open-system architecture interface standards for sensor-interactive intelligent machine systems used in large-scale manufacturing and construction. Without interface standards, it is difficult to integrate subsystems into intelligent machine systems, or to expand capabilities by adding components. These difficulties lead to limited system functionality, long development times, and high cost. The need is for standard interfaces for commercially available "plug-and-play" components.

With open system architectures, functional control modules will enable Robocrane® systems to:

- manipulate large heavy objects precisely so as to permit rapid semiautomated assembly of large structures,

- manipulate tools precisely so as to perform machining and finishing operations on large structures,

- detect obstacles and avoid collisions in complex dynamic environments, and

- operate safely and reliably in unstructured environments despite perturbations such as sway and oscillations induced by load accelerations or by wind and wave action.

The adoption of open-system architecture standards for large-scale manufacturing and construction operations will lead to more efficient systems for users, greater market opportunities for equipment manufacturers, and lower costs due to greater competition between suppliers. Interface standards will mean easier, faster, and more robust integration of subsystems, less expensive customizing of intelligent machine systems used in multiple applications, and lower costs for spare parts and system up-grades. Emerging markets for large-scale intelligent machines include manufacture of aircraft, ships, and railroad rolling stock; construction and maintenance of buildings, highways, and bridges; environmental clean-up of radioactive or toxic waste sites; and undersea mining, construction, repair, and salvage operations.

Technical Approach: A RoboCrane testbed is being constructed with six degrees-of-freedom control of a work platform suspended by cables driven by winches under computer control. This testbed will be controlled by a PC-based Enhanced Machine Controller (EMC) incorporating a Real-Time Control System (RCS) reference model open-system architecture with standard interfaces between functional modules for servo control, trajectory generation, constrained motion modes, discrete event logic, task sequencing, and an operator interface that incorporates the following elements: joystick control, a graphics programming environment, and a telepresence vision system with virtual reality displays that facilitate remote control by human operators.

A variety of sensors and control methodologies will be tested, and proposed standards for databases and interfaces will be evaluated. NIST will work closely with crane manufacturers and potential users to transfer early versions of this technology into practical applications such as construction of highway bridges, radioactive waste clean-up and undersea salvage operations.

\section{FY95 Accomplishments:}

- A six-meter RoboCrane testbed has been constructed with the ability to precisely manipulate bridge elements, cast iron pipes, steel beams, fifty-five gallon drums, and to perform precise mating and joining operations. Power tools such as grinders and saws have also been manipulated. 
- One and two-operator six-axis joystick interfaces have been implemented.

- A commercial IGRIP graphics programming system has been installed and a LabView development and diagnostic display has been incorporated into the operator interface.

\section{FY96 Plans}

- An EMC controller with a CANbus sensor/effector interface is being installed as part of the opensystem architecture standards adoption.

- A vision system is being designed to provide the operator with full control capability from a remote location.

- A foveal-peripheral camera system is to be maneuvered by mimicking operator head motion allowing a more natural and semiautomatic camera positioning system. Virtual reality and graphic overlays will give the operator the ability to visualize information available from CAD databases and other sources such as a site metrology system, and to overlay such information on live TV images of the real work environment.

Five-Year Plan Goals vs. Fiscal Years:

\begin{tabular}{|l|l|l|l|l|l||}
\hline $\begin{array}{l}\text { ROBOCRANEQ: AN INTEGRATION TESTBED FOR } \\
\text { LARGE-SCALE MANUFACTURING AND } \\
\text { CONSTRUCTION AUTOMATION }\end{array}$ & 96 & 97 & 99 & 99 & 00 \\
\hline $\begin{array}{l}\text { Install standard interfaces for sensors and actuators. Build } \\
\text { camera positioning system. Develop open-architecture } \\
\text { interfaces for off-line programming system and operator } \\
\text { interface. Develop open-architecture interfaces for welding } \\
\text { equipment [STRS] }\end{array}$ & & & & & \\
\hline $\begin{array}{l}\text { Evaluate open-architecture controller interfaces for a variety } \\
\text { of Robocrane applications [STRS] }\end{array}$ & & & & & \\
\hline $\begin{array}{l}\text { Develop performance measures for intelligent system } \\
\text { interface standards in uncertain environments [STRS] }\end{array}$ & & & & & \\
\hline $\begin{array}{l}\text { Develop methods for introducing adaptive and learning } \\
\text { systems into open-architecture interface standards [STRS] }\end{array}$ & & & & & \\
\hline $\begin{array}{l}\text { Intelligent Systems interface standards adopted by national } \\
\text { standards organization [STRS] }\end{array}$ & & & & & \\
\hline
\end{tabular}


Staff: $(0.4$ staff years $) *$ ELENA MESSINA, ${ }^{*}$ David Coombs, ${ }^{*}$ Tom Kramer, ${ }^{*}$ John Michaloski, ${ }^{*}$ Fred Proctor, ${ }^{*}$ Will Shackleford, *Keith Stouffer, ${ }^{*}$ Tsung-Ming Tsai

Objective and MEL Thrust(s) Supported: To characterize and improve the software development process for open-architecture standards testbeds within the Intelligent Systems Division. Intelligent Machines and Systems; Manufacturing Systems Integration

Need(s) Addressed: The researchers within the Intelligent Systems Division develop many complex, software-based systems. Given the software-intensive nature of the division's work, it is critical that the overall process be as efficient and effective as possible. This project examines the current practices and requirements and produces recommendations regarding how to make improvements. The goal is to improve the productivity of software-dependent activities and thereby make more efficient use of resources.

Since so much of the efforts within the division are targeted towards public domain open systems interface standards and component-based software, this project also addresses the needs of these new paradigms. It is important to develop a process for specifying standardizable interfaces and for developing software in a such a way to be able to apply metrics to component-based open systems. Several efforts within the Intelligent Systems Division which reach outside of NIST, such as TEAM and EMC are the ultimate beneficiaries of this project.

Technical Approach: A team representing the diverse facets of software development within the division has been assembled. The group systematically examines the many aspects involved in software development to gain understanding of candidate areas for improvements. The comprehensive examination includes the overall development life-cycle paradigm, software methodologies, tools, reuse, documentation, and implementation issues, such as platform portability. Practices at other research organizations are studied for comparison. A taxonomy of project categories are being developed to guide the process models recommended. The findings are being summarized in a report to be reviewed by the division at large. A pilot project will be selected which will implement the recommendations. The Software Development Process Project Team will work closely with the pilot project team to guide them, see how the ideas are deployed, and incorporate the experiences of the experimental project into the recommendations document.

\section{FY95 Accomplishments:}

- Examined the major aspects of software development within ISD including overall process models, methodologies, implementation issues (such as directory structures, build procedures, multi-platform development), tools and utilities (such as debuggers, CASE, and GUI-builders), real-time software development issues, reuse, implications of RCS methodology and component-based technology on ISD projects, and documentation

- Examined software development environments at other organizations, such as Sandia National Labs and a commercial CAD/CAM/CAE developer.

- Examined alternative concepts for software process models, tools, utilities, and implementation infrastructure.

- Defined the major categories of software projects which are typically undertaken.

\section{FY96 Plans:}

- Begin interaction with MSID to exchange ideas and experiences.

- Define process model recommendations for each category.

- Document findings from above items. 
- Define criteria for desired pilot project.

- Present proposals to ISD management, select candidate project.

- Collaborate with pilot project team members to implement recommendations and learn from their experiences, including purchase of Software Design and/or GUI-builder tool, if appropriate.

- Generate updated software development guidelines for division.

Related Developments: An ATP intramural project was recently awarded within ISD to develop a functional specification for Intelligent Control system software components. This work will look closely at issues related to the overall software development process: for example, how interfaces for components can be specified, how these components can be utilized within a graphical tool which builds real-time control systems, and, ultimately, how software components can evolve to become utilities that can be "plugged into" another system. The ATP project can cross-pollinate with the Software Development Process project.

\section{Five-Year Plan Goals vs. Fiscal Years:}

\begin{tabular}{|c|c|c|c|c|c|}
\hline SOFTWARE DEVELOPMENT PROCESS & 96 & 97 & 98 & 99 & 00 \\
\hline $\begin{array}{l}\text { Determine areas on which to focus studies and } \\
\text { recommendations; Carry out studies and develop } \\
\text { recommendations; Publish recommendations; select pilot } \\
\text { project; conduct evaluations [STRS] }\end{array}$ & & & & & \\
\hline $\begin{array}{l}\text { Update and publish division guidelines; disseminate new } \\
\text { practices on selected projects; using continual improvemen } \\
\text { model, continue to refine and update guidelines. Address } \\
\text { more in-depth component-based development systems } \\
\text { [STRS with potential ATP funding] }\end{array}$ & & & & & \\
\hline $\begin{array}{l}\text { Participate in defining software specification standards for } \\
\text { component-based real-time systems, including compliance } \\
\text { metrics [STRS, potential ATP or OA] }\end{array}$ & & & & & \\
\hline $\begin{array}{l}\text { Interact with industry and other government agencies to } \\
\text { promote proposed specification standards and conduct } \\
\text { experiments on implementation and metrics [STRS with } \\
\text { potential ATP or OA funding] }\end{array}$ & & & & & \\
\hline
\end{tabular}




\section{MANUFACTURING SYSTEMS \\ INTEGRATION DIVISION}

\section{MISSION:}

Provide a focus for national research and development of the infrastructural technologies and standards required for the implementation of virtual enterprises in a manufacturing environment. 


\section{Title: APPAREL INFORMATION TECHNOLOGIES}

\section{Staff: (1.5 staff years) *JEANE FORD, Howard Moncarz, Tina Lee, *Mike Read, *Craig Pawlak}

Objective and MEL Thrust(s) Supported: This project consists of two main tasks. For Task 1, the objective is to develop a formal specification of the enterprise model (including activity and information models) for the requirements-determination phase of the custom therapeutic footwear (CTF) manufacturing life cycle. For Task 2, the objective is to develop a comprehensive data exchange specification for the design and manufacture of garments, combining best practices for both military and commercial requirements. Manufacturing Systems Integration.

Need(s) Addressed: The technologies necessary to automate the manufacture of CTF are imminent, but the effective integration of those technologies, to achieve the maximum benefit from them, remains a major bottleneck for the industry. The key interoperability standards needed at present are those that will support the requirements-determination phase of the CTF manufacturing life cycle, in particular, the foot measurement requirements. A standard for those requirements will also benefit the mainstream custom footwear industry. Assisting the industry to integrate with the developing national information infrastructure can help the industry regain market share in the $\$ 32$ billion-a-year domestic market, as well as help an estimated $10,000,000$ Americans who could benefit from affordable CTF.

Garment product specifications are an important means of communication of product information. Existing Military Standards and Military Specifications for the design and manufacturing of military apparel include an ambiguous product techncal data and unrelated information/data. This creates ambiguity and confusion to apparel bidders and manufacturers. Industry's specification sheets vary in detail and specificity; inadequate specifications are the source of many problems.

Technical Approach: For the first task, NIST will transition the CTF project to be industry driven and supported by presenting the work done on the project to upcoming industry conferences. With its footwear industry partners, NIST will develop a manufacturing exchange specification to support a standards development effort. Specifically, NIST will develop documents for the requirements determination phase of the CTF life cycle, with particular focus on the foot-measurement requirements. Based on the information gathered from CTF-related references, discussions with industry leaders, and product literature and demonstrations (of CTF manufacturing technologies), NIST will develop an activity model for the requirements-determination phase, document the information requirements, assess the status of relevant standards, and participate in an industry standards committee.

For the second task, NIST will develop the information model/prototype specification for the product specification for garment design and manufacturing. The initial activity for this project is to perform the survey of several industry specificaton sheets and military specifications of apparel for identifying the industry need, manufacturing scenario, and/or problem statement. A collection of data describing style's features and construction features will be gathered and analyzed for identifying the commonalties and differences among organizations' requirements. A set of data requirements for representing garment features and construction features will be developed upon the completion of the data analysis. An information model or the prototype spcification will then be developed based on the data requirements. Prototype testing of the specification will be performed at the Defense Personnel Support Center or at a selected company. It is expected the prototype specification to be promoted to the ANSI standard status. 
FY95 Accomplishments:

Task 1:

- Determined the industry technology needs and priorities, and received industry endorsement of the CTF project (documented in the report, "Program Requirements to Advance the Technology of Custom Footwear Manufacturing").

- Created a "top-level" enterprise model and vision for the CTF industry. Included was an example of a manufacturing scenario utilizing the new CTF manufacturing technologies (documented in the paper, "Information Technologies Make Business Sense for the Custom Therapeutic Footwear Industry").

- Catalyzed the initiation of an industry activity for establishing a committee to develop interoperability standards and to secure support for creating a CTF pilot project.

FY96 Plans:

Task 1:

- Transition the NIST CTF project to be industry driven and supported.

- Specify the CTF activity and information requirements and the status of standards to address those for the CTF manufacturing phase that involve requirements specification.

- Create a formal specification of the CTF enterprise model.

Task 2:

- Examine the content of garment product specifications. The FY96 work is to perform the survey of several industry specification sheets and military specifications of apparel for identifying the industry need, manufacturing scenario, and/or problem statement. The analysis of specifications will be concentrate on the areas of style's features and construction features. On completion of this task, a collection of data that are used for describing style's features and construction features will be gathered for further analysis.

Related Developments: The Defense Logistics Agency (DLA) launched a 7-year research and development program, Apparel Research Network (ARN), to support the apparel industry in FY95. The goal of the ARN program is to get the uniform on the customer at the right time, right place, right cost, and right fit. NIST has been participating in the performance of ARN. It is expected this project to be leveraged with the ARN Program.

Five-Year Plan Goals vs. Fiscal Years:

\begin{tabular}{|l|l|l|l|l|l||}
\hline APPAREL INFORMATION TECHNOLOGIES & 98 & 97 & 98 & 99 & 00 \\
\hline $\begin{array}{l}\text { Transition the NIST CTF project to industry driven and } \\
\text { supported [STRS] }\end{array}$ & & & & & \\
\hline $\begin{array}{l}\text { Specify the CTF activity and information requirements for } \\
\text { the CTF requirements-determination phase [STRS] }\end{array}$ & & & & & \\
\hline $\begin{array}{l}\text { Create formal specification of the CTF enterprise model } \\
\text { [STRS] }\end{array}$ & & & & & \\
\hline
\end{tabular}




\begin{tabular}{|c|c|c|c|c|c|}
\hline APPAREL INFORMATION TECHNOLOGIES & 96 & 97 & 98 & 98 & 00 \\
\hline $\begin{array}{l}\text { Analyze the content of apparel product specifications } \\
\text { [STRS] }\end{array}$ & E & & & & \\
\hline Determine apparel data requirements [STRS] & & 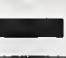 & & & \\
\hline Develop prototype specification for apparel [STRS] & & & $\mathbf{E}$ & & \\
\hline Implement prototype specification for apparel [DLA, STRS] & & & & 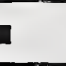 & \\
\hline $\begin{array}{l}\text { Promote the apparel prototype specification to ANSI } \\
\text { standard status [STRS] }\end{array}$ & & & & & \\
\hline
\end{tabular}




\section{Title: APPLICATION PROTOCOL DEVELOPMENT ENVIRONMENT (APDE)}

\section{Staff: (2.5 staff years) Josh Lubell, *MARY MITCHELL, Lisa Phillips, *Donovan Chase}

Objective and MEL Thrust(s) Supported: To accelerate the development of STEP and to aid Application Protocol (AP) developers in creating AP specifications more efficiently, with higher quality and at a lower cost. Manufacturing Systems Integration.

Need(s) Addressed: Current practices for AP development require extraordinary labor expenditures on behalf of developers to define the requirements and document the required technical elements. Our initial customers are defining data exchange standards that meet an industrial need within a U.S. and international standards organizations. However, efficient use of limited technical resources is not being made because the set of tools at their disposal requires many manual and error-prone operations. Further, their distributed work teams complicate the configuration management of these complex technical specifications.

Technical Approach: An integrated suite of software tools will be established to assist STEP AP development. These software tools will use an information registry at NIST consisting of STEP and STEPrelated documents and data. Documents are represented in the Standard Generalized Mark-up Language (SGML) to enable "intelligent" access to any aspect of STEP documents and better transferability among differing computer platforms. The AP development process includes defining information requirements, modeling that information, verifying that the information models are correct, identifying how these requirements are satisfied by STEP core concepts, developing test criteria for implementations, and documenting all components in a mandated format. An integrated toolset will be provided to support each of these process steps.

Industrial partners and specific standards projects have supplied requirements and reviewed the design. A close interaction exists with PDES, Inc., a consortium that is creating APs and accelerating the implementation of them, and several STEP AP projects. These include: AP223 led by Concurrent Technologies Corporation (CTC), AP210 led by PDES, Inc., and AP214 led by the ProSTEP Association in Germany. The Air Force PAS-C project, developers of AP209 and the Technical Data Package, is also involved. Collaborations with various software suppliers will be established to transfer our results to commercial products. Interactions with the following vendors are underway: SoftQuad (SGML Tools), and STEP Tools Inc. and PDIT (STEP Tools).

The initial phase of the project emphasized requirements analysis, specifying services to existing APDE tools, evaluating the commercial tools, and establishing core elements of SGML environment, including Document Type Definitions for STEP. This phase will provide an implementation of remote services, populate the AP information bases, complete the SGML environment, and deploy an initial environment to beta AP teams. The last phase will focus on completing the APDE, provide an integrated environment for all of the tools, support for a full scale deployment of the tools, and identification of maintenance organization (commercialization). The long term APDE strategy is to maintain a STEP information repository which fits well with our existing responsibilities as SC4 Sectretariat.

\section{FY95 Accomplishments:}

- Customized initial SGML editor for STEP to enable production of consistent documents to be produced and to automate aspects of the documentation process.

- Established a collaboration with CTC on the development and integration of AP tools.

- Developed a Latex-to-SGML translation tool for STEP Integrated Resources. Revised the STEP Latex style files to improve consistency of some documents.

- Provided a tutorial on the benefits and use of SGML.

- Provided demonstrations at various conferences, SC4/IPO/consortia meettings.

- Developed new SGML DTDs for STEP, incorporating the use of public identifiers and more 
intuitive element names to improve portability and ease of use.

- Conducted user requirements workshops and surveys to prioritize needs.

- Converted three STEP Integrated Resource (IR) and one AP document to SGML.

- Developed a SGML DTD for APs approved by ISO SC4 editing committee to guide the development of STEP APs.

- Published SGML environment paper in SGML '94 proceedings.

- Implemented initial Remote Access Services to the APDE.

- Built an SGML database of STEP IR documents using Open Text's text retrieval engine and integrated this into the demonstration system.

- Developed initial SGML-to-LaTeX publishing tool to SGML authored documents.

\section{FY96 Plans:}

- Populate the AP information base with remaining approved STEP parts.

- Implement a World Wide Web gateway to the APIB to permit browsing and searching of STEP IR and AP documents.

- Released refined SGML-to-LaTeX publishing tool for production copies.

- Publish technical reports describing the APIB architecture, the World Wide Web gateway, and the SGML DTDS for STEP.

- Conduct alpha testing of APDE components with one or two AP teams.

- Develop STEP-customized editor which complements autogeneration tools developed by CTC.

- Improve STEP DTDs to address user feedback, increase ease of use and improve portability; port at least the SGML formatter application to a PC platform

Related Developments: Concurrent Technologies Corporation is developing additional STEP AP tools which fill voids in the current APDE environment. Also, there is plan by ISO TC184/SC4 to require new work items to be developed in SGML by 1997. ISO Central Secretariat will accept documents in SGML by then and they plan to require documents in an SGML export format.

Five-Year Plan Goals vs. Fiscal Years:

\begin{tabular}{||l|l|l|l|l|l||}
\hline \begin{tabular}{|l|l||} 
APPLICATION PROTOCOL DEVELOPMENT \\
ENVIRONMENT (APDE)
\end{tabular} & 96 & 97 & 98 & 98 & 00 \\
\hline $\begin{array}{l}\text { Extend AP Information Base to include all initial release } \\
\text { STEP Parts, providing access via a World Wide Web } \\
\text { gateway [STRS SIMA] }\end{array}$ & & & & & \\
\hline $\begin{array}{l}\text { Provide a complete editing/publishing environment for } \\
\text { developing STEP AP documents in SGML, including the } \\
\text { development of a STEP-customized editor, an SGML } \\
\text { printing application and continued maintenance and } \\
\text { improvements to STEP DTDs [STRS SIMA] }\end{array}$ & & & & & \\
\hline $\begin{array}{l}\text { Expand APDE capabilities and services to provide a } \\
\text { completely integrated, fully supported environment which } \\
\text { facilitates or supports all phases of AP development [STRS } \\
\text { SIMA] }\end{array}$ & & & & & \\
\hline $\begin{array}{l}\text { Extend APDE to support other standards, including support } \\
\text { for exchange with other ISO standards and for MIPS } \\
\text { development [STRS SIMA] }\end{array}$ & & & & & \\
\hline
\end{tabular}




\begin{tabular}{|c|c|c|c|c|c|}
\hline $\begin{array}{l}\text { APPLICATION PROTOCOL DEVELOPMENT } \\
\text { ENVIRONMENT (APDE) }\end{array}$ & 96 & 97 & 98 & 99 & 00 \\
\hline $\begin{array}{l}\text { Provide configuration management and workflow } \\
\text { capabilities to support a multi-user development } \\
\text { environment [STRS SIMA] }\end{array}$ & & & & & \\
\hline $\begin{array}{l}\text { Find vendors willing and able to take over maintenance and } \\
\text { support of the APDE [STRS SIMA] }\end{array}$ & & & $\square$ & & \\
\hline
\end{tabular}




\section{Title: APs FOR DOD AND INDUSTRY}

\section{Staff: $(0.8$ staff years $) *$ S. JEANE FORD, ${ }^{*}$ Jesse Crusey}

Objective and MEL Thrust(s) Supported: With a goal to address both industry and government priorities and benefits, the effort is focused on the development of a suite of STEP Application Protocols (APs) for Digital Technical Product Data Packages that could provide an international standardized exchange format for specifying procurement and exchange of design data necessary to manufacture, reprocure, repair, or modify a product throughout the life cycle of that product. 'Manufacturing Systems Integration

Need(s) Addressed: The target customer group for this project includes both government agencies and commercial enterprises ranging from large corporations to small suppliers. Currently DoD, other agencies and industry receive and archive technical data for products and systems in varying forms, e.g., drawings, computer models, databases, and microfilm. Vast amounts of technical data are controlled by numerous differing standards. Separate standards are used by Government agencies and within the commercial arena. Lengthy cycle times, data integrity and redundancy issues, non-value added operations and high costs characterize the many processes which are involved in managing technical product data packages. The community of thousands of large corporations, Government facilities and small companies must establish a national and global infrastructure to process and manage electronic product data among business partners. The challenge is to address the specific requirements of each sector and to respond with new ways of doing business, cost-effective/affordable systems and the establishment of common industry/Government standards and specifications.

Technical Approach: International commercial industries and Government consider STEP a key enabling technology to accomplish the transition from hard copy-based data to a digital form of technical information for a product. A STEP Application Protocol (AP) provides standardized sets of information applicable to the exchange of data required to support a specific application use of the data. This project will develop a suite of STEP APs to enable the exchange and use of technical product descriptions for supporting acquisition, production, engineering and product support and will fully adhere to methodologies and guidelines set forth by ISO/TC184/SC4 for the development of the standardized delivery format. The data addressed by this effort collectively defines the design configuration and procedures required to ensure adequacy of product performance. It consists of all application technical data, such as drawings, parts lists, specifications, standards, operational parameters, quality assurance provision and packaging details. The scope supports the common core set of requirements shared by the users of Industry Product Data Packages and DoD Technical Data Packages. This core set of requirements is derived from high demand informational elements within specific life cycle functions and commodity sectors identified through workshops with Government and industry. This effort uses workshops, Industrial Review Boards, and ISO and IGES/PDES Organization forums to monitor and provide input for identifying the required set of common data elements for reuse throughout the life cycle of the product. An Industry Review Board including representation from DoD services, Air Logistics Centers, Federal Aviation Administration, aerospace and automotive corporations, vendors and small suppliers is a major partner. While the focus is currently driven primarily by the mechanical products industries; continuous efforts are underway to harmonize with the construction, process, and electrical/electronic industries models and protocols.

\section{FY95 Accomplishments:}

- Received broad support and technical input from Application Experts (AE) Workshop and the Industry Review Board. The incorporation of end-user requirements and the consensus between industry and Government interest gained during these meeting is essential to smooth deployment.

- Enhanced coordination with national and international STEP projects. Technical data exchange protocols must be integrated with other Application Protocols. The TDP team is a major player in both defining and achieving STEP interoperability. 
- Developed and published updated Application Reference Model (ARM) to incorporate the AE and IRB requirements; completed second draft of the Group 1 Documentation reflecting ARM modifications and initiated an Issue Log and AP Validation Report. The wide distribution of these documents has allowed an international community of users to provide feedback and speed progress.

- Completed all requirements and submitted project proposal to ISO TC184 SC4 for approval as a new Work Item under Working Group 3 Project 11, i.e., Manufacturing Technology Committee. These activities are required to formalize the TDP as an ISO project expanding the number of contributors and gaining the participation of implementators.

FY96 Plans:

- Initiate validation testing of the AP; and validate and test the Requirements Management System (RMS) against the Application Interpreted Model (AIM) development tasks.

- Complete initial testing of ARM and data population of ARM with at least two test parts using DataProbe and conduct prototype testing of the AIM with DataProbe and other off-the-shelf STEP tools.

- Develop ARM-to-AIM Mapping Table; hold Integration Workshops to develop the AIM.

- Submit AP Group 1 Documentation to Qualification and Validation (Q\&V) for Committee Draft for Comment (CDC) review and release approval and submit AP to Q\&V for review for approval for Committee Draft Ballot release.

Related Developments: NIST, the Air Force ManTech PAS-C Program and PDES, Inc. have teamed in an effort to develop and deploy a Suite of APs to enable a STEP-based Technical Data Package environment for both Government and commercial products. This team is closely aligned with the Advanced Weapons System (AWS) and F-22 Digital Product Data efforts. Liaison with the Navy JEDMICS Program, Navy RAMP and projects at the Naval Surface Warfare Center-Crane Division are in place.

Five-Year Plan Goals vs. Fiscal Years:

\begin{tabular}{|c|c|c|c|c|c|}
\hline APs FOR DOD AND INDUSTRY & 98 & 97 & 98 & 98 & 00 \\
\hline \multicolumn{6}{|l|}{$\begin{array}{l}\text { Bring core TDP application protocol to STEP international } \\
\text { standard status [DOD, INDUSTRY] }\end{array}$} \\
\hline \multicolumn{6}{|l|}{$\begin{array}{l}\text { Expand conformance classes and add capabilities to TDP } \\
\text { AP Suite, e.g., technical product data representations, } \\
\text { commodity types, product producer functions, and product } \\
\text { user support functions [DOD, STRS, INDUSTRY] }\end{array}$} \\
\hline \multicolumn{6}{|l|}{$\begin{array}{l}\text { Initiate series of pilot implementations including: aerospace, } \\
\text { automotive, Air Force Air Logistics Center, and Navy RAMP } \\
\text { facilities [DOD, INDUSTRY] }\end{array}$} \\
\hline \multicolumn{6}{|l|}{$\begin{array}{l}\text { Establish parts acquisition workcell to demonstrate and } \\
\text { development application of TDP AP in small supplier base } \\
\text { [NAVY, DOD] }\end{array}$} \\
\hline \multicolumn{6}{|l|}{$\begin{array}{l}\text { Develop link between TDP data definition exchange file } \\
\text { concept and EDI/EDIFACT technology [DOD, INDUSTRY] }\end{array}$} \\
\hline $\begin{array}{l}\text { Complete } 50 \text { percent of the TDP AP Suite as STEP } \\
\text { international standard [DOD, INDUSTRY] }\end{array}$ & & & & & \\
\hline
\end{tabular}


Staff: (3.1 staff years) CHARLES MCLEAN, Swee Leong, ${ }^{*}$ Mike Iuliano, *Frank Riddick, *Shaw Feng, *Al Jones, ${ }^{*}$ C.C. Chen, ${ }^{*}$ Mike Read

Objective and MEL Thrust(s) Supported: The overall goal of the project is to lower manufacturing costs, reduce development and delivery times, and improve product quality through the development and use of advanced manufacturing engineering tools. The project will develop an integrated tool kit which can be used to plan part production and accurately predict product quality and process performance before a job is released to the shop floor. Other project objectives include the development of a process capabilities database, a functional definition of the manufacturing engineering process, and an integrated tools architecture. Manufacturing System Integration.

Need(s) Addressed: Integrated computer-aided manufacturing engineering environments are needed by internal DoD manufacturing sites, primes and subcontractors, and non-defense commercial manufacturing facilities. Although many software tools are currently available for manufacturing engineers, they do not work together and cannot be readily integrated. This lack of integration significantly diminishes the productivity of manufacturing engineers, reduces the quality of their work, and increases the time it takes to plan the production of a part or an assembly. Examples of these tools include: producibility analysis software, process planning systems, and simulation/modeling packages. Data generated by these tools is not guaranteed to produce a correct part the first time. New integrated engineering environments (i.e., tool kits) must be developed to solve this problem. For widespread implementation, environments must be based primarily upon the integration of commercially-available engineering tools.

Integrated engineering tool kits increase the productivity of engineers performing producibility analyses, designing manufacturing systems, evaluating quality costs, and conducting design trade-off studies. A recent study indicated that improved manufacturing and industrial engineering support tools could save the Department of Defense about $\$ 300$ million per year ("Manufacturing Systems Strategic Plan," Report of the Manufacturing Systems Committee, DoD Manufacturing Science and Technology Program, March 1993). The benefits realized from this project will be applicable to defense as well as civilian manufacturing.

Technical Approach: The project will assess industry needs, with respect to manufacturing engineering tools and tool integration. It will develop architectures, interfaces, and databases for integrating engineering tools environments. Prototype integrated engineering tool kits will be constructed from commercial products. Process capability study procedures, process feature sets, database structures, and reference databases will be developed. Solutions will be validated at industry sites. The principal elements of the technical approach are: (1) identify and address critical industrial needs through collaboration, (2) develop solutions to engineering tool integration problems, (3) construct prototype environments using commercial products, (4) validate results through industrial testing of system implementations, (5) specify and promote needed industry standards, and 6) facilitate the rapid commercialization of new technology. A significant level of effort on this project is being carried out through contracts and collaborative efforts.

\section{FY95 Accomplishments:}

- Prepared technical plans for Manufacturing Engineering Tool Kit.

- Established CAME Forum and industrial collaborators for tool kit project.

- Conducted two CAME Forum industry workshops (March and August 1995)

- Procured baseline software systems (initial set) for tool kit environment.

- Procured computer workstation for manufacturing engineering tool kit.

- Established baseline (non-integrated) tool kit environment.

- Prepared architecture and technical specifications for tool kit. 
- Awarded contracts/grants for tool kit development/extensions.

- Developed initial manufacturing engineering functional model.

\section{FY96 Plans:}

- Develop virtual manufacturing demonstration.

- Integrate tool applications under product data and workflow management.

- Develop initial database integration for tooling and resource data.

- Conduct joint CAME Forum and Process Planning Workshop meeting.

- Develop process plan execution system for virtual manufacturing facility.

Related Developments: The DOD Joint Advanced Strike Technology (JAST) Program has indicated an interest in applying CAME technology to next generation strike aircraft. CAME staff are participating in the JAST Manufacturing and Producibility Program.

Five-Year Plan Goals vs. Fiscal Years:

\begin{tabular}{|l|l|l|l|l|l|}
\hline COMPUTER-AIDED MANUFACTURING ENGINEERING & 96 & 97 & 99 & 99 & 00 \\
\hline $\begin{array}{l}\text { Install additional applications, develop extensions, and } \\
\text { integrate [OA] }\end{array}$ & & & & & \\
\hline Develop initial virtual manufacturing demonstration [OA] & & & & & \\
\hline Test, demonstrate, and document tool kit environment [OA] & & & & & \\
\hline Define manufacturing engineering reference model [OA] & & & & & \\
\hline Develop integrated tools architecture [OA] & & & & & \\
\hline $\begin{array}{l}\text { Incorporate additional applications and interfaces into tool kit } \\
\text { environment [OA] }\end{array}$ & & & & & \\
\hline
\end{tabular}




\section{Title: COMPUTER-INTEGRATED MANUFACTURING FRAMEWORK}

\section{Staff: $(0.4$ staff years $){ }^{*}$ Neil Christopher, ${ }^{*}$ Steve Osella , *SELDEN STEWART, ${ }^{*}$ Evan Wallace}

Objective and MEL Thrust(s) Supported: To foster the development, standardization, and adoption by industry of an object-oriented framework for manufacturing applications. Manufacturing System Integration.

Need(s) Addressed: SEMATECH, a consortium of major U.S. semiconductor manufactures, has asked NIST to participate in its project to develop a CIM Application Framework for semiconductor manufactures by assisting in: generalizing the Framework to a broader class of manufacturing; standardizing the Framework; promoting the Framework in industry, and developing conformance test methods and test suites. The economic potential in the semiconductor industry alone is in the hundreds of millions of dollars in reduced integration costs for new fabrication facilities and shorter lead times for getting to market. Other areas of manufacturing would benefit from reuse of the framework in their own manufacturing domain. A successful framework would make U.S. industry more productive and more competitive in world markets.

Technical Approach: Based on the success of the Microelectronics Manufacturing Science and Technology (MMST) project by member-company Texas Instruments, SEMATECH initiated a project to take those results and develop an open framework for the use of manufacturing companies and their suppliers. The new framework is object-oriented and based on the Object Management Group's Common Object Request Broker Architecture (OMG/CORBA). NIST works with SEMATECH on the OMG Special Interest Group on Manufacturing (MfgSIG) to promote the Framework, and on the Common Facilities Task Force and ORB Task Force to standardize the Framework. NIST works with SEMATECH to validate and test the formal specifications, and to develop new formal methods of description and testing for the Framework. The current goal is a completely revised version 2.0 of the Framework by early 1997 with trial implementations, based on work in progress, in 1996. Conformance testing procedures are planned in the future.

\section{FY95 Accomplishments:}

- Published first annual report and recommendations. The Roadmap for Computer Integrated Manufacturing (CIM) Application was published by both SEMATECH and NIST (as NISTIR 5679) and is also available electronically on the World Wide Web.

- Held a joint workshop with industry participation.

- Tested formal, interface definition language (IDL) specifications with commercial object request broker tools.

\section{FY96 Plans:}

- Promote the CIM Framework through the Object Management Group (OMG) Business Objects Domain Task Force (BODTF) and Manufacturing Domain Task Force (MfgDTF).

- Install and demonstrate the CIM Framework reference implementation.

- Develop plan for single-source specification management (S3M) for future versions of the Framework Specification.

- Plan CIM Framework Conference to be held in FY97.

Related Developments: EEEL has equal funding from SEMATECH and STRS that is enabling them to also work on this project. Both the NAMT project in Mechanical Parts and several recent ATP/TIMA awards are closely related to or use the CIM Framework. The work of this project is greatly enhanced through these interactions. The progress of OMG in defining and adopting CORBA 2.0 is of vital importance to this project. Since the Framework is based on CORBA, its success as a standard and in supporting software products is key to the success of the SEMATECH Framework. Other consortia, most notably the National Industrial Information 
Infrastructure Protocols (NIIIP), have programs of work that are synergistic with our program. NIIIP's goal is to combine Internet, OMG, and STEP technology into a virtual enterprise. The SEMATECH Framework has been proposed as a pilot project for the second year of NIIIP.

After the Framework has been adopted as a common facility by OMG, the next step in standardization would be at the ISO level, through TC184/SC5, for example.

The agreement with SEMATECH is for a three year plan that goes to March 1997. Work beyond that date is technically quite reasonable, especially in conformance test development, formal specification of semantics, and international standardization, which are all typically long-term activities. We plan to continue the work through either an extension of this project or through new projects being developed.

Five-Year Plan Goals vs. Fiscal Years:

\begin{tabular}{|c|c|c|c|c|c|}
\hline $\begin{array}{l}\text { COMPUTER-INTEGRATED MANUFACTURING } \\
\text { FRAMEWORK }\end{array}$ & 96 & 97 & 98 & 99 & 00 \\
\hline \multicolumn{6}{|l|}{ Prepare and publish second report [STRS/SEMATECH] } \\
\hline \multicolumn{6}{|l|}{ Prepare and publish third report [STRS/SEMATECH] } \\
\hline \multicolumn{6}{|l|}{$\begin{array}{l}\text { Develop and install a Framework test environment in the } \\
\text { AMSANT [STRS/SEMATECH] }\end{array}$} \\
\hline \multicolumn{6}{|l|}{$\begin{array}{l}\text { Integrate commercial and research manufacturing } \\
\text { applications into the test environment using the Framework } \\
\text { [STRS/SEMATECH] }\end{array}$} \\
\hline $\begin{array}{l}\text { Adopt Framework as a standard through OMG and ISO } \\
\text { [STRS/SEMATECH] }\end{array}$ & & & & & \\
\hline
\end{tabular}




\section{Staff: (2.0 staff years) TED HOPP, Cathleen Diaz}

Objective and MEL Thrust(s) Supported: The objectives of this program are (1) establish a common technical basis for tolerancing, metrology, and measurement traceability of complex dimensional characteristics in the discrete parts industry; (2) reduce industry inspection costs, assure quality of manufactured parts, and provide traceability through the NIST Algorithm Testing and Evaluation Program for Coordinate Measuring Systems (ATEP-CMS); (3) continue deployment of NIST's Algorithm Testing System (ATS) for evaluating the performance of data analysis software embedded in coordinate measuring systems; and (4) support the establishment of national standards based on ATEP-CMS, development of new tolerancing technology, measurement methods, inspection algorithms, and standards for complex, high-precision parts. Manufacturing Metrology.

Need(s) Addressed: The dimensional metrology community, users, vendors, and manufacturers of coordinate measuring systems (CMS) need formal mechanisms for testing and evaluating the performance of data analysis software embedded in CMSs. ATEP-CMS will help industry reduce inspection costs, improve procurement methods, and decrease measurement uncertainties, while provide traceability of measured results to national standards. There is a need for addressing complex geometries, providing tighter coupling between product design and process design, and providing the means to increase the use of statistical tolerancing challenge the field of dimensional tolerancing. Other needs include characterizing data analyses underlying coordinate metrology systems in basic metrological principles and developing algorithm objectives for advanced tolerance verification provides industry with dimensional and metrological methods not available in the past. The Dimensional Tolerancing and Computational Metrology Program will support national goals for the ASME Research Committee on Dimensional Tolerancing and Metrology. Additionally, the national standard, ASME Y14.5.1, Mathematical Definition of Dimensioning and Tolerancing Principles, and the draft national standard, ASME B89.4.10, Methods for Performance Evaluation of Coordinate Measuring System Software, are supported by this program. Furthermore, this program supports the U.S. and international standards communities' efforts to improve coordination of the standards in these areas.

Technical Approach: NIST is providing the ATEP-CMS Special Test Service to industry by performing CMS software tests and evaluations consistent with emerging national standards. NIST will establish a research consortium to carry out work identified by the national research agenda on dimensional tolerancing and metrology. The program will specify requirements for data analysis algorithms and develop new reference software implementations of the algorithms. NIST will collect data on process characteristics and study interaction of part deviations, coordinate sampling plans, and data analysis methods in order to characterize measurement uncertainty from coordinate measurements. NIST will also develop performance metrics and assessment methods for the new algorithms and design algorithm testing tools based on these metrics and integrate tools into an algorithm testing environment.

\section{FY95 Accomplishments:}

- Published U.S. National Standard ASME Y14.5.1, Mathematical Definition of Dimensioning and Tolerancing Principles. This provided, for the first time, an unambiguous, rigorous foundation for the geometrical meaning of tolerances used on mechanical part drawings and computer-based product representations.

- Published "Performance Measures for Geometric Fitting in the NIST Algorithm Testing and Evaluation Program for Coordinate Measurement Systems" in the NIST Journal of Research. This established the theoretical basis for assessing the accuracy of geometric fitting software used in dimensional metrology.

- Published "Algorithm Testing and Evaluation Program for Coordinate Measuring Systems: Long 
Range Plan," (NISTIR 5651). This provides NIST customers with information about the planned evolution of the ATEP-CMS service.

- Published "Algorithm Testing and Evaluation Program for Coordinate Measuring Systems: Testing Methods" (NISTIR 5686). This explains the methods NIST uses to evaluate CMS software.

- Presented and published a paper on ATEP-CMS at the SME Interface '95 Symposium. This publicized the NIST service to a large group of potential customers.

- Published "User's Guide for the Algorithm Testing System Version 2.0" (NISTIR 5674) and "Reference Manual for the ATS Version 2.0" (NISTIR 5722) for users of the NIST-developed ATS software. The software has been distributed to over a dozen companies

- Submitted a journal paper, "Representation of Axes for Geometric Fitting," to Computer-Aided Design. This new method of axis representation can reduce the estimated uncertainty of ATEP-CMS performance measures by as much as an order of magnitude.

- Developed and implemented a quantitative model of pretravel variation for touch-trigger probes used on coordinate measurement systems. This will enable CMS vendors to eliminate up to $80 \%$ of the errors due to probe lobing.

- Submitted a journal paper, "Error Compensation for CMM Touch-Trigger Probes," to the Journal of Precision Engineering documenting the probe lobing model.

\section{FY96 Plans:}

- Continue operation of the ATEP-CMS Special Test Service.

- Publish ASME standard on CMS software performance evaluation.

- Identify, develop, and incorporate new fitting algorithms in the ATS.

- Port the ATS to the Microsoft Windows ${ }^{\mathrm{TM}}$ environment.

Related Developments: The Proposed Draft ISO Standard: Method for Testing Software for Computing Gaussian Substitute Elements in Co-ordinate Metrology, Maurice Cox, National Physical Laboratory, Teddington, Middlesex, specifies a method for testing software used for computing substitute geometric elements from coordinate measurements. The Physikalisch-Technische Bundesanstalt (PTB) offers a service to test CMS software by comparing results for test data sets to results obtained from reference software.

Five-Year Plan Goals vs. Fiscal Years:

\begin{tabular}{|l|l|l|l|l|l||}
\hline $\begin{array}{l}\text { DIMENSIONAL TOLERANCING AND COMPUTATIONAL } \\
\text { METROLOGY }\end{array}$ & 96 & 97 & 98 & 99 & 00 \\
\hline Provide ATEP-CMS service to industry. [OA-Calibrations] & & & & & \\
\hline $\begin{array}{l}\text { Identify and implement objectives for additional fitting } \\
\text { algorithms. [STRS] }\end{array}$ & & & \\
\hline $\begin{array}{l}\text { Establish consortium on Dimensional Tolerancing and } \\
\text { Metrology [STRS] }\end{array}$ & & & \\
\hline $\begin{array}{l}\text { Publish performance models and metrics for tolerance } \\
\text { evaluation software [STRS] }\end{array}$ & & & & & \\
\hline $\begin{array}{l}\text { Make available software testing for tolerance evaluation } \\
\text { functions [STRS] }\end{array}$ & & & & & \\
\hline $\begin{array}{l}\text { Define tolerancing and measurement methods for } \\
\text { sculptured surfaces [STRS] }\end{array}$ & & & & & \\
\hline
\end{tabular}




\begin{tabular}{|l|l|l|l|l|l|}
\hline $\begin{array}{l}\text { DIMENSIONAL TOLERANCING AND COMPUTATIONAL } \\
\text { METROLOGY } \\
\text { Publish framework for tolerancing, metrology, and standards } \\
\text { [STRS] }\end{array}$ & 96 & 97 & 98 & 99 & 00 \\
\hline $\begin{array}{l}\text { Establish new national standards for statistical and complex- } \\
\text { surface tolerancing [STRS] }\end{array}$ & & & & & \\
\hline $\begin{array}{l}\text { Establish new national standards for performance evaluation } \\
\text { of inspection systems for complex surfaces [STRS] }\end{array}$ & & & & & \\
\hline $\begin{array}{l}\text { Provide measurement support for complex-surface } \\
\text { inspection systems [STRS] }\end{array}$ & & & & & \\
\hline
\end{tabular}




\section{Title: ENGINEERING A LA CARTE: IMPROVING THE INTEROPERABILITY OF DISTRIBUTED ENGINEERING SOFTWARE TOOLS.}

Staff: $(0.4$ staff years $) *$ Simon Szykman, ${ }^{*}$ BILL REGLI

Objective and MEL Thrust(s) Supported: To investigate the impact of emerging computer technologies on existing and future approaches toward integrating distributed CAD/CAM software tools. Manufacturing Systems Integration.

Need(s) Addressed: To date, integration of engineering software has been done predominantly (though not exclusively) on the "desktop." This has resulted in integrated packages of sotware tools that are beyond the reach of many smaller design and manufacturing companies due to the high cost of the software as well as the associated required hardware. For companies at the high-end of the user spectrum that can afford these tools, they provide the best integrated suite of tools but not necessarily the integration of the best tools available for a given application.

Predictions regarding the next generation of computational tools describe bringing higher capabilities within reach of smaller companies and allowing engineers to tailor a set of tools to an application through the use of distributed software tools which are accessed across networks. Achieving the envisioned engineering environment requires software integration at a different level. While currently-available integrated packages have addressed many issues that will arise in the development of new software tools, a new set of data and communication issues now arise.

Present computing capabilities provide a number of opportunities untapped by the engineering software community. The use of the emerging technologies that will enable new CAD/CAM environments is becoming more and more widespread. However, applications of these technologies are primarily still at the research stage and the area of integration of distributed software is still in its infancy.

Technical Approach: This project will investigate the use of emerging computer technology to improve the integration of engineering software tools. The types of technologies available exist at several different levels. At the first level are several varieties of network-savvy programming tools, such as Perl and Tcl/Expect. At a second level are programming languages and environments specifically designed for the exchange of executable software components (often in an interpreted language) over a network. The most notable of these is the Java language used over the World Wide Web. Included in a third level are some of the current application development environments in commercial software systems. Environments such as these can be used to create software modules to be shared, accessed or executed over the network from within a CAD environment.

Engineering A La Carte is an experiment in distributed engineering software integration and delivery. As part of this project, a prototype environment is being constructed using existing technologies and tools, such as those described above. This environment will be populated with several common and fundamental engineering tools (CAD engine, data translators, design repositories, manufacturing analysis and planning tools, etc.). Among the technical issues to be addressed are data sharing and encapsulation, data and communication standards, concurrency and parallelization of computation across networks.

This project does not involve the development of new computer technology, but rather will investigate the use of existing technologies to improve integration of existing tools and to map out approaches toward developing the next generation of integrated CAD/CAM software tools. Relevant emerging technologies include Java, CORBA, OLE, VRML and existing communication infrastructure such as the Internet and the World Wide Web. 
FY96 Plans:

- Report on issues relating to CAD/CAM software tool integration that arise during distributed design.

- Initiate development of a prototype system that provides a level of interaction and communication between existing software tools to demonstrate applicability of work to collaborative design.

- Develop summary of critical issues and requirements for larger-scale implementation of project.

- Organize an industry workshop to bring together parties who have an interest in the integration of engineering software tools and address needs for standards and technology required to achieve this integration. 


\section{Staff: $(0.6$ staff years $){ }^{*}$ Ram D. Sriram, ${ }^{*}$ Peter Hart, ${ }^{*}$ KEVIN LYONS}

Objective and MEL Thrust(s) Supported: To provide an environment for facilitating leading edge research and development in design technology and standards that will increase the competitiveness of the U.S. engineering industry. Manufacturing Systems Integration.

Need(s) Addressed: Engineering design plays a significant role in the product development process. The decisions made during the engineering design stage have a considerable impact on the life cycle costs. Various studies indicate that errors made during early design stages tend to add exponential costs to the final product. To effectively compete in the global markets, the U.S. industry should produce quality goods at a competitive price. To do so would involve taking appropriate measures to produce innovate and robust designs, which should include all information needed for other engineering tasks. The engineering testbed is an initiative aimed at addressing technology transfer issues in engineering design. The goal of this testbed is to provide a platform for: testing and validating design methodologies, developing standards for product and process models, storing and accessing design case studies, aiding in supplier-chain integration, and helping in various aspects of technology transfer.

Technical Approach: The project was created to provide facilitation of collaboration and technology transfer among the contractors who participate in the DARPA MADE program, where we provide technical and programmatic support. It has grown to be a useful testbed for demonstration of technologies and standards for the next generation design systems. Our approach is to work with industry, other government agencies, and universities to provide access to state-of-the-art technologies, design practices, and standards, through several mechanisms including the World Wide Web.

\section{FY95 Accomplishments:}

- $\quad$ Created the testbed web pages (internal).

- Initiated the installation of Stanford PENS collaborative engineering notebook tool.

\section{FY96 Plans:}

- Identify the information access needs of small to mid-size design companies and work with commercial vendors (such as Spectragraphics and Autocad) to address these issues.

- $\quad$ Participate in various national initiatives on design to help in standardization of design product and process models, with a particular focus on collaborative design.

Participate in the development of appropriate storage structures for design case studies (or application notes).

- Develop appropriate Web links to various design related activities.

- Complete installation of the Stanford PENS framework.

Five-Year Plan Goals vs. Fiscal Years:

\begin{tabular}{||l|l|l|l|l|l||}
\hline ENGINEERING DESIGN TESTBED & 96 & 97 & 98 & 99 & 00 \\
\hline $\begin{array}{l}\text { Install prototype systems that demonstrate new technologies } \\
\text { [OA] }\end{array}$ & & & & & \\
\hline $\begin{array}{l}\text { Conduct workshops for assessing needs of small designers } \\
\text { (i.e., suppliers) for accessing information resources [OA] }\end{array}$ & & - & & & \\
\hline
\end{tabular}




\begin{tabular}{|l|l|l|l|l|l|l|}
\hline \hline ENGINEERING DESIGN TESTBED & 96 & 97 & 98 & 99 & 00 \\
\hline $\begin{array}{l}\text { Conduct research on object-oriented database needs for } \\
\text { engineering design repositories [OA] }\end{array}$ & & & & & \\
\hline $\begin{array}{l}\text { Implement the design repository and various access } \\
\text { interfaces [OA] }\end{array}$ & & & & & \\
\hline $\begin{array}{l}\text { Interact with industry to provide support for effective design } \\
\text { practices [OA] }\end{array}$ & & & & & \\
\hline
\end{tabular}




\title{
Title: ENHANCED INTEGRATION OF CAD WITH DESIGN SUPPORT AND MANUFACTURING ENGINEERING SYSTEMS
}

\author{
Staff: (2.8 staff years) Kevin Lyons, *RAM D. SRIRAM, Michael Pratt, Peter Hart, *Gerry Kim
}

Objective and MEL Thrust(s) Supported: Enhance the interoperability and performance of design systems through identification of functional, data, and integration requirements, and development of prototype system extensions and enhancements which implement HPCC and integration technology solutions. The emphasis of this project will be on developing data exchange mechanisms between traditional CAD (Computer Aided Design), Augmented CAD (e.g., Analysis, Virtual Reality), Knowledge-based CAD (Design for Assembly) and manufacturing engineering systems such as process planning. Manufacturing Systems Integration.

Need(s) Addressed: Many industries are struggling to identify new methods to remain competitive with U.S. and foreign companies. Design processes have received little attention, yet are of significant importance to the industrial product realization process. Effective engineering design is key to providing improved quality, reduced costs, and reduced time to market. The emergence of new design support systems, such as virutal reality (or augmented CAD) and knowledge-based CAD, has introduced interoperability issues in that these new systems do not properly interact with current traditional CAD applications. Further, the output from the CAD systems is not compatible with the input of other manufacturing applications. This introduces considerable problems in the product development process. Until these barriers are addressed and solved there is little likelihood of industries acceptance of these tools and technologies.

Technical Approach: This project will develop a prototype information exchange mechanism to demonstrate the transfer of data created in a CAD environment to other manufacturing systems (e.g., process planning system) utilizing state-of-the-art support technologies. The project is divided into several tasks as described below.

(1) Design-to-Process Planning: This task involves the exchange of information between traditional CAD systems and process planning systems. Our goal is to develop various extensions to AP 203 and assist in final stages of standardization to AP 224, which are STEP standards.

(2) Knowledge-Based Design to Assembly Analysis: This task involves the exchange of information between knowledge-based design systems and assembly analysis programs, such as stability analysis, augmented assembly modeling, etc.

(3) Augmented CAD-to-Assembly Planning: This task involves the development of exchange standards for data interchange between CAD systems (such as IDEAS, ProEngineer), augmented CAD systems (e.g., simulationbased design), and assembly process planning. Various extensions to the STEP standard (AP 203) for assembly planning will be explored.

(4) Solid Interchange Format: This task involves the use of STEP's generic resources for the development of a standard for the exchange of CAD data with Rapid Prototyping systems, which have been developed for producing physical structures in layers (e.g., 3D Printing).

5) Engineering Ontologies: This task will explore the development of engineering ontologies in EXPRESS or extended EXPRESS. These ontologies will aid in knowledge-level communication.

\section{FY95 Accomplishments:}

- Developed preliminary architectural and information models of the prototype information exchange mechanism which demonstrates the exchange/sharing of information between a solid modeling design system and a virtual environment system.

- Presented paper entitled "Virtual Assembly Design Environment" at ASME Conference in Septmeber 1995. 
- Completed models of NASA's current satellite design and deployment process; work done in collaboration with NASA Goddard engineers and George Washington University.

- Served as the general chair for the ACM/IEEE Solid Modeling Conference'95.

- Published NISTIR 5650: "Virtual Prototypes and Product Models in Mechanical Engineering."

- Published "Cyclides in Computer Aided Design," at CAGD, 1995.

\section{FY 96 Plans:}

- Coordinate with Stanford University for the development of engineering ontologies EXPRESS or extended EXPRESS.

- Demonstrate the various data exchange protocols between design and other applications.

- Initiate the development of a solid interchange format for solid free form fabrication.

- Continue participation in the ISO TC 184/SC4 short term and long term parametrics efforts.

- Work on the exchange standards for data interchange between CAD systems, augmented CAD systems (e.g., simulation-based design), and assembly process planning.

Five-Year Plan Goals vs. Fiscal Years:

\begin{tabular}{|l|l|l|l|l|l||}
\hline $\begin{array}{l}\text { ENHANCED INTEGRATION OF CAD WITH DESIGN } \\
\text { SUPPORT AND MANUFACTURING ENGINEERING } \\
\text { SYSTEMS }\end{array}$ & 96 & 97 & 98 & 99 & 00 \\
\hline $\begin{array}{l}\text { Implement information model for data exchange between } \\
\text { knowledge based design to assembly analysis }\end{array}$ & & & & & \\
\hline $\begin{array}{l}\text { Develop engineering ontologies in EXPRESS or Extended } \\
\text { EXPRESS }\end{array}$ & & & & & \\
\hline $\begin{array}{l}\text { Develop exchange standard for data interchanging between } \\
\text { CAD systems, Augmented CAD and, assembly process } \\
\text { plans }\end{array}$ & & & & & \\
\hline $\begin{array}{l}\text { Develop standard for exchange of CAD data with rapid } \\
\text { prototyping systems using a solid interchange format }\end{array}$ & & & & & \\
\hline
\end{tabular}




\section{Title: FLEXIBLE DESIGN-FOR-ASSEMBLY (DFA) THROUGH CONCEPTUAL ASSEMBLY MODELING}

Staff: (0.8 staff years) ${ }^{*}$ GERARD J. KIM

Objective and MEL Thrust(s) Supported: Develop a methodology for integrating assembly knowledge during various design stages, and ways to customize the method to different design domains in a flexible and systematic manner. Manufacturing Systems Integration.

Need(s) Addressed: Integrated Product/Process Design (IPPD) is an engineering approach that integrates activities from product concept through production and field support, using a multi-functional team to simultaneously optimize the product/process development and agile manufacturing. For example, Design-forAssembly (DFA) is one of many such design criteria that emphasizes designing products for simple or less expensive assembly operations. Most computer-supported DFA methods are practiced in a form of comparative analysis (by employing some kind of a scoring system) of finished products instead of (re)designing products. This still falls short of the objective of IPPD which, in part, is to allow designers "generate" different design alternatives.

Such inadequacy stems, first, from lack of computational support for conceptual modeling of designs, and in particular, assemblies, in current CAD systems. Representing and reasoning about conceptual design is crucial to IPPD, because, when integrated with appropriate tools, it allows for prediction of wrongful design decisions beforehand, and is computationally a better platform for exploring different design alternatives and performing redesigns. Secondly, there is an inherent computational difficulty in extracting, from CAD models, features or information necessary and useful for DFA and redesign: namely, DFA characteristics and design intent. In most cases, DFA characteristics are not well represented in CAD data, and, for a general design domain, very difficult to derive because it requires complex geometric processing and reasoning about the design context. On the other hand, design intent is also very important for validating redesign suggestions, but usually undocumented and lost. Even with design history capture capability, certain design information will still go undocumented because it is simply common sense. In a restricted design domain, however, these difficulties can be assessed to a certain degree by taking advantage of the conceptual modeling framework and domain knowledge.

Technical Approach: Previously, we have developed a model of DFA redesign, and an interactive computeraided DFA tool called REV-ENGE (from REVerse ENGineering). The central idea of REV-ENGE was to achieve DFA redesign by reverse engineering, i.e., by acquiring/inferring the design process, then replaying and modifying the design process rather than "patching up" the result of the final design. The theory of redesign in REV-ENGE can be easily extended to formally specify a framework to model conceptual assemblies. Taking advantage of domain knowledge to assess the computational burden essentially amounts to building design system for the chosen domain. This corresponds to customizing the framework with required domain knowledge, and this process will shed light on the knowledge acquisition process, important for later technology transfer.

The design system is envisioned to be a state-based automata, and the implementation will, therefore, involve defining a design state (and objects that constitute the design state such as the artifact, design intent, etc.), design operators (transfer functions), and design rules appropriate for the chosen domain. The definition of design states forms the basis for representation of conceptual design and assemblies. The definition of design operators and design rules form basis for making gradual refinement of the given design. For visual feedback, each design operators will be associated with a domain dependent shape representation.

To apply DFA rules correctly, design intent must be taken into consideration so that unnecessary design problems are not identified. In addition to representing design intent system by text and classifying them according to certain taxonomy, semantics of design intent must be understood at least to some extent so that 
designers can be prompted, on demand, to enter the information more easily.

\section{FY95 Accomplishments:}

- Implemented design process-based assembly design enviornment for DFA called Conceptual Assembly Modeling Framework.

- Wrote the following papers: (1) "Interleaving Assembly Planning and Design," IEEE Trans. on Robotics and Automation (accepted for publication); (2) "Comparative Assembly Planning during Assembly Design," IEEE ISATP 95, Pittsburgh, PA (conference proceedings); (3) "A Decision Based Design Framework for Exploring Assembly Configurations," CE 95, Washington, DC (conference proceedings); (4) "Combining Interactive Exploration and Optimization for Assembly Design,” ASME DAC 96, Irvine, CA (conference proceedings; with Simon Szykman).

\section{FY96 Plans:}

- Implement Augmented CAD system for Assembly.

- Focus on the cooperative nature between the assembly designer and manufacturing engineering for computing and generating optimal assembly plans and designs.

- Publish results in appropriate conferences and journals. 


\section{Title: HEALTHCARE INDUSTRY: ANALYSIS OF RESEARCH ON HETEROGENEOUS INFORMATION INTEGRATION}

Staff: $\quad(0.5$ staff years $) *$ JIM NELL, $*$ Neil Christopher, $*$ Ram Sriram

Objective and MEL Thrust(s) Supported: To advise the healthcare ATP participants about the most probable environment for information sharing in their industry.

Need(s) Addressed: The healthcare industry appears to be a diverse set of very small virtual enterprises seeking ways to improve their information infrastructure and processes to enable more effective operation in a more integrated mode. The problem appears to be a heterogeneous mix of information resources developed to meet individual needs fitted to the existing platform, communication protocols, legacy information and assets. The investment justification for doing this varies by specific healthcare entity, but there is recognition that access to a common information pool would afford more effective health care to patients and allocate medical practitioner skill more productively.

Enterprise re-engineering using enterprise analysis follows many paths that include such things as examination of strategies and goals, an enterprise-reference architecture, an enterprise-integration framework, an enterprisemodeling process leading to a set of enterprise models. The project should define how these things relate to each other, and when completed how they conform to some kind of standard so that tools can interoperate the models on intra-enterprise and inter-enterprise bases. Much work is being done on this challenge by consortia around the world. This program should identify relevant work so that the healthcare industry can leverage it.

Technical Approach: Investigate information architectures, components of information-exchangeinfrastructure to be expected, role of standards, and role of application developers. Report on healthcare needs/requirements, nature of information integration, and how the related developments can help the healthcare problem as they perceive it. The tasks are to perform a needs analysis from ATP-proposal problem statements, determine the healthcare problem, create a scenario of how the healthcare industry can apply good parts of solutions, and recommend alternatives that will resolve needs and define requirements for solutions.

Related Developments: Users: TC184/SC5/WG1 standards, healthcare information integration requirements; contributors: TC184/SC5/WG1 philosophy with respect to models, W models, literature review (NIIIP), ATP reports, healthcare information integration needs.

\section{FY96 Plans:}

- Perform needs analysis and requirements definition.

- Perform detailed literature review of several on-going projects in heterogeneous information integration, such as Carnot (MCC), and Context Interchange (MIT).

- Characterize the nature of information integration, which will provide the basis for comparing various approaches.

- Form a liaison with ATP healthcare projects; develop examples for the healthcare industry.

- Prepare project report. 


\section{Title: IMPROVING THE DESIGN PROCESS BY PREDICTING DOWNSTREAM VALUES OF DESIGN ATTRIBUTES}

\section{Staff: (0.8 staff years) *SIMON SZYKMAN}

Objective and MEL Thrust(s) Supported: This work involves the development of a computational design tool that estimates downstream values of design attributes based on information available early on in the design process, such as design specifications. Manufacturing Systems Integration.

Need(s) Addressed: Experienced designers are often able to guide the design process toward promising designs from early on in the design process. This foresight is often referred to in the context of vague terms, such as intuition. One of the mechanisms that enables designers to look ahead in this manner is the building internal models that map design specifications to downstream design attributes. Because a large percentage of life cycle costs are committed early on in the design process, such models can be of great benefit. The ability to predict downstream design attributes has potential benefits that include reduction of design iterations, avoiding wasted effort that occurs by exploring paths that lead to infeasible designs, and reducing the need for timeconsuming analysis and simulation as well as physical prototyping. These advantages can translate to reduced design costs and time to market.

There are a variety of barriers that deter the use of these models in design practice. One common one is lack of expertise among designers who don't have the past experience from which to build these models. Because the models are represented internally, rather than explicitly, it is difficult for them to be articulated and passed on to less experienced designers. A second difficulty is that there are problems for which a mapping from specifications to downstream design attributes may exist, but that those relationships are too complex or multidimensional for a designer to be able to capture. A third barrier is that many designed artifacts span across multiple engineering domains. In these cases, building such a model may require more knowledge than a single designer may have. Lastly, although the use of concurrent engineering techniques is becoming more widespread, it is not uncommon for designs to be "thrown over the wall." In these cases, information is known about downstream attributes, but the lack of feedback to the designers makes it difficult for them build these models.

The goal of this research is to develop computational design tools that improve the design process by representing and constructing these models. The purpose of these tools is not to supplant any one part of the design process, but rather to create a tool that provides designers with knowledge that may not otherwise be available to them, thereby aiding them in guiding search in an iterative design process.

Technical Approach: The approach taken in this work is to use artificial neural networks (ANNs) to build these predictive models. An artificial neural network is able to represent a potentially complex functional relationship by producing an output for a given set of inputs. The ANN can therefore be thought of as a response surface that takes as inputs values for a variety of preliminary or upstream design attributes, and outputs predicted values for downstream attributes.

Because ANNs are not unique representations for responses, surface alternative representational approaches can be used for models, including the more traditional polynomial functional representations and Bayesian surrogate models. Artificial neural networks were chosen for initial studies because of their ability to deal with characteristics that are typical of real design problems, including the ability to approximate discontinuities, represent relationships of high dimensionality, tolerate noisy data, and interpolate and (to a lesser extent) extrapolate.

Tobuild models that map specifications to downstream attributes, data corresponding to groups of related designs is required. Consequently, this methodology lends itself to problems where classes of similar artifacts 
have been previously designed (such as routine or variant design tasks), or problems where such data can be generated through simulation.

Current efforts are directed toward developing a prototype tool that can be applied to an industry design problem. One advantage of this approach is that it does not require any a priori knowledge about form of the design space or the domain of design. However, it may be possible to use these predictive models more effectively by using them in conjunction with approaches that include such knowledge when it is available. Long term issues include the ability to make use of additional knowledge as well as he characterization of the types of relationships that can be represented with this approach.

\section{FY96 Plans:}

- Perform research investigating the use of predictive models to aid in various stages of the design process.

- Implement one approach for representing and building these models and discuss alternative representations.

- Report on practical limitations that may affect the use of these models (e.g., among data required and anticipated accuracy). Investigate improved approaches for building these models by reducing data requirements or increasing accuracy for a given amount of data.

- Report on characterization of types of problems to which the methodology is applicable.

- Implement prototype tool with capabilities described above.

- Apply tool to a realistic problem. Anticipate collaboration with industry.

- Publish results in relevant conferences and journals. 
Objective and MEL Thrust(s) Supported: To develop a generic interface specification and exchange protocols which can be used to demonstrate the integration of real-time scheduling tools with shop floor data collection tools. Manufacturing Systems Integration

Need(s) Addressed: During the last 10 years, many U.S. manufacturing facilities have invested in computerbased shop floor scheduling and data collection systems. These data collection systems have made it possible to gather data about the events on the shop floor almost as soon as they happen. A recent study conducted at Purdue University estimated that shop floor throughput could be increased by as much as $30 \%$ by integrating scheduling tools with these data collection tools. Such an integrated system would provide the capability to analyze and react to problems deduced from this data in real-time. In addition, vendors of scheduling products typically spend weeks integrating their products with a user's shop floor data collection system. The vendors estimated that this project will cut the time it takes to build such an integrated system by about $50 \%$.

Technical Approach: This two year project was initiated in FY95. It is a collaborative effort with Pritsker Corporation, Auto Simulation, Inc., AMP, Inc., Ohio University, and Purdue University. A significant amount of work will be done by these collaborators under various contracts and cooperative agreements. The primary focus in this project is the development of the specifications and protocols needed to integrate commercial simulation-based scheduling software with shop floor data collection software. A secondary focus is the improvement of the real-time, functional capabilities of these scheduling tools. To achieve integration, we will develop a set of interface standards and exchange protocols. The interface standards will specify the information that is needed by scheduling. The exchange protocols specify how this information is reported by the shop floor data collection system, and how it actually stored and retrieved by the scheduling software. NIST will work with industry, vendors and universities to develop candidates for those standards and protocols. Testing will be performed to demonstrate their effectiveness at the AMSANT facility at NIST, vendor-sites, and user facilities. For a follow on project, once we are satisfied that they indeed lead to integration, NIST will work with the national and international bodies to develop a set of standards based on those candidates.

Integration provides the key to improving ability of scheduling software to respond to changes on the shop floor in real-time. Providing these real-time capabilities is the secondary focus of this project. It requires the development of a new approach to solve job shop sequencing and scheduling problems. Prior to this project, NIST, Ohio University, and Purdue University initiated an effort to develop such an approach based on the integration of neural networks, simulation, and genetic algorithms. We plan to complete that development, then integrate this new approach into the commercial schedulers used in this project. We will then show that these upgraded schedulers can use the information provided by the shop floor data collection software to respond to problems in real time. These demonstrations will take place at NIST and at one of the manufacturing facilities of our industrial collaborator, AMP, Inc.

Integration testing will take place in several stages. In the initial testing, each scheduling vendor will be paired with one shop floor data collection vendor. Furthermore, initial testing will not include the new scheduling approach. This initial testing will take place during March, 1996. A second suite of tests, in which the pairings will be switched and the scheduling approach included, will be conducted in June, 1996. Finally, a demonstration will be held at an AMP facility in September 1996.

\section{FY95 Accomplishments:}

- Completed development of shop floor sequencing system.

- Completed initial interface specification using EXPRESS. 
- Completed initial definition of exchange protocols.

- Completed assessment of commercial scheduling tools.

- Formed collaborative team of vendors, universities, and users.

- Acquired, installed, and completed training on all commercial software.

- Prepared paper for AMPST conference, Bradford, England, March 1996.

FY96 Plans: This is project is scheduled to be completed by the end of FY96.

- Conduct initial pairs integration tests (without new scheduling approach) at NIST.

- Conduct initial pairs integration tests (with new scheduling approach) at NIST.

- Modify initial specifications and protocols based on integration tests.

- Conduct final integration tests with pairs switched at NIST.

- Demonstrate integration at AMP manufacturing facility.

Related Developments: Systems Modeling Corporation will be releasing a new simulation-based scheduling product this year. They have agreed to participate in additional testing of the interface specification and exchange protocols developed in this project on this new product. Activities being done under SIMA Production project are being leveraged for this project. 


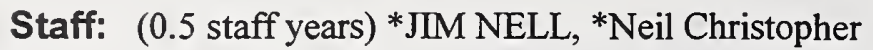

Objective and MEL Thrust(s) Supported: There are three objectives: (1) define the domain of enterpriseintegration frameworks, enterprise-reference architectures, enterprise models, and enterprise modeling, (2) determine the barriers to implementing the architectures, identify solutions, and encourage leveraging and technology transfer of related developments in the domain, and (3) define where international and national standards should be applied, where they should be harmonized, and where they are unnecessary. Manufacturing Systems Integration

Need(s) Addressed: Manufacturing enterprises are seeking ways to improve their infrastructure and processes to enable more effective operation in a more agile, virtual-enterprise mode. The investment justification for doing this varies by specific company, but reasons focus upon higher quality products, better repeatability, lower cycle time, and more customized production capability. Re-engineering should not occur in a vacuum. There should be careful analysis to define the total domain of enterprise representation. Also needed is a guideline regarding how to subdivide the domain logically. This project should define a scenario for representing an enterprise according to a framework, an architecture, and models. The program also should address life cycles of enterprises and models.

Enterprise re-engineering using enterprise analysis follows many paths that include such things as examination of strategies and goals, an enterprise-reference architecture, an enterprise-integration framework, an enterprisemodeling process leading to a set of enterprise models. The project should define how these things relate to each other, and when completed how they conform to some kind of standard so that tools can interoperate the models on intraenterprise and interenterprise bases. Much work is being done on this challenge by consortia around the world. This program should coordinate the work to the extent that existing groups and groups planning to work a sector of the domain are able to identify what has or is being done so that they can leverage their work.

Technical Approach: There are three tasks to be performed. The major task the program plans to undertake is the Role of Standards; that is, where to apply them and where not to apply them. To accomplish this, the program must analyze several areas where to apply standards: enterprises, enterprise models, enterprise modeling, name spaces, languages, standard practices, computing applications, frameworks and reference architectures, hardware, software, communication, and information format. This work will involve a review of related activities to determine the domain and the activities' needs for standards. This will also include convening ISO TC184/SC5/WG1, Modeling and Architecture, to create the correct standards that will allow successful implementations without inhibiting freedom of enterprise design and technical innovation.

A second task, Communication and Presentation of Results, involves a sharing of information, from the NIST program and the WG1 work outward to developers, and from the developers inward to the program. The program plans to communicate through several media: technical papers for NIST use and for external presentation, participation at developer-sponsored workshops and conferences, World Wide Web pages, and Internet exploders or reflectors.

A third task, Implementations (Pilot and Production), will review implementations in place and planned, with the intent to identify gaps and overlaps, and to relate them to work underway and accomplished. This will include validating existing architectures such as SEMATECH CIM Framework, GERAM, ISAM, and CIMOSA with the architecture and enterprise models created by Westinghouse Electronic Systems.

\section{FY95 Accomplishments:}

- Convened four WG1 meetings, in November, April, May, and September, to redefine the content for 
and schedule the preparation of the new CD 14254.

- Solicited and received information from related development activities to define the domain for Enterprise Integration (EI) and to determine needs for EI-related standards.

- Coordinated with CIMOSA Association regarding restarting the ICEIMT'97 activity on enterpriseintegration problem-solving and cooperation.

- Participated in Joint Architects' Round Table seminar in summer 1995 (SIMA, ISAM, Sematech CIM Framework, and Team) to cross-pollenate technology insertion.

\section{FY96 Plans:}

- Prepare and present technical paper on EI standards issues at IFAC/IFIP conference in Nov 95,

- Continue to receive and compile information from development activities.

- Prepare EI activity domain paper for NIST to point where further contribution is needed.

- Convene four WG1 meetings, in December, February, April, and September, to finalize the content for the new CD 14254 and to plan new work.

- Restart the ICEIMT'97 activity on EI cooperation.

- Produce a new work-item proposal for WG1 for: Requirements Which must be Fulfilled by a Candidate Enterprise Reference Architecture and Methodology to be Considered as a GERAM Compliant Architecture. (GERAM stands for Generalized Enterprise Reference Architecture and Methodology.)

- Release CD14258 for ballot for registration as Draft International Standard (DIS).

- Develop strategy for a family of enterprise-integration-related standards for development by WG1 that are patterned after the ISO 9000 family of standards. Purpose is to focus more responsibility for interoperability on vendors and users.

- Convene the Joint Standards Workshop with NIST as Secretariat for JTC1 that will define how ISO, IEC, and JTC1 standards can be better coordinated.

Related Developments: (1) The Architects' Round Table: TEAM, NIIIP, SEMATECH, SIMA, and ISAM. (2) The ICEIMT'97 International Conference on Enterprise Integration Modeling Technology (identify issues and find solutions to barriers to enterprise integration). (3)The JSW: Joint Standards Workshop (Meeting of ISO, IEC, and JTC1 standards organizations to develop a doctrine to harmonize efforts). (4) IEC TC93: Harmonization of electric related standards for representation in STEP.

Five-Year Plan Goals vs. Fiscal Years:

\begin{tabular}{||l|l|l|l|l|l||}
\hline MANUFACTURING ENTERPRISE INTEGRATION & 98 & 97 & 98 & 99 & $\mathbf{0 0}$ \\
\hline $\begin{array}{l}\text { Prepare new work-item-proposal for Work Group, submit to } \\
\text { SC5 secretariat, ballot approve new work item proposal, and } \\
\text { achieve International Standard [STRS] }\end{array}$ & & & & & \\
\hline $\begin{array}{l}\text { Standardize Committee Draft ISO 14258: Release to SC5 } \\
\text { Secretariat, approve register as Draft International Standard, } \\
\text { ballot Draft International Standard, and approve to } \\
\text { International Standard [STRS] }\end{array}$ & & & & & \\
\hline $\begin{array}{l}\text { Restart International Conference on Enterprise Integration } \\
\text { Modeling Technology (ICEIMT'97): Convene 5 interim } \\
\text { workshops and then co-host the ICEIMT'97 [STRS] }\end{array}$ & & & & & \\
\hline
\end{tabular}


Staff: (4.3 staff years) Allison Barnard, *Jesse Crusey, *Sharon Gray, SHARON KEMMERER, *Mary Mitchell, Gaylen Rinaudot, Ellen Trager, Joan Wellington, Guest Researchers-*'IPO Chair William Gruttke, *SC4 Chair Richard Wandmacher, USPRO President Bob Willis

Objective and MEL Thrust(s) Supported: Ensure the timely development and processing of manufacturing product data standards with the quality, integrity, and completeness required to support industrial needs. Manufacturing Systems Integration

Need(s) Addressed: This effort targets developing and enhancing neutral data exchange standards within the international and U.S. standards development community to support industrial requirements. Such standards efforts include: the Standard for the Exchange of Product Model Data (STEP, ISO 10303), the representation of parts library information (P-LIB, ISO 13584), and manufacturing management data (MANDATE). The worldwide interest in STEP is motivated by the following:

(a) STEP enables a number of improved product development strategies, such as concurrent engineering, enterprise integration, electronic commerce and quality function deployment;

(b) STEP facilitates multiple companies working together as a virtual enterprise on new and improved product developments; and

(c) STEP makes possible the use of new and better approaches to increase the efficiency of revisions and upgrades to the design of a product.

Nationally, this effort facilitates developing U.S. consensus on product data exchange standards and is responsible for the maintenance and transition plan for the Initial Graphics Exchange Specification (IGES) (ANSL/USPRO-100).

Technical Approach: This effort is responsible for the technical and administrative leadership of a dynamic worldwide standardization effort under the International Organization for Standardization Technical Committee 184, Subcommittee 4 (ISO TC 184/SC4), and the corresponding national effort within the ANSI-accredited IGES/PDES Organization (IPO). As such it leverages the collective resources from more than 400 technical experts in 18 participating nations and more than a dozen associated liaison organizations.

NIST provides the technical infrastructure to develop and implement these critical manufacturing standards. NIST is also the electronic document repository and configuration management site for product standards and supporting development methods. The repository averaged over 15,000 accesses from 1,500 users each month. Among the many services offered, NIST maintains Standards on-line document access, maintains a unique name repository for STEP and Parts Library, and verifies the correct and consistent use of the formal specification language EXPRESS across the STEP standards.

Application Protocol integration and interoperability is critical to the success of STEP, yet there is currently an inadequate allocation of industry resources to make adequate progress. NIST provides leveraged resources to give technical leadership and put operational procedures in place, thereby minimizing resource requirements and maximizing technical expertise focused on manufacturing standards development.

\section{FY95 Accomplishments:}

ISO TC184/SC4:

- Recruited and selected a new chair from U.S. industry.

- Tracked and disseminated status of approximately 100 projects to $400+$ experts in 29 countries.

- Established a STEP Implementors' Forum to define recommended practices and implementors' agreements.

- Initiated the STEP Standard Enhancement and Discrepancy System (SEDS) for reporting, managing, 
and resolving in a timely manner any weaknesses in the standards.

- Expanded SC4 on-line document access, maintained repository of unique names and ensured correct and consistent use of EXPRESS across these standards.

- Provided technical leadership to various projects and served as the Secretariat.

- Improved integration methods for application interpreted models (AIM), application interpreted constructs (AIC), and mapping tables; and wrote major revisions to related STEP methods documents.

- Refined STEP part qualification procedures and ran working sessions to apply these techniques.

- Contributed to AP integration and interoperability issue resolution workshops.

IGES/PDES Organization (IPO):

- Published ISO 10303 (STEP) as an American national standard.

- IGES Version 5.3 approved as an American national standard.

- Coordinated dozens of U.S. ballots on SC4 draft specifications and documented the ballot process.

- Identified and selected an IPO Chairman from industry.

- Provided leadership by serving as the IPO Deputy Chair and various committee chairs, and contributed to USPRO Board and IPO Steering Committee initiatives.

- Transitioned US TAG administration duties to USPRO.

- Developed a mentoring program for meeting newcomers and improved technical training to standards makers.

\section{FY96 Plans:}

ISO TC 184/SC4:

- Establish recognized SC4 methods documents and update directives to improve document consistency.

- Put into production a new project management scheme based on the ISO Directives.

- Reorganize the operational structure of SC4 to promote built-in quality into the standards development process.

- Restructure the SOLIS repository to better accommodate the growing user requirements.

- Continue effort on issues of AP integration and interoperability.

IGES/PDES Organization:

- Complete technical work on IGES Version 6.0 with a transition plan for STEP.

- Identify persons to fill key leadership positions and train leaders such as PDES and Deputy PDES Project Managers.

- Revise the management and technical structure to better serve the interests of U.S. industry (e.g., consolidate projects and establish new focus activities).

Related Developments: MSID resources are contributing to the technical and administrative development of the Initial Manufacturing Exchange Specifications concept currently under development within MSID.

Five-Year Plan Goals vs. Fiscal Years:

\begin{tabular}{|l|l|l|l|l|l|}
\hline MANUFACTURING STANDARDS DEVELOPMENT & 96 & 97 & 98 & 99 & 00 \\
\hline $\begin{array}{l}\text { Complete IGES Version 6.0, including a transition plan for } \\
\text { STEP [STRS] }\end{array}$ & & & & & \\
\hline $\begin{array}{l}\text { Reorganize the ISO TC 184/SC4 to better meet industrial } \\
\text { requirements [STRS] }\end{array}$ & & & & & \\
\hline
\end{tabular}




\begin{tabular}{|c|c|c|c|c|c|}
\hline MANUFACTURING STANDARDS DEVELOPMENT & 96 & 97 & 99 & 99 & 00 \\
\hline $\begin{array}{l}\text { Reorganize the IGESTPDES Organization to better address } \\
\text { the interests of U.S. industry [STRS] }\end{array}$ & $\bar{n}$ & & & & \\
\hline $\begin{array}{l}\text { Implement a new project management scheme which will } \\
\text { track project schedules and resource distribution, and assist } \\
\text { in identifying voids [STRS] }\end{array}$ & & & & & \\
\hline $\begin{array}{l}\text { Establish recognized SC4 methods under which SC4 } \\
\text { standards development will operate. Make these operational } \\
\text { for STEP development in the first year, and bring in line the } \\
\text { remainder of the SC4 standards development in the second } \\
\text { year [STRS] }\end{array}$ & $=$ & & & & \\
\hline $\begin{array}{l}\text { Integrate appropriate electrical/electronic, electronic data } \\
\text { interchange, physical file transfer, syntax notation, and } \\
\text { graphical presentation standards into the evolving STEP } \\
\text { development efforts [STRS] }\end{array}$ & & & & & \\
\hline
\end{tabular}




\section{Title: MODELING FEATURES WITH SHAPE ALGEBRAS AND FORMAL LOGIC}

\section{Staff: (1.0 staff years) SCOTT C. CHASE}

Objective and MEL Thrust(s) Supported: Develop a feature-based geometric reasoning system, with algebraic representations used in shape grammars and logic specifications of features. Manufacturing Systems Integration.

Need(s) Addressed: Research in the development of design modeling systems has identified the need for evolutionary models which support dynamic schema modification. However, the development of current design systems does not easily support such a goal. They tend to be constructed in a bottom-up manner, with the design of low level data structures and operations first. This can be seen as a 'kit-of-parts' approach, and is often done in order to develop efficient operations for object manipulation. What this generally does is force the designer/user into a specific manner of representing and manipulating objects. Thus, the structure of a model must be decided at the start. Essentially this is akin to the philosophy of reductionism, which considers the universe to be composed of separate parts which, in various combinations, make up the whole.

The decision to classify and structure up front may preclude the possibility of other desirable forms and structures in the future. It is extremely difficult, if not impossible, to anticipate all possible ways in which one might wish to view or classify parts of a model. This often requires an unmanageable amount of information. The problems with this approach were among the causes of the failure of early CAD building modeling systems in the 1970s and early ' 80 s, which often required the predetermination of all types of information of interest, and for this information to be stored in a single model.

On the other hand, the philosophy of holism considers the universe to be a whole rather than the sum of its parts. A system which forces no preconceived structure upon the user, but rather, allows one to find all sorts of emergent features and properties from within the whole, would be extremely desirable. This might enable an easier development path in a top-down fashion, from the abstract to the specific.

Technical Approach: The algebras of shape, as used in shape grammars, can support both holistic and reductionist views. By considering shapes as finite sets of elements which can carry fixed properties, a reductionist view is supported. The real power of such algebras, however, lies in the fact that the elements of a shape and their properties may be defined in such a manner as to enable the emergence of features which are not apparent in the initial formulation of a shape. In addition, the generality of their representations, their reliance upon a minimum of structure, and their use in combination can provide the semantic richness needed for design generation and analysis.

Representing shapes and features in first order predicate logic provides an easy way to develop complete computer systems for reasoning about designs. The use of logic provides a natural, intuitive method of generating precise definitions of parametric shapes and high level spatial relations. In addition, logic formulation serves as a powerful specification language for computer programs: classes of logic specifications can be easily transformed in working programs, with ongoing research seeking to improve these techniques.

The proposed work builds upon doctoral research recently completed, in which a model of shape, spatial relations and non-spatial properties was developed, constructed from first principles of geometry, topology and logic. A major effort here will consist of computer implementation of the modeling system described above. This involves the construction of a feature recognition system, with the features encoded from the dependency network of shape relations previously specified as logical expressions. The likely implementation platform will be a deductive database, which provides a simple mechanism for encoding facts and rules.

To date, the application domains tested have been architectural design and geographic information systems. 
Here, we intend to examine the applicability of the approach to the domain of mechanical engineered parts. This would involve the development of libraries of feature sets and a comparison to other work in feature-based modeling and reasoning.

A further look at non-geometric properties of shapes is also proposed. The existing model permits computations with labels (set-based properties) and weights (properties that can combine), which can provide an additional richness for defining designs. An important question is, can properties such as functionality be captured using these constructs? In the future, an additional research goal is an investigation of how current STEP standards for product modeling can be extended to incorporate such emergent feature based representations.

\section{FY96 Plans:}

- Explore the use of a deductive database as an implementation platform for a reasoning system for features, based upon the model.

- Examine the applicability of the existing model to the domain of mechanical part assemblies.

- Construct a library of feature sets with the model and compare it to other efforts.

- Examine the applicability of the model to non-geometric attributes such as function. 


\section{Title: MULTI-AGENT MANUFACTURING SYSTEMS}

\section{Staff: $(1.0$ staff years) $*$ NEIL CHRISTOPHER, $*$ Don Libes}

Objective and MEL Thrust(s) Supported: Investigate the viability of developing systems of software agents to support design engineering, manufacturing engineering, production engineering, and production operations. The project investigates the need for standards required to support multi-agent manufacturing system communications, interfaces, behavior, and information exchange. It investigates the impact of multiagent systems on manufacturing operations, the behavior of multi-agent manufacturing systems, and the performance measures for agent-based manufacturing systems. This project also investigates the opportunity to create libraries of reusable agents to reduce manufacturing system development time. Manufacturing Systems Integration, Intelligent Machines and Systems.

Need(s) Addressed: The U.S. manufacturing industry seeks to increase its competitiveness by increasing the quality of its products, reducing product development times, and increasing the agility of its operations. The cost of software development, deployment, and maintenance is becoming a significant portion of operation costs. Software systems for engineering design, planning, scheduling, and control have become a very significant part of industry's push to increase its competitiveness. This project addresses the need for manufacturing software which is able to solve complex problems, is easily reconfigured to suit new processes, and has low development, deployment, and maintenance costs.

Technical Approach: This project addresses industry's needs through work in four areas: (1) development of standards for agent system communication and specification, (2) characterization of the behavior of multi-agent manufacturing systems, (3) a prototype or simulation of a multi-agent manufacturing system, and (4) a library of reusable software agents.

This project's industry collaborators, faced with shorter product developments cycle times and variable market demands, have chosen manufacturing execution systems as a target application of this project. Manufacturing Execution Systems (MES) help to determine sequence and timing of operations on the factory floor but increased variability in factory load and product mix invalidates many traditional approaches embodied in these systems. Recent research indicates that multi-agent manufacturing execution systems could be constructed to schedule and balance factory loads. To improve operational reliability, multi-agent MES must be constructed with well defined interfaces, messaging protocols, information exchange, and communications. The fundamental concepts for the structure of agents and multi-agent systems must be widely accepted and the application of some of these concepts must be standardized in order to be of maximum benefit to industry. This project will pursue, where appropriate, standardization of the work in multi-agent manufacturing applications and support systems.

Multi-agent systems are made of a collection of software components that cooperate with each other to manage complexity by decomposing the solution to manufacturing problems. The system agents then cooperate to solve the overall problem. The cooperation among agents in a multi-agent environment may lead to system behaviors that have not been predicted. This project will simulate the emergent behaviors of multi-agent manufacturing systems using variable models of manufacturing conditions. T his simulation will be the basis for understanding the potential performance measures for multi-agent manufacturing systems.

\section{FY95 Accomplishments:}

- Developed a proof-of-concept multi-agent control system for a manufacturing quality control station using the Expert Control System Shell (ECSS).

- Published a paper on the use of agents as tools to manage electronic mail and news group mailings, "Tcl/Tk-based Agents for Mail and News Notification" (Don Libes; publication pending). 
- Participated in the "First International Conference on Multi-Agent Systems," June 1995, San Francisco, CA.

- Participated in the "Chaos in Manufacturing Systems Conference," April 1995, hosted by the Santa Fe Institute, Santa Fe, NM.

\section{FY96 Plans:}

- Establish NIST/MEL as a beta test site for the Swarm multi-agent system behavior simulation software developed by the Santa Fe Institute.

- Develop a multi-agent manufacturing execution system reference model that includes variable input conditions and then simulate the system behavior using the Swarm software.

- Analyze and report on the beneficial and detrimental system states that emerge from the multi-agent manufacturing execution system simulation.

- Analyze and report on the state of agent related technology developments that may be suitable bases for industry standardization.

Related Developments: Related work in the use of multi-agent systems to manufacturing problems is being initiated at several major industrial sites and research institutions. Workshops and conferences are no longer an anomaly.

\section{Five-Year Plan Goals vs. Fiscal Years:}

\begin{tabular}{|c|c|c|c|c|c|}
\hline MULTI-AGENT MANUFACTURING SYSTEMS & 96 & 97 & 98 & 99 & 00 \\
\hline $\begin{array}{l}\text { Investigate opportunities for standardization of multi-agent } \\
\text { development languages, agent interfaces, messaging } \\
\text { protocols, knowledge and information representation } \\
\text { paradigms, and information exchange, and communications } \\
\text { protocols [STRS] }\end{array}$ & & & & & \\
\hline $\begin{array}{l}\text { Establish NIST/MEL as a Swarm beta-test site, develop a } \\
\text { multi-agent manufacturing execution system reference } \\
\text { model, simulate agent system behavior using Swarm, } \\
\text { analyze and report on the beneficial and detrimental } \\
\text { emergent manufacturing system states [STRS] }\end{array}$ & & & & & \\
\hline $\begin{array}{l}\text { Participate with industry partners on the specification, } \\
\text { development, simulation, and testing of a industry pilot } \\
\text { implementation of a multi-agent manufacturing execution } \\
\text { system [STRS] }\end{array}$ & & & & & \\
\hline $\begin{array}{l}\text { Pursue application of multi-agent systems to engineering } \\
\text { design and process planning problems [STRS] }\end{array}$ & & & & & \\
\hline $\begin{array}{l}\text { Investigate opportunities for national repository of reusable } \\
\text { software agents [STRS] }\end{array}$ & & & & & \\
\hline $\begin{array}{l}\text { Explore the establishment of formal standardization process } \\
\text { for agent related protocols [STRS] }\end{array}$ & & & & & \\
\hline $\begin{array}{l}\text { Develop conformance testing service for multi-agent system } \\
\text { components [STRS] }\end{array}$ & & & & & \\
\hline
\end{tabular}


Title: NATIONAL INDUSTRIAL INFORMATION INFRASTRUCTURE PROTOCOLS (NIIIP)

Staff: (2.5 staff years) Peter Denno, *Mary Mitchell, K.C. MORRIS, *David Sauder, *Selden Stewart

Objective and MEL Thrust(s) Supported: To foster the development of technology enabling industrial virtual enterprises and the adoption of STEP in the operation of industrial virtual enterprises. Manufacturing Systems Integration.

Need(s) Addressed: The NIIIP Consortium, funded through a TRP award, is a consortium of various manufacturers, technology providers, universities, and the government. NIIIP's goals are to develop, demonstrate, and transfer into wide-spread use the technology to enable industrial virtual enterprises. A virtual enterprise is a temporary consortium of companies which come together to share costs and skills to exploit fast-changing opportunities. The technology of NIIIP industrial virtual enterprises is expected to provide the following benefits: a) enable enterprise teaming on an ad hoc basis; b) provide a means for rapid reaction to business opportunities; c) enable concurrent engineering practices, through the use of shared data representations and workflow management technology; and d) allow organizations to overcome inhibitors system interoperability through the use of product data, object-oriented, communication, and workflow standards.

Technical Approach: Using a spiral development process the NIIIP Consortium will deliver 3 iterations of a) a reference architecture, b) toolkits which are the building blocks of an instantiated reference architecture, c) research prototypes, and d) pilot demonstrations. In the development of these deliverables NIIIP will adopt and converge existing standards and technology from STEP, the Object Management Group (OMG, a consortium of software vendors), the Internet Society, and the Workflow Management Coalition.

The core competencies that MSID contributes to NIIIP are expertise in the areas of STEP technology and standards and, more generally, expertise in testing, standardization, and integration technology and architectures. The technical research of the NIST project has focused on the integration of STEP technology and standards with object-oriented technology and standards emerging from OMG. NIST is providing direction for and implementation of components of a toolkit to bind the STEP Data Access Interface (ISO 10303 Part 22, a.k.a SDAI) to OMG standards for distributed computing. The development of this capability is key to the NIIIP goal of providing data sharing and STEP information modeling in the context of a NIIIP industrial virtual enterprise. Additionally, along business lines NIIIP looks to NIST's expertise in testing and standardization to validate and promote the results of the NIIIP work. To this end we have been a major contributor in the development of a standards roapmap for NIIIP.

FY95 Accomplishments:

- Contributed to the NIIIP Cycle 1 Reference Architecture including a chapter regarding NIIIP adopted computing standards.

- Contributed to the Cycle 1 NIIIP STEP Toolkit Definition.

- Tracked SDAI/IDL binding proposals from ISO/TC184/SC4 Working Group 7.

- Developed and demonstrated a NIST STEP Product Data Facility for Cycle 1 which exercise data exchange capabilities based on STEP and distributed computing capabilities using OMG standards.

- Co-authored a journal article published in Communications of the ACM.

- Investigated OMG standards and their applicability to product data sharing within the virtual enterprise.

- Extended the NIST STEP class library to support level 2 implementation of STEP part 22 and validate the $\mathrm{C}++$ binding. 
FY96 Plans:

- Participate in definition of NIIIP Cycle 2 STEP Toolkit, implement aspects of the toolkit, and participate in Cycle 2 demonstration.

- Write paper "A Survey of Standards for Persistence."

- Write paper "SDAI Architecture" (C++ and IDL bindings).

- Participate in definition of NIIIP Cycle 3 STEP Toolkit.

Related Developments: The development of products supporting the OMG standards are essential to development of key components of NIIIP including the NIIIP STEP toolkit. The project is premised on the adoption of STEP Data Access Interface (ISO 10303: part 22) as a international standard. Part 22 was promoted to Draft International Standard status this year. This project will validate the proposal for an SDAI/IDL binding. The binding was approved as a work item within ISO 10303 this year.

Five-Year Plan Goals vs. Fiscal Years:

\begin{tabular}{|l|l|l|l|l|l||}
\hline $\begin{array}{l}\text { NATIONAL INDUSTRIAL INFORMATION } \\
\text { INFRASTRUCTURE PROTOCOLS (NIIIP) }\end{array}$ & 98 & 97 & 98 & 99 & 00 \\
\hline $\begin{array}{l}\text { Define and demonstrate Cycle 2 NIIIP STEP Toolkit. } \\
\text { Contribute to NIIIP Cycle 2 Reference Architecture [STRS, } \\
\text { IBM] }\end{array}$ & & & & & \\
\hline $\begin{array}{l}\text { Define and demonstrate Cycle 3 STEP Toolkit. Contribute } \\
\text { to NIIIP Cycle 3 Reference Architecture [STRS, IBM] }\end{array}$ & & & & & \\
\hline Contribute to NIIIP Phase Two Plan [STRS, IBM] & & & & & \\
\hline
\end{tabular}


Staff: (0.7 staff years) ${ }^{*}$ Jeane Ford, TINA LEE, *Howard Moncarz

Objective and MEL Thrust(s) Supported: The Defense Logistics Agency (DLA) launched a 7-year R\&D program, Apparel Research Network (ARN), to support the apparel industry in early FY95. NIST has been participating in the performance of ARN since the program launched. The objective of NIST's participation is to bring technical expertise to the improvement of the apparel industry's ability to meet DLA apparel needs.

Manufacturing Systems Integration

Need(s) Addressed: The primary objective of DLA's ARN is to strengthen the U.S. apparel industry's ability to meet $\mathrm{DoD}$ requirements through a program of research, education, industrial extension, and factory implementation. The goal of the ARN program is to get the uniform on the customer at the right time, right place, right cost, and right fit. DLA has selected $24 \mathrm{ARN}$ partners from industry to help the coordination of the process of the overall ARN technical strategy, management and reporting. Each partner brings a specific technical expertise to the improvement of the apparel industry's ability to meet DLA apparel needs. NIST, under DLA sponsorship, has been working on developing apparel product data exchange standards (APDES) to support computer integration of the apparel life cycle. With DLA's special arrangement, NIST has participated in all ARN workshops and has been actively involved with the development of the ARN roadmap.

Technical Approach: Both NIST and DLA have a strong interest in encouraging the development of advanced apparel manufacturing technology that supports CALS objectives. NIST's participation in the ARN Program provides an opportunity to further this mutual interest.

Our primary interests in ARN include systems integration; product data definition, exchange and management; and special measurements. NIST's apparel experiences that have built up from working on the APDES project include: understanding apparel product data, understanding needs of small businesses, knowledge of apparel sizing/body dimensions, expertise in STEP, STEP testing, etc., and understanding the Apparel Manufacturing Architecture. NIST will participate and coordinate in the process of the overall ARN technical strategy and management.

\section{FY95 Accomplishments:}

- Published the NISTIR 5727, "Extensions of the Prototype Application Protocol of Ready-to-Wear Pattern Making." The report presents an IDEF0 activity model and an information model with the EXPRESS language and the EXPRESS-G graphical notation for ready-to-wear pattern making. The report can be used as the initial proposal for developing official STEP Application Protocol for apparel.

- Supported the development of the first version of the roadmap for the Apparel Research Network Program. We drafted project quad charts and project descriptions of five potential projects to support the development of the ARN roadmap. Systems integration and product data exchange standards was the major area we recommended to be included into the roadmap.

\section{FY 96 Plans:}

- Provide technical expertise. We will participate in the ARN workshops and focus group meetings. Our goal is to provide technical expertise to the ARN team when needed/requested. We will help to build/update the ARN roadmap. We will work closely with ARN partners for teaming up for a common interest task/project.

- Prepare technical proposal. We will submit project proposal to DLA in the area of standard management and product data exchange standard. It is expected this project to be leveraged with the 
SIMA's apparel IMES project.

Five-Year Plan Goals vs. Fiscal Years:

\begin{tabular}{||l|l|l|l|l|l||}
\hline $\begin{array}{l}\text { PARTICIPATION IN THE APPAREL RESEARCH } \\
\text { NETWORK PROGRAM }\end{array}$ & 96 & 97 & 98 & 99 & 00 \\
\hline $\begin{array}{l}\text { Participate in DLA sponsored workshops and planning } \\
\text { meetings [DLA] }\end{array}$ & & & & & \\
\hline $\begin{array}{l}\text { Develop project descriptions, quad charts, and technical } \\
\text { proposal [DLA] }\end{array}$ & & & & & \\
\hline $\begin{array}{l}\text { Develop apparel interface and exchange specifications to } \\
\text { support ARN activities [DLA] }\end{array}$ & & & & & \\
\hline
\end{tabular}


Staff: $(0.3$ staff years $) *$ STEVEN RAY, *Shaw Feng, ${ }^{*}$ Visiting researchers

Objective and MEL Thrust(s) Supported: To provide a research-enabling environment dedicated to the development of technology and standards in the area of manufacturing process planning. Manufacturing Systems Integration.

Need(s) Addressed: Manufacturing process planning is now recognized as one of the functions critical to achieving an integrated engineering and production process. Indeed, it serves as the bridge between the engineering domain and the manufacturing shop floor. Tackling the integration of these applications demands collaboration as the complexity and scale of the problems expand. In many areas, engineers have either used generic tools and technology, or developed their own tools, to meet their specific needs. This has been difficult, as funding for tool development by numerous projects is redundant, and often the building of tools is not seen as necessary to the accomplishment of project goals. A more explicit partnership between manufacturing engineers and computer scientists can inspire development of computing technology that better meets the needs of the manufacturing research and development community. The Process Planning Testbed Project seeks to foster this partnership by assembling supporting tools, sample data, and contributed planning systems at a single, nationally accessible location at NIST.

Technical Approach: The project has been attacking this problem along four avenues: information services; workshops; a laboratory for testing and integration; and a collaborative research program. This project heavily leverages common interests in other projects to further the goals described. Information services have been put in place to allow the diverse process planning community to communicate with one another easily. Components of the service include electronic mailing lists, an on-line focussed bibliographic citation database, an on-line repository of product and process, and other information available via the World Wide Web. Three workshops have been held, bringing together various constituencies (vendors, users, researchers) involved in manufacturing planning. The ultimate aim is to create a "Collaboratory" (collaborative laboratory) dedicated to process planning research and development. The project is currently focussing its resources on collaborations with visiting researchers and postdoctoral candidates.

\section{FY95 Accomplishments:}

- Expanded the process planning repository to include sample product designs and experimental process planning systems.

- Collaborated with related NIST programs to assemble suites of software tools to accelerate the research and development activities within industry and academia. These last two activities have received strong endorsement by industrial and academic developers, as they greatly reduce the amount of startup work required of them in their own projects.

- Hosted a visiting professor (Dr. Chuck Zhang, FSU/FAMU) under the NSF GOALI (Grant Opportunities for Academic Liaison with Industry) program, who worked at NIST on the definition of a modular, composable architecture for the rapid development of customized process planning systems. This work led to a technical paper that was submitted to the IIE Transactions Focused Issue on Design and Manufacturing.

\section{FY96 Plans:}

- Host a workshop which would for the first time bring together the participants and conclusions of the prior three workshops.

- Host two or three visiting researchers under external sponsorship to tackle problems common to all system developers, in the areas of representation, architectures and integration. 
- Complete the joint work with Dr. Zhang on the modular process planning architecture.

Related Developments: SIMA Planning Application Project 'Information Workshops.'

Five-Year Plan Goals vs. Fiscal Years:

\begin{tabular}{||l|c|c|c|c|c||}
\hline PROCESS PLANNING TESTBED & 96 & 97 & 98 & 99 & 00 \\
\hline $\begin{array}{l}\text { Co-sponsor nationwide workshop series designed to } \\
\text { improve sharing of industrial needs and technical solutions } \\
{[\mathrm{OA}]}\end{array}$ & & & & & \\
\hline
\end{tabular}




\section{Title: RAPID RESPONSE MANUFACTURING (RRM) INTRAMURAL PROJECT}

\section{Staff: (2.7 staff years) Mary Beth Algeo, *Jim Fowler, KEVIN JURRENS}

Objective and MEL Thrust(s) Supported: Primary FY96 objectives for the RRM Intramural Project are to build upon recent project results in the area of a common representation for manufacturing resource (MR) information and to carry through with plans for validation, industry consensus, standardization, and technology transfer. The project has addressed a limited scope of MR data representation, including milling and turning machine tools; cutting tools appropriate to the processes of milling, drilling, boring, reaming, tapping, and turning; cutting tool inserts; and the tool holding and assembly components required to mount the cutting tools to the machines. This effort will demonstrate that there exists a common set of MR data which can be used to support the functions performed by a variety of computer aided engineering (CAE) software applications. Manufacturing System Integration.

Need(s) Addressed: In the domain of mechanical design and manufacturing, information sharing between CAE applications is typically synonymous with product design data exchange. Other information elements which are relevant to and necessary for the functions performed by CAE applications are frequently overlooked. As an example, information describing machine tool capabilities is necessary for manufacturing planning and simulation purposes. Additionally, information describing specific process characteristics is required for manufacturing analysis and cost estimation. Each CAE vendor uses and maintains this information in subtly different ways which prevents application system integration. The problem is compounded because the originating sources of such information (e.g., machine and cutting tool manufacturers) do not provide equivalent characterizations of their products.

Several efforts have been initiated within industry to develop information constructs (e.g., databases, information models) that describe manufacturing resources. These efforts have typically resulted in company-specific data structures and system implementations. The implementations are typically applicable to only a single CAE application within the organization, resulting in multiple redundant stores of MR data and much duplicated effort to implement additional systems in other application areas.

Technical Approach: Information models which specify a common subset of manufacturing resource data will be developed, implemented, and tested to ensure that the requirements of targeted CAE applications are met. The initial focus of this project will be in the application areas of manufacturing cost estimating, manufacturing process planning, and $\mathrm{NC}$ toolpath generation. The completeness, validity, and usability of the information constructs will be evaluated by implementing the information models in a single database to supply MR data to multiple engineering applications in a multi-vendor environment.

It is expected that project results will provide a catalyst for a standardized and publicly available manufacturing resource data structure by providing proven results and a working strawman to appropriate standards organizations. Additionally, an accepted MR data structure will permit more seamless application system integration and allow $\mathrm{CAE}$ application vendors and research organizations to concentrate on application-specific problems as opposed to acquisition, representation, and maintenance of MR data. Standard MR information models could also be used by manufacturing resource providers (e.g., machine tool vendors) to disseminate specifications for their products and could facilitate the establishment of electronic MR "data books" and catalogs for use throughout the manufacturing industry.

It is likely that this project will transition with a STRS-based effort in FY98, with the following tasks to be accomplished: (1) Update requirements specification and information model based on industry review and standards activity, (2) Integrate additional engineering applications with the resource database, and (3) Extend the MR data structure to include other manufacturing resource types. 
FY95 Accomplishments:

- Concluded analysis and documentation of the initial set of MR data requirements. The resulting document, "Modeling of Manufacturing Resource Information, Requirements Specification" (NISTIR 5707) culminated over one year of focused effort. The document formally describes the characterization of the MR data types based on assessment of CAE software tools, industry tooling databases, relevant standards, and vendor specifications.

- Developed an information model based upon the MR requirements document using the Express modeling language (ISO 10303-11). Created both textual and graphical (Express-G) forms of the model.

- Disseminated the MR requirements specification for review by a wide cross-section of cutting tool and machine tool vendors, manufacturing users, and software vendors (over 130 total contacts). Collected industry comments for consideration in standards activities and future updates.

- Joined efforts with U.S. industry to define requirements for electronic tooling catalogs. Provided RRM MR requirements specification for consideration.

- Initiated contact with various national (ANSI) and international (ISO) standards bodies with potential interest in standardization of MR data.

- Submitted the RRM MR requirements specification as a strawman proposal for standardization of an electronic representation for cutting tools to ISO TC29 (small tools). Served as U.S. technical representative for creation of a new working group (WG34) within ISO TC29 for computerized machining data exchange.

\section{FY96 Plans:}

- Implement Express model into database system.

- Integrate process planning system with resource database.

- Evaluate resource models in process planning context.

- Develop appropriate machining application cost models with RRM collaborators.

- Integrate cost estimating system with resource database.

- Evaluate resource models in cost estimating context.

- Demonstrate and report results.

- Pursue standardization for the representation of MR data.

Related Developments: The Rapid Response Manufacturing (RRM) Consortium is organized through the National Center for Manufacturing Sciences (NCMS). A principal objective of the RRM Intramural Project is to establish collaborations with the RRM Consortium to support RRM program efforts and to leverage NIST skills and technologies. With this support role in mind, activities of the RRM Intramural Project are selected based upon specific needs of consortium member companies.

Five-Year Plan Goals vs. Fiscal Years:

\begin{tabular}{||l|l|l|l|l|l|}
\hline $\begin{array}{l}\text { RAPID RESPONSE MANUFACTURING (RRM) } \\
\text { INTRAMURAL PROJECT }\end{array}$ & 96 & 97 & 98 & 99 & 00 \\
\hline $\begin{array}{l}\text { Implement Express model into database system [ATP] } \\
\text { Integrate process planning system with resource database } \\
\text { [ATP] }\end{array}$ & & & & & \\
\hline Evaluate resource models in process planning context [ATP] & & & & & \\
\hline
\end{tabular}




\begin{tabular}{|c|c|c|c|c|c|}
\hline $\begin{array}{l}\text { RAPID RESPONSE MANUFACTURING (RRM) } \\
\text { INTRAMURAL PROJECT }\end{array}$ & 96 & 97 & 98 & 99 & 00 \\
\hline \multicolumn{6}{|l|}{$\begin{array}{l}\text { Develop appropriate machining application cost models with } \\
\text { RRM collaborators [ATP] }\end{array}$} \\
\hline \multicolumn{6}{|l|}{$\begin{array}{l}\text { Integrate cost estimating system with resource database } \\
\text { [ATP] }\end{array}$} \\
\hline \multicolumn{6}{|l|}{ Evaluate resource models in cost estimating context [ATP] } \\
\hline \multicolumn{6}{|l|}{ Demonstrate and report results [ATP] } \\
\hline $\begin{array}{l}\text { Pursue standardization for the representation of MR data } \\
\text { [ATP, STRS] }\end{array}$ & & & & & \\
\hline
\end{tabular}



(AMSANT)

Staff: (3.6 staff years) ROBERT DENSOCK, *Deborah Fowler, *Peter Hart, *Don Libes, *Julie Parker, *Steven Ray, MICHELLE POTTS STEVES

Objective and MEL Thrust(s) Supported: Provide a distributed, multinode facility at NIST that will enable collaborative development of manufacturing systems integration specifications to support distributed and virtual manufacturing enterprises through an advanced computing and communications infrastructure with advanced digital library services. Manufacturing Systems Integration

Need(s) Addressed: The Systems Integration for Manufacturing Applications (SIMA) and National Advanced Manufacturing Testbed (NAMT) programs share a need for a high performance computing and communications infrastructure consisting of special purpose, high performance computers equipped with high speed networking capabilities located in multi-purpose research and demonstration facilities. Also needed, are easily accessible repositories of manufacturing research information and computer-mediated collaboration services to facilitate technology transfer and advances in manufacturing standards and technologies. The AMSANT project was created to fulfill these needs.

Technical Approach: This year's AMSANT project is a merger of the FY95 AMSANT and Manufacturing Information Technology Transfer (MTT) projects. The combination of these projects provides a research environment that includes a computing and communication infrastructure as well as information technology services.

The first AMSANT node opened its doors in early FY95. This node houses many high performance computer workstations and servers, Asynchronous Transfer Mode (ATM) networking capabilities, and large screen computer display systems. Since its completion, the first AMSANT node has been host to daily research activities, several large demonstrations, and several software training classes.

In early FY96, MEL's NAMT program began to take shape and immediately identified the need for a similar infrastructure to support its goals. The AMSANT project was elected to increase its infrastructural capabilities to meet the needs of the NAMT program. An in-depth requirements analysis was conducted which lead to planning efforts for a second AMSANT node and a guest researcher facility to support the growing needs of both the SIMA and NAMT programs.

This second node, like the first, will serve as a working laboratory that industrial collaborators and NIST researchers can utilize as well as serve as a demonstration site to show proof-of-concept for the research and development activities at NIST. The guest researcher facility will provide office space and computers that can be assigned to guests for the duration of their assignments at NIST.

The AMSANT ATM network will be greatly expanded to reach the second AMSANT node as well as several NAMT project labs around NIST. This network will pull the sites closer together with high speed data, voice, and video capabilities. A state-of-the-art network management system will begin to take shape by the end of FY96 to effectively monitor and control the AMSANT network.

Computing capabilities in the new node will include a Sun SPARCserver 1000 for mass storage of software applications and project data. Other systems within the new facility will include several SGI, Sun, and PC workstations. The new node will also include a large screen projection system, an electronic whiteboard, a video tape player, an overhead projector, a plotter, printers, and several tables to support daily research activities as well as demonstrations. 
This year's efforts relating to information technology services will focus on two areas: establishment of a computer-mediated collaboration environment and support for the evolving information dissemination infrastructure of the SIMA and NAMT programs.

An Internet-based collaborative laboratory environment will be constructed to catalyze the teaming of NIST with industry to solve key industrial manufacturing problems. Efforts in this area will include evaluation of computer-mediated collaborative tools and environments, as well as pilot tests of tools to determine achievable capabilities relative to different network configurations. These collaborative tools will be used extensively throughout the SIMA and NAMT projects.

New information dissemination technologies will be evaluated and incorporated based on program needs and support for established services will be transitioned to ITL (NIST's Information Technology Laboratory), where appropriate. This year's efforts include evaluating hypermail to facilitate interproject information sharing, transitioning the SIMA program World Wide Web (WWW) and File Transfer Protocol (FTP) repositories to ITL, and providing ITL with new SIMA and NAMT program requirements to aid their capacity planning efforts.

A yearly requirements analysis will be conducted throughout the life of the AMSANT project to assure that the AMSANT continues to provide an adequate and appropriate computing, communications and services infrastructure.

\section{FY95 Accomplishments:}

- Completed construction of first AMSANT node. This node has successfully enabled SIMA researchers and external collaborators to develop, refine, test, and transfer advanced manufacturing integration technologies and standards.

- Upgraded capabilities of information servers and authoring/searching/retrieval tools. This work has lead to a greatly enhanced information repository which also allows more efficient access to that information.

- Completed NISTIR 5656, "The MITT Electronic Library: An Implementation Description." This paper will increase the effectiveness of digital repository populators and maintainers by providing configuration management and presentation guidelines.

- Drafted the paper "Organization of MSID's On-line Information--Experiences and Recommendations." This paper describes SIMA's electronic library which serves the manufacturing community by allowing users to search, browse and retrieve manufacturing information using a wide range of access methods freely available on the Internet.

\section{FY96 Plans:}

- Design and build a second AMSANT node and implement network and computing environment enhancements.

- Resolve data organization and maintenance issues identified in paper: “Organization of MSID's Online Information--Experiences and Recommendations."

- Evaluate achievable computer-mediated collaboration capabilities relative to different network configurations. 
Five-Year Plan Goals vs. Fiscal Years:

\begin{tabular}{|c|c|c|c|c|c|}
\hline $\begin{array}{l}\text { SIMA ADVANCED MANUFACTURING SYSTEMS AND } \\
\text { NETWORKING TESTBED (AMSANT) }\end{array}$ & 96 & 97 & 96 & 96 & 00 \\
\hline $\begin{array}{l}\text { Expand ATM network and test the benefits of ATM [STRS, } \\
\text { OA] }\end{array}$ & & & & & \\
\hline Design and construct second AMSANT node [STRS, OA] & & & & & \\
\hline $\begin{array}{l}\text { Establish computer-mediated collaborative environment for } \\
\text { AMSANT [STRS] }\end{array}$ & & & & & \\
\hline $\begin{array}{l}\text { Transition established information dissemination services to } \\
\text { ITL [STRS] }\end{array}$ & & & & & \\
\hline $\begin{array}{l}\text { Increase the number of communications links to external } \\
\text { testbeds in support of distributed manufacturing research } \\
\text { and related standards development [STRS] }\end{array}$ & & & & & \\
\hline $\begin{array}{l}\text { Migrate proven computing, networking, and collaboration } \\
\text { technologies to the desktop of NIST researchers [STRS] }\end{array}$ & & & & & \\
\hline $\begin{array}{l}\text { Upgrade the design of other NIST computing labs based on } \\
\text { the AMSANT design in order to allow cooperative research } \\
\text { among the NIST laboratories [STRS] }\end{array}$ & & & & & \\
\hline
\end{tabular}


Staff: (2.8 staff years) Shaw Feng, Amy Knutilla, *STEVEN RAY, *Bill Regli, *Dave Sauder, Craig Schlenoff

Objective and MEL Thrust(s) Supported: To improve the capabilities and integration of manufacturing planning applications. This is being addressed in three ways: the specification of a series of information and process models and communication protocols needed by planning systems; the implementation of these specifications as part of an integration activity using commercial planning system software; and the development of a repository of information supporting the research, development and integration of future planning system applications. Manufacturing Systems Integration.

Need(s) Addressed: There are two principal obstacles impeding the successful adoption of integrated manufacturing process planning technology by American industry. The first is the lack of infrastructure and standards to allow the integration of process planning subsystems with each other, and with external engineering and production functions. The second obstacle is the fragmentation of the process planning research and development community. The intent of this project is to address the first problem, while a related project, the Process Planning Testbed, addresses the second.

Commercial system vendors, systems integrators, and industrial manufacturers have all expressed a desire for NIST to play an active role in establishing an integration infrastructure for manufacturing planning systems. Some evidence of this interest is manifested in the form of three active CRADAs with this project, with other companies expressing interest in forming additional CRADAs. Thus, NIST has both the mandate and the ability to put in place a series of representation and communication specifications to which a variety of engineering systems can conform. Adoption of technically complete specifications will significantly ease the job of systems integrators, drastically reduce the cost of integration for manufacturers, and increase the market for commercial software vendors, especially in the small and medium sized manufacturing sector. On a broader scale, the use of this technology will allow more rapid response of American manufacturers to changing product and market needs, which will let them remain competitive while responding to these changes.

Technical Approach: The process planning applications project will tackle the barriers to integration of process planning systems into the larger engineering context by focussing on the two communication mechanisms among systems. First, the information shared between the planning functions and other engineering functions such as design, scheduling and production will be identified, formally modeled, and implemented as a series of databases. Access to these databases will be via accepted or emerging standard mechanisms such as SQL (Structured Query Language) or SDAI (Standard Data Access Interface). Example models include product data, process plan data, and manufacturing resource data. Second, the "dialogue" between the planning function and other engineering functions, both "upstream" and "downstream" will be formally characterized.

Specifications for a formal communications protocol will be defined and tested by means of prototype implementations. Both of these technical tasks will be validated by building prototype integrated environments which include several commercial process planning systems. Present plans call for implementations using the PART system by Tecnomatix, the MultiCAPP system by International Technegroupe, Inc., and the METCAPP system by the Institute of Advanced Manufacturing Sciences Inc.

\section{FY95 Accomplishments:}

- Collected and formally characterized the data models and storage schemes of several commercial process planning systems, using the EXPRESS-G modeling language. Some areas, such as product data and process plans for numerical code machining, can immediately benefit from emerging standards, such as STEP (ISO 10303). Other areas still lack an identifiable standardization effort, specifically the standardization of manufacturing resource capability models. 
- Installed two commercial process planning systems. These are being used as test cases to gather information requirements, and as platforms upon which to test candidate integration solutions.

- Assembled a repository of sample product designs from CAD vendors and manufacturing researchers, available for staff and collaborators to test engineering applications.

- Defined an activity model of manufacturing process planning, as a first step toward a standard process model. Completed a paper describing the activity mode.

- Wrote a paper on a modular, composable process planning architecture, submitted to the Transactions Focused Issue on Design and Manufacturing.

- Established CRADAs with International Technegroupe, Inc., a commercial process planning system vendor; Advanced Databases, Inc., an object-oriented database vendor; and American Heuristics, Inc., a custom software developer and system. In addition, collaborations have been established with related in-house projects, such as the Rapid Response Manufacturing (RRM) project funded by the Advanced Technology Program, and the Computer Aided Manufacturing Engineering project funded by the Navy Manufacturing Technology Program, and, informally, with IAMS (Institute of Advanced Manufacturing Sciences), which is committing personnel to work with us.

\section{FY96 Plans:}

- Build several pilot implementations of the Draft International Standard Application Protocol, ISO 10303-213, "Process Plans for NC Machining." These implementations will initially be file-based, using the ISO 10303-21 file specification, then based upon object-oriented database technology, using the SDAI (Standard Data Access Interface) specification (ISO 10303-22).

- Manage the balloting and modifications of ISO 10303-213 pursuant to its transition to an ISO International Standard.

- Perform a detailed requirements study of process representation needs in a variety of manufacturingrelated application areas.

- Define a process representation model, building upon the requirements study, and earlier work with ALPS (A Language for Process Specification).

- Collaborate on prototyping databases, based upon the models defined above.

- Collaborate on the integration of several commercial process planning systems by means of the neutral database and communication protocol implementations.

- Begin work on the definition of an API (Application Programming Interface) for a manufacturing process planning system. This specification will capture the "message model"--the semantics of a dialogue which is carried out between the process planning function and any other manufacturing engineering function, such as design.

- Collect industrial data describing product data, process plans, and manufacturing resources, to populate the databases described above. Build a repository of realistic data for use by collaborators and the research and development community.

Related Developments: ISO TC184/SC4/WG3 is sponsoring the development of ISO 10303-49, Process Structure and Properties, which will support the representation of process plans. As this model becomes a standard, efforts will be made to incorporate this representation into our integration approach.

\section{Five-Year Plan Goals vs. Fiscal Years:}

\begin{tabular}{||l|c|c|c|c|c||}
\hline SIMA PROCESS PLANNING APPLICATIONS & $\mathbf{9 8}$ & $\mathbf{9 7}$ & $\mathbf{9 8}$ & $\mathbf{9 9}$ & $\mathbf{0 0}$ \\
\hline Refine process representation model [STRS] & & & & & \\
\hline Establish Process Planning Collaborative Laboratory [STRS] & & & & & \\
\hline Define Abstract Test Suite for ISO 10303-213 [STRS] & & & & & \\
\hline
\end{tabular}




\begin{tabular}{|l|l|l|l|l|l||}
\hline SIMA PROCESS PLANNING APPLICATIONS & 96 & 97 & 98 & 99 & 00 \\
\hline Define process representation grammar [STRS] & & & & & \\
\hline Define process representation syntax [STRS] & & & & & \\
\hline Implement process representation language [STRS] & & & & & \\
\hline $\begin{array}{l}\text { Develop integration conformance tests for process planning } \\
\text { [STRS] }\end{array}$ & & & & & \\
\hline $\begin{array}{l}\text { Participate in standardization efforts re. process planning } \\
\text { [STRS] }\end{array}$ & & & & & \\
\hline
\end{tabular}


Staff: $\left(2.0\right.$ staff years) ${ }^{*}$ CHARLES MCLEAN, Al Jones, *Swee Leong, *Mike Iuliano, *Frank Riddick, *Ed Barkmeyer, Loreau-Guest Researcher, Others

Objective and MEL Thrust(s) Supported: To address integration problems associated with production engineering, scheduling, product data management, and simulation systems. The project will develop process models, information models, and interface specifications, databases, and extensions to commercial production software which resolve facilitate system integration. Manufacturing Systems Integration.

Need(s) Addressed: The world wide market for CAD/CAM/CAE software applications increased by more than $5 \%$ to $\$ 16.5$ billion dollars in 1993 . The computer professional services business which includes systems integrators is expected to grow to considerably in the coming years. The growth of the systerns integration portion of the computer professional services business is highly dependent upon the growth of the CAD/CAM and CAE software market because data exchange formats and interface protocols between CAD/CAM/CAE software applications are incompatible. This incompatibility results in an increased business for professional integrators who create custom integration solutions to support data exchange between software applications. These solutions are expensive to implement, require a great deal of time to develop, are very inflexible, and lack the incorporation of standards. These custom solutions result in numerous problems that can be broken down into three major technical impediments: (1) the lack of understanding on what information and knowledge is required between design, planning, and production areas, (2) the lack of information exchange standards that support both product and process data exchange between applications, and (3) the lack of interface standards which define interface protocols between applications. This project addresses this problem in the area of production engineering and production scheduling systems and interface standards.

Technical Approach: The project will assess industry needs, with respect to production engineering, production scheduling, and systems integration. The project will select and install software applications that are used to engineer production systems, perform production scheduling, and simulate production. The project will define requirements, develop information and process models, and specify applications architectures, interfaces, and databases for integrating production software systems. Prototype integrated systems will be constructed from commercial products. The principal elements of the technical approach are: (1) Identify and address critical industrial needs through collaboration, (2) Develop solutions to production software integration problems, (3) Construct prototype environments using commercial products, (4) Validate results through industrial testing of system implementations, (5) Specify and promote needed industry standards, and (6) Facilitate the rapid commercialization of new technology.

\section{FY95 Accomplishments:}

- Contributed to and edited SIMA Background Study document.

- Established baseline testbed of engineering tools, product data management, simulation and scheduling software.

- Developed production system engineering process model.

- Developed initial information model for scheduling and shop floor data collection.

- Authored a number of technical papers on production applications.

- Established collaborations with researchers, industrial users and software vendors.

FY96 Plans:

- Develop SIMA manufacturing applications integration scenario.

- Select test parts for baseline demonstration.

- Develop initial specifications for production applications. 
- Specify models, processes, and interfaces for product data management.

- Implement baseline production applications demonstration.

Related Developments: This project is leveraging work underway in the Navy Mantech Scheduling and Computer-Aided Manufacturing Engineering projects.

Five-Year Plan Goals vs. Fiscal Years:

\begin{tabular}{|l|l|l|l|l|l||}
\hline $\begin{array}{l}\text { SIMA PRODUCTION AND PRODUCT DATA } \\
\text { MANAGEMENT }\end{array}$ & 96 & 97 & 98 & 99 & 00 \\
\hline $\begin{array}{l}\text { ldentify existing and needed production software standards } \\
\text { [STRS] }\end{array}$ & & & & & \\
\hline $\begin{array}{l}\text { Establish Version 1 interface and data exchange } \\
\text { specifications [STRS] }\end{array}$ & & & & & \\
\hline Implement Version 1 production systems prototype [STRS] & & & & & \\
\hline $\begin{array}{l}\text { Initiate and promote data exchange standard specifications } \\
\text { [STRS] }\end{array}$ & & & & & \\
\hline Test prototype tools at selected sites [STRS] & & & & & \\
\hline Support development and testing of standards [STRS] & & & & & \\
\hline Implement commercial integrated implementations [STRS] & & & & & \\
\hline Promote draft production interface standards [STRS] & & & & & \\
\hline
\end{tabular}


Staff: (2.0 staff years) Allison Barnard, *Rachael Inn (student), *MARY MITCHELL, ${ }^{*}$ David Rosenfeld, David Sauder, and five Industrial Technology Institute staff years under a cooperative agreement

Objective and MEL Thrust(s) Supported: Provide an objective means of evaluating the ability of software systems to meet the STEP requirements, thereby accelerating the adoption of this standard by industry. Manufacturing Systems Integration.

Need(s) Addressed: STEP is an international standard (ISO 10303) designed to let companies effectively exchange engineering information with their customers and suppliers, as well as internally. The adoption of STEP has many benefits (see Manufacturing Standards Development) but it requires a considerable investment. Target customers are vendors of Computer-aided design and integrated management/manufacturing systems and users evaluating them for production use, as well as independent test laboratories, which are used when product certification is desired. Experience with complex standards has shown that claims of compliance with a standard are not reliable. Testing methods and tools support this objective measurement and ultimately aid in achieving interoperable systems. Otherwise, the adoption of a needed standard is delayed .

Technical Approach: Provide a means by which STEP products can be objectively measured against the standard. This is being done by developing a set of value-added software tools for use by vendors during product development. These tools must be extensible to accommodate the expanding series of STEP Application Protocols (APs). This is being accomplished by a modular system with two elements: a test system which integrates various testing tools and administers the actual tests, and a set of tools for generating a test suites for each AP which are used in the testing process. This unique approach offers many advantages over traditional conformance testing. Conformance testing is generally challenged by U.S. vendors as not being cost effective. Under this approach, vendors can gain confidence that their product can successfully pass testing, they have access to the tools to improve the quality of their products, and they gain from the expanded market that user confidence in a tested product brings. The same tools can also be employed by end-users to assess the ability of these products to interoperate in an industrial context, further expanding the market for standardsbased products.

Two additional approaches are also being pursued. The first is to leverage early implementation experience to validate the test system and test suites. NIST/ITI has formed alliances with U.S. STEP pilots initiated by PDES, Inc. and the Automotive Industry Action Group and alliances with vendor roundtables. A beta testing program has been initiated to further ensure the utility of this testing capability. The second is providing an infrastructure for an efficient conformance testing program. This opens a world market to U.S.-developed STEP products. Aggressive participation in the international standards effort related to testing and client requirements is required by this second approach.

This year's work completes the original five-year $\$ 7$ million dollar Research and Development proposal (RD6) to the Navy (total actual funding at about two thirds of the original estimate). However, the scope of the original RD6 does not meet the needs of the current scope of STEP. An additional three year plan has been developed to address the incremental needs that have been identified since the original proposal.

\section{FY95 Accomplishments:}

Provide an extensible, objective test system:

- Produced an enhanced open and modular STEP testing system.

- Developed tools to aid creation of an Abstract Test Suite (ATS) and test cases for STEP APs.

- Developed guidelines for creating test suites; worked with U.S. AP teams to transfer methods.

- Made ATS generation tools available via the NIST express-server@cme.nist.gov. 
- Developed tools to check STEP exchange files, including the specific requirements in AP 203.

Ensure testing system is usable:

- Worked with US pilots (PowerSTEP, AutoSTEP) to validate the test system, and AP 203 test suite.

- Applied the conformance testing tools to CAD interoperability trials (i.e., PDES, Inc. STEPNet and ProSTEP STEP Rally); about a dozen vendors were represented in each cycle.

- Made some of the testing tools available via the World Wide Web.

Establish a testing program:

- Authored/edited STEP testing methods, contributed to other conformance testing (ISO 10303-30 series) documents, and wrote ATS guidelines to build international consensus on testing requirements.

- Developed the first executable test suite for Application Protocol ISO 10303-203.

- Wrote Federal Information Processing Standard (FIPS) and certification procedures.

- Initiated a Beta Testing Program with the vendors involved in PowerSTEP.

- Established a STEP file testing service (over the World Wide Web).

\section{FY96 Plans:}

- Complete STEP Testing Harness which includes: a) develop a semantic checker for geometry in STEP data files; b) develop a semantic checker for ARM data elements; c) integrate the AP203 visualizer functionality into testing harness; d) validate testing harness and tools through beta testing program and interoperability trials.

- Develop analyzers for STEP Resource Parts for reuse by additional APs.

- Define Test Suites for APs: a) develop initial draft and remaining technical content of a test suite for Associative Drafting, ISO 10303-302; and add this test suite and test campaigns into the testing harness.

- Integrate Abstract Test Suites (ATS) tools and add new capability for the development of the ARM test purposes, the ARM-based test data, and verdict criteria generation.

- Complete AP 203 Beta Conformance Testing Program and provide remote testing capability for vendors.

- Develop accreditation and certification procedures for use in a STEP testing program.

- Provide pilot support: a) incorporate pilot test data; b) build test campaigns for Implementors' Agreements; c) participate in the STEPNet; d) provide testing support to PDES Inc. pilot teams.

- SC4 Conformance Testing Specifications: a) complete/stabilize the ATS development methods and test methods, and b) resolve issues resulting from international review against processes and draft documents.

- Identify, select and initiate work with a commercialization agent to transfer the integrated testing tools.

Related Developments: A Conformance Testing Framework and Concepts was approved as part of the international standard in December 1994. ISO 10303-32, Requirements for Test Laboratories and Clients, recently passed its ballot as a Draft International Standard. The STEPNet interoperability events sponsored by PDES, Inc. are both providing excellent feedback and driving CAD developers towards arriving at interoperable systems. These events are being expanded to include the Product Data Management (PDM) market. 
Five-Year Plan Goals vs. Fiscal Years:

\begin{tabular}{|l|l|l|l|l|l|}
\hline STEP CONFORMANCE TESTING & 96 & 97 & 96 & 99 & 00 \\
\hline $\begin{array}{l}\text { Enhanced testing harness which integrates related testing } \\
\text { tools [Navy] }\end{array}$ & & & & & \\
\hline Geometry analyzer and semantic ARM checker [Navy] & & & & & \\
\hline $\begin{array}{l}\text { Semantic checker for testing resource parts: 41-44, 46 and } \\
101 \text { [Navy] }\end{array}$ & & & & & \\
\hline $\begin{array}{l}\text { Enhance AP203 structure checker and develop AP202 } \\
\text { structure checker [Navy (anticipated)] }\end{array}$ & & & & & \\
\hline $\begin{array}{l}\text { ISO WD 10303-302 Associative Drafting Test suite; add to } \\
\text { the testing harness [STRS] }\end{array}$ & & & & & \\
\hline $\begin{array}{l}\text { Integrated ATS generation tools with user's manual [Navy } \\
\text { (anticipated)] }\end{array}$ & & & & & \\
\hline $\begin{array}{l}\text { Web-based testing tools for use by STEP product vendors } \\
\text { (e.g., CAD systems) [Navy (anticipated)] }\end{array}$ & & & & & \\
\hline $\begin{array}{l}\text { Report results of products to participating vendors; and } \\
\text { results of pilot testing [STRS] }\end{array}$ & & & & & \\
\hline Accreditation and certification procedure document [STRS] & & & & & \\
\hline $\begin{array}{l}\text { Document issues and revise ATS Guidelines, test suites, } \\
\text { test methods documents [STRS] }\end{array}$ & & & & & \\
\hline Identify commercialization partner [Navy (anticipated)] & & & & & \\
\hline
\end{tabular}


Staff: (2.5 staff years) SIMON FRECHETTE, *Mary Mitchell, *David Rosenfeld, *Peter Wilson

Objective and MEL Thrust(s) Supported: To accelerate the adoption of STEP by demonstrating the advantages of using STEP for product data communication. Manufacturing Systems Integration

Need(s) Addressed: For the above stated objective to be reached, several needs must be addressed. The initial customers are STEP Pilot Implementation projects, specifically those in the automotive industry who are advancing the state of the art in STEP data sharing applications. Now that the initial set of STEP specifications has been approved as an International Standard, U.S. industry must implement real-life business scenarios to provide concrete information on the benefits and risks of full-up STEP implementations. To do this effectively, industry needs STEP expertise and STEP software tools. The success of these pilot implementations is key to the successful adoption of STEP. Additionally, implementation experience is needed within the STEP community as it will raise new issues for STEP and lead to improved methods. Discussion between industry users, vendors, and STEP developers needs to be facilitated in order to develop recommendations for the rapid resolution of problems related to the practical implementation of STEP.

Technical Approach: NIST will provide software toolkits and develop metrics to support the data exchange and analysis of implementations using the STEP standard. NIST will provide expertise in STEP methods and testing. NIST will act as a neutral participant and provide a neutral testbed site to establish communications infrastructure. Under this project, NIST STEP toolkits will be upgraded in response to user needs. These toolkits will be freely available to the public and NIST will provide network access so users can interactively use the toolkits without the effort of installing and maintaining the software locally.

This SIP project is leveraging work ongoing in industry by forming a strategic partnership with PDES, Inc. (a memorandum of understanding is in place) and the Automotive Industry Action Group (AIAG). (NIST has received a contract from the AIAG's AutoSTEP pilot project under an DARPA BAA). AIAG partners have agreed to adopt STEP throughout the automotive supply chain. AIAG has initiated the AutoSTEP pilot project to implement STEP in a production environment. NIST is providing its expertise on requirements analysis, STEP methodology, issue management, and STEP testing tools to the pilot team. NIST-developed software will be extended where needed to meet the demands of the pilot and this technology will be transferred pilot members to accelerate commercial implementations and their use by industry.

NIST is uniquely positioned to provide the needed interface between pilot implementation projects and the STEP development community. In accordance with its traditional role, NIST will act as a neutral party to convene implementor forums between key industry users and the vendor community to develop recommendations for the rapid resolution of problems related to the practical implementation of STEP. NIST has established a neutral site for Internet communications between AutoSTEP pilot project members.

NIST will facilitate driving modifications to STEP and STEP methods by communicating implementation issues and building consensus their resolution within the STEP development community. By extending the STEP methods in support of implementations and by establishing implementation guidelines, the use of STEP will be accelerated as an advanced manufacturing technology.

\section{FY95 Accomplishments:}

- Performed interoperability requirements analysis for AIAG AutoSTEP project.

- Published STEP CAD interoperability methodology guidelines.

- Released NIST Toolkit and Conformance Testing software to STEP pilot teams.

- Established reporting system and database of vendor issues for AIAG AutoSTEP project. 
- Set up testbed facility at NIST to facilitate communications among AutoSTEP members.

- Provided training on STEP Methods and NIST software tools to pilot members.

- Provided consulting on STEP exchange test design and concepts.

- Assisted AIGA in developing the supply chain integration project.

\section{FY96 Plans:}

- Collaborate with pilot implementation project(s).

- Sign CRADAs and contracts with industry pilot projects.

- Demonstrate potential for cost savings using STEP.

- Document STEP translators issues.

- Provide STEP and software expertise to pilot teams.

- Upgrade NIST STEP Toolkit software.

- Make toolkit available over Internet.

- Respond to user requests.

- Facilitate STEP Implementor's Forum.

- Organize and conduct workshops for implementors.

- Establish NIST testbed site to facilitate communications and remote toolkit access.

- Transfer technology.

- Provide STEP training to Electronic Commerce Resource Centers ("train the trainer").

Related Developments: There are currently eight significant, ongoing STEP implementation pilot programs worldwide with dozens of smaller pilots also in place. Nationally, these include projects led by AIAG and PDES, Inc. Results from the AreoSTEP/PowerSTEP pilot project led by PDES, Inc. are being put into production by Boeing/Rolls Royce and McDonnell Douglas to improve product data exchange within their enterprises. ISO 10303 "Product Representation and Exchange" was published as an international standard.

\section{Five-Year Plan Goals vs. Fiscal Years:}

\begin{tabular}{|l|l|l|l|l|l||}
\hline STEP IMPLEMENTATION PROTOTYPES (SIP) & 96 & $\mathbf{9 7}$ & $\mathbf{9 9}$ & $\mathbf{9 9}$ & $\mathbf{0 0}$ \\
\hline $\begin{array}{l}\text { Sign CRADAs and contracts with industry pilot projects } \\
\text { [STRS] }\end{array}$ & & & & \\
\hline $\begin{array}{l}\text { Develop test procedures to evaluate cost effectiveness of } \\
\text { using STEP [STRS, AIAG] }\end{array}$ & & & & & \\
\hline $\begin{array}{l}\text { Organize STEP pilot implementation with AIAG members; } \\
\text { select test parts; develop exchange procedures; establish } \\
\text { reporting mechanism [STRS, AIAG] }\end{array}$ & & & & & \\
\hline $\begin{array}{l}\text { Collect and evaluate STEP transaction data for AIAG } \\
\text { [STRS, AIAG] }\end{array}$ & & & & & \\
\hline $\begin{array}{l}\text { Maintain STEP translators issues log for pilot projects } \\
\text { [STRS, AIAG] }\end{array}$ & & & & & \\
\hline $\begin{array}{l}\text { Report STEP issues to vendors and standards bodies } \\
\text { [STRS] }\end{array}$ & & & & & \\
\hline $\begin{array}{l}\text { Establish industry collaborations on new STEP pilots in } \\
\text { other application areas and industry sectors [STRS] }\end{array}$ & & & & & \\
\hline \begin{tabular}{l} 
Facilitate STEP implementor's forum [STRS] \\
\hline
\end{tabular}
\end{tabular}




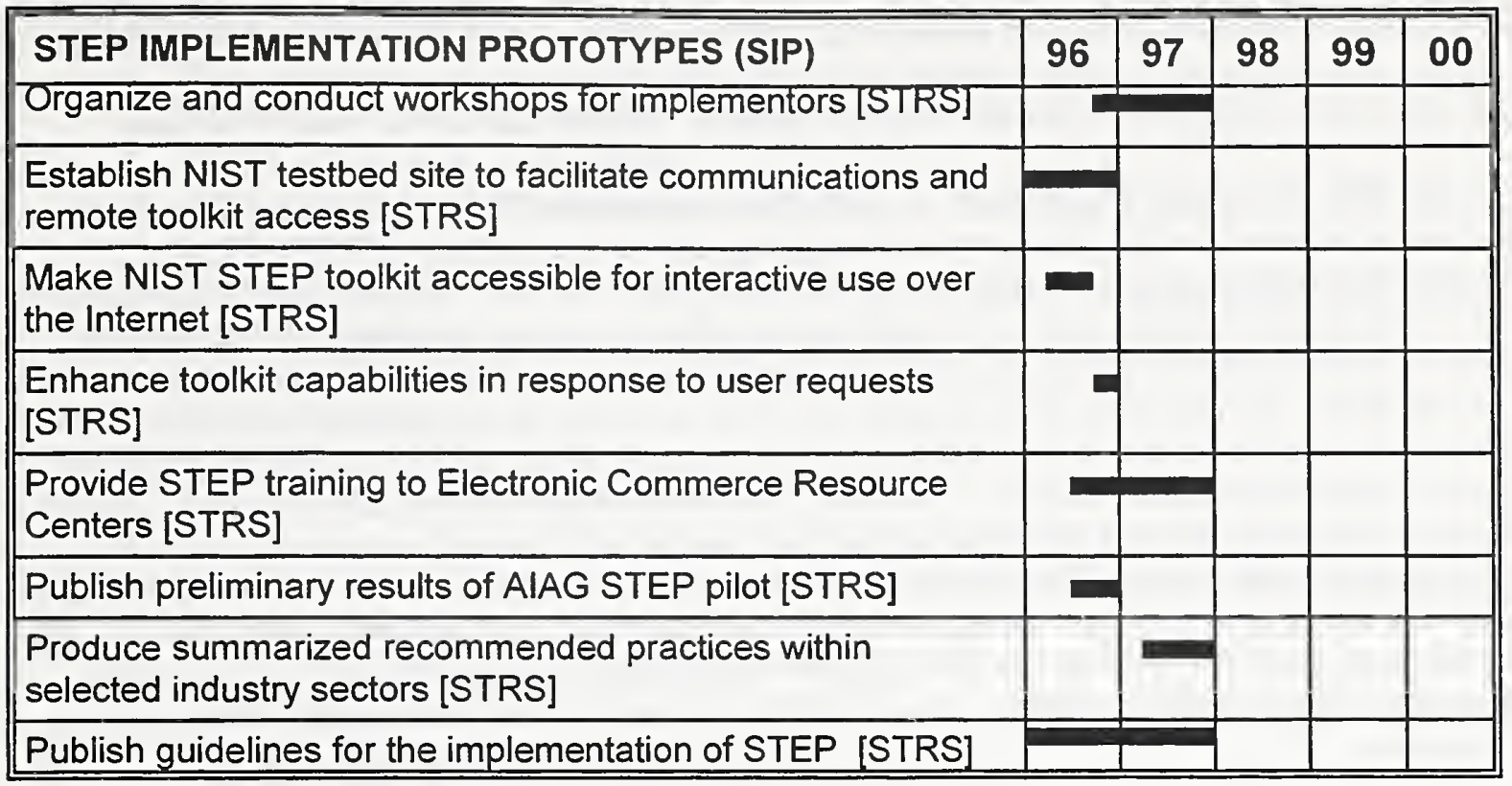

203 


\section{Title: SYSTEMS INTEGRATION FOR MANUFACTURING APPLICATIONS (SIMA) PROGRAM}

\section{Staff: (2.4 staff years) JAMES E. FOWLER, Clarence Johnson, *Sharon Kemmerer, *Joan Wellington}

Objective and MEL Thrust(s) Supported: In 1994, NIST initiated the SIMA program as part of a new federal government initiative on High Performance Computing and Communications (HPCC), which is described in the High Performance Computing Act of 1991 and Senate Bill S-4, "The National Competitiveness Act of 1993." This project oversees a total of 57 staff years of effort on projects in seven NIST laboratories. The program is included under the Information Infrastructure Technology Applications (IITA) program category of the HPCC initiative. The objectives of the program are: (1) to accelerate the development and deployment of HPCC technologies required for the National Information Infrastructure (NM), and (2) to apply and test these technologies in a manufacturing environment. Ultimately, these technologies will radically transform America's manufacturing environment, allowing individual companies to interact electronically as part of a "virtual enterprise" to produce world class products for the 21st century. The SIMA program will focus on technologies and standards that can improve computer systems integration and networking as applied to manufacturing. The program involves all seven NIST laboratories with emphasis in manufacturing systems integration through protocols supporting engineering, manufacturing, and electronics data access and interchange. Manufacturing Systems Integration.

Need(s) Addressed: American manufacturers strive for international market leadership. The specific technical goals are to exploit lean manufacturing (e.g., greater efficiency and lower cost), flexibility (e.g., variation in production runs to allow for customer preferences), and agility (e.g., supporting small production runs, rapid retooling, and exploitation of electronic commerce services). In addition, companies will be able to band together to jointly manufacture goods. This will require a integrated framework of software applications and rapid configuration, tailoring and composition of shared information services such as inventory control, work scheduling, collaborative design systems, planning and production systems, and product delivery. Potential machine tool vendors and other manufacturing support companies will be able to provide simulations of new process-control and planning software to enable companies to test before they buy. In addition, software development companies will provide access to powerful computer-aided design tools that are currently too expensive for purchase by small companies. This is economically viable because a small company can access both the software and the human expertise that lies behind it, through integrated frameworks, data exchange standards, and online consulting services.

Technical Approach: Emphasis is on systems integration technologies that support flexible and rapid access to information for manufacturing applications. A standards-based data exchange effort for computer integrated manufacturing focuses on improving data exchange among design, planning and production activities. Prototype data exchange specifications, interface specification repositories, and reference manufacturing information implementations will be pilot-tested in conjunction with industry alliances and through use of the Advanced Manufacturing Systems and Networking Testbed (AMSANT). NIST will distribute standards reference data, manufacturing standards-related information, and manufacturing exchange specifications via internet-based technologies.

NIST's manufacturing testbed will support R\&D in high performance manufacturing systems and testing computer and networking hardware and software in a manufacturing environment, and will be used to include applications in mechanical, electronics, construction, apparel, and chemical industries; electronic commerce applications in mechanical and electronic products; integration of materials performance data into computer aided design; development and validation of product data exchange standards; technology transfer of information for electronics and construction industries; and an integrated Standards Reference Data system. The testbed will serve as a demonstration site for use by industrial technology suppliers and users, and assist industry in the development and implementation of voluntary standards. 
SIMA funded projects in MEL are:

- SIMA Advanced Manufacturing and Networking Systems Testbed (AMSANT)/Manufacturing Information Technology Transfer,

- Apparel Information Technologies,

- Application Protocol Development Environment,

- Conformance Testing,

- Enhanced Integration of CAD with Design Support and Manufacturing Engineering Systems,

- Operator Interface,

- Reference Architecture,

- Process Planning,

- Production and PDM,

- NAMT/SIMA Integration Framework

FY95 Accomplishments: Program accomplishments are detailed under specific SIMA technical projects. Selected highlights include:

- Completed construction of the Advanced Manufacturing Systems and Networking Testbed facility.

- Published SIMA Background Study Report.

- Published SIMA Interactive Management Workshop Report.

- Provided annual review of program activities and accomplishments.

FY96 Plans: SIMA project plans are included under specific SIMA technical project descriptions. Program plans include development of NIST Initial Manufacturing Exchange Specifications (IMES) in response to industry requirements for rapid development/adoption of data exchange standards. Program activities will continue to ensure that the technical efforts of SIMA funded projects provide standards-based solutions to advanced manufacturing integration problems.

- Publish Initial Manufacturing Exchange Specification Concept document.

- Demonstrate integrated manufacturing applications based on industry scenario.

Related Developments: The MEL NAMT Program leverages experience, results, and facilities developed through the SIMA Program. The ARPA TRP program on National Industrial Information Infrastructure Protocols (NIIIP) cycle two milestones which include virtual enterprise architectural component interface specifications and industry demonstrations. The DOE Technologies Enabling Agile Manufacturing (TEAM) program's strategic plan includes similar technology demonstrations for systems integration. The SIMA program shares several STEP-related projects with the Navy MANTECH program. Additional related developments are defined in SIMA-supported project plans.

Five-Year Plan Goals vs. Fiscal Years:

\begin{tabular}{|l|l|l|l|l|l||}
\hline $\begin{array}{l}\text { SYSTEMS INTEGRATION FOR MANUFACTURING } \\
\text { APPLICATIONS (SIMA) PROGRAM }\end{array}$ & 96 & 97 & 97 & 99 & 00 \\
\hline $\begin{array}{l}\text { Publish annual report summarizing program's previous } \\
\text { year's accomplishments. [STRS] }\end{array}$ & & & & & \\
\hline $\begin{array}{l}\text { Publish annual technical program report describing program } \\
\text { plans. [STRS] }\end{array}$ & & & & & \\
\hline $\begin{array}{l}\text { Provide annual review of program activities and } \\
\text { accomplishments. [STRS] }\end{array}$ & & & & & \\
\hline
\end{tabular}




\section{Acronyms}

$\mathrm{AE}$

AAMACS

ACM

ADACS

$\mathrm{AE}$

AFM

AGMA

AIAG

AIC

AIM

AMRF

AMPST

AMSANT

ANN

ANSI

AP

APDE

APDES

APIB

APTD

ARM

ARN

ASA

ASME

ASTM

ATEP

ATL

ATP

ATS

AWMS

BAA

BESOI

BFRL

BIPM

C-AFM

CAD

CADET

CAE

CAGD

CALS

CAM

CAME

CASE

CBN

$\mathrm{CCM}$
Acoustic Emission

Advanced Automated Master Angle Calibration System

Association for Computing Machinery

Advanced Deburring and Chamfering System

Acoustical Emission

Atomic Force Microscope, Atomic Force Microscopy

American Gear Manufacturers Association

Automotive Industry Action Group

Application Interpreted Constructs (related to STEP)

Application Interpreted Model (related to STEP)

Automated Manufacturing Research Facility

Advanced Manufacturing Processes, Systems and Technologies (a conference)

Advanced Manufacturing Systems Applications Networked Testbed

Artificial Neural Network

American National Standards Institute

Application Protocol (related to STEP)

Application Protocol Development Environment

Apparel Product Data Exchange Standards

Application Protocol Information Base

Automated Production Technology Division

Application Reference Model

Apparel Research Network

Acoustical Society of America

American Society of Mechanical Engineers

American Society for the Testing of Materials (now called ASTM)

Algorithm Testing and Evaluation Program

Advanced Technology Laboratory (future buildings on NIST campuses)

Advanced Technology Program (NIST)

Abstract Test Suite (related to STEP), Algorithm Testing System

Automated Welding Manufacturing System

Broad Area Announcement (DARPA)

Bonded Etched-back Silicon on Insulator

Building and Fire Research Laboratory (NIST)

Bureau International des Poids et Mesures (France)

Calibrated Atomic Force Microscope

Computer Aided Design

Chamfering and Deburring End-of-arm Tool

Computer Aided Engineering

Computer Aided Graphic Design (an annual conference)

Continued Acquisition and Life Cycle Support (a DoD program)

Computer Aided Manufacturing

Computer Aided Manufacturing Engineering

Computer-Aided Software Engineering

Cubic Boron Nitride

Consultive Committee on Mass 


\begin{tabular}{|c|c|}
\hline CDC & Committee Draft for Comment \\
\hline CENAM & Centro Nacional de Metrologia (Mexico) \\
\hline CID & Charge Injection Device \\
\hline CIFP & Capital Improvement of Facilities Project (NIST) \\
\hline CIM & Computer Integrated Manufacturing \\
\hline CIMOSA & Computer Integrated Manufacturing Open Systems Architecture \\
\hline CMM & Coordinate Measuring Machine \\
\hline CMS & Coordinate Measuring System \\
\hline $\mathrm{CNC}$ & Computer Numerical Control \\
\hline COGM & Committee on Gear Metrology (ASME) \\
\hline CORBA & Common Object Request Broker Architecture \\
\hline CRADA & Cooperative Research and Development Agreement \\
\hline CSTL & Chemical Science and Technology Laboratory (NIST) \\
\hline CTF & Custom Therapeutic Footwear \\
\hline $\mathrm{DAC}$ & Design Automation Conference \\
\hline DARPA & Defense Advanced Research Projects Agency \\
\hline DDC & Direct Digital Control \\
\hline DKD & Deutscher Kalibrierer Dienst(Germany) \\
\hline DLA & Defense Logistics Agency \\
\hline DOC & Department of Commerce \\
\hline DOD & Department of Defense \\
\hline DOE & Department of Energy \\
\hline DTD & Data Type Definition \\
\hline DVM & Digital Voltmeter \\
\hline ECSS & Expert Control System Shell \\
\hline EEEL & Electronics and Electrical Engineering Laboratory (NIST) \\
\hline EIF & Enterprise Integration Framework \\
\hline EMC & Enhanced Machine Controller \\
\hline EU & European Union \\
\hline FAMU & Florida Agriculatural and Mechanical University \\
\hline FCIM & Flexible Computer Integrated Manufacturing \\
\hline FEA & Finite Element Anaysis \\
\hline FIPS & Federal Information Processing Standard \\
\hline FSU & Florida State University \\
\hline FTD & Fabrication Technology Division \\
\hline FTP & File Transfer Protocol \\
\hline GERAM & General Enterprise Reference Architecture Model \\
\hline GMAW & Gass Metal Arc Welding \\
\hline GOALI & Grant Opportunities for Academic Liaison with Industry (NSF program) \\
\hline GPL & General Purpose Laboratory (buildings on NIST campus) \\
\hline GUI & Graphical User Interface \\
\hline HPCC & High Performance Computing and Communications \\
\hline HRC & Rockwell C Hardness \\
\hline IAMS & Institute of Advanced Manufacturing Sciences \\
\hline IDEF & Integrated Computer-Aided Manufacturing Definition \\
\hline IDL & Interface Definition Language \\
\hline IEC & International Electrotechnical Commission \\
\hline IEEE & Institute of Electronica and Electrical Engineers \\
\hline IGES & Initial Graphics Exchange Specification \\
\hline
\end{tabular}




\begin{tabular}{|c|c|}
\hline IGRIP & Interactive Graphics Robot Instruction Program \\
\hline IITA & Information Infrastructure Technology Applications (HPCC program) \\
\hline IMGC & Instituto di Metrologia “G. Colonnetti" (Italy) \\
\hline IPM & Intelligent Processing of Materials \\
\hline IPO & IGES/PDES Organization \\
\hline IR & Infrared (light) \\
\hline ISATP & International Symposium on Assembly and Task Planning \\
\hline ISD & Intelligent Machines Division \\
\hline ISO & International Organization for Standardization \\
\hline ITA & Interim Testing Artifact \\
\hline ITL & Information Technology Laboratory (NIST) \\
\hline JAST & Joint Advance Strike Technology (a DOD program) \\
\hline JEDMICS & Joint Engineering Data Management Information Computer Systems \\
\hline JSW & Joint Standards Workshop \\
\hline LFAD & Laser-Focused Atomically Deposited \\
\hline LSI & Line Scale Interferometer \\
\hline $\mathrm{M}^{3}$ & Molecular Measuring Machine \\
\hline MADE & Manufacturing Automation Design Engineering Project (a DARPA project) \\
\hline MANTECH & Manufacturing Technology (a DOD program) \\
\hline MBE & Molecular Beam Epitaxy \\
\hline MEL & Manufacturing Engineering Laboratory \\
\hline MES & Manufacturing Execution System \\
\hline MfgTF & Manunfacturing Task Force (an OMG program) \\
\hline MITT & Manufacturing Information Technology Transfer \\
\hline MR & Manufacturing Resource \\
\hline MRD & Materials Reliability Division (NIST Materials Science and Engineering Laboratory) \\
\hline MSEL & Materials Science and Engineering Laboratory \\
\hline MSI & Manufacturing Systems Integration \\
\hline MSID & Manufacturing Systems Integration Division \\
\hline NADC & Naval Air Development Center \\
\hline NAMAS & National Measurement Accreditation Service (England) \\
\hline NAMT & National Advanced Manufacturing Testbed \\
\hline NC & Numerically controlled (machine tools and equipment) \\
\hline NCS A\&T & North Carolina State Agricultural and Technical University \\
\hline NCMS & National Center for Manufacturing Sciences \\
\hline NCSL & National Conference of Standards Laboratories \\
\hline NGIS & Next Generation Inspection System \\
\hline NII & National Information Infrastructure \\
\hline NIIIP & National Industrial Information Infrastructure Protocols \\
\hline NIM & National Institute of Metrology (China) \\
\hline NIST & National Institute of Standards and Technology \\
\hline NISTIR & National Institute of Standards and Technology Interagency/Internal Report \\
\hline NORAMET & North American Metrology Cooperation (with NRC of Canada and CENAM of Mexico) \\
\hline NPL & National Physical Laboratory (U.K. or India) \\
\hline NRC & National Research Council (U.S. and Canada \\
\hline NRLM & National Research Laboratory of Metrology (Japan) \\
\hline NSF & National Science Foundation \\
\hline NVLAP & National Voluntary Laboratory Accreditation Program \\
\hline $\mathrm{OA}$ & Other (government) Agency \\
\hline
\end{tabular}




\begin{tabular}{|c|c|}
\hline OI & Operator Interface \\
\hline OIML & Organization Internationale de Metrologie Legale \\
\hline OMG & Object Management Group \\
\hline OMP & Office of Microelectronics Programs \\
\hline ORMC & Oak Ridge Metrology Center \\
\hline OSRM & Office of Standard Reference Materials \\
\hline PC & Printed Circuit or Personal Computer \\
\hline PDES & Product Data Exchange Using STEP \\
\hline PED & Precision Engineering Division \\
\hline PMI & Phase Measuring Interferometer \\
\hline PRT & Platinum Resistance Thermometer \\
\hline PSD & Power Spectral Density \\
\hline PTB & Physikalisch-Technische Bundesanstalt (Germany) \\
\hline PZT & Piezo-electric Transducer \\
\hline Q\&V & Qualification and Validation \\
\hline QIA & Quality In Automation \\
\hline RAMM & Rapid Agile Metrology for Manufacturing (an ATP sponsored program) \\
\hline RAMP & Rapid Acquisition of Manufactured Parts (a DoD sponsored program) \\
\hline RCS & Real-Time Control System \\
\hline RRM & Rapid Response Manufacturing \\
\hline $\mathrm{SC}$ & Subcommittee (under ISO) \\
\hline SCLD & Scanning Capacitance Line Detector \\
\hline SDAI & Standard Data Access Interface \\
\hline SEM & Scanning Electron Microscope, Scanning Electron Microscopy \\
\hline SET & Single Electron Tunneling \\
\hline SGML & Standard Generalized Mark-up Language (an ISO standard) \\
\hline SI & Systeme Internationale d'Unites (the modern metric system) \\
\hline SIA & Semiconductor Industry Association \\
\hline SIGMA & Supersonic Inert Gas-Metal Atomizer \\
\hline SIMA & Systems Integration for Manufacturing Applications \\
\hline SIMOX & Separation by Implantation of Oxygen \\
\hline SIP & STEP Implementation Prototype \\
\hline SOI & Silicon-On-Insulator \\
\hline SOLIS & SC4 On-Line Information Services \\
\hline SPM & Scanning Probe Microscopy, Scanning Probe Microscope \\
\hline SQL & Standard Query Language \\
\hline SRM & Standard Reference Material \\
\hline STEP & Standard for the Exchange of Product Model Data \\
\hline STM & Scanning Tunneling Microscope, Scanning Tunneling Microscopy \\
\hline STRS & Scientific and Technical Research and Services (NIST appropriated budget) \\
\hline STS & Scanning Tunneling Spectroscopy \\
\hline SXPL & Soft X-ray Projection Lithography \\
\hline TAG & Technical Advisory Group \\
\hline TC & Technical Committee (under ISO) \\
\hline TDP & Technical Development Plan, Technical Data Package \\
\hline TEAM & Technologies Enabling Agile Manufacturing (DOE) \\
\hline TEM & Transmission Electron Microscope, Transmission Electron Microscopy \\
\hline TIMA & Technologies for the Integration of Manufacturing Applications (ATP program) \\
\hline TIS & Tol Induced Shift \\
\hline
\end{tabular}


LM Technology Learning Modules

UTAP Unified Telerobotic Architecture Project

UTRC United Technologies Research Center

UHV Ultrahigh Vacuum

US TAG United States Technical Advisory Group

USPRO United States Product Data Association

UV

Ultraviolet (light)

VA Department of Veterans Affairs

WWW World Wide Web

XCALIBIR X-ray Optics Calibration Interferometer 


